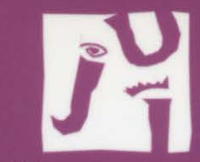

UNIVERSITAT

JAUME•I

\title{
LA TRADUCCIÓN EN LOS MEDIOS AUDIOVISUALES
}

\section{Frederic Chaume Rosa Agost (eds.)}

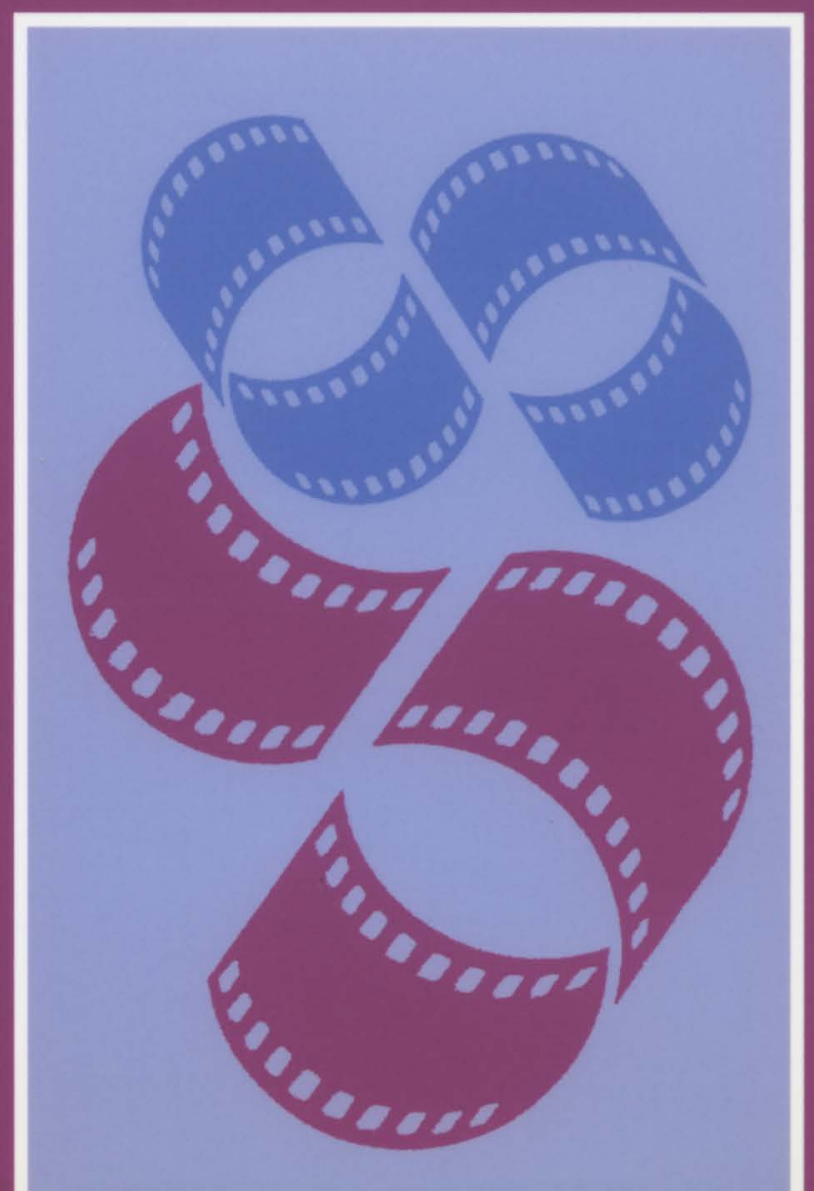


Col·lecció «Estudis sobre la traducció» Núm. 7

\title{
LA TRADUCCIÓN EN LOS MEDIOS AUDIOVISUALES
}

\author{
Rosa Agost \\ Frederic Chaume (EDS.)
}

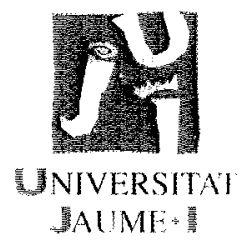


BIBLIOTECA DE LA UNIVERSITAT JAUME I. Dades catalogràfiques

La TRADUCCIÓ en los medios audiovisuales / Frederic Chaume, Rosa Agost (eds.). Castelló de la Plana : Publicacions de la Universitat Jaume I, D.L. 2001

p. ; cm. (Estudis jurídics ; 7)

Bibliografia

ISBN 84-8021-321-3

1. Traducció. 2.Mitjans de comunicació de massa i llenguatge. I. Chaume Varela, Frederic, ed. lit. II. Agost, Rosa, ed. lit. III. Universitat Jaume I (Castelló). Publicacions de la Universitat Jaume I, ed. IV. Títol. V. Sèrie.

82.035

$659.3: 81$

Cap part d'aquesta publicació, incloent-hi el disseny de la coberta, no pot ser reproduïda, emmagatzemada, ni transmesa de cap manera, ni per cap mitjà (elèctric, químic, mecànic, òptic, de gravació o bé de fotocòpia) sense autorització prèvia de la marca editorial.

Entidades colaboradoras .

Fundació Caixa Castelló-Bancaixa

\section{BANCAIXA}

Ministerio de Educación y Cultura

Conselleria de Cultura, Educació i Ciència

Ajuntament de Castelló

(C) Del text: els autors, 2001

(C) De la present edició: Publicacions de la Universitat Jaume I, 2001

Asistencia técnica en la edición y la corrección del texto:

Esther Monzó. Universitat Jaume I. Becaria FPI (Generalitat Valenciana).

Proyecto GV98-09-113

Edita: Publicacions de la Universitat Jaume I. Servei de Comunicació i Publicacions Campus del Riu Sec. Edifici Rectorat i Serveis Centrals. 12071 Castelló de la Plana Tel. 9647288 19. Fax 964728832

http://sic.uji.es/publ c/e: publicacions@uji.es

Imprimeix: Gráficas Castañ, S.L.

ISBN paper: $978-84-8021-321-9$

ISBN pdf: 978-84-16546-23-7

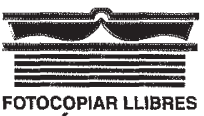

FOTOCOPIAR LLIBRES

Dipòsit legal: CS-118-2001

DOI: http://dx.doi.org/10.6035/EstudisTraduccio.2001.7 


\section{ÍNDICE}

Horizontes cercanos: la consolidación académica de la traducción audiovisual, Frederic Chaume Varela y Rosa Agost Canós

\section{ASPECTOS PRAGMÁTICOS DE LA TRADUCCIÓN AUDIOVISUAL}

Coherence in Subtitling: The Negotiation of Face, Ian Mason

El espectador y la traducción audiovisual, Roberto Mayoral Asensio

\section{ASPECTOS METODOLÓGICOS DE LA TRADUCCIÓN AUDIOVISUAL}

La traducción de textos audiovisuales y la investigación traductológica, Patrick Zabalbeascoa

La traducció per al teatre i per al doblatge a l'aula: un laboratori de proves, Eva Espasa

La previsió del procés d'ajust com a estratègia de traducció per a

l'ensenyament del doblatge, Francesca Bartrina

L'ensenyament de la traducció d'audiovisuals en el marc de la formació de traductors, Natàlia Izard

La pretendida oralidad de los textos audiovisuales y sus implicaciones en traducción, Frederic Chaume Varela

\section{ASPECTOS PROFESIONALES}

Les traducteurs face aux écrans: Une élite d'experts, Yves Gambier..... 91

Els recursos del traductor, Joan Fontcuberta $i \mathrm{Gel}$

Qualitat i recepció en la traducció per al doblatge, Joan Sellent Arús

La intervenció lingüística en versions doblades i subtitulades. El cas català, Martí Garcia-Ripoll

Sous-titrage: Le cas de la traduction de l'allemand vers le français, Jean-Jacques Alcandre.

Cuestiones sobre la norma culta y los criterios de calidad para la traducción de doblaje y subtitulación en España, Xosé Castro Roig

\section{EXTRANJERIZACIÓN O ADAPTACIÓN}

Cloning Cultures: The Return of the Movie Mutants, Candace Whitman . 143 
Culture and Translation. The Referential and Expressive Value of Cultural References, Laura Santamaria

Doblaje y nacionalismo. El caso de Sangre y arena, Ana Ballester

Inevitable Exoticism: The Translation of Culture-Specific Items in Documentaries, Eliana P. C. Franco

Extranjerización y adaptación en la traducción de espots publicitarios,

Cristina Valdés Rodríguez

In Video Veritas: Are Danish Voices Less American than Danish Subtitles?,

Henrik Gottlieb 193

\section{LA ADAPTACIÓN CINEMATOGRÁFICA Y DRAMÁTICA COMO TRADUCCIÓN}

Adaptación, traducción y otros tipos de transferencias, Raquel Segovia

Traducción, adaptación y censura de productos dramáticos, Raquel Merino

Traducció, mediació i dramatització: proposta per a l'estudi descriptiu de l'adaptació dramàtica, Vicent Montalt i Resurrecció 


\title{
HORIZONTES CERCANOS: LA CONSOLIDACIÓN ACADÉMICA DE LA TRADUCCIÓN AUDIOVISUAL
}

\author{
Frederic Chaume Varela y Rosa Agost Canós \\ Universitat Jaume I
}

Escribir sobre traducción, ya en el año 2000, no es una novedad. Hoy en día, hablamos de Estudios sobre Traducción, o de Traductología, sin tener que buscar otra disciplina que nos aclare su significado. Sin embargo, el camino no ha sido fácil. Prácticamente hasta bien entrada la década de 1970, los Estudios sobre Traducción no eran más que aproximaciones aisladas (no por ello con menor rigor), que, siguiendo aquella máxima escolástica de Philosophia, ancilla Theologiae, consideraban la traducción como un ejercicio lingüístico y siempre se acercaban al hecho traductor desde el punto de vista de la corriente lingüística floreciente en el momento (Traductio, ancilla Linguisticae, podríamos decir).

La emancipación de la disciplina de la traducción ha posibilitado realizar investigaciones concretas sobre modalidades de traducción que, hasta hace poco, se consideraban patrimonio de las artes y oficios y recibían un trato más propio de la formación profesional que de una actividad con base académica. Este es el caso de la traducción audiovisual, una modalidad en la que, aún hoy en día, no se reconoce la autoría de la traducción ni en las pantallas cinematográficas, salvo en contadas excepciones, ni en la televisión, ni en los vídeos de consumo doméstico, ni en los derechos de autor. Sin embargo, el atractivo y la peculiaridad de esta actividad, así como especialmente su consumo en todo el planeta, merece mayor atención académica de la que ha recibido hasta la fecha, entre otras razones por lo que su estudio puede aportar a las teorías generales de la traducción.

Es innecesario insistir en el papel que ha adquirido la comunicación audiovisual en estos últimos años. Las plataformas digitales, las televisiones vía satélite, la televisión por cable, el auge del cine, del vídeo y de la televisión, 
la irrupción de los productos multimedia en los hogares, el futuro, ya inmediato, de las nuevas tecnologías aplicadas a los medios audiovisuales, como el DVD, la elección de lengua en el visionado de un filme, la subtitulación para sordos, la narración para ciegos, entre otras, se disponen a inaugurar un milenio caracterizado por la comunicación audiovisual.

La ilusión que depositamos en el presente volumen no puede ser otra que la de ayudar a entender el fenómeno complejo de la comunicación interlingüística codificada y transmitida a través de los medios audiovisuales. Una actividad mayoritariamente de ocio como la asistencia a las salas de cine o el visionado de una película en la pantalla del televisor se convierte, a lo largo de estas páginas, en un ejercicio académico de observación y de análisis de datos. Las opiniones de los autores y los resultados de los artículos que aquí recogemos pueden ser de utilidad al traductor profesional, al docente, al estudiante y al investigador de esta materia, puesto que los cuatro ámbitos mencionados se encuentran todavía en un momento inicial de formación. Traductores, profesores, estudiantes e investigadores se enfrentan ante un nuevo siglo marcado por la era de las comunicaciones: la aldea global que preconizaba McLuhan en 1964 se ha instaurado de tal manera que ya es difícil encontrar ciudadanos que no hayan tenido contactos con otras culturas y que, por tanto, no necesiten de la descodificación linguística y cultural de esos textos ajenos, precisamente aquello que es capaz de proporcionarle el traductor bien formado. En este sentido, es realmente paradójico que un campo que cuenta con un impacto social sin precedentes haya recibido tan poca atención académica, en cuanto al fenómeno de la traducción se refiere.

El volumen que aquí presentamos constituye ya el número 7 de la colección Estudis sobre la Traducció, cuyo primer ejemplar vio la luz en 1994. Los números anteriores se han centrado en la teoría de la traducción (1), en la traducción literaria (2), en la metodología y la didáctica de la traducción (números 3 y 5) y en la serialidad desde un punto de vista interdisciplinario (número 6). El séptimo volumen quiere contribuir a la compleción de esta serie recogiendo las aportaciones invitadas sobre la traducción audiovisual que tuvieron lugar en las $V$ Jornadas sobre la Traducción: La Traducción Audiovisual en el siglo XXI, celebradas en la Universitat Jaume I, del 28 al 30 de octubre de 1999, y organizadas por el Departament de Traducció i Comunicació de nuestra universidad.

El volumen se estructura en cinco grandes ámbitos, que responden a aquellos campos que han recibido mayor atención en los diferentes estudios sobre traducción audiovisual: un primer apartado dedicado a aspectos pragmáticos de la traducción audiovisual, un segundo bloque que incide en los aspectos metodológicos de este ámbito, un tercer apartado centrado en los aspectos profesionales, un cuarto bloque que se ocupa del eterno dilema entre extranjerización 
o adaptación en la traducción de textos audiovisuales y, para cerrar, una quinta sección que ha tenido la voluntad de indagar en la adaptación cinematográfica y dramática como traducción.

El primer apartado, los aspectos pragmáticos de la traducción audiovisual, recoge dos aportaciones sobre el trasvase de los factores pragmáticos en juego en un intercambio comunicativo y sobre la incidencia del espectador en el acto de traducción. Ian Mason, en la más pura tradición discursivista y siguiendo los postulados de sus anteriores trabajos, realza la faceta lingüística y pragmática de la construcción retórica del texto origen y del texto meta. Desde un punto de vista descriptivo, Mason se pregunta qué ocurre en un acto de comunicación en el que el discurso oral del filme se ha de representar en un modo escrito que necesariamente presentará los enunciados originales truncados, con la restricción añadida de la discontinuidad entre subtítulo y subtítulo para el espectador. El autor describe los mecanismos pragmáticos que dotan de coherencia al texto origen y su representación en el texto meta subtitulado. Por su parte, Roberto Mayoral ensalza la figura del espectador como motivador del acto de traducción. Después de repasar la especificidad de la traducción audiovisual, Mayoral se centra en los umbrales de permisividad del producto traducido por parte del espectador, un aspecto que ha recibido escasa atención académica. Mayoral subraya la heterogeneidad del espectador tanto desde un punto de vista diacrónico como sincrónico y cierra su aportación enumerando una serie de perspectivas de futuro en este campo.

El segundo bloque del volumen, aspectos metodológicos, lo constituyen las aportaciones en torno a la metodología y a la didáctica de la traducción audiovisual. En este bloque, Patrick Zabalbeascoa da por concluida la etapa de investigación en torno a los aspectos específicos de traducción audiovisual y propone abrir una nueva etapa en la que se investiguen aquellos aspectos que la traducción audiovisual comparte con otras modalidades de traducción, pero que se habían considerado específicos hasta la fecha. Eva Espasa justifica la inclusión de la traducción teatral en los cursos de traducción audiovisual por las características que comparten ambas manifestaciones, así como por razones metodológicas que pueden ayudar al estudiante a encarar con mayor preparación la traducción audiovisual, como las propuestas de la autora sobre la consecución de la concisión y de la oralidad en ambas modalidades de traducción. Francesca Bartrina nos detalla una propuesta metodológica en las fases del aprendizaje de la traducción para el doblaje, desde el visionado del guión, pasando por las herramientas de documentación, hasta la propia traducción. Bartrina apuesta, muy acertadamente desde nuestro punto de vista, porque traductor y adaptador sean la misma persona y, por tanto, por la incorporación del ajuste en el currículum del traductor de textos audiovisuales, así como por el reconocimiento profesional del tra- 
ductor. Natalia Izard reivindica la inclusión de la traducción audiovisual en el currículum del traductor. De todos los aspectos en juego en esta modalidad de traducción, Izard se centra en el equilibrio entre oralidad y verosimilitud, por un lado, y normativa lingüística por el otro, puesto que la consecución de la credibilidad a través de la rescritura del guión fílmico es uno de los grandes objetivos del profesional de este tipo de transferencias. Finalmente, y a partir de los postulados básicos de los capítulos de este apartado, Frederic Chaume realiza una propuesta de descripción de los rasgos de la oralidad de los textos audiovisuales: una oralidad prefabricada, elaborada, cuyos rasgos característicos se encuentran en la intersección entre los discursos propiamente orales y lo políticamente correcto en términos de normativa lingüística y de las corrientes de política lingüística imperantes en cada época y en cada sociedad.

El tercer bloque lo constituyen las aportaciones en torno a los aspectos profesionales de la traducción audiovisual. Este apartado se inicia con una detallada aportación de Yves Gambier que pretende avanzar los nuevos retos que el mercado de la traducción audiovisual, y el de los medios audiovisuales en general, ha de afrontar en el siglo xxi. En este sentido, Gambier repasa, entre otros aspectos, las características del perfil del traductor, las nuevas exigencias del mercado, la educación de los clientes y la necesidad de diálogo entre el mundo académico y el profesional. Gambier propone seis retos interesantes para el mercado de los medios audiovisuales en una época de convergencia cultural como la que vivimos. Joan Fontcuberta realiza un repaso a los recursos del traductor de esta modalidad. Fontcuberta defiende que cualquier lengua dispone de los recursos necesarios para resolver los problemas de creatividad y de interacción entre palabras e imágenes que presenta el texto origen, sin necesidad de recurrir a otras lenguas dominantes. El autor recomienda la práctica de la traducción audiovisual durante los años de formación del traductor, como finalidad en sí misma pero también como ayuda para la consecución de traducciones de mayor calidad en otros ámbitos. Joan Sellent incide en que la traducción en general adolece de desprestigio social y que, en el caso del doblaje, tal carencia es todavía mayor. Sellent analiza los factores sociológicos y profesionales del estatus de la traducción audiovisual y se centra en el caso del doblaje en Cataluña. Martí García Ripoll expone la cadena compleja de la traducción audiovisual en televisión, tanto en la modalidad del doblaje como en la de subtitulación. En este sentido, el autor explicita los problemas más habituales con que se suele encontrar tanto el traductor como el asesor lingüístico, desde el punto de vista profesional, así como los recursos de que ambos disponen hoy en día, especialmente en el caso de la televisión autonómica catalana, TV3. Jean Jacques Alcandre realiza un análisis comparativo entre ciertas características de la lengua alemana y sus traducciones al francés. Partiendo de la especi- 
ficidad del texto audiovisual y de los imperativos de su traducción para la subtitulación, Alcandre establece cinco puntos conflictivos entre el alemán y el francés en la línea del comparatismo y analiza las tendencias en las soluciones en lengua meta en el entorno audiovisual. Finalmente, Xosé Castro nos plantea una paradoja que, según el autor, resulta de la poca atención hacia los doblajes efectuados al castellano, por comparación con los doblajes efectuados en las lenguas autonómicas del Estado español y pone de manifiesto el excesivo celo normativo que impera en las televisiones autonómicas en contraposición a la aparente indiferencia de las televisiones de ámbito estatal. El autor también incide en la necesidad del uso de las nuevas tecnologías en traducción y en el erróneo distanciamiento que existe entre el mundo profesional y el universitario, que se muestra reacio a incorporarlas. Finalmente, Castro propone dignificar la profesión mediante actitudes activas hacia las televisiones y los estudios de doblaje.

El cuarto apartado, que intenta recoger las diferentes opiniones académicas en torno al eterno dilema de la extranjerización frente a la adaptación en la traducción audiovisual, comienza con un repaso de Candace Whitman a los errores más frecuentes en traducción audiovisual. La autora subraya la necesidad de alejarse del tradicional análisis de errores desde un punto de vista linguístico, para fijar la atención en aspectos más singulares como la presencia de diversas lenguas en un mismo filme o la traducción de las referencias culturales. En especial, Whitman nos llama la atención sobre las referencias culturales con soporte visual, así como sobre la traducción de dialectos, rimas y aliteraciones. Laura Santamaria incide en la traducción de las referencias culturales, pero desde un enfoque más social e ideológico: tras resaltar la definición de cultura como categoría social y alertarnos de la heterogeneidad de los grupos que supuestamente conforman la misma cultura, la autora nos recuerda que los hechos de un filme determinado se nos presentan siempre bajo un punto de vista, y que los problemas para el traductor se originan especialmente cuando la ideología que muestra el filme no concuerda con la representación que la audiencia meta tiene de esa cultura. Ana Ballester se alinea con las tesis de Danan sobre las causas históricas de la elección entre doblaje y subtitulación: para la autora el nacionalismo ha jugado un papel preponderante en la elección del doblaje en España como modalidad de traducción audiovisual, a diferencia de las tesis más extendidas que defienden las causas económicas como razones de esta elección. Ballester nos muestra que la presencia de dos normas de traducción (la naturalización y la eufemización) en el filme Sangre y Arena, ratifica la tesis del nacionalismo como causa última del triunfo del doblaje en España. Eliana Franco analiza la adaptación de referencias culturales en la traducción de documentales y destaca el equilibrio entre extranjerización y adaptación que 
se produce en la transferencia de estos textos. La autora postula que es la noción de género la que subyace a la elección de uno u otro polo y el que el equilibrio que muestran los documentales se debe a que su traducción no se ve afectada por el imperativo de parecer un original, sino que más bien el espectador espera un cierto grado de exotismo en el producto traducido. Los ejemplos que nos muestra evidencian los esfuerzos del traductor por compensar la inevitable carga exótica de los documentales. Cristina Valdés elige la traducción de espots publicitarios para debatir el tema propuesto en este apartado. Después de reivindicar la traducción publicitaria en el marco de la traducción audiovisual por su omnímoda presencia en la vida cotidiana, la autora define el texto publicitario y nos ofrece un cuadro que muestra desde las estrategias de traducción más extranjerizantes hasta las más naturalizadoras. Valdés concluye tratando la polémica de la homogeneización de las culturas a partir de las estrategias extranjerizantes de traducción. Finalmente, Henrik Gottlieb cierra este amplio bloque con un detallado y extenso estudio sobre la presencia de anglicismos en los doblajes y subtitulaciones daneses. Para ello, expone una categorización sistemática de los anglicismos en lengua danesa y apunta las razones de su uso, con constantes comparaciones entre las tendencias observadas en Dinamarca y en España. El estudio empírico de tres filmes doblados y subtitulados al danés le lleva a afirmar que la modalidad del doblaje cuenta con todavía más anglicismos que la modalidad de la subtitulación. El autor, lejos de adoptar una postura pesimista y reivindicativa de las supuestas esencias de la lengua, opta por resaltar las influencias que las lenguas meta ejercen, a su vez, en la lengua inglesa, pese a la aparente univocidad del proceso de traducción.

El quinto apartado del volumen va dedicado a la adaptación cinematográfica y dramática como traducción. Raquel Segovia delimita el término adaptación y ofrece una nueva clasificación de los transvases entre textos transmitidos a través de diferentes medios. Tras una revisión crítica de la clasificación tripartita jakobsoniana, y del término rescritura que, desde Lefevere, inunda los Estudios sobre Traducción, ofrece una nueva clasificación de las transferencias intersemióticas basada en el concepto de medio como elemento clave de la clasificación. A partir de este concepto, la autora establece una serie de semejanzas y diferencias entre traducción y adaptación. Raquel Merino propone realizar estudios de traducciones dramáticas en el contexto en el que surgen con el fin de predecir las regularidades y tendencias de traducción en un espacio y tiempo determinados. La autora repasa con detalle las diferencias entre traducción y adaptación, pero también las zonas de intersección y el carácter consecutivo que, en ocasiones, muestran estos procesos. En este marco, Merino analiza la censura como un proceso socio-histórico de adaptación de la primera traducción que se sometía al control del aparato censor. El último bloque y, con ello, 
el volumen se cierra con una propuesta metodológica de Vicent Montalt sobre la traducción, la mediación y la adaptación dramática, en donde el autor presenta un modelo de análisis de las adaptaciones dramáticas a partir del estudio de El sueño de una noche de verano de William Shakespeare. Después de discutir las relaciones entre un texto origen y un texto adaptado, el autor nos ofrece una serie de preguntas sobre las que construye su marco de análisis y que revelan las relaciones entre texto origen y texto meta en la época, así como el estatus y tolerancia de la traducción como fenómeno de mediación linguística y cultural.

Como se ha observado del repaso de las contribuciones del volumen, el análisis de la especificidad de la traducción audiovisual, así como de aquellos aspectos que nuestra modalidad de traducción comparte con otras modalidades, ha sido el eje que ha centrado transversalmente todos los apartados del presente volumen. La interacción entre palabras e imágenes, la simultaneidad de la información transmitida por el canal visual y el canal verbal, la suma de todos los códigos de significación presentes en los textos audiovisuales, han guiado los diferentes enfoques con que los autores y autoras se han acercado a la traducción audiovisual. Dado que toda producción cultural tiene significado, en este volumen el lector tendrá la oportunidad de comprobar que los textos audiovisuales muestran una densidad y una complejidad semántica que va más allá de la que exhiben aquellos textos que se transmiten por un único medio.

Finalmente, el volumen como tal pretende ser un referente de la consolidación del ámbito de estudio de la traducción audiovisual: lo que parecía hace simplemente una o dos décadas un horizonte lejano es hoy ya un campo de investigación consolidado. La traducción audiovisual empieza a ser uno de los ámbitos temáticos a los que las editoriales, españolas y extranjeras, comienzan a dedicar su atención. Prueba de ello son la más de media docena de libros que, publicados ya en prensa, han saludado el nuevo siglo en apenas dos años en el panorama europeo. Esperamos que el lector disfrute del volumen. 


\section{ASPECTOS PRAGMÁTICOS DE LA TRADUCCIÓN AUDIOVISUAL}




\title{
COHERENCE IN SUBTITLING: THE NEGOTIATION OF FACE
}

\author{
IAN Mason \\ Centre for Translation and \\ Interpreting Studies in Scotland, \\ Heriot-Watt University, Edinburgh
}

\section{INTRODUCTION}

Given the overall focus of this volume, it is important that I establish at the outset that my interest in screen translating is linguistic and pragmatic. That is, I believe that, as a complement to technical, semiotic, sociological and cultural studies of audio-visual translating, analysis of the linguistic and pragmatic factors involved in the mode-shift from soundtrack speech to written subtitle does have an important role to play. When I say "linguistic", I do not have in mind some narrowly based source text/target text comparison at word or phrase level, nor do I envisage the even-worse option of conducting some kind of ill-informed error analysis of the translator's work. Indeed, my point of departure is that it is futile to attempt to find fault in subtitlers for not achieving what they are not even aiming to achieve in the first place! All too often, judgements about inadequate, "stilted" or "insipid" subtitled versions of films are made by the film-going public in the absence of any appreciation of what is involved in the task, how it is done and what it aims to achieve.

Rather, my goal is a descriptive one: what happens to communication when speech is represented in writing in a necessarily truncated form, with the added constraints for the reader of discontinuity between one utterance and the next and short processing times? More specifically: given that some loss must occur in subtitling between two languages and cultures, what is the nature of the loss and what are its potential effects? 
In some previous studies, 'I have considered subtitles not as a "summary" of the source (that is, a more-or-less equal reduction of all effects) but more as a "selective reduction" (that is, the preference for relaying certain communicative effects over others). From the evidence of these and other studies conducted for me by postgraduate students at the Centre for Translating and Interpreting Studies in Scotland, Heriot-Watt University, it would appear that there is a general preference for relaying propositional meaning, while interpersonal pragmatics tend either not to be relayed or to be relayed in a way which may give rise to unintended meanings. There may be many reasons for this, principal among them the obvious fact that cinema and television audiences expect to and actually do pick up from paralinguistic and non-linguistic visual signals on screen a greater proportion of meaning than from the text of the subtitles. In observing these trends, therefore, no judgement of inadequacy is being made. Simply, a trend is observed which, from the admittedly limited evidence available so far, appears to hold true irrespective of the language pair involved.

In this paper, I propose, firstly, to re-examine some key assumptions which have been made in recent studies of audio-visual translating. Then, I shall focus on a hitherto neglected area, namely, the interpersonal dynamics of communication between fictional characters on screen and the ways in which these dynamics are signalled to an audience dependent on translation. Finally, I propose to consider these issues in the light of insights afforded by the work of Grice (e.g. 1975) and by politeness theory (Brown and Levinson 1987). In doing so, I wish to move beyond consideration of individual speech acts, a tendency which is difficult to resist for two reasons. Firstly, the nature of the subtitle is such that it often corresponds to a unit of the source text which is equivalent in length to an individual speech act. As viewers, we are presented with these speech acts in isolation from preceding and following text ${ }^{2}$ and are consequently tempted to consider them as independent units. Secondly, Brown and Levinson's (1987) account of politeness theory and analysis of it in three unrelated languages and cultures frequently focuses on the speech act. Yet studies have shown that the illocutionary force of speech acts can only be perceived in sequences. From our perspective, it is not the individual speech act but rather the "text act" which is interesting. In other words, we seek answers to questions such as: what has shifted in the perceived interpersonal dynamics of communicators during the whole of a particular sequence of film? What perlocutionary effects have been sought?

1. See Mason (1989) and Hatim and Mason (1997), chapter 5 - reproduced in Venuti (2000).

2. It is this factor which essentially distinguishes the reading of subtitles from the reading of continuous text, where the eye can dart backwards or forwards in the search for cohesion and coherence. 


\section{SOME KEY ASSUMPTIONS}

In the literature of subtitling studies, many views have been put forward as to what does/does not get relayed. One suggestion, supported by Goris (1993). who quotes Lambert (1990: 233), is that subtitles are characterised by a "style zéro" or linguistic standardisation (Goris 1993: 186):

(...) standardization in subtitling (...) imposes the elimination of dialectal language (...) The social differentiation of the language is not maintained. The vulgar terms and expressions are eliminated, and even the popular elements are "corrected".

In terms of register analysis, then, it is suggested that what gets sacrificed is use and user variables, leading to a standardised, neutral style. This phenomenon is, no doubt, well documented and may partly explain some of the disappointed reactions of film-goers, mentioned above. Nevertheless, norms in subtitling are changing -at least in English - as may be apparent from a comparison of old subtitled films with those produced in recent years. For example, the French feature film La Haine (M. Kassovitz 1995), with its portrayal of disaffected youth culture in the notorious high-rise suburbs of French cities, contains many speech sequences in verlan, a variety of back-slang associated with this social group. The English subtitled version for cinema release substituted Black US street slang for this, in an attempt to represent not just the degree of non-standard usage but also the social connotations inherent in such items as:

$\begin{array}{lll}\text { nique ta mère } & > & \text { motherfucker } \\ \text { tiéquar } & > & \text { hood } \\ \text { meuf } & > & \text { bitch } \\ \text { enculé } & > & \text { nigger }\end{array}$

This brave attempt at functional equivalence is, however, fraught with problems. Even from these isolated examples, it can be appreciated that the connotations and the taboo are not the same in the two cultures identified. Moreover, attempts to find equivalents to match the geographical, social and age variation among users are often doomed to failure. For example, a separate subtitled version of the same film, commissioned by the BBC for a televised screening in the UK, includes such items as "bugger off", an expression whose range of users by no means includes the kind of social group featured in $L a$ Haine. ${ }^{3}$ Although these criticisms might seem to be a rationale for neutralisation,

3. I am indebted to Elise Rana for her insights into the issues involved in the subtitling of this film. 
I believe that the expectations of cinema audiences have increased and that, whereas the search for equivalent social dialects is unlikely to bear fruit, it is possible to represent in subtitles in some way stigmatised or rejectionist nonstandard uses of language, as many recent subtitled versions have shown.

A second proposition which merits consideration is that one standard of textuality which is inevitably affected in the transfer from source to target text is "cohesion". De Linde and Kay (1999 $a$ : 17) advance the hypothesis that the omission of cohesive devices in subtitles may affect comprehension. They also point out that this is a neglected area of linguistic research into subtitling and call for further studies to be carried out. It is clear that, in any sequence of subtitles, overt cohesion is restricted to a minimum. For example, in the sequence reproduced as Table 2 below, it is noticeable that, in the set of subtitles, there is only one cohesive tie ("that" = anaphoric reference to the previous utterance, "It's Linda's day off"). In the French source speech exchange, on the other hand, plenty of cohesive ties are identifiable, the majority referring anaphorically to a previous utterance, as listed below:

$$
\begin{aligned}
& \text { ça }=\text { viens chez le coiffeur } \\
& y=\text { chez le coiffeur } \\
& \text { ça }=\text { j'y suis allé samedi } \\
& \text { son = Linda } \\
& \text { ça }=\text { c'est son jour de sortie } \\
& \text { en = j'ai promis à Linda } \\
& y=\text { chez le coiffeur }
\end{aligned}
$$

There is no reason to suppose that this short exchange is anything other than typical in this respect. Markers of cohesion are frequently redundant and it is precisely redundancy which is expendable in any succinct or telegraphic style such as that of subtitles. Studies are indeed needed of the effects of this reduced cohesion on the processing efforts of audiences.

There is, however, a point of overriding importance here. It has long been recognised in linguistics that sequences do not have to be cohesive in order to be coherent. Widdowson (1978: 29) offers the following example.
A- "That's the telephone"
B- "I'm in the bath"
A- "OK" 
There is no surface connectivity between the three utterances here. Yet such an exchange would be perfectly coherent for its users in a given context. Pragmatically, $A$ is requesting of $B$ that $\mathrm{s} / \mathrm{he}$ perform an action; $\mathrm{B}$ utters a reason for non-compliance with the request; $A$ agrees to perform the action instead. In fact, coherence requires much more than text cohesion because it is bound up with interpersonal meaning. The elliptical style of this exchange shows how, for communication to be successful, the amount that needs to be said is conditioned by the assumptions users make about each other's assumptions. That is, coherence is a condition of users, not a property of texts. The converse case to that cited above would be a text which is fully cohesive but lacks coherence for particular receivers because it has not been geared to their communicative needs, as for example if a laboratory report in the field of optoelectronics were read aloud to a group of primary-school children. For our purposes then, it is important to realise that coherence is established through a gearing of what is spoken on-screen to assumptions about what an audience may be expected to know already or assume in the light of the full range of other stimuli to which they are being subjected.

A related issue here is the influence of the "conduit metaphor" (Reddy 1979) in analyses of audio-visual translating. That is, a tacit assumption is made that meaning can be quantified and conveyed as an entity via a process of linguistic encoding, message sending and de-coding. Although few would explicitly claim that meaning is an entity capable of being transported in this manner, the use of such terms as "message" and "encode" is prevalent in the literature (e.g. Luyken et al. 1991; de Linde and Kay 1999 a: 26-8), resulting in a certain lack of clarity concerning the nature of language communication in audiovisual contexts.

The processing of film text involves not just establishing sequentiality of underlying propositional meaning of any linguistic exchange but also a search for the sequentiality of interpersonal dynamics. Thus, any discussion of film text cannot really avoid consideration of pragmatics, including especially the ability of text users to infer unexpressed intended meanings.

At the same time, such text has to be seen as just one part of the viewer's overall processing of the range of stimuli to which s/he is exposed. As Smith, in Gambier (1998: 148), observes, film subtitles are in effect "no more than a support for the visuals". Any consideration of film text in isolation from the context of the moving image and soundtrack is consequently doomed to failure. Viewers are engaged in a constant process of matching emerging text with accompanying sound and moving image, including (especially for our purposes) the paralinguistics, kinesics and proxemics of characters on screen and awareness of both the fictional context in which they operate (that is, what is assumed to be assumed) and the overall context of the cinematic event. 
In Gottlieb's (1998: 245) terms: films are polysemiotic. Signs interact with each other, resulting in the availability of added meanings. Intended meaning is thus inferred not from subtitles as text but rather through the interaction of

polysemiotic systems. From this standpoint, it follows that there would be no onus on the subtitler to ensure that the subtitles relay all such meanings. Yet it is interesting to note the apparently contrary view of professional audio-visual translators in this matter. S. Smith in Gambier (1998: 145) advances the view that subtitles need to "interpret" what is being said because the audience cannot be expected to pick up elements of meaning carried by the intonation of utterances in the spoken source text. Likewise, Reid in Luyken et al. (1991: 156) claims that subtitling is "concerned with the "intention" of what the speaker wanted to say".

Despite these views of what should happen, there is plenty of evidence from empirical observation (e.g. Mason 1989, Hatim and Mason 1997), that what tends to be omitted is explicit markers of the interpersonal pragmatics of dialogue, including the negotiation of "face" (Brown and Levinson 1987) conducted by characters portrayed on screen. For example, in a sequence from a French television soap opera, Châteauvallon, screened on British television, an election agent seeks to overcome his candidate's reluctance to indulge in a dirty-tricks campaign. Our analysis found that the outcome of the linguistic power struggle between the two characters was not retrievable from the subtitles, which nevertheless were successful in relaying the propositional meaning of the utterances involved.

\section{POLITENESS}

To see how these factors come into play at the level of individual subtitles, let us briefly review some of the evidence presented previously (Hatim and Mason 1997: 78-96) from the English subtitled version of the French feature film Un Coeur en hiver (Sautet 1992). Largely because of the necessarily concise style of the subtitles, the hesitant and tentative utterances in French of stéphane, a central character in the film, begin to appear more assertive and categorical in English. Conversely, Camille, whose relationship with Stéphane is problematic precisely because of the latter's inability to be decisive and to commit himself, opts for a very direct challenging of his behaviour and motives. In the subtitles, on the other hand, she appears conciliatory. In Table 1 below, a literal translation of the source-text utterance is given between square brackets, the corresponding subtitle is shown on the right and an indication is given of the politeness features involved, using the terminology of Brown and Levinson (1987). 


\section{Stéphane:}
Au fond vous êtes à peu près d'accord
Basically, you agree
[Really, you more or less agree]
(Use of hedging, as redressive action, partly reduced in translation)
Vous n'avez pas joué un peu vite?
You took it a bit fast
[Didn't you take it a bit fast?]
(shift from "off-record' to "on-the-record" face-threatening act)

\section{Camille:}

Vous partez déjà?

Leaving already?

[Are you leaving already?]

(direct question in source becomes conciliatory in translation; conciseness signals

"claiming common ground")

Vous avez d'autres rendez-vous? Other business?

[Have you other business?]

("bald, on-record" challenge shifts to sympathetic "claiming common ground")

Table 1. Shifts in politeness in Un Coeur en hiver

The reduction in translation of Camille's questions in Table 1 are a particularly good example of the claims being made here. In the film, Stéphane has picked up his overcoat and is visibly making plans to leave. He says nothing. Camille's questions are obvious challenges to Stéphane's behaviour and clearly implicate (1) that he is leaving too soon (déjà?) and (2) that he is putting "other business" before the option of staying. They are face-threatening acts, performed "bald, on-record". Now, subtitlers tend, for obvious reasons, to operate on the rule of thumb that the shortest translation compatible with establishing coherence is always to be preferred. Thus, "leaving already?" and "other business?" both meet the criterion of giving full semantic access to what Camille is saying in the shortest possible manner. The translations are efficient in this respect. The problem is that elision of subject and auxiliary verb in questions of this kind in English is a conventional way of signalling solidarity, understanding, sympathy, etc. (cf. "Feeling peckish? Try Mega-Pizza" or "Lost? We'll help you find your way...", etc. in advertising slogans). In other words, the default reading of Camille's questions in English is that they are conciliatory, expressing understanding of Stéphane's predicament in having to leave so soon; the opposite of what is implicated in the source text. 
At this point, it is important to stress that this analysis is intended to be a descriptive, not a prescriptive account. There is no intention here to criticise subtitlers, who are just doing their job according to the requirements. Even less is this an exercise in error analysis. The point is that, in subtitling, something has to be omitted. So is this omission a random selection of source text features or are there consistent patterns in what is retained? As indicated earlier, there does indeed appear to be a consistent trend.

Having established this much, the question that then arises is: Does it matter? To what extent do film viewers rely on subtitles to form their understanding of the interpersonal relations of characters on screen? Provided overall coherence is established, particular meanings may be retrieved by the process of matching the moving image to a range of paralinguistic features described above. We do not know enough about this and there is a need for comparative studies of audience response to original soundtrack and to subtitles, for example, in the form of tests of recall, impressions of directness and so on. It is possible, perhaps even probable, that attentive viewers can and do retrieve intended effects. However, reading subtitles at the same time as "reading" a moving image clearly imposes a strain on the viewer's processing resource. If each stimulus confirms and reinforces each other stimulus, then the load is manageable. If stimuli appear to contradict each other, an additional strain is imposed. In short, the following hypothesis would seem worthy of investigation:

a) When the intersemiotic match is good, the processing load is manageable.

b) When the match is problematic, processing is also problematic, leading to an overload of cognitive tasks to be performed in the time available.

A further implication of our analysis of the examples referred to above is that, in films, interpersonal relationships are negotiated over whole sequences and not in individual utterances. So, instead of adopting an atomistic speech act approach to the analysis of dialogue, we should be looking at the negotiation process as it evolves over a whole speech event. A relevant question would be: What is the shift in interpersonal dynamics we are intended to retrieve (or better: we may retrieve) in a given sequence? For example, Stéphane's abrupt departure in the sequence referred to above may be seen as gratuitous. But if it is seen as motivated, then the reasons for it must be sought in something which has occurred in the sequence in question.

\section{AN EXAMPLE}

Our final example of pragmatics at work in subtitling is taken from another French film, The Wages of Fear (Clouzot 1954). In this multilingual production 
(characters belonging to an assortment of nationalities each speak in their own language), there is no single source language although French increasingly predominates as events unfold. The version we are considering is one in which all utterances not sourced in English are subtitled in English. The tale involves two Frenchmen who become acquainted in the alien environment of a tough (un-named) Latin American country. As the senior partner in the friendship, Jo totally dominates Mario in the first half of the film but the tables are turned when the two undertake a dangerous assignment together, involving driving a lorry loaded with kegs of nitro-glycerine for many miles over a rocky, potholed track, strewn with obstacles of all kinds. Mario turns out to be the more ruthless of the two, eventually driving the lorry over Jo's legs, rather than lose the reward for delivering the assignment.

The development of this relationship is gradual and under-played: it takes place both linguistically and paralinguistically, as in the short sequence to be considered here, where gaze and posture are crucial to an understanding of what is going on. The sequence shows an exchange between Mario and Jo when the latter, still in a dominant position in the early stages of the film, suggests to Mario that he accompany him to the hairdresser. Mario reveals that he has arranged to go out with Linda, a local girl he has befriended, whom Jo manifestly disapproves of. The dialogue is reproduced as Table 2, again with a literal version of the French source provided between square brackets; and with relevant action and paralinguistics in round brackets and small caps. Subtitles appear on the right of the table. The timings for duration of subtitles on screen and gaps between appearance of subtitles are given in whole seconds on the right of the table.

It was noted earlier that the incidence of explicit markers of cohesion is noticeably lesser in the set of subtitles than in the screenplay. The real problem for the subtitler in this sequence, however, is the rapidity of the dialogue, which makes necessary considerable abbreviation. The three-second gap between the first and second subtitles, for example, does not allow for any representation of the sequence: "ça nous distraira/J'y suis allé samedi/Ben, ça ne fait rien" ["It'll keep us amused/I went on Saturday/Well, that doesn't matter"]. Of course, segmentation of the subtitles could have been arranged differently and other items could have been selected for inclusion instead of those represented here. But the degree of omission required would, no doubt, remain about the same. Mario's reluctance to accede to Jo's proposal has to be inferred from his facial expression and from the implicature created by the apparent flouting of the maxim of relevance. That is, the fact that it is Linda's day off, to be made relevant to Jo's offer, has to be seen as an off-record rejection of the offer. The problem, then, is not primarily one of cohesion but of coherence. Still, readers of subtitles are endowed with the same inferencing abilities as anyone else and 


\begin{tabular}{|c|c|c|c|}
\hline Jo & $\begin{array}{l}\text { Allez, viens chez le coiffeur, ça nous } \\
\text { distraira } \\
\text { [Come on, come to the hairdresser's. } \\
\text { It'll keep us amused] }\end{array}$ & $\begin{array}{l}\text { Come to the barber's. } \\
\text { Keep me company }\end{array}$ & (4) \\
\hline Mario & $\begin{array}{l}\text { J'y suis allé samedi. } \\
\text { [I went on Saturday] }\end{array}$ & & (3) \\
\hline Jo & $\begin{array}{l}\text { Ben, ça ne fait rien, tu me tiendras } \\
\text { compagnie. } \\
\text { [Well, that doesn't matter, you'll keep } \\
\text { me company] } \\
\text { (STARTS WALKING OFF) }\end{array}$ & & \\
\hline Mario & $\begin{array}{l}\text { C'est que... (JO TURNS ROUND) } \\
\text { Aujourd'hui j'ai promis à Linda. C'est } \\
\text { son jour de sortie. } \\
\text { [It's that... Today I've promised Lin- } \\
\text { da. It's her day off] } \\
\text { (Jo's EXPRESSION HARDENS) }\end{array}$ & It's Linda's day off... & (3) \\
\hline Jo & $\begin{array}{l}\text { Ah pardon, ça change tout... Parfait, } \\
\text { parfait! } \\
\text { [Oh sorry, that changes everything... } \\
\text { Perfect, perfect] } \\
\text { (turns round, walks off) }\end{array}$ & $\begin{array}{l}\text { Sorry, that changes } \\
\text { everything. }\end{array}$ & (4) \\
\hline Mario & $\begin{array}{l}\text { Tu m'en veux? } \\
\text { [Do you hold it against me?] }\end{array}$ & Do you mind? & (2) \\
\hline \multirow[t]{2}{*}{ Jo } & $\begin{array}{l}\text { (TURNS BACK, UNSMILING) Mais pour qui } \\
\text { tu te prends? T'es pas regardé mon } \\
\text { petit gars. }\end{array}$ & & (2) \\
\hline & $\begin{array}{l}\text { [But who do you take yourself for? } \\
\text { You're not taken into account, my kid] } \\
\text { (TURNS ROUND, WALKS OFF) }\end{array}$ & $\begin{array}{l}\text { Who do you think you } \\
\text { are, kid? }\end{array}$ & (4) \\
\hline Mario & $\begin{array}{l}\text { Non, Jo, attends-moi. Attends-moi, Jo, } \\
\text { j'y vais. } \\
\text { [No, Jo, wait for me. Wait for me, Jo, } \\
\text { I'm coming] }\end{array}$ & Jo, wait for me. & (3) \\
\hline
\end{tabular}

Table 2. Subtitles: H-G. Clouzot, Le Salaire de la peur/The Wages of Fear (1954) 
one might surmise that, despite the lack of explicitness and the rapidity of the dialogue, there would be relatively little difficulty in understanding that Mario is reluctant to go to the hairdresser with Jo.

In the remainder of this short dialogue, however, the ellipsis is even more problematical because of the interpersonal dynamics involved. From the Englishlanguage viewer's perspective, the problems of coherence are:

1. Why does the fact that it is Linda's day off "change everything"? The potential meaning of "Sorry, that changes everything" is merely a change of plan (i.e. Linda's day off means that the plan to go to the barber's cannot be implemented).

2. Why does Mario's "Do you mind?" elicit the response "Who do you think you are?"? Of course, the meaning potential of "Do you mind?" is variable according to intonation, a feature to which viewers relying on subtitles have limited access. Yet, under any interpretation, the retort "Who do you think you are?" is not obviously motivated unless extra meanings are inferred.

3. Why does Mario change his mind and run after Jo? There must surely be some reason other than a sudden impulse to accompany Jo to the barber.

None of these questions can be answered from the sequence of subtitles alone. Facial expressions and posture do give strong clues but leave much to be intuited. If we return to the source-language soundtrack, however, we find plenty of evidence for the reasons behind the manifest reactions of each character.

1. Rather than merely alluding to a change of plan, Jo uses heavy irony (" $A h$ pardon!"), creating an implicature along the lines of "Excuse me for having presumed to ask!". Thus, the reason why Linda's day off "changes everything" can now be seen as a comment on the state of the relationship between Mario and Jo: Linda comes first! Retrieving the irony in this utterance is crucial to an understanding of the pressure that Jo is now putting on Mario. Jo concludes: "Parfait, parfait", a conventional ironic judgement with a standard implicature of the type "That settles it!". By saying the opposite of what he means (things are far from "perfect" from Jo's point of view), Jo is using an off-record politeness strategy. Brown and Levinson's (1987: 221-2) account of irony suggests that flouting the maxim of quality (say what you believe to be true) is a means of face redress in a situation of considerable threat to face. In order for the implicature to be retrieved, there have to be clues that the intended meaning is being conveyed indirectly. In this case the clues are prosodic (Jo utters his "Parfait, parfait", with a rising intonation), kinesic (he turns round and makes to walk away) and broadly contextual: relevance is here established only by interpreting this comment as a suggestion that their friendship is at an end. 
2. Mario's response is to enquire whether his not coming to the barber's really matters to Jo ("tu m'en veux?"), from which it could be inferred that he had only "promised Linda" because he didn't think Jo would care either way. However, the question can also be taken as implicating that Jo needs Mario, i.e. that Mario holds the power in the relationship between the two friends. To put right this apparent presumptuousness on the part of Mario, Jo snubs him: "Mais pour qui tu te prends?" ["But who do you take yourself for?"], clearly reasserting his own dominance.

3. In case the implicature (via the maxim of relevance) is not strong enough, however, Jo is keen to place on record his own estimation of Mario: 'T'es pas regardé, mon petit gars" ["You don't count, kid"]. The form of address is insulting and deprecating while the pronouncement itself has an air of finality. Yet both of these strong indicators are omitted from the subtitles, making it less obvious to subtitle-reliant viewers why Mario has such a sudden change of mind.

\section{CONCLUSION}

In this short study, we have merely analysed one sequence from one film, subtitled from French into English. The analysis is intended simply as an illustration of the factors that are at play in retrieving intended meanings. We have suggested that politeness mechanisms and the linguistic traces they leave are central to this process and that, within the culture and language of the source text in the original soundtrack of the film, there are unlikely to be inordinate problems in the negotiation of meaning between producer and receiver. We have further suggested that, because subtitling necessarily involves a process of selection and abbreviation, linguistic clues to politeness and face-work are frequently sacrificed. Kinesic clues (gesture, posture, etc.), on the other hand, are still fully available since the moving image is the same for source-language and target-language viewer alike. We do not know enough about the use of prosodic clues (intonation) by viewers who do not have access to the source language. It may be that, where languages share some prosodic features (say, English, French, Spanish), some meaning is indeed derived in this way. But, we have argued, the retrieval is surely hampered, especially when apparently non-matching clues are encountered.

In order to test hypotheses of this nature, empirical studies are needed of audience response. It is striking that little, if any, work of this kind has been carried out. What meanings do subtitle-reliant viewers retrieve? How is coherence established when clues are apparently contradictory? And beyond these considerations, what happens to retrieval of meaning from intonation, gaze, posture and so on, when source and target cultures are remote from each other (say, Chinese 
and English or Spanish)? The scope for empirical studies of audience response is enormous. Let us hope that they will form part of the research agenda of the future.

\section{REFERENCES}

Brown, P. and S. Levinson (1987): Politeness. Some Universals in Language Usage, Cambridge, Cambridge University Press.

DE Linde, Z. and N. KAY (1999 a): The Semiotics of Subtitling, Manchester, St. Jerome.

DE LINDE, Z. and N. KAY (1999 b): "Processing subtitles and film images. Hearing vs. Deaf viewers", The Translator, 5 (1), 45-60.

FERraRA, A. (1980 $a$ ): "An extended theory of speech acts: appropriateness conditions for subordinate acts in sequences", Journal of Pragmatics, 4, 233-52.

FERrara, A. (1980 b): "Appropriateness conditions for entire sequences of speech acts", Journal of Pragmatics, 4, 321-40.

GAMBIER, Y. (ed.) (1998): Translating for the Media, Turku, Painosalama Oy.

GoRIS, O. (1993): "The question of French dubbing: towards a frame for systematic investigation", Target, 5 (2), 169-190.

Gottlieb, H. (1998): "Subtitling” in Baker, M. (ed.) (1998): Routledge Encyclopedia of Translation Studies, London, Routledge, 244-48.

Grice, H.P. (1975): "Logic and Conversation" in Cole, P. and J. Morgan (eds.) (1975): Syntax and Semantics: Speech Acts, New York, Academic Press.

LAMBERT, J. (1990): "Le Sous-titrage et la question des traductions: Rapport sur une enquête" in Arntz, R. and G. Thome (eds.) (1990): Übersetzungswissenschaft: Ergebnisse und Perspektiven. Festschrift für Wolfram Wilss zum 65. Geburtstag, Tübingen, Narr, 228-38.

Hatim, B. and I. MASON (1997): The Translator as Communicator, London, Routledge.

LUYKEN, G.M. and others (1991): Overcoming Language Barriers in Television, Manchester, The European Institute for the Media.

MAson, I. (1989), "Speaker meaning and reader meaning: preserving coherence in screen translating" in KöLmel, R. and J. PAYNE (eds.) (1989): Babel. The Cultural and Linguistic Barriers Between Nations, Aberdeen, Aberdeen University Press, 13-24.

Reddy, M. (1979): "The conduit metaphor" in Ortony, A. (ed.) (1979): Metaphor and Thought, Cambridge, Cambridge University Press, 164-201.

Venuti, L. (ed.) (2000): The Translation Studies Reader, London, Routledge. Widdowson, H.G. (1978): Teaching Language as Communication, Oxford, Oxford University Press. 


\title{
EL ESPECTADOR Y LA TRADUCCIÓN AUDIOVISUAL
}

\author{
Roberto Mayoral Asensio \\ Universidad de Granada
}

\section{EL PAPEL ACTIVO DEL ESPECTADOR}

Este tema ha contado con bastante atención en la bibliografía, ya abundante, de nuestro campo (destaca de Linde y Kay, 1999; Gottlieb, 1997; Kovačič, 1995; Ivarsson, 1992; Ivarsson y Carroll, 1998; Fodor, 1976; Agost, 1999, así como distintas referencias en ellos incluidas). Mientras que en otras especialidades de traducción la presencia del destinatario o usuario no resulta tan evidente y puede quedar muy enmascarada por la impresionante presencia del autor y del texto, en la traducción audiovisual, la consideración del espectador es inevitable en cualquier estudio. El acto de la traducción no concluye en el momento en que se fabrica el vídeo o la cinta de celuloide, con su traducción incorporada, sino en el momento en que se proyecta o consume esta cinta y se produce el milagro comunicativo de que cada uno de los consumidores entienda el mismo producto y el mismo mensaje de una forma distinta, dependiendo de su cultura, su familiaridad con el género, la obra y el autor, su experiencia vital, su estado de ánimo, su concentración en ese momento, etc. En realidad, este proceso de comprensión no concluye más que con el olvido, pues la obra audiovisual continúa siendo digerida mientras permanece en el recuerdo, en la mente del espectador y da lugar, así, en cada momento, a nuevas interpretaciones sometidas a variaciones continuas conforme se modifican los parámetros. Esta situación no es exclusiva de la traducción audiovisual: ocurre así con cualquier acto de comunicación, no solamente con la interlingüística; ocurre especialmente con las formas de comunicación más relacionadas con la literatura y, lo mismo que acabo de decir sobre la obra audiovisual, lo podría haber dicho de la lectura de una novela. 


\section{LA ESPECIFICIDAD DE LA TRADUCCIÓN AUDIOVISUAL}

Estoy de acuerdo con casi todos nuestros colegas especialistas en este tema en que, si realmente queremos que avance el conocimiento en nuestra especialidad o incluso si pretendemos elaborar una teoría particular de la traducción audiovisual, cuando hablemos de traducción audiovisual hay que hablar de lo que es específico de este tipo de traducción, en lugar de, como se hace en muchas ocasiones, tomar situaciones contempladas en general para todo tipo de traducción y constatar su cumplimiento en nuestro caso particular de traducción. Esta declaración previa me compromete a discutir el tema de la traducción audiovisual y el espectador en aquello que es peculiar de la traducción audiovisual; compromiso que inevitablemente romperé en más de una ocasión a lo largo de mi exposición, debido a la falta de rigor que a casi todos nos aqueja.

La pregunta inevitable, después de esta introducción, es ¿qué es lo específico de la traducción audiovisual? Pero antes de entrar en la respuesta, haré un par de aclaraciones.

Primera aclaración. Al referirme a traducción audiovisual (Mayoral, 1997), incluyo no sólo los productos transmitidos a través de cine, vídeo, DVD y televisión, sino también los productos multimedia que reciben difusión a través de los ordenadores o, desde hace poco tiempo, de las consolas de videojuegos.

Segunda aclaración. Al objeto de mi trabajo, la dependencia de la traducción del tipo de destinatario -hipótesis o constatación previa de la que partono debe ser privativa de un solo tipo de traducción audiovisual (en ese caso, me vería obligado a rectificar el título de la exposición y restringir su alcance), sino que debe afectar, de una u otra forma en cada caso concreto, a todos los tipos de traducción audiovisual (subtitulado, doblaje, half-dubbing, voice-over, etc.).

Llegada la hora de responder a la pregunta planteada, encuentro cuatro tipos de peculiaridades en la traducción audiovisual:

a) La primera peculiaridad es que la comunicación en el caso de la traducción audiovisual se realiza mediante múltiples canales y a través de diferentes tipos de señales; básicamente, hablamos a través de los canales auditivo y visual y de sus diferentes tipos de señales característicos: imagen en movimiento, imagen fija, texto, diálogo, narración, música y ruido. Esta convivencia da lugar, habitualmente, a la necesidad de una sincronización o ajuste entre todos estos tipos diferentes de sistemas de señales para que la obra concebida por el director se transmita de forma eficaz (Mayoral y otros, 1988).

Para el doblaje, la sincronización exige la coincidencia de silencios, inicios y pausas (siempre que no estemos en off o fuera de boca) y la sincronía visual, 
que se aplica con diferentes grados de rigor (desde los sistemas muy exigentes como el de Fodor, 1976, hasta los sistemas habituales en estos momentos en España, que sólo aplican condiciones de sincronismo a labiales en primer plano o planos de detalle).

Para el voice-over, la sincronización exige el inicio tras una pausa de tres o cuatro palabras respecto a la versión original y una coincidencia más o menos estricta de los finales de los parlamentos.

Para el subtitulado, la sincronización exige una coincidencia entre principios y finales de parlamentos (con las correcciones hechas por Ivarsson, 1992. que comentaremos más adelante), la observancia de una velocidad de lectura que resulte cómoda al espectador y el respeto a los límites de espacio y otras convenciones para la presentación de los subtítulos en pantalla. Para el traductor, estos condicionamientos se pueden materializar en una proporción entre la duración del spot (el segmento del diálogo original que debe encontrar correspondencia en un solo subtítulo) y la extensión de su correspondiente texto traducido. En el caso del traductor de subtítulos con guión posteditado (con master titles o diálogos especialmente adaptados para el subtitulado, además de fonolocalización mediante metraje), esta proporción viene dada en este mismo guión o en las instrucciones de la productora. En el caso del traductor que trabaja sobre el sonido original, la proporción se establece, de forma más libre y creativa, de oído, por el propio traductor (Mayoral, 1993; Torregrosa, 1996). Así, un subtítulo puede variar su extensión desde 20 hasta 40 matrices por línea (Ivarsson, 1992, describe este tema con amplitud), sólo puede tener una o dos líneas (salvo en los subtítulos para sordos o enseñanza de lenguas, que pueden utilizar hasta tres líneas) y la velocidad de lectura es muy variable. En cuanto a este último aspecto, la $20^{\text {th }}$ Century Fox señala 10 fotogramas por pie de película (entre 14 y 15 caracteres por segundo), mientras que la televisión y el vídeo imponen un ritmo más lento. De hecho, el programa de ordenador para subtitulado en televisión Screen Subtitling Systems Ltd (1998) apunta una velocidad de lectura de 9 caracteres por segundo para adultos y, para los niños, oscila entre la mitad y los dos tercios de esta cantidad, dependiendo de su edad. Por otra parte, entre un subtítulo y el siguiente, debe haber una pausa con una duración aproximada de entre 3 fotogramas (Screen Subtitling Systems Ltd, 1998) y 6 fotogramas (Ivarsson, 1992: 39, ofrece la cifra de 4 a 6 fotogramas para la televisión sueca).

La segunda peculiaridad de todo tipo de traducción audiovisual es que la traducción no es realizada tan sólo por el traductor, sino también por toda una serie de protagonistas, como son los actores, el director de doblaje, el director de subtitulado, los ajustadores, etc., ninguno de los cuales tiene por qué conocer ni bien ni mal la lengua original y muchos de los cuales ni siquiera han visto 
la obra completa antes de abordar su traducción. Esta situación viene dada por las condiciones de ajuste, por las peculiaridades técnicas y también por la vertiente artística de este tipo de trabajo (Mayoral, 1995).

Profundizando en la traducción audiovisual, habría que concluir como tercera peculiaridad que, en los casos de subtitulado, voice-over, half-dubbing e interpretación o traducción simultánea, el espectador percibe el producto audiovisual en un mínimo de dos lenguas diferentes de forma simultánea (es un producto bilinguie), por los mismos canales (voice-over, half-dubbing, traducción simultánea) o por canales diferentes (subtitulado) e incluso, en ocasiones, se combinan varios de estos dos sistemas. Hay que advertir que si se percibe el mismo mensaje dos veces por el mismo canal en dos lenguas diferentes se produce un ruido importante en la comunicación (Jeanne Martinet, 1976 [1973]: 26-9).

La cuarta peculiaridad de la traducción audiovisual es que tiene su propio repertorio de convenciones entre el producto traducido y el espectador (para el subtitulado, Marleau, 1982) que, una vez asumidas (casi siempre de forma inconsciente), permiten que un producto traducido se pueda percibir en mayor o menor grado como un producto original. Estas convenciones son:

a) Para el doblaje:

- La sincronía visual o concordancia entre los movimientos articulatorios visibles del habla y las palabras que se escuchan simultáneamente (Fodor, 1976).

b) Para el subtitulado:

- La letra cursiva en el subtítulo indica que el personaje que habla no se encuentra visible en la pantalla; está en voice-over (V.O.).

- Un subtítulo de dos líneas en el que cada línea pertenece a un personaje diferente se marca con un guión al principio de cada línea.

- Cuando un subtítulo termina en puntos suspensivos y el siguiente comienza de la misma manera, esto indica que se trata de un mismo parlamento dividido por ser demasiado largo para la extensión del subtítulo.

- Una palabra o frase escrita totalmente en letras mayúsculas indica que constituye un título narrativo, es decir, que aparece escrita en pantalla y no es dicha oralmente por los actores.

- En busca de la mayor brevedad, la mecanografía, la puntuación, el uso de siglas y abreviaturas, etc. pueden admitir en el subtitulado formas apartadas de la norma en la comunicación habitual. 
c) Para el voice-over:

- El voice-over para cada parlamento comienza cuando ha transcurrido una pausa de tres o cuatro palabras en la que sólo se escuchan las palabras originales y a todo su volumen.

- La letra cursiva se utiliza para todo aquello que no se dice realmente: pensamientos, recuerdos, lectura, lo que no se escucha directamente de otra persona, poemas, noticiarios cinematográficos, canciones, etc. (Marleau, 1982). Estos usos pueden aparecer también en otras formas de traducción audiovisual.

\section{LOS UMBRALES DE PERMISIVIDAD}

Las necesidades del ajuste tienen muy en cuenta al espectador. El espectador es capaz de advertir en grados diferentes la presencia o ausencia de ajuste entre los diferentes tipos de señales, incluso en el doblaje, en el que es capaz de advertir si lo que oye en la versión traducida es compatible con lo que ve en las imágenes en pantalla (Fodor, 1976). Diferentes tipos de espectadores tienen diferentes sensibilidades ante esta cuestión, dependiendo de su edad (los niños muestran atención sintética), su sexo (atención sintética para las mujeres o analítica para los hombres), su profesión (las profesiones en las que escuchar lo que dicen otras personas es importante, como vendedores, profesores, etc., muestran mayor sensibilidad hacia la falta de sincronismo), su educación, su familiaridad con la lengua extranjera, etc. Puede resultar, pues, muy diferente la traducción de una película de Chuck Norris que la de una película de Bergman, y no sólo ni fundamentalmente por la diferencia de géneros entre ambas películas (el género es otro factor ineludible aunque ciertamente inestable o difuso), sino principalmente por los diferentes tipos de espectadores que habitualmente tienen. Lo mismo podríamos afirmar para un producto multimedia de las diferentes traducciones que precisan un CD-Rom de juego de evasión y un CDRom que sea un producto cultural o educativo. Esta faceta del ajuste se intersecta con la faceta de la interpretación artística, pues en algunos lugares, como en España, se trabaja con unas condiciones de ajuste no demasiado exigentes que quedan enmascaradas al desviarse la interpretación del espectador hacia la interpretación de los actores o la acción (es un aspecto del principio minimax, pues cualquier esfuerzo no necesario dedicado al ajuste puede ir en detrimento de la interpretación artística).

El elemento del ajuste o de la sincronización no sólo se intersecta con el de la interpretación artística, sino también con el del medio de difusión. Diferentes medios de difusión (cine, vídeo, televisión, multimedia) exigen diferentes tipos de ajuste, pero lo exigen tanto por razones técnicas (legibilidad, velocidad de 
proyección) ${ }^{\prime}$ como por el tipo de consumidor del producto. El cine tiene un tipo de espectador con una capacidad de apreciar el asincronismo visual, con una capacidad de lectura y con una familiaridad con la cultura y la lengua extranjeras que normalmente son superiores a las del espectador de televisión; el consumidor de vídeo, por otro lado, ocupa una posición intermedia entre ambos (Ivarsson, 1992). El género, además, interviene con carácter decisivo en el tipo de traducción exigida por un producto multimedia (más que el factor de la difusión por ordenador). Como describe Ivarsson (1992: 41-42), los subtítulos de cine son más largos, más seguidos y permanecen menos tiempo en pantalla que los subtítulos para televisión. Como señala el mismo autor (1992: 43-44), una cadena de televisión pública y generalista atiende a una enorme diversidad de espectadores, a todos los cuales tiene que ofrecer una mínima satisfacción, independientemente de su cultura, nivel de alfabetización, conocimiento de la lengua de proyección, defectos visuales y auditivos, etc., con lo cual este tipo de cadenas no debe apuntar en su tipo de traducción (o expresión en general) ni siquiera al espectador medio, sino a los espectadores con capacidades más bajas de entre todos los suyos. Por ello, en el subtitulado de televisión, según el mismo Ivarsson (1992: 46-48), es posible o conveniente dejar pausas de reconocimiento (fixation pauses) de los personajes al principio de la traducción de cada título con una duración aproximada de $1 / 4$ de segundo y es posible no respetar el final del parlamento y hacer continuar el subtítulo en pantalla cuando ya se ha llegado al silencio anterior al siguiente spot. Esto no siempre es así y en España los padres nos vemos obligados a traducir los subtítulos de televisión a nuestros hijos, dado que los subtítulos no respetan su capacidad de lectura. Nos preguntamos lo que ocurre también con otros espectadores adultos españoles.

Respecto a la velocidad de lectura y su relación con la extensión de la traducción, queremos hacer el siguiente comentario. Al igual que se habla de voces superpuestas, en la traducción audiovisual se podría hablar de velocidades superpuestas: en el caso del doblaje y del voice-over, la de interpretación de los actores de doblaje y la de dicción del traductor; en el caso del subtitulado, la de lectura mental del espectador, la de lectura mental del traductor, la de interpretación de los actores originales y el ritmo impuesto por las normas de los master titles. El traductor de voice-over y el de doblaje debe hacer que su texto pueda ser leído cómodamente a la velocidad de dicción de los actores de doblaje (normalmente tiene tendencia a hacer traducciones demasiado largas y a leer mucho más deprisa que los actores, en su afán por no reducir el significado). En

1. En cuanto a éste último, Ivarsson (1992: 39-40, 45-6) señala 24 fotogramas por segundo en cine y 25 fotogramas por segundo en televisión -un $4 \%$ más corto--, lo cual no deja de ser controvertido. 
el caso del subtitulado con spotting, el traductor debe ajustar la extensión de su traducción no a la velocidad de los actores sino a la velocidad o capacidad de lectura (en silencio) del espectador. Al traductor poco experimentado le resulta difícil alcanzar este ajuste, porque su propia velocidad de lectura puede llegar a ser el triple de la del espectador (Ivarsson, 1992: 44) y el traductor también tiene siempre la tendencia de escribir textos demasiado largos. En el caso del subtitulado con guiones posteditados, se establece una norma única de correspondencia entre la duración del original y la extensión del subtítulo, independientemente de la velocidad de dicción de los parlamentos originales (por ejemplo, en el caso de la $20^{\text {th }}$ Century Fox para el cine, la correspondencia es de 10 matrices por pie de película). El problema surge del hecho de que los actores de la versión original no hablan siempre a la misma velocidad, con lo que podemos encontrarnos, por ejemplo, con un parlamento que en el original está constituido por una sola palabra pero que, por su duración, es obligado traducir, según la norma de la productora, por varias palabras (por ejemplo, en La familia Addams, hay que traducir «Pugsley» por un subtítulo de 20 matrices). En estos casos, es muy posible que el espectador perciba la falta de correspondencia entre el original y la traducción. (Por el contrario, el traductor que hace el spotting lo resuelve normalmente dando la misma extensión a ambas versiones (Torregrosa: 1996).)

El segundo factor mencionado como característico de la traducción audiovisual, el de la intervención de varios tipos de profesionales en el proceso de traducción, guarda una relación más clara con la fidelidad al original que con el espectador, aunque es indiscutible que la participación de todos estos profesionales suple habitualmente el desconocimiento que el traductor pueda tener sobre el tipo de destinatario y sus necesidades y condicionamientos.

Respecto al tercer factor, el de la simultaneidad de recepción del mismo mensaje en lenguas diferentes, hay que decir que nos parece decisivo para todos los tipos de traducción excepto para el doblaje. Se puede decir que, aunque en el doblaje sólo se perciban los diálogos en la lengua de la traducción, el espectador sigue recibiendo, con frecuencia, mucha información en otra lengua o en otra cultura a través de las imágenes y los textos que aparecen en la pantalla (en casos de traducciones descuidadas, a través de la música y sonidos que no han sido traducidos). En otros tipos de traducción, la afirmación general no ofrece ningún tipo de dudas: en el subtitulado, el consumidor o espectador recibe mensajes correspondientes como texto subtitulado en una lengua y como mensaje oral en la lengua original (intervienen más lenguas en casos de subtitulados bilingües); en el caso del voice-over, el espectador recibe dos mensajes orales casi simultáneos en las dos lenguas implicadas; así ocurre también en los casos de half-dubbing y de traducción (o interpretación) simultánea. 


\section{LA HETEROGENEIDAD DEL ESPECTADOR}

El tipo de espectador y la traducción que se realiza tienen una importancia incontestable por unas razones que, a nuestro entender, no reciben la debida atención.

La primera razón es que diferentes tipos de espectadores tienen diferentes conocimientos de la lengua original: desde un conocimiento que les permita una comprensión cercana a la de un nativo (países nórdicos para el caso del inglés) a una comprensión prácticamente nula (caso de una buena parte de los espectadores de productos subtitulados en la televisión española). Díaz (1997: 225-226) hace la oportuna distinción entre receptor pasivo y receptor activo. Una primera conclusión de esto es que el subtitulado es la principal fuente de comprensión de los diálogos para un espectador como el español, mientras que para el espectador nórdico la comprensión procede tanto de la lectura de los subtítulos como de la audición de los diálogos originales. Marleau (1982) da como regla de oro para evaluar la eficacia de una traducción de subtítulos el que el espectador piense que ha comprendido la película sin necesidad de leer los subtítulos; esta afirmación resulta sencillamente ridícula si se intenta aplicar al caso concreto del espectador español, aunque puede ser perfectamente válida para un público bilingüe o casi bilingüe como el canadiense o el norteuropeo (o para el escaso espectador español con conocimientos suficientes de la lengua inglesa oral). Si el espectador español debe prestar más atención a los subtítulos que otros espectadores, esto podría significar también que hubiera que subtitular de forma diferente, ofreciendo más información y, al mismo tiempo, aunque de forma contradictoria, disminuyendo el ritmo de lectura de los títulos. Siguiendo la distinción de Nord (1997: 47-48) entre traducción documental y traducción instrumental, la traducción para un público desconocedor de la lengua original exige una traducción instrumental, mientras que un público conocedor de la lengua original exige una traducción tanto documental como instrumental al mismo tiempo (algo imposible o muy difícil de conseguir en la mayoría de las ocasiones).

Una segunda razón es que el espectador que comprende la lengua de los diálogos originales y la lengua de los subtítulos está constante e inevitablemente comparando ambas versiones. Y, esta comparación, la hace siguiendo sus propios criterios sobre lo que es o deja de ser una traducción acertada. Pues bien, para aquellos espectadores poco o nada familiarizados con la traducción profesional, la traducción más adecuada sigue siendo la traducción más literal, entendiendo aquí como traducción más literal la que traduce íntegramente, sin añadir ni quitar nada, la que ofrece los significados en el mismo orden que el original y la que rinde los significados más habituales de las palabras según los 
diccionarios. Esto conduce a dos cosas: la primera es la inevitable insatisfacción del espectador familiarizado con la lengua extranjera con los subtítulos, pues siempre que oiga turkey esperará leer pavo. Todos sabemos que este tipo de traducción es inconveniente o imposible por las diferencias entre las lenguas, las exigencias de la comunicación y, sobre todo, porque el mensaje subtitulado casi siempre debe ser más corto que el original (la reducción habitual se ha estimado en un 25-30\%) y, cuando las formas sintéticas no son convenientes, no queda más remedio que acudir a la omisión de los significados reiterados, obvios o secundarios (no olvidemos que lo que se cuenta con los diálogos también se está contando, al menos en parte, con imagen y con todos los demás recursos originales del producto). Pero en el caso que estamos considerando, al traductor no le queda más remedio que plegarse ante las exigencias del espectador, pues, si éste percibe la versión subtitulada como mal traducida, va a experimentar un rechazo hacia el conjunto de la película. Díaz (1997: 225) denomina acertadamente a este tipo de traducción traducción vulnerable. La versión subtitulada para espectadores conocedores de la lengua original de los diálogos va a ser, pues, necesariamente, un tipo de traducción marcado por la síntesis, por la comunicación de la integridad de los significados y por el literalismo. No ocurre así en casos como España, donde el público mayoritario va a apreciar más un estilo más natural con respecto a su lengua y a las leyes generales de la expresión, un público que va a diferenciar menos claramente el subtitulado como la versión traducida y, sobre todo, que no va ser consciente de recursos expresivos como la omisión, el cambio de orden, etc. Paradójicamente, la traducción de subtítulos para espectadores poco conocedores de la lengua original permitirá traducciones que (si logramos abstraernos del destinatario y desde un punto de vista académico) pueden parecer más idóneas que en los otros casos.

Algo parecido ocurre con el voice-over o el half-dubbing, aunque en esta ocasión se trate de mensajes orales simultáneos.

El gran problema es que el estudio de la traducción, como otras disciplinas, especialmente las lingüísticas, ha pecado de etnocentrismo y ha girado siempre en torno al inglés y a determinados tipos de espectadores (generalmente, los más cualificados). Esto no debe entenderse como una crítica a los colegas del norte de Europa, que están mostrando una actitud crítica envidiable. No se dan normas de traducción audiovisual para diferentes países (las velocidades de lectura se establecen habitualmente $^{2}$ en palabras por minuto [WPM] aun cuando la extensión media de las palabras puede ser muy diferente para distintas lenguas) y el concepto de localización abarca, por ahora, tan sólo elementos linguiísticos y culturales, pero no los que aquí nos ocupan, que están directamente relacionados con el tipo

2. P. ej. Ivarsson, 1992, y Screen Subtitling Systems Ltd, 1998. 
de destinatario. La velocidad de dicción no sólo depende del origen sino incluso del sexo; Fodor (1976: 31) ofrece, por ejemplo, los siguientes datos de 1952: la velocidad media en sílabas por minuto de un francés es de 350 sílabas, mientras que para un hombre norteamericano es de 150 y para una mujer norteamericana es de 175. Los guiones posteditados que las grandes productoras ofrecen, para el subtitulado de un mismo producto a varias lenguas, una única norma que no tiene en cuenta las diferencias geográficas en cuanto a los espectadores.

El otro gran problema asociado es que las disciplinas que tratan de temas relacionados con la lingüística suelen reconocer la cuestión de la diacronía tan sólo en teoría, pero, en la práctica (el caso de la sociolingüística), otorgan a cualquier resultado una validez eterna, sin tener en cuenta que los destinatarios o hablantes cambian de características a lo largo del tiempo en todos aquellos parámetros que determinan la forma de traducir. Un guión para subtitulado en todo el mundo de la $20^{\text {th }}$ Century Fox en la década de los años 80 ofrece la mismas normas y parámetros para la traducción de subtítulos que hace más de tres décadas (lo hemos constatado en el guión para subtitulado de OSS-117 Terror in Tokyo, de 1966, y en el de The Man from Snowy River, de 1982). Sin embargo, en estas últimas décadas, ha variado enormemente el nivel de alfabetización, de escolarización, la capacidad de lectura (Ivarsson, 1992: 41-42) y muchas más cosas que exigen ya una adaptación de las normas de traducción a:

- el medio de difusión

- el género

- la geografía del espectador y

- la época

\section{ASPECTOS DIACRÓNICOS}

Una nueva razón que exige el replanteamiento de cómo se realiza la traducción audiovisual es que el dinamismo que imponen los cambios derivados de la época se manifiesta también en la relación entre un mismo tipo de espectador y el tipo de traducción que se le ofrece $y$, de forma asociada a lo anterior, entre el género y el tipo de traducción. Lo vamos a ilustrar a continuación.

Todos estamos siendo testigos de un gran cambio que se produce en España en nuestros días: el subtitulado era una forma de traducción reservada al cine de arte y ensayo y a las premuras de los festivales de cine, pero, con la introducción de las plataformas digitales de televisión y con la difusión del DVD, la oferta de subtitulado en España es inmensamente mayor y está alcanzando a un número cada vez más elevado de espectadores. El hecho de que el subtitulado sea una forma más económica de producción puede llevar a España, y a otros países, a 
romper con la tradicional separación entre países subtituladores y países dobladores. ${ }^{3}$ Vamos a plantear una cuestión relacionada en el campo del voiceover. ¿Habrá habido en España algún espectador que haya aceptado alguna vez el voice-over como la forma más natural de ver los documentales? Si la razón principal del voice-over es añadir verosimilitud manteniendo el original, en el caso español este argumento pierde casi toda su razón de ser, porque, para el espectador normal, el voice-over ha sido una forma incómoda de consumir productos audiovisuales en la que, de forma permanente, como en el subtitulado, ha estado recibiendo un mensaje en una lengua incomprensible, lo cual no ha hecho más que entorpecer su recepción. Todos sabemos que no existe una vinculación eterna y universal entre géneros audiovisuales y tipos de traducción y que los mismos documentales que en España se transmiten con voice-over en los países del Norte de Europa se transmiten mediante subtitulado, o que en los países del Este de Europa se ha pasado del doblaje sincrónico al half-dubbing por cuestiones económicas. No estaría de más plantearse cuál es, en estos momentos, la forma más eficaz de traducir documentales para las cadenas y plataformas de televisión españolas: si en voice-over (como hasta ahora) o en doblaje, en subtitulado, en narración sin versión original o de cualquier otra forma.

Pero éste no es el único aspecto diacrónico que debe considerarse. Hemos sido testigos en los últimos tiempos de cómo se han modificado o intentado modificar en España algunas de las convenciones tradicionales entre la traducción y el espectador en diferentes géneros y un primer ejemplo se refiere al subtitulado. La convención tradicional de que en un subtítulo con dos líneas, cada una ellas correspondiente a un personaje, se debía comenzar ambas líneas con un guión se ha sustituido por subtitulados del mismo tipo en los que tan sólo se marca con guión la primera línea. Un segundo ejemplo es que, durante cierta época (afortunadamente concluida), en cadenas especializadas en programación infantil se ofrecieran series dobladas en las que tan sólo se ajustaban principios y finales de parlamentos, sin respetar siquiera los silencios intermedios y despreciando la convención de que debe existir una mínima sincronización de labios entre los principios y los finales intermedios. Un público infantil sometido a esta práctica durante un número de años hubiera terminado por aceptarla como la forma habitual de ver productos doblados y, en su edad madura, podría haber desaparecido la tradicional sincronización de labios con una pérdida enorme de calidad como consecuencia, aunque también con un considerable ahorro para las cadenas.

3. Según Luyken y otros, 1991, son países subtituladores Bélgica, Chipre, Dinamarca, Finlandia, Grecia, Holanda, Noruega, Portugal y Suecia; son países dobladores Austria, Francia, Alemania, Italia, España y Suiza, y en Inglaterra e Irlanda sólo se traduce cuando es imprescindible y combinando ambos sistemas. 
Para otros lugares del mundo, y partiendo de la misma línea de razonamiento, habría que plantearse la substitución del half-dubbing por un doblaje sincronizado, como en los países del Este de Europa. Es cierto que existen culturas de doblaje o subtitulado o de voice-over, pero estas culturas pueden y en algunos casos deben cambiar. Hace ahora un año, un periódico ofrecía un destacado titular: «Un culebrón conquista Vietnam» (Heraldo de Aragón, 30 de agosto de 1998). En el artículo, se nos contaba que, en Vietnam, para culebrones anteriores que no habían conseguido tamaño éxito, se utilizaba el half-dubbing propio de los antiguos países socialistas como sistema de traducción. ( «La Esclava Isura tuvo en Vietnam un desafortunado debut debido a que, cuando se proyectó por primera vez, una sola persona se encargaba de repetir, con el mismo tono y énfasis, todas las voces de niños, jóvenes, adultos y ancianos de ambos sexos que aparecían en esa producción.») Pero los espectadores vietnamitas disfrutaban en masa de una telenovela brasileña, como Todavía moza, «gracias a un buen trabajo de doblaje que crea la ficticia impresión de que los protagonistas hablan con soltura la lengua nacional». Como evidencia del éxito alcanzado por las versiones dobladas, la introducción del doblaje de los culebrones en Vietnam parece haber conducido a que muchos niños reciban los nombres de sus actores principales y ha introducido cambios en el corte de pelo de muchas mujeres. Como contraste, durante un reciente viaje a Ucrania de este autor, las autoridades de este país responsables de la traducción en televisión se oponían radicalmente a considerar el cambio de sistema de traducción basándose para su oposición en particularidades nacionales y en la idoneidad del half-dubbing.

\section{PERSPECTIVAS DE INVESTIGACIÓN}

Todo esto exige una investigación aplicada que hasta el momento no se está desarrollando de forma suficiente o se está desarrollando de forma etnocéntrica. Tan sólo el estudio del subtitulado para sordos (de Linde y Kay, 1999; las cadenas de televisión británicas como la ITC y la BBC; Ivarsson, 1992) constituye una digna excepción y hay que estar al tanto de sus resultados, pues pueden ser de utilidad para los casos de traducción clásica. Salvo casos ejemplares, como el del Laboratorio de Psicología Experimental de la Universidad Católica de Lovaina, con d'Ydewalle y otros) o el trabajo de Gottlieb (1997), la universidad no ha tomado la iniciativa en este tipo de soluciones, que serían posibles en un marco de cooperación tanto interdepartamental como con el sector empresarial, pero que, en mi opinión, resultan inabordables hoy por hoy desde el campo único de la traducción, por la falta de familiaridad de los estudiosos universitarios de la traducción con una actividad experimental que corresponde fundamentalmente a psicólogos. (Otra actividad implica el diseño de muestras 
aleatorias, una metodología rígida, el uso de tecnología como la de los monitores de movimientos de ojos durante la lectura, condiciones de replicabilidad, etc.) Pero esto no debe ser motivo para la renuncia, sino estímulo para buscar entre todos un ámbito en la investigación aplicada en el que la Universidad y los esfuerzos dedicados a los estudios de traducción puedan resultar útiles, tanto al sector empresarial audiovisual como a los espectadores.

\section{BIBLIOGRAFÍA}

Agost, R. (1999): Traducción y doblaje: palabras, voces e imágenes, Barcelona, Ariel.

DíAz, J. (1997): El subtitulado en tanto que modalidad de traducción fílmica dentro del marco teórico de los Estudios sobre Traducción (Misterioso asesinato en Manhattan, Woody Allen, 1993), tesis doctoral de la Universidad de Valencia [en microfichas].

FODOR, I. (1976): Film Dubbing: Phonetic, Semiotic, Aesthetic and Psychological Aspects, Hamburgo, Buske.

Gottlieb, H. (1997): Subtitles, Translation and Idioms, 2 vol., Copenhague, Center for Translation Studies and Lexicography, Department of English, University of Copenhaguen.

IVArsson, J. (1992): Subtitling for the Media: A Handbook of an Art Estocolmo, Transedit.

Ivarsson, J. y M. CARroll. (1998): Subtitling, Simrishamn, Transedit.

Kovačlč, I. (1995): «Reception of Subtitles - The non-existent ideal viewer» en Gambier, Y. (ed.) (1995): Audiovisual Communication and Language Transfers (International Forum, Estrasburgo, 22-24 de junio de 1995). Número especial de Translatio (FIT Newsletter), 14, 3-4, 376-83.

DE Linde, Z. y N. KAY (1999): The Semiotics of Subtitling, Manchester, St. Jerome.

LUYKEN, G-M. y otros (1991): Overcoming language barriers in television: Dubbing and subtitling for the European Audience, Manchester, European Institute for the Media.

Marleau, L. (1982): «Le sous-titres... un mal nécessaire», Meta, 27, 3, 27185.

Martinet, J. (1976): Claves para la semiología, Madrid, Gredos (traducción de Catalina, M. ${ }^{a}$ V. de Martinet, J. (1973): Clefs pour la semiologie, París, Éditions Seghers).

MAYORAL, R. (1993): «La traducción cinematográfica, el subtitulado», Sendebar, 4, 45-68.

- (1995): «La traducción para doblaje de películas, traducción impura» en INIESTA, E.Ma . (ed.) (1995): Perspectivas hispanas y rusas sobre la traduc- 
ción (II Seminario Hispano-ruso de Traducción e Interpretación, Granada, 3-7 de abril de 1995), Sendebar (número extraordinario), 115-125.

- (1997): «Sincronización y traducción subordinada: de la traducción audiovisual a la localización de software y su integración en la traducción de productos multimedia» en MAYORAL, R. y A. TEJADA (eds.): I Simposium de Localización Multimedia (Granada, 3-5 de julio de 1996), Granada, Departamento de Lingüística Aplicada a la Traducción e Interpretación/ITP Spain.

MAYORAL, R. y otros (1988): «Concept of constrained translation. Non-linguistic perspectives of Translation», Meta, 33, 3, 356-67.

NORD, C. (1997): Translation as a Purposeful Activity: Functionalist Approaches Explained, Manchester, St. Jerome.

Screen Subtitling Systems Ltd (1998): Win2020 V2.0-2.03. User Guide. Ipswich, Screen Subtitling Systems.

Torregrosa, C. (1996): «Subtítulos: traducir los márgenes de la imagen», Sendebar, 7, 73-88. 


\section{ASPECTOS METODOLÓGICOS DE LA TRADUCCIÓN AUDIOVISUAL}




\title{
LA TRADUCCIÓN DE TEXTOS AUDIOVISUALES Y LA INVESTIGACIÓN TRADUCTOLÓGICA
}

\author{
Patrick Zabalbeascoa \\ Universitat Pompeu Fabra
}

\section{INTRODUCCIÓN}

Para identificar, comprender y asimilar los fenómenos que se producen en nuestro entorno, es posible recurrir a dos procedimientos complementarios. Por un lado, podemos identificar o definir un determinado fenómeno incidiendo en las diferencias e idiosincrasias que presenta con respecto a lo ya conocido. Por otro, existe el recurso de la analogía: el intento por entender algo aparentemente nuevo y diferente a través de los rasgos que comparte con otros fenómenos. Posiblemente, los avances más espectaculares de la ciencia se han dado justamente cuando se han encontrado diferencias entre lo que se tenían por iguales o equivalentes o cuando se han encontrado similitudes trascendentales entre cosas de las que sólo se había notado sus rasgos distintivos más llamativos, p.e. paralelismos entre la astronomía y la física atómica.

Mi punto de partida es que, hasta el momento, se han descrito el doblaje y el subtitulado, principalmente, en función de unos rasgos distintivos muy evidentes (el ajuste y la sincronía temporal y visual, sobre todo), subrayando las diferencias hasta tal punto que las versiones extranjeras de textos audiovisuales se catalogaban como traducción subordinada, en el mejor de los casos, o si no, de simple adaptación.

Creo que en un ámbito de estudio tan joven como el de la traducción audiovisual (TAV) era previsible que primero se hiciera hincapié en los rasgos específicos del doblaje, del subtitulado y de otras formas de TAV. Sin embargo, en la elaboración de teorías o explicaciones generales de la traducción, convie- 
ne también examinar la TAV con el fin de descubrir qué rasgos comparte con otras modalidades de traducción, o con posibles universales de traducción, y cómo pueden las teorías parciales sobre la TAV alimentar teorías sobre la traducción en general (siguiendo, por ejemplo, la propuesta del mapa de Holmes). Los hallazgos que se produzcan pueden tener aplicaciones pedagógicas importantes, tanto en la confección de materiales didácticos como en la presentación y resolución de problemas para el aula.

A continuación, voy a presentar, repartidas en siete puntos, algunas de las características que tradicionalmente se han visto como propias de la TAV y las relacionaré con aspectos de otras formas de traducción o con plantamientos teóricos de larga tradición. La conclusión, que anticipo ya aquí, es que la complejidad de la traducción, de toda traducción, se ve a veces de forma más clara en la TAV, pero esto no se debe a que sean rasgos exclusivos de esta forma de traducir, sino a que en la TAV los ejemplos son más visibles, más frecuentes o más extremos, según el caso.

\section{TRADUCCIÓN DE CINE, TV Y VÍDEO COMPARADA CON OTRAS FORMAS DE TRADUCCIÓN}

\subsection{Géneros y clasificaciones textuales}

Tradicionalmente, desde un planteamiento teórico general de la traducción, se han propuesto clasificaciones por géneros, por grado de especialidad, por categorías discursivas, por temas, etc. El cine y, sobre todo, la televisión pueden reflejar o adaptar todas las demás modalidades textuales tradicionales y crear otras propias. Si nos proponemos trazar denominadores comunes con textos tradicionales, podemos ver, por ejemplo, que el remake (nueva versión de un film) tiene más puntos en común con la traducción teatral que con el doblaje o el subtitulado, ya que se traduce el guión para ser interpretado por un reparto distinto bajo el criterio de un nuevo equipo de dirección y producción. También es interesante estudiar la TAV en relación con algunos aspectos de la adaptación de un género a otro, por ejemplo, adaptar una novela al cine o la Biblia a CD-ROM. Estas adaptaciones a menudo representan casos de traducción intralingüística mucho más interesantes que los primeros ejemplos propuestos por Jakobson (1959) (paráfrasis de frases sueltas).

\subsection{Métodos y técnicas de traducción}

El método que se le supone a la TAV es el que está en función del ajuste y de la sincronía y, sin embargo, es fácil ver que este planteamiento entronca con una 
tradición muy larga de formas distintas de traducción literal y de la técnica llamada traducción resumen. Podríamos relacionar la traducción interlineal tanto con el doblaje (cuando se traduce frase a frase o línea a línea) como con la traducción poética (verso a verso). Y el subtitulado tiene mucho en común con la traducción resumen e incluso con algunos aspectos de la interpretación. Por otra parte, el doblaje no está solo en su afán de búsqueda de la sincronía labial o fonológica. Autores de tanto prestigio como Lefevere y Venuti nos recuerdan la existencia de la traducción fonológica y su importancia, si no en su impacto social, sí, al menos, en sus implicaciones teóricas.

En cuanto a las llamadas técnicas de traducción, la TAV nos obliga a tener en cuenta la compensación entre elementos verbales y no verbales. Tanto el doblaje como el subtitulado pueden aportar mucha información sobre técnicas para compensar elementos orales por otros escritos, y viceversa. Ya en un plano más amplio, conjugando combinaciones posibles de distintos tipos de compensación, llegamos a la verdadera dimensión semiótica de la traducción, lo que Jakobson probablemente llamaría traducción intersemiótica, aunque él sólo tenía previsto cambios del lenguaje natural a lenguajes formales e inventados (1959).

\subsection{Componente no verbal de todos los textos}

Enlazando con el tema de los métodos y las técnicas, cabe preguntarse precisamente por la dimensión semiótica y los contenidos no verbales de otros tipos de traducción y, al menos en mi caso, es precisamente el estudio del doblaje lo que ha suscitado esta pregunta. Desde la perspectiva de las personas que reciben un texto, la técnica del voice-over tiene interesantes puntos en común con la interpretación, ya que la voz que «recita» esta modalidad de traducción no tiene tanta pretensión de suplantación total como en el caso del doblaje. aunque sigue siendo necesario observar atentamente en los tres casos (doblaje. voice-over, interpretación) el lenguaje corporal y paralingüístico del hablante original para no perder una dimensión importante del texto. La subtitulaciór podría considerarse complementario a la traducción a la vista, ya que uno va d $\epsilon$ escrito a oral y el otro de oral a escrito. El subtitulado también tiene puntos er común (la combinación de palabras e imágenes) con la traducción de textos cor profusión de diagramas, gráficos e ilustraciones. La sincronía gestual tan propia de la TAV es también un requisito de los intérpretes, salvando algunas dife. rencias importantes, en cuanto a la importancia de coordinar elementos paralingüísticos y no verbales (el lenguaje corporal con el mensaje verbal).

Debemos ser más conscientes del ingrediente audiovisual de aquellos textos que no son los típicos que se ven en las salas de cine, a través del televisor, con e aparato de vídeo o a través de la pantalla del ordenador, es decir, las canciones, las 
viñetas, las diversas formas de la publicidad, la localización de productos informáticos, los textos ilustrados, $y$, en definitiva, cualquier texto escrito que incluya elementos visuo-verbales (como los acrósticos), gráfico-paralingüistícos (colores, tamaños y formatos), o aspectos fonéticos, como la rima, la aliteración, el ritmo, la cacofonía, etc.

\subsection{Problemas de traducción}

Un problema que a veces se presenta como específico del doblaje es el tratamiento de los acentos y las variantes geográficas representadas en el habla de los distintos personajes. Sin embargo, este problema es uno de los más antiguos y recurrentes en la traducción en diálogos en novelas y obras teatrales, por citar los dos ejemplos más obvios. Hay que insistir, además, en que toda la cuestión de la coherencia de los diálogos y de las reacciones que provoca o refleja cada frase en el doblaje y la subtitulación, la comparte también cualquier texto con rasgos de oralidad, como los ya mencionados, y todos se pueden beneficiar de las propuestas y descubrimientos que llegan de disciplinas como el análisis conversacional y del discurso, como, por ejemplo, las máximas de Grice.

Hemos dicho que la televisión y el cine pueden reflejar los demás géneros, por lo que es perfectamente comprensible que recojan también toda una serie de problemas tradicionales de traducción, con la única diferencia de que el modo textual y discursivo puede introducir variantes en el planteamiento o en las posibles soluciones de estos problemas. Entre éstos, encontramos la traducción de la metáfora, del juego de palabras, la traducción del humor, el tratamiento de elementos culturales, etc. Por motivos de brevedad, digamos ahora simplemente que, en el caso de la TAV, todos estos problemas se pueden plantear y solucionar conjuntamente a través del canal sonoro y del visual, con elementos verbales, no verbales o una combinación de ambos.

\subsection{El nivel de difusión y el impacto social}

Otra de las características típicas de la TAV es su pertenencia a lo que llamamos la comunicación de masas, aunque sería más exacto llamarlo comunicación a las masas. En este sentido, nos interesa saber cómo influyen los medios de comunicación de masas en la TAV, así como en la prensa escrita, la radio e Internet. Lo que tienen en común (en cuanto a impacto social y políticas de edición, venta y distribución) productos que se distribuyen físicamente: los vídeos, los DVD, los videojuegos y los productos multimedia, con los libros y fascículos (pensemos, además, en todas las colecciones que combinan revistas y vídeos). Además la gran inversión necesaria en algunos proyectos de traducción 
que forman parte de grandes campañas de venta invita a relaciones su estudio con teorías sobre el mecenazgo y la dimensión económica de la traducción.

\subsection{El impacto de la evolución tecnológica}

En la TAV, es donde se ve mejor cómo determinadas formas de traducir dependen de unos soportes técnicos y de la evolución tecnológica. Las innovaciones tecnológicas dan pie a nuevas modalidades de traducción y, en un sentido estricto, sólo la interpretación de enlace puede realizarse sin ningún artilugio ni invento, si consideramos que la escritura, junto con sus diversos materiales y técnicas, es también un invento. Como en otros ámbitos de la vida de nuestros tiempos, la informática es, sin duda, el elemento tecnológico más importante que afecta a todos los modos tradicionales de traducción, desde la literaria hasta la subtitulación, además de ayudar a crear formas y especialidades totalmente nuevas, como los servicios de traducción para conversaciones telefónicas o la traducción por Internet. Para la TAV y la traducción multimedia, un avance muy importante es la implantación de la digitalización de la imagen y del sonido. En general, el crecimiento de la informática y de las telecomunicaciones ha provocado una evolución progresiva de las formas tradicionales de producción, distribución y recepción de los textos hacia la digitalización e Internet, como, por ejemplo. los hipertextos, las transacciones comerciales, las vídeo-conferencias, el correo electrónico, etc., en cuyo tratamiento se utiliza, en casi todos los casos, servicios online de traducción.

\subsection{Una labor de responsabilidad compartida}

A menudo, se ha representado la traducción como una labor individual en la que toda la responsabilidad recaía sobre el traductor. El doblaje es una forma de traducción donde este modelo simplemente no se sostiene y, de esta observación. se desprende que hay que investigar el grado real de responsabilidad del traductor en otras formas de traducción y averiguar quiénes son las otras personas que trabajan en equipo con uno o más traductores y que deben, compartir al menos. parte de la responsabilidad de la calidad del resultado final. En el doblaje, identificamos al doblador, al ajustador, al actor, al director, etc., en contraste con el subtitulado, que necesita menos participantes. En las teorías generales, ya se ha identificado al iniciador o cliente, al traductor (uno o más), al corrector o al editor, aunque tampoco debemos olvidar la posibilidad de la autoedición ni la importancia del receptor. En este sentido, un concepto clave es el de la tolerancia: hemos aprendido, por ejemplo, que el grado necesario de sincronía y ajuste en el doblaje está en función de la tolerancia de los espectadores a las imperfecciones. 
Para finalizar se ofrece un cuadro resumen a modo de conclusión en el que se recoge lo expuesto en este artículo.

Cuadro comparativo de la TAV con otras modalidades

\begin{tabular}{|l|l|}
\hline Traducción de cine / TV / vídeo & Otras formas de traducción \\
\hline
\end{tabular}

\section{Géneros y clasificaciones textuales}

\begin{tabular}{l|l} 
Nueva producción o remake (= traducción & Traducción del texto teatral
\end{tabular}

/ adaptación del guión solamente)

El cine y, sobre todo, la televisión pueden reflejar o adaptar todas las demás modalidades textuales y crear otras propias.

Clasificaciones por géneros, por grado de especialidad, por categorías discursivas, por temas, etc.

\section{Métodos y técnicas de traducción}

\begin{tabular}{l|l} 
Subtitulado / sincronización & Interlineal / resumen \\
\hline Sincronía & Literal / fonológica \\
\hline $\begin{array}{l}\text { Compensación: verbal <--> no verbal } \\
\text { Compensación: oral <--> escrito }\end{array}$ & Intersemiótica / compensación
\end{tabular}

3. Modos audiovisuales reconocidos $v$. textos con elementos no verbales

\begin{tabular}{l|l} 
Voice-over & Interpretación / a la vista \\
\hline Subtitulado & Escrita (con gráficos e ilustraciones) \\
\hline La sincronía gestual & $\begin{array}{l}\text { Elementos paralingüísticos y no verbales } \\
\text { en la interpretación }\end{array}$ \\
\hline $\begin{array}{l}\text { Sala de cine, televisor, aparato de vídeo, } \\
\text { (pantalla del ordenador: CD-ROM, } \\
\text { Internet audiovisual) }\end{array}$ & $\begin{array}{l}\text { Canciones, cómics, interpretación, publi- } \\
\text { cidad en diversos medios, localización de } \\
\text { software, textos ilustrados, acrósticos y } \\
\text { otras relaciones visuo-verbales. }\end{array}$
\end{tabular}

4. Medios de comunicación de masas

\begin{tabular}{l|l} 
Televisión / cine & Prensa escrita / radio / Internet \\
\hline Vídeo / DVD / multimedia & Libros / fascículos
\end{tabular}

\section{Problemas de traducción}

\begin{tabular}{l|l} 
La interpretación de los dobladores & Dialectos \\
\hline Coherencia de los diálogos y reacciones & Análisis conversacional y del discurso \\
\hline $\begin{array}{l}\text { Visualización (representación semiótica) } \\
\text { de la metáfora, del humor, de elementos } \\
\text { culturales, etc. }\end{array}$ & $\begin{array}{l}\text { Traducción de la metáfora, del humor, de } \\
\text { elementos culturales, etc. }\end{array}$ \\
\hline
\end{tabular}


El impacto de la evolución tecnológica

\begin{tabular}{|c|c|}
\hline Informatización del subtitulado & Traducción asistida (por ordenador) \\
\hline Vídeo / TV digitalizado y multilingüe & Traducción simultánea multilingüe \\
\hline $\begin{array}{l}\text { Creciente presencia de la informática y de } \\
\text { las telecomunicaciones: progresiva adap- } \\
\text { tación de la televisión y del vídeo a la } \\
\text { digitalización y a Internet }\end{array}$ & $\begin{array}{l}\text { Creciente presencia de la informática y de } \\
\text { las telecomunicaciones: progresivo paso } \\
\text { de las formas tradicionales de producción. } \\
\text { distribución y recepción de textos hacia la } \\
\text { digitalización e Internet, p.ej. hipertextos. } \\
\text { transacciones comerciales, vídeo-confe- } \\
\text { rencias, correo electrónico, etc., (con ser- } \\
\text { vicios online de traducción). }\end{array}$ \\
\hline
\end{tabular}

Traductor: componente de un equipo / responsabilidad compartida

Doblador, ajustador, actor, director, etc.

En contraste con el subtitulado, con menos participantes
Iniciador, traductor (uno o más), corrector, editor, etc.

En contraste con la autoedición

Tabla 1. La traducción de géneros audiovisuales 


\section{BIBLIOGRAFÍA}

Bassnett-McGuire, S. (1991): Translation Studies Revised Edition, Londres, Routledge.

de Beaugrande, R. y W. Dressler (1981): Introduction to Text Linguistics. Londres, Longman.

Delabastita, D. (1989): «Translation and Mass-communication: Film and T.V. Translation as Evidence of Cultural Dynamics», Babel, 35: 4.

GutT, E. (1991): Translation and Relevance, Oxford, Basil Blackwell.

Grice, H.P. (1975): «Logic and Conversation» en Cole, P. y J.L. Morgan (eds). Syntax and Semantics III, Speech Acts. Nueva York: Academic Press, págs. 41-58.

Hatim, B. y I. MASON (1990): Discourse and the Translator, Harlow, Inglaterra. Longman.

Holmes, J. (1988): «The Name and Nature of Translation Studies» en Holmes, J. (ed.) Translated! Papers on Literary Translation and Translation Studies. Amsterdam: Rodopi, págs. 67-80.

JAKOBSON, R. (1959): «On Linguistic Aspects of Translation» en Brower, R.A. (ed.) (1959): On Translation, Cambridge, Harvard University Press.

Lefevere, A. (1975): Translating Poetry: Seven strategies and a Blueprint, Assen, Van Gorcum.

- (1992): Translation, Rewriting, and the Manipulation of Literary Fame, Londres, Routledge.

Mayoral, R. (1994): «La Traducción Cinematográfica: el Subtitulado», Sendebar, 4.

Nedergaard-Larsen, B. (1993): «Culture-bound Problems in Subtitling», Perspectives. Studies in Translatology, 1993: 2.

Rowe, T. (1960): «The English Dubbing Text», Babel, 6: 3.

Snell-Hornby, M. (1988): Translation Studies: an Integrated Approach, Filadelfia, John Benjamins.

Toury, G. (1995): Descriptive Translation Studies and Beyond, Amsterdam. John Benjamins.

Venuti, L. (1995): The Translator's Invisibility, Londres, Routledge.

Zabalbeascoa, P. (1997): «Dubbing and the Nonverbal Dimension of Translation» en Poyatos, F. (ed.) (1997): Nonverbal Communication and Translation, Amsterdam, John Benjamins.

- (1996): «Translating Jokes for Dubbed Television Situation Comedies» en Delabastita, D. (ed. invitado) (1996): The Translator. Special Edition: Wordplay and Translation, vol. 2, 2. 


\title{
LA TRADUCCIÓ PER AL TEATRE I PER AL DOBLATGE A L'AULA: UN LABORATORI DE PROVES ${ }^{1}$
}

\author{
Eva Espasa \\ Universitat de Vic
}

\section{INTRODUCCIÓ}

A la Universitat de Vic, en la Facultat de Ciències Humanes, Traducció i Documentació, l'alumnat de quart que s'especialitza en traducció cursa l'assignatura de traducció audiovisual. Aquesta assignatura quadrimestral, de sis crèdits, se seqüiencia segons un triple eix progressiu: s'inicia amb la traducció de textos teatrals, es passa al doblatge (segons una gradació de dificultat per gèneres) i, per últim, s'ofereix una introducció a la traducció de subtítols.

Tot i que la tasca traductora sol ser solitària, l'avantatge de la docència és que permet posar a prova en grup, com en una mena de laboratori, les troballes individuals: la lectura en veu alta de textos originals i traduïts, de teatre i de doblatge, són una pràctica habitual en la docència, que permet, fins a cert punt, comprovar la concisió i l'oralitat dels textos. En el cas del teatre, la lectura en grups, o en parelles, dels textos a traduir com a pas previ per a la traducció potencia una interpretació activa de l'obra teatral per part de l'alumnat, el qual pot examinar així el dinamisme de les relacions entre personatges, per exemple. Amb això, aquesta primera tasca interpretativa dels textos teatrals per part de

1. Després de rellegir Sellent (1998), veig que afirma que «la traducció per al doblatge constituei» un camp de proves valuosíssim per a la codificació del que podríem anomenar un estàndard col-loquia (1998: 52; l'èmfasi és meu), encara que en aquesta comunicació aplico la metàfora del laboratori de proves en un altre sentit, el de la docència. 
l'alumnat obeeix a una de les dificultats i riqueses de la traducció teatral: la necessitat d'interpretar el text, d'imaginar-ne una posada en escena que després s'haurà de negociar amb l'equip escènic. En canvi, en la traducció audiovisual, la imatge ja ve donada, cosa que comporta la necessitat de sincronització; tanmateix, alhora, la imatge té l'avantatge de facilitar les possibles dificultats i ambigüitats interpretatives dels textos teatrals. Com afirma Joan Sellent, parafrasejant Edmond Cary (Sellent, 1998: 53):

El traductor i tots els altres responsables d'un muntatge teatral, generalment, només disposen de les acotacions que acompanyen el text com a orientació sobre criteris expressius i d'entonació. El traductor de doblatge, en canvi, té incondicionalment a la seva disposició, com diu Cary, uns actors que ja han fet la seva feina i li serveixen amb safata -si els sap aprofitar- tots els matisos interpretatius que hi ha incorporat.

I pel fet de treballar a l'aula, en grups, la traducció per al doblatge té l'avantatge que, per exemple, un alumne es concentra en els processos de transferència textual, mentre que una altra estudiant comprova la sincronia temporal i visual.

Considerem que el teatre és una bona preparació per a la traducció audiovisual, especialment per al doblatge, a causa de la necessitat que hi ha en aquestes modalitats traductores $a$ ) d'una certa concisió en el llenguatge, $b$ ) de la (re)creació de nivells de llenguatge d'una oralitat versemblant, i $c$ ) de la negociació del text per part d'una complexa cadena d'agents emissors i iniciadors. $^{2}$

\section{CONCISIÓ}

En primer lloc, cal considerar els requisits d'un llenguatge concís i directe, perquè, tant en la traducció teatral per a l'escena com en els doblatges per a la televisió i el cinema, el text es rep immediatament i no hi ha possibilitat de relectura,

2. Hurtado (1989), Mateo (1995, 1996) i Massip (1998) han examinat les repercussions de la concisió, l'oralitat i la complexitat de la comunicació per a la traducció teatral. Pel que fa a aquests aspectes en la traducció audiovisual, vegeu Agost (1999), Ávila (1997), Izard (1999), Whitman (1992), Zabalbeascoa (1993). En un article recent, Feliu Formosa qüestiona que la concisió i l'oralitat siguin específiques de la traducció teatral. Proposa que, en comptes d'una distinció per gèneres (narrativa, teatre), es consideri el «grau d'oralitat i concisió que posseeixen i exigeixen de la traducción (Formosa, 1999: 81; l'èmfasi és meu). La conclusió de Formosa ens resulta útil per explorar les similituds entre traducció teatral i traducció audiovisual: «l'oralitat i la concisió poden ser imprescindibles per al text teatral, però no són exclusives del text teatral» (Formosa, 1999: 82). 
de tornar a sentir el que s'acaba d'emetre (deixant de banda l'excepció de la reproducció en vídeo). Com especifiquen les indicacions per al doblatge de Televisió de Catalunya (d'ací endavant, TVC): «la comprensió immediata que imposa la recepció instantània per part de l'espectador exigeix estructures sintàctiques poc complexes, un lèxic corrent i una pronunciació clara» (TVC, 1997: 11).

Quant a la concisió com a criteri per controlar la duració dels textos teatrals, Ángel-Luis Pujante ha parlat de «la naturaleza teatral de un texto que opera contra el reloj de la representación» (Pujante i Centenero, 1995: 93). La concisió en el teatre no és tan estricta com en el doblatge i, per tant, suposa una bona preparació per a aquest últim. «No es cuestión de traducir teatro con la precisión de un doblaje de cine, sino de que las dos horas del original no se conviertan en tres o más en la traducción» (Pujante, 1995: 12). És cert que, en el teatre, no cal centrar-se estrictament en la duració dels textos. Tot i així, per la necessitat habitual d'un text directe, immediatament comprensible per al públic, al llarg de l'ensenyament de textos teatrals es va treballant la concisió de forma progressiva. Cal no oblidar, a més, que els textos traduïts de l'anglès a l'espanyol i al català (la combinació lingüística de la nostra assignatura), en general, resulten més llargs que els originals. Amb una traducció teatral concisa es pot evitar que l'obra representada s'allargui molt més que l'original o bé que l'equip actoral hi hagi d'introduir altres omissions per aconseguir una duració global breu.

D'aquesta manera, l'alumnat acara la traducció de textos per al doblatge, després d'un mes de traducció teatral, amb una certa tendència cap a la concisió, que acaba de polir en la traducció de documentals, on l'èmfasi rau en una adequació a la durada de les intervencions que fan els diversos narradors $\mathrm{i}$ personatges entrevistats. Aquest èmfasi se segueix en la traducció de dibuixos animats, amb la dificultat afegida que els parlaments dels personatges solen ser més breus i més fragmentats. Així, ja s' ha adquirit el costum de buscar la concisió (sempre que s'escaigui), quan ja s'acaren gèneres televisius en què hi ha la dificultat afegida de l'ajust. ${ }^{3}$

3. Pel que fa a la progressió pedagògica en el doblatge segons els gèneres audiovisuals, vegeu Agost i Chaume (1996: 209-210). 


\section{ORALITAT ${ }^{4}$}

El doblatge i el teatre comparteixen la tasca paradoxal de (re)crear uns textos versemblants, que semblin orals, tot i que es parteix de textos o guions escrits i el resultat que s'entrega a l'equip actoral/de doblatge és també en forma de textos escrits. És prou coneguda la caracterització del text audiovisual com un text escrit per ser llegit com si no fos escrit, com si fos parlat espontàniament. ${ }^{5}$ Aquest «com si» condiciona tot el procés: hi ha la necessitat d'una certa versemblança, dins de la trampa que sempre suposen els productes de ficció. És a dir, parafrasejant Keir Elam, el llenguatge teatral ens mostra un model pur d'interacció social, amb un diàleg que té semblances molt limitades al que passa de debò en els intercanvis lingüístics quotidians (Elam, 1980: 178). I, pel que fa al doblatge, una de les primeres pautes al manual de TVC sobre el llenguatge a utilitzar en el doblatge fa referència als textos «escrit[s] per ser $\operatorname{dit}[s]$ fingint espontaneïtat» (TVC, 1997: 11, l'èmfasi és meu).

En aquest punt, voldria fer un incís sobre aquest fingiment de l'oralitat $i$ apuntar que també es pot aplicar a la trampa que suposa el procediment mateix del doblatge. Candace Whitman, després d'exposar els diferents tipus de sincronia que requereix el doblatge, ens recorda que cal centrar-nos només en el que resultarà més visible per al públic, el que el podria distreure de la ficció. Perquè Whitman considera que una sincronia labial minuciosa és un animal en vies d'extinció. «What matters is the impression, the credibility of the artistic work viewed as an integral whole. Ultimately (...), cinema is a factory of illusions. Dubbing attempts to give the illusion of an illusion» (Whitman, 1992: 54-55).

Tornem ara a la ficció de l'oralitat. Els agents iniciadors professionals solen requerir, en els textos traduïts, certa simplicitat lèxica i sintàctica (sempre i quan el text de partida, la caracterització dels personatges, etc., no indiquin altres requisits). En el cas del català, es dóna la dificultat afegida de (re)crear registres, perquè no hi ha una tradició consensuada de nivells de llengua baixos. especialment quan la (re)creació de registres comporta la influència d'altres llengües, com l'espanyol. Per tant, en l'àmbit de Catalunya, es busca en la

4. Sobre la variació linguística en traducció, vegeu Agost (1998); i pel que fa a l'oralitat en el doblatge. vegeu Dolç i Santamaria (1998). Tots dos estudis reconeixen el caràcter fỉctici d'aquesta oralitat i la influència que hi tenen els factors professionals i/o institucionals que emmarquen l'activitat traductora. De forma molt gràfica i concisa Chaume anomena la peculiar oralitat del doblatge «oralitat prefabricada» o «pseudo-oralitat».

5. Em baso en l'esquema de Gregory i Carroll sobre la complexitat dels canals orals i escrits. que ha estat aplicat a la traducció per Hatim i Mason (1990: 49) i al doblatge per Televisió de Catalunya en el seu manual Criteris lingüístics sobre traducció i doblatge (TVC, 1997: 11, 13). 
docència un difícil equilibri entre la versemblança i la correcció lingüística. Aquesta tensió es pot veure en les indicacions de TVC al seu manual. D'una banda «el doblatge s'ha de moure dins la varietat estàndard i ha de ser cautelós en l'ús de dialectalismes, cultismes i anacronismes» (TVC, 1997: 11). Però en la mateixa pàgina que es recomana cenyir-se a la varietat estàndard, es reconeix que «alhora, el doblatge ha de recollir tota la diversitat lingüística de les obres originals i, per això, un altre principi fonamental és el de l'adequació. Treballar amb textos doblats demana tenir ben clares les situacions comunicatives que van sorgint per poder adequar els registres de personatges i narradors» (TVC, 1997: 12). I s'afirma que aquests objectius «no són pas incompatibles amb una orientació normativa $[\ldots]$ només que els criteris de correcció són diferents segons si es treballa $a m b$ textos escrits $o$ amb textos orals destinats a un mitjà de comunicació de masses» (TVC, 1997: 12).

Factors professionals i institucionals com aquests, que es recreen de forma virtual a l'aula, poden restringir la gamma de decisions traductores pel que fa als registres. Així, els criteris lingüístics a l'aula tenen en compte els manuals generals d'estil, els manuals institucionals de TVC, així com les normes internes de diversos estudis de doblatge i subtitulació. A l'aula, hi ha una negociació constant entre un llenguatge normatiu i un llenguatge versemblant. Però és innegable el pes que té el criteri inicial d'una adhesió a llenguatges normatius. Per tant, fóra incongruent acceptar a classe tota mena d'opcions traductores quan la pràctica de TVC ve marcada per la presència de la correcció linguística en les diverses fases del doblatge, que recull Natàlia Izard en la seva tesi doctoral (Izard, 1999: 146, 151): a) l'existència d'una correctora d'estil que revisa els textos traduïts; $b$ ) la presència del corrector a l'estudi de doblatge, qui sol-licita retakes si hi ha errors de dicció i/o de traducció; $c$ ) una nova revisió per part de la Comissió de Normalització Lingüística de TVC amb la consequiència que, si s'hi troben errors, es demanen retakes a l'estudi, amb el consegüent encariment del producte i la possibilitat de baixar punts en el rànquing d'estudis de doblatge.

Aleshores, quines vies hi ha per compatibilitzar la normalització lingüística en traducció i la versemblança d'un català col-loquial? Joan Sellent ha apuntat la necessitat d'anar més enllà d' «amanir la traducció amb frases fetes i [...] la capa superficial del lèxic i la fraseologia més o menys pintoresca» i proposa explorar altres mecanismes idiomàtics, com per exemple l'elisió i el sobreentès, i jugar amb mecanismes sintàctics, prosòdics i discursius (Sellent, 1998: 52). Dolç i Santamaria suggereixen «la utilització d'expressions populars relaxades ('nem, aviam, mecasom...)» (Dolç, 1998: 104). En aquest aspecte, la dinàmica de classe pot ser un bon laboratori de proves. El debat amb/entre estudiants en la classe de traducció teatral $i$ audiovisual sempre aporta opcions molt profitoses. Per exemple, cada any, l'alumnat tradueix una obra teatral contemporània inèdita, 
completa, en forma d'encàrrec professional virtual: es tradueix per a un teatre concret i les opcions traductores s'ajusten a aquest encàrrec. Enguany, l'obra escollida, Lakeboat, de David Mamet, és farcida d'argot mariner i de llenguatge col·loquial i vulgar. I en l'aula es tracten les diverses opcions traductores com en un veritable laboratori de proves, tot explorant els avantatges i inconvenients de les alternatives proposades. La inclusió de català no normatiu, les contradiccions de l'adaptació cultural, la combinació de català i espanyol en una obra traduïda, etc., són qüestions que sempre surten i que interessen, en primer lloc, per les solucions que s'arriben a establir a classe i, sobretot, pel fet de plantejar-les com a possibilitats de traducció.

\section{LA COMPLEXA CADENA DE LA COMUNICACIÓ TEATRAL I AUDIOVISUAL}

En tercer lloc, en la docència de la traducció teatral i audiovisual cal conèixer fins a quin punt el text s'insereix en un complex procés comunicatiu: fins a quin punt el traductor pot establir decisions més enllà del text. Si bé se sol atribuir als equips actorals o de doblatge les decisions interpretatives dels textos traduïts, traduir sempre significa interpretar $\mathrm{i}$ hi ha decisions que, inevitablement, $\mathrm{i}$ afortunadament, ha de prendre qui tradueix i, si és possible, negociar-les amb els equips actorals o de doblatge. Això es concreta en l'ensenyament de la traducció teatral i audiovisual amb el coneixement dels diferents agents iniciadors de la traducció: mitjançant la lectura de textos especialitzats, amb les visites de traductors que es dediquen exclusivament a la traducció audiovisual, amb les visites a estudis de doblatge, amb els contactes amb la Filmoteca de Vic per veure sistemes electrònics de subtitulació i amb l'anàlisi de llibres (Agost, 1999; Ávila, 1997; TVC, 1997) i fulls d'estil de diverses agències, així com de pautes per a la traducció teatral (Massip, 1997; The Translators Association, sense datar). També es debaten a classe articles teòrics que posen de relleu les implicacions ideològiques presents en les pràctiques traductores (Bassnett, 1998; Danan, 1991).

Per últim, voldria apuntar un matís sobre la tasca col·lectiva o en equip que suposen la traducció teatral i l'audiovisual. Aquests termes podrien suggerir als i a les estudiants una visió una mica idealitzada dels processos, sovint desiguals, de negociació sobre el producte final, audiovisual o teatral. Per concloure, podríem aventurar-nos a dir que la relació de qui tradueix amb la resta d'agents dels equips actorals o de doblatge, més que no una relació de treball en equip, és d'una mena -si se'm permet aquesta metàfora- de monogàmia consecutiva entre els diferents agents, que solen negociar de dos en dos, i per torns, les decisions professionals traductores. 


\section{BIBLIOGRAFIA}

Agost, R. (1998): «La importància de la variació lingüística en la traducció», Quaderns. Revista de traducció, 2, 83-95.

- (1999): Traducción y doblaje: palabras, voces e imágenes, Madrid, Ariel.

Agost, R. i F. Chaume (1999): «L'ensenyament de la traducció audiovisual» dins HurTAdo AlbiR, A. (ed.) (1996): La enseñanza de la traducción, Castelló, Universitat Jaume I, 207-211.

ÁvilA, A. (1999): El doblaje, Madrid, Cátedra.

BassnetT, S. (1998): «Still Trapped in the Labyrinth: Further Reflections on Translation and Theatre» en BASSNETT, S. i A. LeFEvere (1998): Constructing Cultures: Essays on Literary Translation, Clevedon, Multilingual Matters, 90-108.

Chaume, F. (1999): «la traducción audivisual: investigación y docencia», Perspectives, 7, 2 209-220.

Danan, M. (1991): «Dubbing as an expression of nationalism», Meta, 36: 4, 606-614.

Dolç, M. i L. SANTAMARIA (1998): «La traducció de l'oralitat en el doblatge», Quaderns. Revista de traducció, 2, 97-105.

Elam, K. (1980): The Semiotics of Theatre and Drama, Londres, Methuen.

FormosA, F. (1997): «La traducció teatral: del drama a l'escena», Revista d'Igualada, 2, setembre, 79-84.

Hatim, B. i I. MASON (1990): Discourse and the Translator, Londres, Longman.

Hurtado Albir, A. (e.p.): «Traductologia i traducció teatral. La fidelitat en traducció», Jornades de Traducció Teatral, gener 1989, Barcelona, Institut del Teatre.

IZARD, N. (1999): Traducció audiovisual i creació de models de llengua en el sistema cultural català. Estudi de cas del doblatge d'Helena, quina canya!, Barcelona, Universitat Pompeu Fabra (tesi doctoral inèdita).

Massip, C. (1997): «Traduir teatre», El Pou de Lletres, estiu 1997, 50.

Mateo, M. (1995): «Constraints and Possibilities of Performance Elements in Drama Translation», Perspectives, 1, 21-33.

- (1996) «El componente escénico en la traducción teatral» dins Edo, M. (ed.) (1996): I Congrés Internacional sobre Traducció. Abril 1992, Actes, Barcelona, Universitat Autònoma, 907-917.

Pujante, A. L. (1995): «Traducir Shakespeare: mis tres fidelidades», Vasos comunicantes, tardor 1995, 11-21.

Pujante, A. L. i M. A. Centenero (1995): «Las canciones de Shakespeare en las traducciones alemanas de A. W. Schlegel», Cuadernos de Filología Inglesa, 4, 93-106. 
Sellent, J. (1998): «Traducció teatral i traducció audiovisual» dins BayÀ, M. (coord.) (1998): VI Seminari sobre la Traducció a Catalunya, Barcelona. Associació d'Escriptors en Llengua Catalana, Quaderns Divulgatius, 10. 47-62.

[Tvc] Televisió de Catalunya (1997): Criteris lingüístics sobre traducció $i$ doblatge, Barcelona, Edicions 62.

The Translators Association (sense datar): Guidelines for Translators of Dramatic Works, Londres, The Translators Association.

Whitman, C. (1992): Through the Dubbing Glass: The Synchronization of American Motion Pictures into German, French and Spanish, Frankfurt, Peter Lang.

Zabalbeascoa, P. (1993): Developing Translation Studies to Better Account for Audiovisual Texts and Other New Forms of Text Production (with special attention to the TV3 version of Yes, Minister), Lleida, Universitat de Lleida (tesi doctoral inèdita). 


\title{
LA PREVISIÓ DEL PROCÉS D'AJUST COM A ESTRATÈGIA DE TRADUCCIÓ PER A L'ENSENYAMENT DEL DOBLATGE
}

\author{
Francesca Bartrina \\ Universitat de Vic
}

\section{INTRODUCCIÓ}

A la Facultat de Ciències Humanes, Traducció i Documentació de la Universitat de Vic, la traducció per al doblatge forma part d'una assignatura de quart curs que comença amb la traducció teatral i acaba amb la subtitulació. En aquest context, treballem l'especificitat de la traducció audiovisual tenint en compte les condicions de treball reals del mercat professional. És per això que, a l'aula, es consideren els criteris específics de doblatge de diferents empreses de Barcelona i, també per això, ens visiten regularment professionals de la traducció per al doblatge.

\section{L'ESPECIFICITAT DE LA TRADUCCIÓ PER AL DOBLATGE}

Els materials amb què treballem a classe són textos audiovisuals originals amb els guions corresponents. A l'aula, comptem amb televisió, vídeo estèreo $i$ ordinadors per a l'alumnat, per simular la situació professional, on els guions traduïts prenen forma en disquet i en còpia impresa. Procurem que els textos audiovisuals segueixin una gradació progressiva pel que fa a la posada en pràctica d'estratègies de traducció pròpies del doblatge (Agost, Chaume i Hurtado, 1999: 188). No es pren en consideració, en aquesta assignatura, el material publicitari, ja que les restriccions d'aquest tipus de textos es tenen en compte en una 
assignatura específica de traducció subordinada a la imatge estàtica, que l'alumnat ja ha cursat quan s'acara a la traducció audiovisual. En primer lloc, es treballen els documentals, ja que les restriccions fonètiques i visuals són menors per la frequiència d'ús de la modalitat de la veu superposada (a] text oral original emès a un volum inferior). La traducció per al doblatge de dibuixos animats ocupa un segon lloc, perquè no requereix un èmfasi tan gran en la sincronització labial. Es continua per la traducció per al doblatge de sèries i s'acaba amb els guions de pel-lícules, tenint en compte que les restriccions temporals i de qualitat són especialment estrictes si aquestes s'exhibeixen en sales comercials.

En el transcurs de l'assignatura, fem una insistència especial a conscienciar l'alumnat de les eines de documentació i d'assessorament lingüístic de què disposem en el món contemporani. En aquest sentit, ocupen un lloc prioritari els avantatges de recerca i d'informació que ofereix Internet. També es discuteixen a classe les noves disposicions terminològiques i normatives i s'utilitzen els llibres d'estil de diversos mitjans de comunicació.

\section{LA PREVISIÓ DEL PROCÉS D’AJUST}

Treballem la traducció de guions que han de ser doblats seguint les següents fases inicials:

a) Lectura del guió.

b) Visionat del material audiovisual.

c) Comprovació de la correspondència guió-visionat, traient de pantalla $\mathrm{i}$ prenent nota de tot allò que no presenta correspondència escrita.

Procurem que, en els guions traduïts a classe, la relació text escrit-text visionat presenti diferents graus de dificultat, tenint sempre en compte que el guió per traduir sigui el de découpage, és a dir, el guió que correspon al producte fílmic acabat (Chion, 1995: 218).

En un segon estadi de comprovació guió-visionat, si la cinta de vídeo porta incorporats els codis de temps, els apuntem en el guió original quan hi ha una pausa superior a cinc segons o quan hi ha canvis de personatge o d'escena. Si el material visual no incorpora els codis de temps, podem prendre nota del minutatge que marca l'aparell de vídeo de l'aula i apuntar-lo, com a mínim a les pauses. En aquest visionat, també podem marcar al guió original quan caldrà afegir-hi subtítols a causa de la presència a la pantalla de text en la llengua de sortida que ha de traduir-se. 
En aquests visionats en què es treballa la correspondència text-guió, l'alumnat pot començar a prendre les primeres decisions traductològiques. Així ho expressa Castro (1998):

Durante este proceso de visionado, el traductor debe ir haciendo anotaciones en el guión o en hojas aparte que luego le ayuden a acarar la traducción, con glosas y apuntes sobre situaciones, aclaraciones sobre pronombres personales (you puede ser tú/usted o vosotros/ustedes), decisiones sobre el tratamiento entre personajes (tuteo), dudas terminológicas, insertos, ausencias y omisiones, etc., además de ir concibiendo el perfil de los personajes en función de su interpretación. lenguaje y contexto cultural.

No cal dir que és fonamental haver pres totes aquestes decisions abans de començar la traducció del guió. A més, pel que fa a la presentació dels guions traduits, seguim habitualment les normes internes d'uns estudis de doblatge concrets (quant a aspectes com ara tipus de lletra, format de paràgrafs i elements que cal incorporar a l'encapçalament). També se sol-licita la incorporació d'una llista al final del guió amb el nom i el sexe dels personatges de la pel-lícula, per tal de facilitar l'organització del doblatge.

Tot seguit, fem un tercer visionat i demanem a l'alumnat que marqui en el guió original els símbols que s'utilitzen tradicionalment en l'ajust. Aquests símbols són incorporats al guió traduït a mesura que va elaborant-se la traducció, de manera que el traductor pren decisions que fan referència a la sincronia visual al mateix temps que pren decisions sobre la traducció interlingüística. Aquests símbols varien segons les normes de cada comunitat autònoma; utilitzem a classe una selecció eclèctica (seguim Àvila, 1997: 81; Agost, 1999: 68, i normes internes de les agències de doblatge):

(ON) El diàleg es troba en el pla d'imatge i es veu la boca del personatge.

(OFF) El diàleg no es troba en el pla d'imatge, però se sent la veu del personatge.

(DE) D'esquena.

(SB) Es veu el personatge però no la seva boca.

(DC) De costat.

(ALHORA) Els personatges intervenen al mateix temps.

(AD LIBITUM) Molts personatges que parlen al mateix temps i no se'ls entén bé.

(LL) Els personatges es troben lluny i la vocalització passa més desapercebuda. 
Aquest signe pot utilitzar-se al principi, al final o enmig d'una frase

Riure o somriure.

Xisclar.

Començar a parlar abans que l'original. Trepitja. Un personatge comença a parlar abans que l'altre hagi acabat. Inici de l'efecte so (telèfon, ràdio, televisió, megàfon, etc.).

Fi de l'efecte so.

Pausa llarga.

Pausa menys llarga.

Pausa breu. També per indicar dubte.

El guió traduït ha d'incorporar, a més dels codis de temps, els signes de l'ajust. D'aquesta manera, els traductors poden prendre decisions com ara adaptar les paraules i les frases a la mètrica del text $i$ al moviment dels llavis dels personatges en els fragments del guió que figuren en oN; en aquests plans, les consonants labials i semilabials $(b, m, p, v$ i $f)$ han de traduir-se per un so equivalent. A més, els traductors són més conscients del criteri de concisió i podem compensar la traducció en determinats moments mitjançant el signe (A). També es veuen obligats a dirigir la seva atenció cap als signes no verbals del text fílmic i, d'aquesta manera, a incorporar-los en la presa de decisions de traducció. És important incloure, en aquest nivell, el procés d'ajust, ja que permet que les decisions del traductor es vegin reflectides en el resultat final: la pel-lícula doblada.

\section{LA TRADUCCIÓ I L'AJUST COM UN PROCÉS ÚNIC}

La nostra intenció és que les decisions preses pel traductor siguin visibles en el producte final. Ara bé, sempre que parlem de traducció, parlem també d'un context sociocultural concret; si bé podem proposar la traducció i l'ajust com un sol procés en el mercat espanyol del doblatge (en català i en castellà), la bibliografia existent sobre traducció audiovisual confirma que aquesta proposta no seria possible en altres mercats. Whitman descriu una situació molt diferent en el mercat alemany: «The original script is first handed over to the rough 
translator, who then submits his work to the screenplay author, called the dialogue writer» (Whitman, 1991: 105). Segons això, la mateixa separació de les tasques de traducció i de traducció i ajustament està massa ben delimitada en el context alemany de la traducció per al doblatge; i també ho està en el mercat italià. De la mateixa manera, quan Pommier (1988: 31-32) parla dels traductors de guions en el mercat francès, diu:

Ce travail est simplement une transposition littérale d'une langue dans une autre: le traducteur ne se préoccupe pas de chercher un synchronisme entre la prononciation de ses nouvelles phrases et les mouvements des lèvres de l'acteur à l'image ni d'adapter éventuellement les textes pur une meilleure compréhension par un public de culture très différente de celle du pays où a été realisée la version originale.

És a dir, que, després d'aquest primer esborrany de traducció, hi haurà el treball de détection i d'adaptation. Si ho comparem amb la pràctica de la traducció per al doblatge a Catalunya, podem afirmar que, en el nostre mercat, la figura del traductor i de l'ajustador s'acosten i es barregen cada vegada més. Serveixin com a exemple les declaracions dels traductors que van ser convidats al VII Seminari sobre la traducció a Catalunya: la traducció audiovisual, que va tenir lloc a Vilanova i la Geltrú el maig de 1999. Aquests invitats van expressar de maneres diferents que la traducció i l'ajust no eren processos independents: «La funció de l'ajustador (que de vegades és el mateix traductor) consisteix a preparar el text per facilitar la sincronia de l'actor de doblatge» (Roig, 1999: 11); «moltes vegades un guió nostre pot tenir sequiències que ens semblin gairebé desconegudes» (Sàrries, 1999: 28); «cal que el traductor (o bé l'ajustador) sincronitzi el text amb les boques dels personatges» (Sàrries, 1999: 29). Alguns altres autors (Creus, 1994: 64) són més explícits:

Precisament perquè el procés del doblatge és una cadena de muntatge típicá (encara que no de forma visible) hi ha multitud de casos en què s'hauria d'optar decididament per les fórmules més adequades als passos següents que vindran després de la traducció fins a arribar a l'emissió doblada del producte.

La feina de traducció ha d'incorporar el procés d'ajust; el traductor no solament s'ha d'ocupar de la sincronia de contingut, sinó que també ha de preveure la sincronia visual, la tasca tradicional de l'ajustador. Es tracta dels dos tipus de sincronia identificats per Whitman (1991, 17-55):

a) La sincronia visual/òptica (labial o fonètica, articulació sil-làbica, llargada de l'enunciació i expressió facial o gestual). 
b) La sincronia àudio/acústica (tipus de veu, elements paralingüístics. prosòdia, variacions culturals, accents i dialectes).

Tots dos tipus de sincronia són importants i no podem prioritzar-ne un sobre l'altre; la feina tradicional de l'ajustador no és més important que la del traductor: «lip synchrony is an animal threatened with extinction, especially since this is probably the easiest to distract the audience away from with other sensory input» (Whitman, 1991: 54). La traducció ha d'incorporar la sincronia visual: el diàleg només pot ser creible i natural si incorpora totes dues sincronies.

De fet, la sincronia visual apareix indissoluble a la sincronia de contingut en les versions doblades. Segons Olivier Goris: «the image, i.e. the point of view of the camera, has a great influence on film translation» (Goris, 1993: 182); la sincronia visual no pot considerar-se un procés independent de la traducció. Aquest investigador demostra que quan es prioritza la sincronització s'evita l'explicitació; i al contrari: hi ha un grau molt elevat de compensació en la traducció audiovisual i els dos processos són indissolubles. És indiscutible que, si el traductor incorpora l'ajust a la seva traducció, la seva presència serà més gran en l'autoria del producte final. D'aquesta manera, no caldrà que ofereixi diferents alternatives de traducció (ja sigui separades per una barra o en nota a peu de pàgina), que obliguen l'ajustador a prendre decisions en detriment del traductor. A més a més, les característiques pròpies de la llengua del guió traduït per al doblatge (oralitat, concisió, naturalitat, etc.) se sotmeten i són producte, al mateix temps, dels criteris de l'ajust.

\section{TRADUCCIÓ, AJUST I AUTORIA}

Incorporar l'ajust com a criteri per justificar decisions de traducció en el guió traduït vol dir apostar per l'especificitat de la traducció audiovisual com a traducció especialitzada subordinada a una imatge dinàmica. A més, també indica una voluntat de fer visible l'autoria del traductor en el producte doblat: les restriccions tècniques del doblatge poden deixar d'anar en detriment de la qualitat del producte i passar a ser incorporades com a estratègies específiques d'aquest tipus de traducció. En aquest sentit, Yvane reclamava l'any 1996 un enfocament acadèmic del doblatge que fos alhora qualitatiu (incorporant les restriccions tècniques) i quantitatiu (en el sentit de proposar una política audiovisual europea que permeti l'amortització dels programes doblats).

Voldríem que l'increment de l'autoria dels traductors en el producte doblat pogués contribuir a millorar les seves condicions de treball i a canviar l'estatus marginal que han tingut tradicionalment en el procés de doblatge. D'aquesta manera, el nom del traductor i el dels membres de l'equip de doblatge hauria 
d'aparèixer sempre en els crèdits del les pel-lícules doblades, tant per a la seva exhibició en sales comercials com en format de vídeo. Tanmateix, no podem deixar de banda les condicions reals del mercat; en aquest sentit, ens fem ressò d'un comentari de Creus (1994: 65) sobre el fet d'incorporar els dos processos: «si fas traducció i ajust, arrodoneix a la baixa el preu del rotlle, perquè si saps fer-t'ho venir bé encara et diuen que et surt a compte». En definitiva, esperem que incorporar el procés d'ajust a la traducció porti a millorar les quiestions de caire professional, com ara la velocitat amb què es veuen obligats els traductors a produir una traducció de qualitat i els mitjans amb què compten realment.

\section{BIBLIOGRAFIA}

Agost, R. (1999): Traducción y doblaje: palabras, voces e imágenes, Barcelona, Ariel.

Agost, R., F. Chaume i A. Hurtado (1999): «La traducción audiovisual», en Hurtado, A. (coord.): Enseñar a traducir, Madrid, Edelsa.

Ávila, A. (1997): El doblaje, Madrid, Cátedra.

CASTRO, X. (1998): «Curso de traducción para doblaje y subtitulación», Màlaga, Universidad de Málaga, del 16 al 20 de febrer.

CREUS, J. (1994): «Traduir per a la televisió: repte o submissió?», VII seminari sobre traducció a Catalunya, Barcelona, AELC, 57-70.

CHION, M. (1995): Cómo se escribe un guión, Madrid, Cátedra.

GoRIS, O. (1993): «The Question of French Dubbing: Towards a Frame for Systematic Investigation», Target, 5: 2, 169-190.

Pommier, C. (1988): Doublage et Postsynchronisation, París, Éditions Dujarric.

RoIG, R. (1999): «La traducció de sèries a la televisió: el nostre pa de cada dia», VII seminari sobre traducció a Catalunya, Barcelona, AELC, 11-26.

SÀRRIES, T. (1999): «Pragmàtica de la traducció de guions: conflictes i avantatges». VII seminari sobre traducció a Catalunya, Barcelona, AELC, 27-40.

Whrtman, C. (1991): Through the Dubbing Glass, Frankfurt am Main, Peter Lang.

YVANNE, J. (1996): «Le doublage filmique: fondements et effets» dins Gambier. Y. (ed.): Les Transfers Linguistiques dans les Médias Audiovisuels, París, Presses Universitaires du Septentrion, 133-143. 


\title{
L'ENSENYAMENT DE LA TRADUCCIÓ D'AUDIOVISUALS EN EL MARC DE LA FORMACIÓ DE TRADUCTORS
}

\author{
NATÀLIA IZARD \\ Universitat Pompeu Fabra
}

\section{INTRODUCCIÓ}

Una vegada, un traductor va rebre el seu primer encàrrec per traduir una pel-lícula. El client era una cadena de televisió. La feina li va resultar tan enriquidora i tan interessant que, el dia en què es programava per televisió la pel-lícula que ell havia traduït, va convidar a casa seva un grup de companys per veure la pel-lícula plegats. La pel-lícula va començar amb gran sorpresa per al traductor, ja que els diàlegs que sentia per televisió no eren pas els que ell havia traduit. A la sorpresa va seguir la decepció, quan va comprendre el que havia passat: en el procés d'ajust, càsting i doblatge, la seva traducció havia anat canviant fins convertir-se en un producte que ja no era la seva creació.

Una altra traductora assistia al doblatge de la pel-lícula que havia traduit. Es tractava d'Along The Great Divide (1951), de Raoul Walsh (en català, Camí de la forca, traducció literal de Camino de la horca, el títol amb què s'havia estrenat als cinemes espanyols el 1952). Un dels personatges de la pel-lícula era un home vell a qui el sheriff ha condemnat a mort. Els altres li diuen Pop. En anglès, $P o p$, que és una manera molt familiar de dir pare, es fa servir per anomenar amb respecte i estima una persona gran. La solució més senzilla hauria sigut inventar-se un nom propi qualsevol. Però l'argument girava al voltant del sentiment de culpabilitat que tenia el sheriff perquè ell, en el seu dia, havia deixat morir el seu propi pare. Així, el fet de tenir algú a prop a qui constantment 
anomenaven pare, i a qui ell enviava a la forca, li produïa un fort sentiment de culpa. Si es canviava el nom del vellet, la pel-lícula perdia un element connotatiu important. La traductora, a falta d'una solució perfecta, va optar per anomenar el vellet $a v i$, que indicava un parentiu prou fort com per fer sentir culpable el sheriff. Un cop a la sala, mentre es procedia al doblatge, un dels actors va dir: «Avi? Com que avi? En anglès diuen Pop. Li hem de dir Pop.» La traductora va justificar la seva solució, però no va servir de res. En la versió catalana, el vellet es va dir Pop.

\section{EL TRADUCTOR D'AUDIOVISUALS}

Aquestes anècdotes, que de fet no són gens anecdòtiques, ens plantegen una pregunta: per què passa tot això?

La resposta és decebedora: perquè a Espanya el traductor d'audiovisuals no té un rang propi, perquè no se'l considera un traductor especialitzat, com ho seria un traductor mèdic, jurídic o poètic.

I com es podria aconseguir que el traductor d'audiovisuals aconseguís aquest estatus? Incloent l'ensenyament de la TAV en els programes d'estudis, amb la qual cosa n'aconseguiríem dues:

a) Que la societat acceptés el traductor d'audiovisuals com un especialista amb una formació específica al darrera seu.

b) Que els traductors estessin prou ben formats com per defensar ells mateixos la seva posició i la seva feina.

Però, tot i que considerem que la formació de traductors audiovisuals és una finalitat en si mateixa, també creiem que l'aprenentatge de la modalitat del doblatge pot ensenyar tècniques traductores beneficioses per a qualsevol mena de traductor. Atès que el text verbal dels productes audiovisuals consisteix bàsicament en diàlegs, aprendre a traduir audiovisuals serà útil per a traduir novel-les, peces teatrals, entrevistes, literatura infantil, i tots aquells gèneres que inclouen diàlegs.

\section{EL DISCURS ORAL}

La principal condició dels diàlegs audiovisuals («writing to be spoken as if no written», segons la classificació de Gregory i Carroll, 1978) és que han de ser versemblants.

En aquest sentit, en la llengua catalana tenim el problema afegit que la normativa està molt allunyada de l'ús real de la llengua. En certes ocasions en què 
s'ha intentat aconseguir diàlegs versemblants, el que s'ha fet és buscar aquesta versemblança sense respectar la normativa (recordem la sèrie de TV3 Plats bruts, en què el que més crida l'atenció és la profusió de castellanismes). La nostra opinió és que es pot obtenir una impressió de versemblança d'una altra manera: a base de reflectir les característiques del discurs oral, cosa que no es contradiu amb la normativa.

Les característiques principals del discurs oral són:

a) Presència de totes les variacions lingüístiques. En altres paraules, que cada ocasió utilitzi un registre diferent i cada personatge un dialecte diferent. Especialment important (i difícil) és reproduir el tenor del discurs adequat. En ocasions, alguns diàlegs traduïts sonen estranys, perquè, en comptes de buscarse el tenor de la LC2 (llengua de cultura 2), el que s'ha fet és reproduir literalment el tenor de la LC1. En definitiva, s'ha d'intentar que els diàlegs resultants semblin tan polifònics com els de la vida real.

b) Redundància del discurs, mitjançant repeticions (tant lèxiques -repetició de certes paraules- com sintàctiques -repetició de certes estructures). La redundància és un mecanisme que reforça la cohesió.

c) Ús del discurs exofòric, ple d'elements referencials.

d) Des del punt de vista de la sintaxi, poca subordinació i predomini de la juxtaposició (i, per consegüent, pocs connectors). Amb un ús molt reduït de la veu passiva.

e) Presència d'elements expressius i afectius: renecs, augmentatius i diminutius, vocatius, datius ètics, termes argòtics o procediments de deformació com els de l'argot, ordre de presentació dels elements diferent de l'habitual, en benefici del ritme, de l'eufonia, o per emfasitzar un element concret de l'oració, frases fetes, locucions, refranys i gestos vocals (elements no verbals però amb gran càrrega significativa: dubte (euh...), fàtic ( $h a !)$, apel-lació (ep!), fer callar $(x t !)$, desgrat (pse...), fàstic (ecs), esforç (uf!), dolor (ai!), menyspreu (bah!). etc.).

La formació de traductors especialistes en doblatge s'ha de fixar, com un dels objectius principals, ensenyar els alumnes a produir diàlegs versemblants. I aconseguir un efecte de versemblança és un objectiu especialment desitjable en la llengua catalana, en què l'equilibri entre l'ús normatiu i l'ús real de la llengua és tan difícil d'aconseguir. 


\section{BIBLIOGRAFIA}

GreGoRY, M. i S. CARRoll (1978): Language and Situation, Londres, Routledge \& Kegan Paul.

Hatim, B. i I. Mason (1991): Discourse and the Translator, Londres i Nova York, Longman.

Payrató, L. (1990): Català col-loquial. Aspectes de l'ús corrent de la llengua catalana, València, Universitat de València. 


\title{
LA PRETENDIDA ORALIDAD DE LOS TEXTOS AUDIOVISUALES Y SUS IMPLICACIONES EN TRADUCCIÓN
}

\author{
Frederic Chaume Varela \\ Universitat Jaume I
}

\section{LOS CÓdIGOS DE SIGNIFICACIÓN DEL TEXTO AUDIOVISUAL}

Toda producción cultural tiene significado. Si bien el disfrute de una producción cultural puede realizarse sin centrar la atención en los elementos que configuran la obra, el análisis académico se suele sustentar en la exégesis del texto, según una metodología o un enfoque determinado. Los textos audiovisuales muestran una densidad de significado y una complejidad retóricá fruto de su configuración textual: nos enfrentamos ante unos textos que, al menos, transmiten información mediante dos canales, el acústico y el visual, codificada a través de diversos sistemas de significación. Nuestra propuesta metodológica parte de la desconstrucción y análisis de tales códigos de significación. con el fin de descubrir las convenciones retóricas de cada uno de ellos y extraer, posteriormente, conclusiones válidas para la traducción, en especial, para la construcción de un nuevo texto meta que respete el entramado semántico del texto original y no conculque las reglas de configuración textual propias del género en cuestión en la cultura meta.

En un trabajo anterior distinguíamos al menos 10 códigos de significación, presentes en los textos audiovisuales, cuya construcción retórica incide directa- 
mente en las operaciones de traducción audiovisual (Chaume, 2000). En el trabajo mencionado señalábamos el código lingüístico, el código paralingüístico, el código musical y de ruidos, el código de colocación del sonido, los códigos iconográficos, los códigos fotográficos, los códigos de movilidad, el código de planificación, los códigos gráficos, y los códigos sintácticos o montaje. La interacción de todos estos códigos singulariza la potencialidad semántica del texto audiovisual y su textura, es decir, no sólo las estructuras narrativas dotan de significado al texto, sino que las convenciones mediante las que se construyen esas estructuras narrativas ocupan un papel tan, o más, preponderante como la narración en sí misma. El significado transmitido a través de cada uno de los códigos, así como, especialmente, el significado extra que se produce mediante la interacción de los diferentes códigos de significación en cada momento, dota a los textos audiovisuales de su particular idiosincrasia y resume la especificidad de los textos objeto de este estudio. En esta ocasión, sin embargo, restringiremos nuestro análisis al código linguiístico, que ha ocupado las contribuciones del apartado que ahora cerramos. De cualquier modo, la configuración textual por lo que respecta a este código viene igualmente condicionada por la presencia simultánea de otros códigos de significación.

El código lingüístico ocupa el lugar preponderante entre todos los códigos emitidos a través del canal acústico (código lingüístico, paralingüístico, musical y de ruidos y código de colocación del sonido). Sin él, no hablaríamos de traducción y ni siquiera nuestra disciplina se ocuparía de las transferencias de textos audiovisuales entre distintas culturas.

El código lingüístico transmitido a través del canal acústico llega al espectador mediante un modo del discurso oral. En él incluimos todas las intervenciones orales (excepto las paralingüísticas) de los personajes del filme, diegéticos y extradiegéticos, y en ambos casos, tanto las de aquellos personajes que se encuentren en pantalla $(\mathrm{ON})$ como las de los que se encuentren en fuera de pantalla (OFF), o dicho de otro modo, dentro y fuera de campo, incluidas en este último apartado las voces de los posibles narradores en OFF. En este trabajo no nos ocuparemos, por razones de espacio, de las instancias del código linguístico que se transmiten mediante un modo del discurso escrito pero a través del canal visual (rótulos, carteles, etc.), sino sólo de aquellas instancias del código linguiístico que se transmiten mediante un modo del discurso oral a través del canal acústico.

\section{UNA ORALIDAD PREFABRICADA}

Desde el punto de vista del texto origen, hablamos de código lingüístico oral. Sin embargo, sus características lingüísticas no son del todo las propias 
del lenguaje oral espontáneo, puesto que, en realidad, el discurso oral de los personajes de pantalla no es más que el recitado de un discurso escrito anterior. Sin embargo, tal recitado ha de parecer oral. Así lo explica Whitman-Linsen (1992: 31-32):

One more unhinging peculiarity of spoken dialogue is precisely that: it is spoken and not written. More accurately, it is written to sound spoken. People pause. collect their thoughts, begin again, clear their throats, change paths halfway down the syntactical road. Such anacolutha, deemed bad style and poorly thought out in a written text, are exactly what make a spoken dialogue animated, credible. authentic and human.

La aportación de Televisió de Catalunya (1997: 12-14), por lo que respecta a la definición del lenguaje característico de estos textos, es concreta y útil para el traductor (y para el guionista), especialmente en la fase de rescritura del guión. Las propuestas estilísticas de la corporación catalana siguen una de las tres máximas (Chaume, 2000) en las que se basa el acuerdo tácito entre el emisor de un texto audiovisual y las expectativas del espectador que visiona un texto audiovisual (traducido o no): la confección de unos diálogos verosímiles, que cumplan las convenciones del registro oral de la lengua de llegada. Estas recomendaciones se dirigen especialmente a la modalidad del doblaje, pero no serían demasiado diferentes de las exigidas para la subtitulación, y se resumen en los siguientes apartados:

1. Niveles de la lengua:

- Nivel gramatical: sintaxis poco compleja.

- Nivel léxico-semántico: léxico corriente.

- Nivel prosódico: pronunciación clara.

2. Registros lingüísticos:

- Se aconseja huir de los dialectalismos, de los cultismos y de los anacronismos.

- Se aconseja también trabajar en pro de la adecuación de los personajes al registro lingüístico que convencionalmente tienen asignado.

3. Géneros audiovisuales:

- Para los documentales, los autores recomiendan

a) el uso de un léxico preciso,

b) un orden gramatical canónico, compuesto por sujeto + verbo + complementos, 
c) un uso adecuado de los conectores, que dé como resultado un texto más cohesionado, con pocas elipsis de conectores,

d) el uso de un registro formal,

e) para los actores de doblaje, una articulación fonética muy precisa, de acuerdo con el registro lingüístico escogido para este género.

- Para los géneros de ficción recomiendan

a) el uso de un registro coloquial,

b) en nuestra opinión, contradictoriamente con lo acabado de decir, un modo del discurso claramente no espontáneo, es decir, sin digresiones ni redundancias, como ciertas marcas características del registro oral (dubitaciones, hipérbatos, anacolutos, etc.), cuando éstas no sean significativas en la descripción del personaje,

c) el empleo de frases cortas,

d) el uso de la yuxtaposición,

e) la preferencia de las oraciones activas frente a las pasivas más propias, en todo caso, de los documentales,

f) la focalización de la información,

g) un amplio uso de la elipsis,

h) un amplio uso de los deícticos,

i) el empleo de estructuras conversacionales estereotipadas,

j) el empleo de clichés.

Con matices, es posible suscribir la propuesta de los autores del libro de estilo. En su descripción, vale la pena poner el acento en aquellos recursos lingüísticos y retóricos que van a otorgar al texto su carácter pretendidamente oral y espontáneo, lo que Gambier y Suomela-Salmi denominan «written discourse imitating the oral» (1994: 247); los géneros de ficción exigen especialmente la sintaxis sencilla y el léxico corriente que postulan estos autores. Sin embargo, los recursos de la coloquialidad encuentran su límite en la supresión de digresiones, redundancias, hipérbatos, anacolutos y dubitaciones que cansarían al espectador y que, probablemente, poco cooperarían a cumplir con las convenciones formales de longitud, inmediatez y relevancia lingüística establecidas en este género de textos. Se borran, pues, las fronteras entre los dos polos clásicos: el código restringido (en donde tendría cabida el discurso oral espontáneo) y el código elaborado (que comprendería el discurso escrito), pues deberíamos buscar un espacio para el supuesto lenguaje oral de los textos objeto de este estudio. Como afirma Salvador (1990: 22), la llegada de los medios de comunicación tecnológicos ha contribuido a borrar las diferencias entre oralidad y escritura: 
[...] el que es pot anomenar inscriptura tecnológica de l'oralitat (Salvador, 1990). Aquesta inscriptura permet combinar en diverses fórmules les característiques de la comunicació oral (utilització de la veu, aparença d'immediatesa, etc.) amb alguns dels avanços de l'escriptura (fixació, difusió massiva en l'espai i en el temps, conservació més enllà de les coordenades pragmàtiques de la producció discursiva, etc.). En aquest sentit es podria dir que els mass media representen una via important de neutralització de la dicotomia que ens ocupa.

Si en vez de establecer dos polos dicotómicos aislados, representáramos un continuum de mayor a menor elaboración, el discurso de los textos audiovisuales se encontraría a medio camino entre ambos extremos. Se trata, por tanto, de un discurso oral prefabricado, pensado, elaborado según unas convenciones determinadas, en una palabra, controlado. Como también opina Payrató (1990: 52):

La diferència entre un text escrit per ser dit (com si no fos escrit) i la parla espontània és que el primer està planificat i el segon no. El text «falsament» oral és més compacte, més cohesiu. La parla espontània és més vacil-lant i menys sistemàtica.

\section{LAS CARACTERÍSTICAS DEL DISCURSO ORAL ELABORADO DE LOS TEXTOS AUDIOVISUALES}

A lo ya expuesto por Televisió de Catalunya nos parece recomendable añadir algunas características en los niveles mencionados. No pretendemos realizar un análisis exhaustivo de las diferencias entre un discurso oral prefabricado y un discurso oral espontáneo (eso sería objeto de otro trabajo más extenso). sino apuntar aquellos rasgos más notorios del lenguaje oral espontáneo que, sin embargo, el traductor debe obviar para conseguir un equilibrio entre la verosimilitud que se le exige, por un lado, y la relevancia en la disposición de la información y el acatamiento de la normativa linguística y estilística, por otro. Nuestra descripción se va a centrar mayoritariamente en textos de ficción, aunque las tendencias nombradas sirven, prácticamente, para la totalidad de los textos audiovisuales. Seguiremos, para ello, los trabajos de Brown y Yule, 1983, para la lengua inglesa, y Payrató, 1990, Vigara, 1992, Bibiloni, 1997, y Alcoba, 1998, para el español y el catalán.

\subsection{Nivel prosódico}

a) En doblaje, la reflexión sobre este nivel le ha correspondido históricamente al ajustador, encargado de rescribir los diálogos para entrar en sala, así 
como al director de doblaje y a los actores. De todos modos, bueno es que el traductor conozca los filtros que va a sufrir su producto antes de entrar en sala y, si es posible, evitarlos ya en la traducción. Aparte de la articulación fonética tensa y de la pronunciación clara (frente a la articulación relajada del verdadero discurso oral coloquial), se recomienda, tácita o explícitamente, a través de las correcciones de adaptadores y correctores lingüísticos:

- evitar la reducción o incluso la supresión consonántica propia del discurso oral coloquial;

- evitar la caída de la $d$ intervocálica;

- evitar la caída de las vocales átonas;

- evitar las metátesis;

- evitar añadir vocales de apoyo iniciales o epentéticas, propias de registros muy coloquiales (*amoto, por ejemplo);

- evitar la elisión en los enlaces intraoracionales;

- evitar asimilaciones y disimilaciones;

- acentuar la entonación y evitar ambigüedades prosódicas;

- evitar cacofonías que en el discurso oral coloquial podrían aparecer espontáneamente.

Algunos de estos aspectos, en especial el último, están plenamente en manos del traductor y este debe esforzarse notablemente para que tal fenómeno fonético no aparezca en su traducción. Para ello, conviene una lectura en voz alta de los párrafos traducidos.

Como se aprecia, por tanto, el discurso no es tan oral (ni tan coloquial) como podría parecer. Se podría argumentar que en los documentales no hay pretensiones de emular un discurso oral coloquial: es cierto, pero ello no hace más que confirmar que lo expuesto es de aplicación para cualquier género audiovisual, incluso para aquellos que pretenden conseguir mayor verosimilitud a través de la presentación de registros más orales y coloquiales.

b) En subtitulación, no cabe hablar de prosodia del mismo modo en que lo hacemos en el doblaje. Sin embargo, sí se utilizan ciertos elementos ortotipográficos para señalar rasgos del discurso oral del texto origen. Lakoff (1982), en un trabajo significativamente titulado «Some of my favourite writers are literate: the mingling of oral and literate strategies in written communication», ofrece un amplio repertorio de los recursos que posee el registro escrito para reproducir las tendencias del lenguaje oral (uso de comillas, cursiva, mayúsculas, elipsis, anacolutos, pausas, etc.). El traductor hace uso de los puntos suspensivos para marcar pausas y vacilaciones; de palabras fragmentadas para marcar dubitaciones; de la cursiva para 
marcar voces en $O F F$ o lejanas, o también pensamientos en voz alta; del guión para introducir los diálogos de cada personaje, etc.

\subsection{Nivel morfológico}

En este nivel, también se aprecian diferencias entre los rasgos propios de un registro oral espontáneo y los de un registro oral prefabricado. Así, tanto en español como en catalán, existe una tendencia muy estricta a ajustarse a sendas normativas lingüísticas. No cabe duda de que, bajo esta elección, subyace un afán de protección linguiística (más justificado en catalán que en español) a través de la difusión de un estándar con el mínimo número de grietas posible. algo con lo que podemos estar, o no, de acuerdo: personalmente nos parece que el uso del registro coloquial en el nivel morfológico no conlleva los riesgos que los defensores de la normativa claman.

Comparando el registro oral prefabricado con el espontáneo, el traductor el traductor evita:

- la creación de singulares o plurales analógicos

- la creación de masculinos o femeninos analógicos

- las flexiones verbales incorrectas por analogía

- las concordancias agramaticales

\subsection{Nivel sintáctico}

De nuevo, el análisis de este nivel delata la planificación con que se ha escrito el pretendido discurso oral de los textos audiovisuales, en los casos en que existe un guión previo. En esta ocasión, la modalidad de la subtitulación suele presentar un discurso muy normativo, puesto que las variaciones sintácticas llevarían a una dispersión en la lectura de los subtítulos y a una confusión por parte del espectador, que acabaría perdiendo información y saliéndose de la película.

Los consejos mencionados en el libro de estilo de Televisió de Catalunya siguen la línea de imitar un discurso oral espontáneo y es que, en realidad, en este nivel y en la modalidad del doblaje, el discurso prefabricado otorga mayores concesiones al discurso verdaderamente espontáneo. Si bien lo expuesto por la Comissió de Normalització Lingüística en el manual mencionado concuerda con las descripciones del habla coloquial (empleo de frases cortas, yuxtaposiciones, elipsis, deícticos, oraciones activas frente a las pasivas, estructuras conversacionales estereotipadas y clichés), estos autores ya avisan de que ciertas concesiones no son (supuestamente) del agrado del espectador. Además de aconsejar un orden gramatical canónico y un uso correcto y abundante de 
conectores para los documentales, su propuesta postula un modo del discurso claramente no espontáneo, es decir, sin digresiones ni redundancias como ciertas marcas características del registro oral: dubitaciones, hipérbatos, anacolutos, etc. A estas precisiones, nosotros podemos añadir otras observadas a partir de la práctica de la traducción:

- evitar la segmentación del enunciado en sucesivos fragmentos, lo que conferiría un cierto aislamiento y una expresión discontinua;

- evitar la supresión de preposiciones propia del lenguaje oral (t'acompanye [ ] el sentiment o dame un cacho [ ] pan, por ejemplo);

- evitar la supresión de conectores y marcadores discursivos;

- evitar las ampliaciones y reducciones expresivas del núcleo de comunicación;'

- evitar los incumplimientos de las restricciones gramaticales o semánticas (las llamadas colocaciones o impropiedades semánticas en la asociación de los términos, por ejemplo);

- evitar, por regla general, las vacilaciones y los titubeos;

- evitar, finalmente, las inserciones de paréntesis asociativos o interferencias momentáneas sin conexión gramatical con lo que se viene diciendo, en forma de opinión personal, de explicación añadida, etc.

No obstante hemos apuntado que, en este nivel, la presencia de rasgos propios del discurso oral espontáneo es superior a la presencia en otros niveles. Además de los rasgos apuntados por el libro de estilo de la televisión catalana, nosotros podemos añadir:

- procurar el uso abundante de interjecciones en doblaje;

- procurar la topicalización de los elementos más relevantes informativa o expresivamente;

- procurar usar de más a menos enunciados yuxtapuestos, coordinados y subordinados (en este orden);

- procurar hacer uso del énfasis o realce de una parte del enunciado;

- procurar introducir concordancias improvisadas, aunque sólo las sancionadas por el uso;

1. Vigara (1992: 129) explica así el fenómeno: «las suspensiones (inconscientes, afectivas) que dejan la frase inacabada se suceden en la hablante sin que su interlocutora llegue a pedirle en ningún momento explicaciones: prevalece en estos casos la «intención de comunicación» mostrada por el hablante (aceptada por su interlocutor) y pasa a segundo término la cantidad de información.» Lo que es un hecho común en el discurso oral espontáneo, se suele evitar en la traducción de textos audiovisuales (así como en la construcción del guión original). 
- procurar elaborar el discurso con las expresiones de apertura y cierre propias del registro oral (las muletillas iniciales o finales, por ejemplo, oye...,...verdad?, ...ंno?);

- procurar utilizar repeticiones y adiciones;

- procurar utilizar la elisión en fragmentos que lo permitan.

\subsection{Nivel léxico-semántico}

La pretendida oralidad de los textos audiovisuales basa sus cimientos en la emulación del léxico oral espontáneo. En este nivel, sí podemos afirmar que el discurso oral espontáneo y el discurso prefabricado de los textos audiovisuales es muy similar, pues, de hecho, es este último el que toma del primero todos los rasgos (a su alcance) que le van a conferir ese tono verosímil con el que establecerá su relación con el espectador. En realidad, las relaciones del léxico con la verosimilitud en el campo de la traducción vienen de antaño. Entre la profesión, por ejemplo, circula la norma de utilizar anacronismos léxicos al elaborar la traducción de una obra clásica ${ }^{2}$ (Televisió de Catalunya, 1997: 16) y, sin embargo, no introducir rasgos diacrónicos propios de los otros niveles que probablemente dificultarían la comprensión de la obra.

En este nivel, son más los elementos de intersección entre discurso oral real y discurso oral elaborado que los elementos de divergencia. Entre los escasos elementos de divergencia que acusan al texto de su previa planificación destacan las normas tácitas o explícitas de:

- evitar palabras ofensivas, groseras o malsonantes. Se prefiere la sustitución de las mismas por eufemismos o disfemismos, según el registro del personaje que las enuncie;

- evitar tecnicismos innecesarios, incluso aquellos que son ya de uso habitual en lenguaje coloquial (por ejemplo, palabras que han penetrado en casi todos los sectores como interferencia, incompatibilidad, infraestructura, peso específico, tanto en español como en catalán, Bibiloni, 1997: 105 y 114);

- evitar dialectalismos y procurar respetar las convenciones léxicas del estándar;

- evitar anacronismos, que, en el caso de los registros coloquiales, suelen ser también dialectalismos, es decir, cuando el registro oral espontáneo utiliza un anacronismo, la causa puede encontrarse en que ese anacronismo quizá for-

2. No sólo en el campo de la traducción. Muñoz Seca, en su celebrada La venganza de Don Mendo, emula una situación propia de la España del Siglo de Oro a través, esencialmente, de ciertas pinceladas léxicas ( $\mathrm{y}$ ciertos juegos sintácticos) que al espectador del siglo xx le traen a la memoria representaciones teatrales o textos de aquella época. 
ma parte del caudal léxico de un determinado dialecto (o de un determinado idiolecto) y se considera anacrónico con respecto al estándar;

- y, sobre todo, evitar términos no normativos.

Las zonas de intersección son, sin embargo, mucho más amplias en este nivel. A las ya descritas (uso de clichés, fórmulas estereotipadas, etc.) cabe añadir:

- facilitar la creación léxica espontánea;

- hacer uso de la intertextualidad, especialmente por lo que respecta a refranes y dichos, letras de canciones, eslóganes publicitarios;

- hacer uso de términos genéricos y comodines, de amplio alcance semántico;

- facilitar la entrada de argot (escolar, juvenil, argots profesionales, sociales, etc.), siempre que este no se restrinja a una zona muy concreta;

- utilizar toda clase de figuras estilísticas (comparaciones, metáforas, dobles sentidos, personificaciones, etc.).

Estamos, pues, parcialmente de acuerdo con las conclusiones de Alcoba (1998), quien define los textos escritos para ser oralizados como si no estuvieran escritos, como textos con una estructura ordenada y cerrada, con mayores niveles de coherencia y cohesión que los textos verdaderamente orales y con menor dependencia del contexto situacional, rasgos todos que hemos comprobado en nuestro análisis. Sin embargo, en su trabajo se postula que en los textos objeto de este estudio existen menos deícticos o anafóricos cuya referencia se sitúe fuera del texto: ${ }^{3}$ esta característica puede ser válida para otro tipo de textos que compartan el mismo modo del discurso, pero no para los textos audiovisuales, que utilizan constantemente los elementos y objetos presentes en la situación ficticia en donde se producen, en lo que podríamos llamar el contexto situacional diegético.

\section{CONCLUSIONES}

La oralidad de los textos audiovisuales es una oralidad pretendida, elaborada, prefabricada. Pese a los consejos reiterados de los libros de estilo y de los clientes del mundo de la traducción audiovisual, el traductor no debe caer en la tentación de reproducir un registro oral espontáneo. En la representación de la

3. Si el autor considerase que el texto lo forman no sólo los enunciados lingüísticos sino el conglomerado de información visual y verbal, tal y como se postula en este trabajo, entonces su afirmación sería válida, puesto que es cierto que son escasos los textos que hacen referencia directa a la situación en la que se encuentran los espectadores. Al ser el suyo un estudio muy centrado en los aspectos linguísticos, no ha sido esa la lectura que hemos realizado de sus conclusiones. 
lengua de llegada hemos observado reiteradamente la misma tendencia: fingir un discurso oral, pero con unas limitaciones muy concretas que lo separan del verdadero registro oral espontáneo. El traductor debe tomar buena nota de las claves de la oralidad de los textos audiovisuales y encontrar el equilibrio entre la oralidad y las convenciones normativas de los clientes, que suelen responder a criterios de recepción, históricos, políticos y culturales. Del mismo modo, el uso de los signos iconográficos también responde a una motivación. Por las limitaciones de espacio en este estudio, no podemos más que avanzar que la elaboración y planificación del uso de la iconografía, fotografía, etc., en un texto audiovisual ha de ser tenida en cuenta para el análisis de dichos textos desde el punto de vista de la traducción (Chaume, 2000).

La descripción ofrecida en este artículo nos presenta un lenguaje elaborado, alejado de los tópicos que afirman que el registro oral es más pobre que el registro escrito. Estamos de acuerdo con Briz (1993: 145 y ss.) en que, aunque se observe una menor presencia de conjunciones o de proposiciones subordinadas con respecto al escrito, por ejemplo, el registro oral (y más todavía el registro oral prefabricado) dispone de otros medios para manifestar esos elementos perdidos, que van desde la entonación de los enunciados hasta la expresividad y emotividad más extrema actualizada mediante repeticiones, vocativos, etc. A ello debemos añadir la presencia simultánea de la imagen y de los códigos de significación transmitidos a través del canal visual, que confieren mayor expresividad a la narración: en el análisis del discurso oral, por tanto, no podemos restringirnos a las palabras pronunciadas por los actores, y ni siquiera a la secuencia de sucesos que constituye la historia, sino a la manera en que se nos cuenta esa historia a través del lenguaje icónico, de la iluminación, de la movilidad y situación de los personajes, del montaje de las diferentes secuencias, etc.

No hemos pretendido realizar un estudio exhaustivo, pero sí hemos querido recoger las líneas básicas del discurso prefabricado que sustenta la escritura de guiones y la posterior rescritura de las traducciones. Hemos intentado hacer hincapié precisamente en aquellos rasgos del discurso pretendidamente oral que difieren sustancialmente de las tendencias observadas en el verdadero discurso oral espontáneo. En ese sentido, también hemos querido delimitar un poco más qué se entiende realmente por lenguaje oral de los textos audiovisuales. un registro especial que se le exige al traductor profesional que se ve obligado a nadar entre las aguas de los registros coloquiales y de los llamados registros formales neutros. 


\section{BIBLIOGRAFÍA}

AlcoBa, S. (coord.) (1998): La oralización, Barcelona, Ariel.

BibILONI, G. (1997): Llengua estàndard $i$ variació lingüística, Valencia, 3 i 4, Col. Contextos.

BRIZ, A. (1993): «Los conectores pragmáticos en español: su papel argumentativo (I)», Contextos XI, 21/22, págs. 145-188.

Brown, G. y G. Yule (1983): Discourse Analysis, Cambridge, Cambridge University Press.

Chaume, F. (2000): La traducción audiovisual: Estudio descriptivo y modelo de análisis de los textos audiovisuales para su traducción. Tesis doctoral presentada en la Facultat de Ciències Humanes i Socials de la Universitat Jaume I.

GAmbier, Y. y E. SuOMELA-SAlmi (1994): «Subtitling: A type of transfer» en Eguíluz, F. y otros (eds.): Trasvases Culturales: Literatura, Cine, Traducción, Vitoria-Gasteiz, Universidad del País Vasco-Euskal Herriko Unibersitatea, págs. 243-252.

LAKOFF, R. (1982): «Some of my favourite writers are literate: the mingling of oral and literate strategies in written communication», en D. TANNEN (ed.): Spoken and Written Language. Exploring Orality and Literacy, Norwod: Ablex, P.C.

PAYrató, L. (1990): Català col-loquial. Aspectes de l'ús corrent de la llengua catalana, Valencia, Universitat de València, Col. Biblioteca Lingüística Catalana.

SALVAdOR, V. (1990): «L'anàlisi del discurs, entre l'oralitat i l'escriptura», Caplletra 7, p. 9-31.

Televisió de Catalunya (1997): Criteris Lingüístics sobre Traducció i Doblatge, Barcelona, Edicions 62.

Vigara, A.M. (1992): Morfosintaxis del español coloquial. Esbozo estilístico, Madrid, Gredos.

WhitMAn-Linsen, C. (1992): Through the Dubbing Glass, Frankfurt, Peter Lang. 
ASPECTOS PROFESIONALES 


\title{
LES TRADUCTEURS FACE AUX ÉCRANS: UNE ÉLITE D'EXPERTS
}

\author{
Yves Gambier \\ Université de Turku (Finlande)
}

Les transferts linguistiques sur les petits et grands écrans (télévision, cinéma, vidéo, ordinateurs) ainsi que pour les produits et services en ligne (localisation de logiciels) et hors ligne (CD-Rom) semblent connaître un développement rapide, avec la croissance et la diversité des usages des supports audiovisuels et multimédias. L'exercice de la traduction dans cet environnement exige de nouvelles compétences du traducteur. Les représentations habituelles du travail, et donc l'identité professionnelle, en sont aussi transformées.

\section{LA TRADUCTION: UN CONCEPT ÉCLATÉ}

Les évolutions du marché, l'augmentation et la diversification des demandes de traduction (avec des exigences accrues de rapidité), l'ambiguité du rôle politico-culturel de la traduction (au service des entreprises dominantes, des secteurs de pointe, des producteurs de biens culturels de masse et/mais aussi de communautés aujourd'hui minorées, fragilisées), les nouvelles hiérarchisations dans l'ordre linguistique mondial, l'essor rapide de l'informatisation des outils de travail, les mutations des conditions de la pratique professionnelle, tout cela brouille les profils du traducteur. Aussi et surtout, tout cela diversifie de plus en plus les attentes, les représentations même de la notion de traduction qui n'a jamais fixé sur elle une définition consensuelle.

Il ne s'agit pas ici et maintenant de s'arrêter sur les fondements et les traits éventuels d'une telle définition mais de constater l'éclatement désormais des 
dénominations touchant le transfert, le passage, le transculturel - travail qui se paie, avec de l'argent, par de l'anonymat et de l'indifférence souvent, que certains payent de leur liberté, de leur vie. Je ne pense pas aux catégories traditionnelles comme traduction spécialisée ou littéraire, interprétation de conférence ou de communauté, sous-titrage ou doublage- catégories qui relèvent, je dirai, de la tribu des traducteurs.

Je pense aux étiquettes qui s'imposent dans divers milieux professionnels commanditaires, demandeurs de traduction mais niant le mot, au profit par exemple de: localisation, adaptation, documentation multilingue, editing, rédaction technique multilingue, médiation langagière, transferts linguistiques, versionisation, etc. Deux raisons au moins expliquent certainement cette prolifération relative: la traduction resterait confondue toujours avec le mot à mot; le concept de texte, avec le développement des multimédias (c'est-à-dire du langagier mêlé au visuel, au sonore, au graphisme, etc.) n'est plus perçu comme suite linéaire de phrases. Cette double justification dit combien l'idée de traduction et l'univers des traducteurs demeurent archaiqques aux yeux de beaucoup. Cela n'empêche pas que les mêmes milieux des affaires, de l'audiovisuel, de l'industrie de l'informatique, etc. vivent eux-mêmes sur des archétypes, préférant ainsi concevoir la langue comme une mécanique statique plutôt que comme une dynamique, préférant envisager la communication comme un ensemble d'informations plutôt que comme une interaction, préférant affirmer qu'un message, c'est une concaténation de données plutôt que l'expression d'une identité.

Quoi qu'il en soit, le concept éclaté oblige à s'interroger: quel objet enseigne$\mathrm{t}$-on ou va-t-on enseigner pour former les passeurs langagiers de demain? Quelles compétences, multiples, faut-il prévoir? Certains traductologues ont-ils intérêt à se borner à une vision prescriptive du terme traduction? L'élargissement conceptuel s'applique-t-il à toutes les sociétés, à toutes les langues? Si translation se porte mal dans le monde anglo-saxon, käännös se porte bien en Finlande.

Plusieurs questions essentielles sont soulevées, avec cette pluralité de désignations. J'en traiterai trois.

\subsection{Connaissance du marché de la traduction}

D'abord celle de la connaissance du marché de la traduction. Comment en effet envisager les besoins de demain à partir des tendances d'aujourd'hui si on ne peut pas avoir des informations fiables, chiffrées sur la demande et l'offre actuelles?

Les autorités de l'Union Européenne ont tenté de cerner le marché mais se sont vite heurtées à l'absence d'accord général sur ce que sont la traduction et 
les vendeurs de traduction car d'une part les services de traduction ne sont pas l'apanage des traducteurs déclarés, qualifiés et d'autre part il n'est pas toujours facile de différencier dans les agences de traduction, rachetées par de plus grandes compagnies, ce qui relève ou pas de la traduction.

Par ailleurs, la situation se complique si on pense à la sous-traitance et à la délocalisation. Une part du volume de traductions dans les grosses entreprises, comme par exemple celles de logiciels, peut être ainsi réalisée en interne et une autre achetée à l'extérieur. Un relevé statistique devrait donc plutôt se faire à partir des clients. Cela ne saurait indiquer toutefois l'ampleur du marché latent, potentiel c'est-à-dire des documents qui pourraient être traduits si les coûts étaient moindres, si le travail était plus rapide, si les ressources pour faire les traductions étaient plus connues ou plus accessibles.

\subsection{Besoin de traducteurs}

Une telle enquête statistique servirait bien sûr à mieux traiter les besoins en traducteurs pour le futur, et donc à se préoccuper dès maintenant des exigences nécessaires pour certifier, accréditer les professionnels de demain et à adapter en conséquence les cursus de formation.

\section{3 Éducation des clients}

Autre question corrélée à la pluralité des désignations: celle des attentes. En effet si les clients ont leurs propres attentes, en partie spécifiques car déterminées par leurs types de communication, par la nature de leurs messages échangés, encore est-il qu'il faudrait qu'ils comprennent aussi ce qu'ils sont en droit d'obtenir d'un traducteur. C'est la problématique de l'éducation des clients. Ceux-ci devraient être sensibilisés aux différences entre ce que produit un professionnel et ce que propose un amateur et être informés des tenants et aboutissants d'une assurance qualité.

Des forums et colloques existent désormais qui font se rencontrer traducteurs et usagers, commanditaires de traductions, par exemple sous les auspices de LISA (Language Industries Standards Association, centrée sur l'industrie des logiciels), sous les auspices de ITALICS à propos de la communication dans le monde des affaires; ou encore dans des efforts conjoints entre associations de traducteurs et associations de rédacteurs, comme en Allemagne; ou encore autour de spécialisation pointue comme les conférences sur la traduction audiovisuelle (entre sous-titreurs et producteurs de télévision, distributeurs de films), sur les marchés financiers (entre traducteurs et agents boursiers). 
Je suis de plus en plus convaincu que les traducteurs spécialisés ou en droit. ou en télécommunications, ou en médecine, etc. sont plus proches les uns des autres - en deça et au-delà de leurs frontières, qu'avec leurs collègues compatriotes, exerçant aussi la traduction mais dans une autre spécialité. Ces traducteurs spécialistes ont certainement plus à gagner, au moins dans l'immédiat et au niveau transnational, à se confronter avec leurs clients, dans un effort de mutuelle reconnaissance, qu'à poursuivre un dialogue exclusif entre traducteurs. Franchement dit, un traducteur espagnol, habitué aux besoins et contraintes du commerce international par exemple, peut partager davantage avec un autre traducteur (mettons: hongrois) travaillant dans le même domaine qu'avec un autre traducteur espagnol, habitué lui aux textes littéraires.

\section{AUDIOVISUEL ET MULTIMÉDIAS: MISE EN PERSPECTIVE}

Les réflexions sur les langues dans et via les médias audiovisuels (AV) sont assez récentes. Une recherche bibliographique avant 1994 avait donné 730 entrées; en 1997, on avait 1300 références. De même au niveau des rencontres internationales: avant 1995, on note essentiellement la réunion de 1987 organisée par l'UER/EBU à Stockholm. Depuis 1995, il y a presque chaque année un événement consacré aux langues, aux transferts linguistiques à la télévision, au cinéma, pour les vidéos, etc. Quant à la localisation des multimédias, elle semble avoir en partie échappé aux milieux traditionnels, professionnels et universitaires, de la traduction.

\subsection{Des malentendus toujours possibles}

L'émergence de la traduction AV et des multimédias n'exclut pas les malentendus terminologiques (cf. 1). En outre, il y a des divisions hiérarchiques du travail qui ont cours dans certains studios, agences de sous-titrage ou chaines de télévision mais qui n'ont pas cours ailleurs (cf. 4.1): ici, la traduction est un transcodage qui est ensuite adapté puis découpé en sous-titres, incrustés par un technicien; là, la traduction implique adaptation, découpage en sous-titres et ajustation synchrone aux images. Dans le premier cas, il y a plusieurs intervenants successifs; dans le second, le traducteur est sous-titreur. C'est ce dernier sens qui est implicite dans l'exposé qui suit - que le sous-titrage porte sur des répliques de films, des interviews de documentaires ou des dialogues de programmes télévisés.

Autre malentendu: l'extension qu'il faut donner à média puisque certains y incluent films, TV, théâtre, $\mathrm{BD}$, opéras, etc. 
Je considérerai la traduction audiovisuelle, dans tous ses modes possibles (sous-titrage; doublage; voice over; narration; surtitrage; traduction simultanée), en pensant l'élargir aux multimédias, entendant par là tout discours intégrant plusieurs (et non simplement un ou deux) systèmes sémiotiques (langagier: écrit et oral; visuel: images fixes et animées, icones, pictogrammes, etc.; sonore; graphique, etc.) concourant à faire sens. La traduction audiovisuelle (film, télévision, vidéo), la traduction de logiciels, la traduction sur et pour la Toile (web) et autres produits et services en ligne, ainsi que la traduction de produits hors ligne (disques compacts optiques ou CD-Rom), relèvent de la traduction multimédia.

\subsection{Quatre spécificités de la traduction AV et multimédia}

Outre le caractère multisémiotique, quatre spécificités méritent d'être soulignées:

a) Il s'agit toujours d'un travail d'équipe, la collaboration étant simultanée (cf. 5) et non linéaire, cumulative comme par exemple dans la traduction littéraire ou de pièce de théâtre, où le commanditaire, l'éditeur, le traducteur, le metteur en scène, le réviseur, etc. enchainent successivement leurs décisions.

b) Il s'agit toujours d'un travail sur des textes intermédiaires (scénarios, scripts), dépassant ainsi la dichotomie habituelle entre texte dit de départ et texte dit d'arrivée - ce qui pose de façon différente les problèmes, entre autres, d'auteur, de copyrights. Par ailleurs, on travaille pour réaliser et diffuser autant que possible des produits internationaux et qui auront une durée de vie très courte. Les perspectives ne sont donc pas celles d'un traducteur qui affine, pour un marché local, un texte stable qui va être utilisé ou être diffusé pendant plusieurs années.

c) Les critères qui s'appliquent aux traductions $\mathrm{AV}$ et multimédia sont ceux de compréhensibilité, d'accessibilité, d'utilisabilité, plutôt que ceux de lisibilité ou d'acceptabilité, trop centrés sur le système et les normes de l'écrit (cf. 3).

d) Enfin, les caractéristiques mentionnées ci-dessus ont des implications pour la formation; la coupure entre le monde universitaire, académique et le monde professionnel devient intenable (cf. 6).

Une fois ces mises au point faites, certains problèmes, dilemmes et paradoxes méritent d'être mis en perspective, dans chacun des domaines en question, toujours pour mieux envisager les qualifications du traducteur de demain, devant les écrans. 


\subsection{Transformations du marché de l'audio-visuel}

Le paysage de l'AV multilingue se transforme sous l'influence de différents facteurs, parmi lesquels on citera la distribution, le numérisation et l'offre de programme.

\subsubsection{La distribution}

Son internationalisation rapide modifie les stratégies de circulation des longs métrages et programmes télévisés. Parallèlement à ce mouvement, comme à la fois cause et effet, l'emprise des majors américaines (Columbia, Fox, Warner, Disney, MCA/Universal, Paramount, Metro-Goldwyn-Mayer) ne cesse de se renforcer, soit directement dans chaque pays, soit par l'intermédiaire de fusions et d'alliances avec des distributeurs locaux. En France en 1998, le cinéma français a enregistré sa plus petite part de marché: à peine $26 \%$ (contre $49,6 \%$ en 1981), alors que dans le même temps 148 films ont été produits et que les salles ont enregistré le plus grand nombre de spectateurs depuis 1985 (avec $170 \mathrm{M}$. d'entrées). Le taux de pénétration du film américain n'a jamais été aussi fort dans l'Hexagone. Un autre exemple: en Belgique, de 1960 à 1996, le nombre de spectateurs de cinéma est passé de 80 M. à 21 M. En 1996, 80\% des projections étaient américaines. Le long métrage de Jaco von Dormael (Le $8^{\text {ème }}$ Jour) était à la $4^{\text {eme }}$ place (avec 700 000 spectateurs) tandis que le second film européen le mieux placé (Trainspotting) était à la $25^{\text {ème }}$ place. Soit sur les 25 films les plus vus en Belgique en 96, 24 étaient de langue anglaise! C'est dire l'importance des conversions linguistiques pour que les produits $\mathrm{AV}$ demeurent des produits populaires auxquels on puisse se référer, sinon s'identifier. En fait très peu de films en Europe sortent de leurs frontières: Hollywood n'est pas en compétition avec l'Europe mais séparément avec chacun des pays membres. La part de marché moyenne des films américains en salle et à la télévision est supérieure à $60 \%$. Celle du film européen aux Etats-Unis n'est que de 3\%. Le déséquilibre de la balance des échanges AV (films, feuilletons télévisés, vidéocassettes) entre l'UE et les Etats-Unis ne cesse de s'aggraver: le déficit est passé de 2 milliards de dollars en 1988 à 6,5 milliards en 1998. Dans les deux dernières décennies, le cinéma européen a connu de larges pertes sur son propre marché. Cette évolution a lieu malgré les mesures prises pour soutenir l'industrie européenne des programmes, malgré l'augmentation des coproductions, à la fois pour les longs métrages et les films d'animation - manière nouvelle pourtant d'aborder la gestion du plurilinguisme européen (Jäckel, 1995).

Par ailleurs, l'intégration relative des ressources financières entre télévision et cinéma ainsi que la synergie de diffusion entre les deux médias font dépendre 
de plus en plus l'exploitation des produits et services AV de groupes transnationaux de la communication. En un mot, la concentration de tous les secteurs (production, distribution, exportation, exploitation, édition vidéo) s'est considérablement accrue. La concurrence entre les chaînes de télévision, les bouquets numériques n'a que renforcé la tendance parce qu'il a fallu alimenter les grilles de programme avec des films (américains) et donc négocier avec les majors companies hollywoodiennes.

Un long métrage suit en général une chronologie de diffusion assez linéaire (film préacheté par une chaîne, sortie en salle, commercialisation en cassette vidéo, diffusion sur les chaînes cryptées puis de paiement à la séance (pay per view) enfin non cryptées). Cette chronologie selon divers circuits et supports est loin d'être stabilisée et continue d'être l'objet d'âpres discussions, entre producteurs, diffuseurs, propriétaires de chaînes et autorités de l'Union Européenne (avec la nouvelle directive Télévision sans frontières, en vigueur depuis le 1.1.1999).

\subsubsection{La numérisation}

Elle va métamorphoser dans les prochaines années la production et la diffusion et accélérer la convergence des secteurs des télécommunications, des médias et des technologies de l'information. Le volume des programmations va augmenter en conséquence. D'autres innovations technologiques risquent également de bouleverser les rapports entre cinéma, télévision et spectateurs. On peut signaler déjà l'impact de l'Internet sur la mise en mémoire et la mise en circulation de films, d'émissions télévisées et autres produits AV dérivés. On peut aussi rappeler l'émergence du DVD (Digital Versatile Disc) qui rend possibles, pour un même film, jusqu'à 32 sous-titres différents, soit de langues différentes, soit de la même langue mais de nature différente (un sous-titrage pouvant par exemple être plus lent ou avec de plus gros caractères pour mieux servir les spectateurs qui ont des problèmes de lecture ou de vue; ou encore être intralinguistique pour les sourds et mal entendants).

\subsubsection{L'offre}

Très souvent la perception de la production, de la circulation, de l'exploitation des oeuvres cinématographiques et télévisuelles reste dominée par les schémas de la communication de masse, entendue comme unilatérale, unidirectionnelle, d'un lieu émetteur vers les postes recevant le même programme à la même heure, pour tous. Ces schémas impliquent souvent aussi une homologie entre un pays (territoire) $=$ une langue $=$ un mode de transfert linguistique. Aujourd'hui, l'analogie se réduit entre communication dite de masse et l'AV placé désormais sous les signes du relais, du réseau. 
entrainé par la TV à péage, les chaînes transfrontalières, thématiques, locales, ethniques ou communautaires - multipliées grâce au câble, au satellite. Il y a dorénavant un balancement continu entre service universel et besoins régionaux, entre libre accès sans entraves et accès plus ou moins contrôlé au nom de la protection de la vie privée, de l'enfance, de la non-discrimination raciale, etc.

Cette évolution n'est pas sans conséquences ni effets linguistiques: en regardant une chaîne d'histoire, de sports ou de la Bourse, le téléspectateur veut retrouver son jargon, une certaine terminologie, un certain style. La fragmentation des publics se définira-t-elle à la fois en terme sociologique et en terme linguistique, entrainant des exclusions, reproduisant et/ou renforçant des inégalités entre groupes d'âge, entre natifs et migrants, entre citadins et ruraux? En fait, l'évolution décrite signale la fin d'un modèle centralisateur, la remise en cause d'une norme linguistique rigide - le téléspectateur naviguant d'une chaîne (généraliste) à une autre (thématique). Dans la mondialisation en cours, dans l'émergence difficile d'une identité culturelle européenne, nos pays sont de plus en plus nos langues; certaines crispations sectaires sur la langue, sur l'ethnicité soulignent d'ailleurs avec force la valeur accordée à nos idiomes comme symboles d'appartenance identitaire.

Hier, les normes du langage étaient définies par la littérature, l'école, la presse. Est-ce un rôle joué aujourd'hui par l'AV? Si les écrans ont modifié les hiérarchies entre les genres (BD, programmes pour enfants, documentaires, science-fiction, horreur...ne sont plus mineurs), on ne peut pas pour autant affirmer qu'ils sont désormais le pouvoir de standardisation linguistique. Il n'empêche: par leur omni-présence, ils concourent à un certain état de la langue, ils sont un des lieux de normaison, c'est-à-dire où certains usages sont pratiqués, se mettent en place.

Aux trois facteurs sus-mentionnés, on ajoutera les changements dans les conditions de travail des traducteurs de l'AV, liés à la privatisation de nombre de chaînes de télévision, à la délocalisation, au développement de la soustraitance et à l'apparition de compagnies multinationales de sous-titrage et de doublage. Ces conditions font que par exemple des chaînes de télévision préfèrent aujourd'hui recourir à des free lance plutôt qu'à du personnel maison. Les tarifs sont ainsi à la baisse; les copyrights, par exemple pour les rediffusions, sont maltraités. Qu'on se rappelle des mouvements de mécontentement des sous-titreurs et doubleurs, en 1994-1995 en Belgique, aux Pays-Bas, en France et durant l'été 1998 en Italie. Que devient la qualité des prestations, sous ces nouvelles pressions, quand producteurs. programmateurs, compagnies de télévision, importateurs de films ignorent souvent le poids de la langue dans les produits qu'ils diffusent? 


\subsection{Les méandres langagiers dans les multimédias}

Dans l'explosion des multimédias, qui force à réinterroger nos rapports au passé, au patrimoine, au savoir, la question de la langue devient aussi essentielle. Un certain usage de la langue assurait naguére à l'école le rassemblement des connaissances, lui donnait sens. Aujourd'hui chacun surfe d'un forum entre physiciens nucléaires à un chant grégorien, d'une information touristique à une description de fouilles archéologiques, des communiqués d'un chef d'Etat à la propagande d'une secte.

Globalisation et multimédia intensifient c'est-à-dire focalisent davantage la dimension langagière et cela non seulement pour les interactions entre individus (clients, usagers, etc.). Ils modifient aussi rapidement les pratiques verbales en milieu professionnel, dans les restructurations actuelles du travail: de plus en plus les compétences communicationnelles jouent un rôle fondamental à cause des postes informatisés, de la production fondée sur la manipulation de données. de la circulation des informations via des sites intranets. Le traducteur, sur un lieu de travail (industriel, commercial, administratif) n'est plus le seul à être confronté au verbal, verbal mêlé de chiffres, de dessins, de schémas, etc.

Peut-on un instant différencier divers supports? Internet est un moyen de communication puissamment intégré au langage: il est une organisation internationale d'échange multilatéral de données. C'est un lieu de transit comme une autoroute, un hall d'aéroport. C'est une source quasi instantanée d'informations multiples, archivées, automatiquement indexées, un espace fluide qui défie les frontières nationales et culturelles (au contraire des médias écrits). qui défie les lieux matériels de mémoire (bibliothèques, archives, centres de documentation). Dans ce cyberespace, tout un chacun lit plus, prend conscience de l'importance de l'écrit en élaborant des pages pour son site.

D'où viennent données et informations? Elles sont anglophones à $70 \%(90 \%$ il y a 3 ans), germaniques (allemande, néerlandaise et de langues de l'Europe du Nord) à $11 \%$, romanes à $9 \%$ et japonaises à 5\%. Ces chiffres de fin 1997 ne sont qu'indicatifs car ils évoluent vite. Ils n'en reflètent pas moins lá diversification linguistique du réseau. On peut prévoir que la question de la compréhension des sites en langues étrangères va devenir essentielle, si on ne veut pas que la Toile (web) ne se transforme en Tour de Babel. Le recours à la traduction automatique (TA) semble inévitable comme fonction intégrée aux logiciels de navigation. Systran par exemple propose, depuis 1996, le premier service de traduction en ligne des pages d'Internet (pour l'anglais et le français, dans les deux sens, et de l'allemand, italien, espagnol, portugais et russe vers 
l'anglais): il suffit d'indiquer l'adresse d'une page sur le site de Systran pour lire, après quelques minutes, la traduction. Mise en page, publicités, images sont reproduites à l'identique. Certaines erreurs de traduction peuvent laisser perplexes mais face à une langue inconnue, on passe de l'incompréhension totale au sens général du contenu.

Deux observations: les langues qui ne seront pas informatisées c'est-àdire qui n'entreront pas dans les logiciels de traduction automatique, risquent demain d'être déclassées. Par ailleurs, une technologie dont le danger était de devenir monolingue voit au contraire les langues se multiplier sans que la barrière linguistique soit infranchissable.

Qu'en est-il avec des produits en ligne comme les logiciels et hors ligne comme les CD-Rom? La production de ces derniers se diversifie: on distingue ainsi entre produits culturels et éducatifs, produits de références comme les encyclopédies et les dictionnaires, et produits ludiques (jeux). Eux aussi voient leur développement intégrer le facteur langue et donc traduction. Paradoxalement c'est leur distribution, leur commercialisation qui fait problème!

Que conclure momentanément de ce survol? Les médias AV, héritiers d'une tradition où le partage des rôles dans la communication était fortement hiérarchisé et où la littérature restait un modèle prégnant, connaissent une métamorphose - métamorphose accélérée par le numérique et les nouveaux rapports complémentaires entre télévisions généralistes et technologies de l'information. La convergence (technologique, commerciale) entre petits écrans et Internet, par exemple, implique désormais complémentarité entre les deux secteurs et supports (Livre vert 1997). Ainsi une chaîne de TV peut aujourd'hui offrir sur la Toile des informations sur ses programmes, des dossiers s'ajoutant à ses émissions, des dépêches en continu, des jeux, des forums de discussion, etc.

L'opposition médias $\mathrm{AV} /$ multimédias parait donc désormais trop rigide. Six défis sont lancés par les petits et grands écrans ainsi que par les consoles d'ordinateurs.

\section{SIX DÉFIS}

1. Défi de la reconnaissance de la diversité linguistique et culturelle et de la tolérance qu'elle entraîne. On dit que le marché est traversé de rapports de force entre une lingua franca et des langues mal ou peu équipées pour faire face aux nouveaux besoins et aux nouvelles réalités à dénommer. À l'ère du numérique et de la mondialisation, le multilinguisme est néanmoins de moins en moins une exception. 
2. Défi de la fragmentation des audiences (non sans analogie avec l'opposition entre inforiches et infopauvres) - ce qui ne doit pas conduire à des exclusions ou à de nouvelles formes de ghettoïsation. La multiplication des chaines de télévision peut entraîner une certaine atomisation des récepteurs. Mais ceux-ci zappent entre des programmes généralistes et des programmes spécialisés. Les médias AV sont, semble-t-il, à la fois facteur de différenciation et facteur d'homogénéisation. De cette manière, on l'a vu (cf. 2.3), ils cessent d'être exclusivement médias de masse, d'où la distinction faite entre uniformisation (broadcasting) et l'adaptation toujours plus ciblée (narrowcasting) parce que les audiences ont des attentes sociolinguistiques et terminologiques particulières (cf. 2.3).

3. Défi de la qualité des sous-titres et doublages (cf. 4), tandis que les transformations du travail tendent à déqualifier les spécialistes de ces transferts linguistiques (cf. 2.3). Dans le même temps, nombreux sont ceux qui accordent à la télévision un rôle important dans le maintien, les modifications, la diffusion des normes sociolinguistiques (cf. 2.3).

4. Défi aux utilisateurs en vue de préciser leurs besoins et exigences, par ex. sur la Toile, en vue d'enrichir leurs capacités d'interactivité ou façon de cheminer à sa guise dans les contenus proposés - d'autant que les catégories traditionnelles (affaires-vie privée; travail-loisirs; formation-consommation) sont brouillées de plus en plus.

5. Défi pour les documents traduits sur la Toile des normes de compréhensibilité (la logique de la composition et de la lecture des hypertextes n'étant pas celle d'un texte en continu), des normes d'accessibilité et d'utilisabilité, la fonction de ces documents l'emportant sur la qualité de leur seule écriture. Or on reste très souvent inhibé d'une part par les conventions de la lisibilité de l'écrit soutenu (littéraire) alors que les nouveaux supports obligent à se réinterroger sur les rapports entre écrit et oral, et d'autre part par une conception (idéaliste) de la traduction qui devrait être plus parfaite que n'importe quelle interaction quotidienne ou qui est souvent perçue dans ses impossibilités ou ratages.

6. Défi de la formation des traducteurs, plus polyvalents que jamais, avec des comportements nouveaux et des compétences nouvelles à acquérir, à maîtriser (cf. 5).

Pour mieux saisir certains de ces défis, considérons maintenant le problème de qualité. 


\section{QUALITÉ EN TRADUCTION}

\subsection{Dans l'AV: cas du sous-titrage}

\subsubsection{La qualité}

Il n'y a pas de consensus sur une définition absolue de cette notion. On peut cependant viser une qualité optimale: celle-ci, pour le sous-titrage, implique que le traducteur produise des sous-titres lisibles et acceptables (accessibles) et qui rendent de manière aussi précise que possible les paroles de l'original (dialogues, monologues, voix off) et les informations écrites des images (noms de rue, menus, lettres, titres de journaux, etc.). Cette qualité visée sera toujours évaluée en fonction des conditions de travail qui prévalent; par ailleurs, les sous-titres ne sont pas qu'un produit langagier émis: ils sont aussi reçus. Il y a donc à prendre en considération la situation et les moyens du traducteur, les fonctions du verbal dans l'ensemble audiovisuel et les conditions de réception. Plutôt que de bons sous-titres, trop limitatif, mieux vaut par conséquent parler d'un bon sous-titrage qui inclut aussi les bons sous-titres.

\subsubsection{La réception}

Pour le spectateur, les sous-titres commandent jusqu'à un certain point la compréhension du film, de l'émission télévisée; cela dépend de sa connaissance du sujet traité, de sa maitrise de la langue de départ, du rapport entre texte et image. Très souvent, on réduit le sous-titrage à des règles de durée (de $1 \frac{1}{2} / 2$ seconde à 6 secondes par exemple). En fait, peu de recherches systématiques ont été menées sur la lecture des sous-titres. Les travaux réalisés en Suède, au Danemark, en Belgique ou datent déjà un peu ou sont trop limités dans le nombre et les types de récepteurs testés (publications de d'Ydewalle entre 1985 et 1996, listées dans Gambier, 1997; Gottlieb, 1995; Mortensen, 1996). Or il faut admettre que si le public du cinéma est plutôt jeune, éduqué, habitué aux ordinateurs, élevé avec la télévision, l'audience de la télévision est bigarrée: elle inclut de jeunes enfants en cours d'apprentissage de la lecture, des personnes âgées aux réactions plus lentes, des gens avec des problèmes de vision et d'oreille (plus de $80 \mathrm{M}$. de mal entendants dans l'Europe des 15), des cadres de haute formation, des étudiants, etc.

D'évidence, l'heure de programmation va sélectionner certaines catégories de téléspectateurs au détriment d'autres. Un film classique projeté à minuit le dimanche n'appelle pas une même vitesse de sous-titres qu'une interview intégrée au Journal télévisé; il en est de même pour un documentaire sur un club de $3^{\text {ème }}$ âge émis en plein après-midi ou un feuilleton en prime time.

Sont donc à considérer l'âge, le niveau d'éducation (en particulier les habitudes de lecture), le degré de compréhension de la langue originale du 
programme ou du film, le genre d'émission ou du film (les sous-titres d'une série à la narration conventionnelle n'ont pas à remplir les mêmes exigences que ceux d'une pièce retransmise ou adaptée de Shakespeare), l'heure de programmation, le rythme global de la production regardée c'est-à-dire des plans successifs, le type d'action sur l'écran (une scène de ménage ou une conversation téléphonique, une déclaration d'amour ou un kidnapping, etc.). Jusqu'où par exemple tient-on compte du fait que les populations chez nous vieillissent?

Quoi qu'il en soit, les sous-titres d'un film pour le cinéma repris tels quels à la télévision sont ressentis comme trop rapides, malgré la diminution aujourd'hui des variations entre sous-titres de cinéma et sous-titres de télévision (le nombre moyen de sous-titres pour un film de 90 minutes étant de 900 pour le cinéma, de 750 pour la vidéo et de 650 pour la télévision).

\subsubsection{Le traducteur}

Pour parvenir à un travail de qualité, le sous-titreur doit avoir les outils appropriés. Parmi ceux-ci, on relèvera: .

a) le script (ou dialogue list) de post-production, incluant toutes les réparties telles qu'elles ont été prononcées, les noms propres bien orthographiés, avec si possible un glossaire ou des explications des mots dialectaux, argotiques, des plaisanteries locales et autres termes inhabituels, comme les noms de la flore et de la faune;

b) une copie du film/programme sur vidéo ou DVD, etc.

Ces deux outils sont loin actuellement d'être distribués à tous les traducteurs, dans des versions ad hoc - ce qui influe bien évidemment sur la rapidité et la fiabilité de la réalisation des sous-titres.

La projection pour saisir l'ambiance, le rythme, le style du film/programme. avec code temporel, la maîtrise du montage des sous-titres c'est-à-dire leur moment d'apparition, leur durée ou défilement (timing, cueing, spotting) sont servis par un équipement technique minimal (ordinateur, appareil vidéo, générateur de soustitres. etc.) - où images et sons doivent être de haut niveau. Dans certains cas, ce minimal n'est pas assuré, aggravé parfois même par une division du travail qui fait que la traduction du script, le découpage en sous-titres, l'incrustation de ceuxci sont faits par deux ou trois personnes différentes opérant dans des conditions différentes et avec des compétences linguistiques très inégales (cf. 2.1).

La station de travail du traducteur-sous-titreur est aujourd'hui sophistiquée, ce qui n'est pas nécessairement synonyme de coûts exorbitants. A cet équipement qui autorise par exemple le télétravail, s'ajoutent les moyens de documentation et d'accès à la documentation (dictionnaires, encyclopédies sur CD-Rom, Internet et la Toile, etc.). 


\subsubsection{Les sous-titres proprement dits}

Une bonne réception de sous-titres est corrélée aussi à leur rapidité de défilement, à leur position, à leur longueur, à la dimension de leurs caractères, à leur densité informationnelle, à leur cohérence formelle, à leur rapport au visuel. On peut distinguer deux ensembles de traits qui concourent à la qualité optimale des sous-titres: les traits spatio-temporels et les traits textuels et paratextuels (EBU programme, 1987; Ivarsson \& Carroll, 1998: 157-159; Karamitroglou, 1998; Lindberg, 1998). Les premiers comprennent par exemple les caractères, la position (avec justification à gauche pour la télévision et la vidéo et justification centrée pour le cinéma), le nombre de caractères par ligne, la durée de présence des sous-titres d'un mot, d'une ou de deux lignes, liée au rythme des dialogues, au rythme des changements de séquence et de plan. On peut dire que c'est la saisie du rythme de l'original et la superposition du rythme du sous-titrage qui différencie un bon sous-titreur d'un traducteur ordinaire. Non seulement il doit y avoir corrélation entre les dialogues et le contenu des sous-titres, synchronisation entre les langues en présence mais aussi correspondance entre ce qui se dit sur l'écran et la présence concomitante des sous-titres. Parmi les traits textuels, on peut citer la nécessité de segmenter les sous-titres en des unités sémantiques cohérentes et syntaxiquement cohésives, la nécessité de choisir les registres de langue appropriés, la nécessité d'une statégie continue touchant les éléments spécifiquement culturels, les acronymes, les chiffres, etc. (BBC Subtitling Guide, 1994; ITC Guidance, 1997; SBS Subtitling Manual, 1998; Stijlboeck NOB, 1994).

Les manières de condenser, d'omettre, de paraphraser, de fusionner des répliques, les choix des structures syntaxiques et de vocabulaire (dans le passage de l'oral à l'écrit) reflètent à l'évidence une conception de l'interaction (ce qui est superflu ou pas) et de la langue standard (ce qui est acceptable ou pas).

Pour le spectateur, la compréhension résulte à la fois de la lisibilité scriptovisuelle (legibility) des sous-titres et de leur lisibilité psycholinguistique (readability). Aux deux niveaux, les conventions de ponctuation ou traits paratextuels (tirets, points de suspension, guillemets, points d'exclamation et d'interrogation, virgules, deux points, etc.) (Ivarsson \& Carroll, 1998: ch.8; Carón, 2001) jouent un rôle déterminant: elles donnent en effet aux sous-titres leur respiration et facilitent leur saisie, leur traitement immédiat, leur interprétation.

\subsubsection{Qualité et attentes}

Dans ce qui précède, nous avons souligné l'intégration des facteurs qui concourent à la qualité des sous-titres. Les divers intervenants ont cependant des attentes différentes quant à ces sous-titres: l'auteur et le dialoguiste chercheront à y retrouver un double crédible de l'action et des personnages du scénario; le producteur et le metteur en scène voudront un texte fiable, accessible, 
part intégrante du rythme de leur production; le distributeur et l'exploitant souhaiteront des sous-titres techniquement adéquats; les spectateurs, dans leur diversité (cf. 4.1.2), auront plaisir à suivre des sous-titres clairs, lisibles (Kilborn, 1997). Il s'ensuit que les uns et les autres accorderont plus de poids à l'aspect contenu ou à l'aspect langue ou à l'aspect technique.

\subsubsection{Contrôles de qualité}

Divers contrôles sont possibles pour faire correspondre ces attentes et ce qui est lu sur les écrans (cf. Ivarsson \& Carroll, 1998, 108-110; James, 2001). Par exemple, la correction orthographique, la révision langagière afin d'éviter les phrases ambiguies, illogiques, l'incohérence dans les termes, dans les formes d'adresse, etc., l'édition des sous-titres (leur lien, leur vitesse, etc.).

\subsubsection{La qualité, un effort commun}

Surtout, de ce qui précède, nous voudrions faire ressortir que la qualité optimale n'est pas possible sans tenir compte des divers décideurs et récepteurs, avec leurs intérêts et leurs compétences spécifiques et aussi leur compréhension particulière des enjeux linguistiques et culturels sur les écrans. C'est dire que la qualité des sous-titres ne relève pas exclusivement des aptitudes des traducteurs (émetteurs) mais aussi de leurs conditions de travail. Elle devrait concerner tous ceux qui participent au fonctionnement d'une émission télévisée, à la distribution d'un film: depuis l'agent qui achète les droits de diffusion lors d'un festival jusqu'au producteur, depuis le commanditaire du sous-titrage jusqu'à l'usager assis devant l'écran, depuis le responsable des transferts linguistiques qui recrute, sélectionne, teste les sous-titreurs jusqu'au technicien-ingénieur qui innove dans les systèmes de sous-titrage, depuis le rédacteur qui planifie ses informations jusqu'au réalisateur free-lance (Gummerus \& Paro, 2001).

Le sous-titreur ne remplit son rôle de passeur avec succès que si d'autres spécialistes de la production AV lui facilitent la tâche, ne considérant donc pas la langue comme la cinquième roue du carrosse, un détail périphérique de la diffusion, sinon même comme un obstacle à la communication.

Il resterait à élargir justement toutes ces remarques aux autres modes de la traduction AV. Mais elles suffisent ici pour souligner que le traducteur AV doit avoir une sensibilité quasi socio- et psycholinguistique, un doigté artistique, une prédisposition à la coopération.

\subsection{Dans les multimédias}

Éditer des jeux vidéo, adapter des CD-Rom éducatifs, développer un service multimédia en réseau pour des entreprises, localiser un logiciel appellent des 
stratégies traductionnelles, encore largement inexplorées. Sont-elles nécessaires, régulières, optionnelles? Le recours à la traduction automatique sur le web, approche plutôt statique, décontextualisée, ne contredit-il pas un marketing toujours cibliste?

\subsubsection{Comment considérer la traduction dans les multimédias?}

La traduction des pages web est en émergence rapide. Sur le serveur Hypercoran, par exemple, on a le choix entre la version écrite enluminée du Coran, la version chantée, des traductions en plusieurs langues, la transcription phonétique en caractères latins (pour chanter le texte arabe). Un certain nombre d'entreprises transférent leur documentation sur les intranets: leurs informations sont ainsi centralisées, vite mises à jour et instantanément diffusées sur tout le réseau. S'il faut des versions en langue étrangère, la traduction doit être quasiment aussi rapide, sans que le traducteur reçoive des instructions ou des précisions sur les passages modifiés. Pour tenir le rythme, il doit maîtriser un sytème de mémoire de traduction, des dépouilleurs automatiques; avec un hypertexte, il doit vérifier la cohérence entre le mot clé à traduire et le document associé; avec une nouvelle page $w e b$, il faut insérer le texte entre les vignettes, les illustrations, les icones. On l'a dit plus haut (cf. 2.4), il y a aussi retour de la traduction automatique, pour accélérer la production de contenu. World Community Forum est un des exemples récents de cette intégration de la TA dans l'environnement en ligne: on y trouve des copies parallèles de l'anglais vers l'allemand, l'espagnol et le français ou inversement, avec le message source, pré-édité quant aux noms propres. Le processus de TA est répété tous les trois minutes. Ce service gratuit devrait être étendu au courrier électronique. D'autres logiciels similaires (avec les mêmes langues) existent, toujours avec le but de donner une version de l'essentiel des pages, comme Easy Translator, Web Translator, Webview. Altavista Web Translator reçoit plus d'un million de demandes par jour pour des traductions de l'anglais vers le français, l'allemand, l'italien, l'espagnol, le portugais, et inversement.

On peut penser à l'immense volume de publicités, de petites annonces qui pourra bientôt être mis en circulation, sous plusieurs langues. La traduction sur la Toile, part d'une stratégie de mondialisation ou tout simplement expression d'une sensibilité interculturelle, confirme bien que la langue et les images qui l'accompagnent sont un moyen de marketing: non seulement il faut tenir compte du texte, des couleurs, des dessins mais aussi des restrictions d'importation, des circuits de distribution, etc., chez les clients éventuels. Rien ne serait plus illusoire que de croire que, parce qu'on peut installer son propre site en faisant défiler des pages de texte, on mesure bien tous les problèmes de la production et de la maintenance des pages web. 
4.2.2 Qu'en est-il avec les logiciels, les fichiers d'aide et la documentation afférente (guides d'utilisation, manuels d'emploi)?

On recourt à la localisation; celle-ci vise à adapter aux spécificités linguistiques et culturelles du récepteur produits, services, contenus qui traitent d'information, d'éducation, de culture, d'arts, de formation professionnelle, etc. Toutes les icones et métaphores venues des Etats-Unis (boîte aux lettres en bord de route, tête d'un coach avec casquette de joueur de base-ball, dessin de visage souriant, la pomme croquée, etc.), n'ont pas partout forcément la même signification.

Pour les CD-Rom, on a le même souci: une traduction respectueuse des normes, des conventions, des valeurs des récepteurs. Elle inclut par exemple le doublage des voix, l'adaptation du texte, la modification parfois des images (quand il y a des incrustation de mots, de phrases), l'ajout de bruits et/ou le filtrage des parasites. Ainsi, localiser en français un CD-Rom éducatif de comptines anglaises revient à remplacer les comptines c'est-à-dire à faire que celles-ci soient compatibles avec le contexte du CD, qu'il y en ait des enregistrements dont les droits sont tombés si possible dans le domaine public. L'internationalisation des multimédias pour différents marchés comprend divers aspects et formes de traduction et d'édition, la synchronisation entre ce qui est dit et le déroulement du contenu, des services de studio, la sélection des voix pour le voice over, la réalisation graphique, le mixage des signaux audio et vidéo, sans compter les tâches de gestion (des contrats des intervenants, des locations, etc.) Il est plus simple et sans doute meilleur marché de suivre ces multiples étapes en même temps qu'on développe la version originale, de les traiter par fichiers séparés, sans perdre de vue leur intégration ultime. Dans tous les cas, le traducteur est un élément d'une équipe, la traduction tient compte des items politiques, historiques, humoristiques, folkloriques, religieux, etc. Toutes les célébrités artistiques, sportives d'un lieu ne sont pas forcément connues ailleurs; un morceau de musique ne suscite pas les mêmes sensations partout. Avec les multimédias, tous les sujets sont possibles (cuisine, Indiens du Pérou, biologie, impressionnisme, maladies cardio-vasculaires, contes d'Andersen, enfants et circulation en Europe, etc.). Une traduction ne s'arrête pas au texte mais à la livraison du produit... multisémiotique.

Dans toutes ces productions - quel que soit le nom donné au transfert (cf. 1), le traducteur acquiert un rôle clé s'il sait devenir le spécialiste de cette communication multilingue, multiculturelle, s'il sait élargir ses compétences à la multiplicité des systèmes de signes qui s'ouvrent à lui, s'il sait ajouter à ses capacités linguistiques, un regard interculturel et une maitrise des outils informatiques plus ou moins sophistiqués, s'il sait coordonner toutes ses tâches. 


\section{UN PROFIL PROFESSIONNEL TRANSFORMÉ: COMPÉTENCES ET COMPORTEMENTS}

De la transformation des marchés, des exigences de qualité, des attentes créées par les nouvelles technologies, découle une transformation du profil du traducteur: ce ne serait plus celui/celle qui réagit mais celui/celle qui agit, exige des spécifications, précise son rôle au plus tôt dans le processus d'élaboration des documents multilingues, affirme ce qu'il/elle peut faire ou pas, fait pression (lobbying) sur les institutions qui traitent de ses droits, de sa formation, prend contact avec ses clients, diffuse ses offres de service, discute avec d'autres experts.

Le traducteur (AV/multimédia) acquiert son professionalisme, en cultivant les compétences suivantes (non hiérarchisées et non toutes exclusives de ce type de traducteur). Les trois premières aptitudes ne sont pas propres bien évidemment aux traducteurs AV et multimédia:

a) Aptitude à traduire, supposant la maîtrise de ses langues de travail (avec leur dimension culturelle).

b) Aptitude à la recherche documentaire et terminologique.

c) Aptitude à travailler vite, sous pression, avec un certain stress.

d) Sens de l'écriture propre aux médias et sens du rythme, si essentiel dans la saisie et le rendu des rapports entre texte et image.

e) Aptitude à analyser, reformuler, condenser, post-éditer, tout en respectant des contraintes d'espace et de temps de lecture.

f) Capacité à travailler avec d'autres spécialistes dont l'autorité, les compétences et les modes de décision sont différents (pouvant être techniques, financières, esthétiques, juridiques, etc.). Parmi ces spécialistes, on citera: les journalistes, les producteurs, les experts en marketing, les programmateurs, les techniciens du son, les directeurs artistiques, les acteurs, les informaticiens. Ce travail collaboratif ou coopératif est d'autant plus délicat qu'il se fait dans un milieu sous tension, préoccupé d'efficacité de management et de valeurs culturelles, et qu'il met en situation métadiscursive des experts peu habitués à expliquer ou justifier ce qu'ils font. Il implique du traducteur des capacités de contact et de négociation qui contredisent l'image du traducteur solitaire, enseveli sous des piles de dictionnaires - image encore courante chez les étudiants en traduction.

g) Capacité d'adaptation aux changements (rapides) touchant les équipements techniques.

h) Capacité d'auto-évaluation (pour évaluer en permanence les normes de qualité des produits rendus, pour préciser sans cesse les critères d'acceptabilité et d'accessibilité, pour suivre la déontologie professionnelle). 
i) Sens aigu des responsabilités (décisions à prendre vite; responsabilités vis-à-vis de la qualité des traductions, largement diffusées; vis-à-vis des commanditaires: compagnies de TV — publiques, privées, locales, etc. - . importateurs de films, de vidéo-cassettes, éditeurs de CD-Rom, de CD-vidéo. entreprises et organismes développant des relations publiques via les supports audiovisuels; institutions artistiques, etc.).

j) Parfois compétences juridiques et en organisation du travail, quand le traducteur est appelé à coordonner les efforts de plusieurs traducteurs indépendants, pour créer les conditions d'un travail de qualité.

À l'image du traducteur quasi invisible, homme d'écrit, succède un traducteur, personne de dialogue, qui conquiert sa présence, aussi par la parole - en faisant reconnaître ses propres tâches et responsabilités et en sachant reconnaître les tâches des autres dans la chaîne de production de sens, sur les divers supports existant aujourd'hui ou à venir. Se profilent ici les dimensions à la fois éthiques et déontologiques du traducteur.

Toutes les obligations et compétences devraient impliquer aussi des droits pour le traducteur (AV/multimédia): droit d'accès au script final (cf. 4.1), droit de regard sur le produit fini, droit de consultation des terminologies adéquates, etc. Le stress et l'absence fréquente de documentation de travail cohérents, complets (par exemple, pour élaborer un commentaire de documentaire, pour adopter un logiciel et ses manuels d'utilisation) sont préjudiciables à la qualité du résultat attendu.

\section{IMPLICATIONS POUR LA FORMATION}

Les descriptions proposées jusqu'ici n'excluent pas des convictions, liées à mon interprétation des réalités et des évolutions en cours:

a) La traduction va appartenir de moins en moins aux traducteurs parce qu'elle prend place, de plus en plus souvent, dès qu'on produit un document. À la traduction qui vient après un texte dit original succède une rédaction multilingue c'est-à-dire la création simultanée de plusieurs versions, en 2, 3...n langues.

b) La traduction va appartenir de moins en moins aux traducteurs parce qu'elle dépasse de plus en plus la seule problématique langagière. D'ailleurs, plutôt que de textes (trop centrés sur le verbal), on est amené à réaliser des documents, à travailler sur des matériaux multisémiotiques.

c) La traduction va appartenir de moins en moins aux traducteurs si ceux-ci continuent à être formés selon des modèles de cursus hérités de la tradition littéraire ou philologique et reposant sur des divisions disciplinaires rigides. Or les apprenants d'aujourd'hui doivent se qualifier non pour répondre aux besoins 
des années 70 ou même 90 mais pour faire face aux nécessités des années 20202030, pour s'adapter aux mutations à venir, sinon même pour conduire ces mutations.

d) La prospection en formation ne saurait se confondre avec la fascination pour les outils technologiques. La manipulation de ces outils est une chose: elle n'aide pas nécessairement à esquisser, à penser les profils professionnels de demain.

e) Les exigences des multimédias (avec imbrication de plusieurs systèmes sémiotiques), sources de métiers encore distincts, vont bousculer nos conceptions trop monodisciplinaires, nos représentations des pratiques professionnelles trop hiérarchisées. Ainsi on peut prévoir le développement, par exemple, de concepteurs médiatiques aptes à scénariser, à éditer, à mettre en images, en sons. Ou encore le développement d'agents interactifs servant d'interface entre les usagers et tous les services (documentaires, commerciaux, etc.) offerts par l'internet et proposant des stratégies d'affaires sur les réseaux informatiques.

De ce paysage qui n'est pas futuriste, que peut le traducteur en cours de formation? Jusqu'où doit-il devenir polyvalent? A-t-il à être un administrateur de site ou webmestre (webmaster) sous prétexte que l'entreprise qui va l'employer cherche à se faire visible par un site multilingue? Tout le monde aujourd'hui ne veut pas répondre par l'affirmative, préférant conserver l'actuelle division du travail entre traducteur et webmestre. C'est ignorer à la fois la force intrégratrice des nouvelles technologies et les nouvelles conditions possibles de rémunération: sur quelle base pourrait être désormais payé le traducteur alors que le texte est une des composantes seulement du site, alors que le paiement peut être fonction de l'effet de la page web (on peut savoir le nombre d'usagers qui l'ont visitée et pour quelle durée) - à la manière du traducteur littéraire rétribué au prorata des ventes du livre qu'il a traduit?

L'initiation à la traduction $\mathrm{AV}$ et à la localisation ne doit pas viser nécessairement à une hyperspécialisation trop précoce qui pourrait mener à une impasse dans les 20 prochaines années et aussi susciter des discriminations hâtives parmi les traducteurs. Elle peut servir de moyen pour développer les compétences générales en traduction, prise dans son sens éclaté (cf. 1), surtout pour dépasser les pratiques trop centrées sur l'écrit, les habitudes trop crispées sur les mots (Klerkx, 1998). Dans ces conditions, elle peut faire évoluer des programmes, des méthodes et des pédagogies toujours trop marqués par l'enseignement des langues. Ce n'est pas rien.

On peut aussi envisager une formation professionnelle avancée. À l'intérieur de cette formation, il faut néanmoins différencier entre ce qui relève de la formation continue (pour des traducteurs diplômés voulant se spécialiser, par 
exemple) et ce qui relève de la formation de base. Dans ce dernier cas, il existe déjà quelques cours universitaires, surtout centrés sur les sous-titrage: à Lille, Strasbourg, Gand, Bruxelles et Copenhague. Les contraintes sont trop diverses pour établir présentement un cursus idéal (les cours offerts aujourd'hui vont de quelques heures à $350 \mathrm{~h}$.): on doit en effet tenir compte des facteurs institutionnels, financiers, linguistiques (quel est le statut de la langue d'arrivée?), techniques et des ressources humaines disponibles.

Mais, plus important, il faut au préalable tenter de répondre à la question: y a-t-il beaucoup de besoins à satisfaire ou le marché présent est-il étroit et le restera-t-il? À mon avis et à partir d'estimations locales, ponctuelles, les besoins en traducteurs AV ne portent pas impérativement sur un grand nombre - même si la demande future par exemple pour les DVD pourrait exiger d'accroitre légèrement ce nombre.

Des remarques similaires (en partie) pourraient être faites pour la traduction des multimédias, sauf que les études de prospective dans ce domaine manquent encore plus cruellement, sauf aussi que la formation de base et continue semblent se faire ailleurs que dans les Universités - malgré les efforts soutenus d'une association comme LISA préoccuppée entre autres, via son groupe de travail en éducation (LEIF), des cours existants, possibles, à monter pour qualifier des professionnels de la localisation, des sytèmes de gestion documentaire, des processus de communication multilingue, etc.

Finalement peut-être que les hésitations des lieux académiques quant aux nouvelles perspectives sont-elles dues moins à leur perception des métamorphoses présentes et prévisibles qu'à leur manque en formateurs, ceuxci étant issus maintenant de filières qui ne leur ont pas fourni les moyens, les schémas de pensée, les aptitudes pour s'adapter, pour innover, tant les transformations se sont soudainement accélérées ces deux dernières décennies. Et là, le défi apparaît vital, immense, non seulement parce que c'est une des fonctions de l'Université de prévoir mais aussi parce que ce manque révèle combien les Humanités se sont laissées distancer dans les demandes en formation, formulées explicitement ou pas par le marché. D'ailleurs, quel doit être ou devrait être le profil de ce formateur de demain? Un enseignant? Un informaticien? Un chef de projet? Un traducteur professionnel recyclé en tuteur?

Quoi qu'il en soit, la formation des traducteurs AV et en multimédias doit être plus ouverte, plus en synergie avec d'autres formations - comme celle des journalistes (Maier, 1993). En effet, les deux professions travaillent sur des formes écrites et orales; elles nécessitent des compétences en langues, en vue de l'analyse et de la composition de textes, une curiosité et une aptitude à la recherche documentaire et terminologique pour couvrir des domaines de connaissances et d'activités variées, une capacité à établir des contacts. Dans 
les deux cas, il vaut mieux apprendre une démarche que d'acquérir des savoirs encyclopédiques vite obsolètes; la formation continue est une nécessité; l'autonomie de décision est primordiale; l'auto-évaluation fait se croiser l'éthique professionnelle et la qualité des prestations. Dans les deux cas, on a affaire à des spécialistes ayant des responsabilités socio-culturelles qui dépassent leur seule production immédiate d'énoncés, du fait même de leur intervention dans les échanges internationaux. Les deux professions, enfin, s'exercent depuis longtemps même si leur formation systématique est assez récente et connaît des soubresauts, dans les contradictions du développement économique et technologique contemporain.

\section{EN GUISE DE CONCLUSION}

Dans la mondialisation présente, il y a effacement des frontières (géographiques, économiques, financières, bancaires, commerciales, etc.). La traduction n'a pas attendu pour être un passage, un entre deux, un seuil toujours à négocier. Avec l'AV et les multimédias, les frontières sont désormais brouillées entre centre et périphérie (en terme de production et de réception), entre public et privé (en terme d'organisation), entre distance et proxémité (en terme d'espace), entre direct et différé (en terme de diffusion), entre réalité et fiction (en terme de référence), entre écrit et oral (en terme de code), entre verbal et non-verbal (en terme de systèmes de signes). La nouvelle alphabétisation (media literacy) résulte de l'ubiquité, de la portabilité, de la flexibilité, de l'interconnexion des supports de communication.

Les traducteurs face aux écrans: une élite d'experts? Oui, élite dans le sens qu'il tient à eux de définir une nouvelle position-clé dans les rapports de pouvoir qui existent là où se fabrique la communication internationale. Oui, élite dans le sensoù ce corps de métier ne peut employer une masse d'indépendants (free lancers) taillables et corvéables à merci parce qu'ils ne verraient leur travail que comme une activité mécanique. Oui, élite mais à condition de ne pas confondre les exigences de haut niveau avec élitisme, synonyme de repli.

\section{BIBLIOGRAPHIE}

BBC (1994): BBC Subtitling Guide, Londres, BBC. 20p. (Guide non publié mais disponible auprès de la compagnie qui l'a édité.)

CARÓN, C. (2001): «Punctuating subtitles: Typographical conventions and their evolution» dans GAMBIER, Y. \& H. GotTLieB (éds.) (Multi)media Translation. Concepts, Practices and Research. Amsterdam, John Benjamins. 305 p. 
COMMISSION EUROPÉENNE (1997): Livre vert sur la convergence des secteurs des télécommunications, des médias et des technologies de l'information, et les implications pour la réglementation. Vers une approche pour la société de l'information, Bruxelles, Commission européenne, 3 décembre 1997. 46p. Disponible aussi sur la Toile <http://www.ispo.cec.be/convergencegp/ greenp.html>

Commission Européenne (1999): Politique audiovisuelle européenne, [sur Internet] <http://europa.eu.int/comm/dg10/avpolicy>

EBU-UER (1987): «EBU Programme Standard for Subtitling - Projet de standardisation UER pour sous-titrage 1987», EBU Review, 38 (6).

Gambier, Y. (éd.) (1995): «Communication audiovisuelle et transferts linguistiques. Audiovisual Communication and Language Transfers» (Actes du Forum international, Strasbourg 22-24 juin 1995.) Numéro spécial de Translatio. FIT Newsletter-Nouvelles de la FIT, 14(3-4), 197-499.

- (éd.) (1996): Les transferts linguistiques dans les médias audiovisuels, Villeneuve d'Ascq, P.U. du Septentrion. 246p.

- (éd.) (1997): Language Transfer and Audiovisual Communication. A bibliography, Turku, University of Turku. 102p. Seconde édition revue et augmentée.

- (éd.) (1998): Translating for the Media (Proceedings of the International Conference Language and the Media, Berlin 22-23 novembre 1996.), Turku, University of Turku. $318 \mathrm{p}$.

GotTlieb, H. (1995): «Establishing a framework for a typology of subtitle reading strategies. Viewers reactions to deviations from subtitling standards» dans GAMBiER, Y. (éd.) (1995: 410-417).

Gummerus, E. \& C. PARo (2001): «Translation quality. An organizational viewpoint» dans Gambier, Y. \& H. GotTlieb (éds.) (Multi)media Translation. Concepts, Practices and Research. Amsterdam, John Benjamins. 305 p.

ITC (1997): ITC Guidance on Standards for Subtitling, Londres, Independant Television Commission. 28p.

Ivarsson J. \& M. Carroll (1998): Subtitling, Simrishamn, TransEdit HB. 186p.

JÄCKEL, A. (1995): «Politiques linguistiques et coproductions cinématographiques en Europe. Vers une nouvelle gestion du multilinguisme européen?» dans Gambier, Y. (éd.) (1995: 462-477).

JAMES, H. (à par.): «Quality control of subtitles: Review or preview?» dans Gambier, Y. \& H. Gottlieb (éds.) (Multi)media Translation. Concepts, Practices and Research. Amsterdam, John Benjamins. 305 p.

Karamitroglou, F. (1998): «A proposed set of subtitling standards in Europe» dans Translation Journal, 2(2). 14 pages. [sur Internet]: <http:// accurapid.com/journal/04stndrd.htm> 
KILBORN, R. (1993): «Speak my language. Current Attitudes to Television Subtitles and Dubbing», Media, Culture and Society, 15(4), 641-660.

KLERKX, J. (1998): «The Place of Subtitling in a Translator Training Course» dans GAMBIER Y. (éd.) $(1998,259-264)$.

LiNDBERG, I. (1991): Nogle regler om TV-tekstning, Copenhague. 25p. [Sur Internet] <http://www.titlevision.dk/tekstnin.htm>

LISA (1999): LISA, the Localisation Industry Standards Association. [Sur Internet] <http://www.lisa.unige.ch>.

LISA (1999), LISA Education Initiative Task Force (LEIT) [Sur Internet] $<$ www.ttt.org/leit>.

Maier, C. \& F. Massardier-Kenney (1993): «Toward an Expanded Pedagogy of Specialized Translation» dans S. \& L. WRIGht (éds) (1993): Scientific and Technical Translation, Amterdam, J. Benjamins. 151-160.

MorTensen, H.P. (1996): «Reception of Subtitles by the Danish Audience» dans Contamine, C. et al. (éds) (1996): Pour un véritable marché audiovisuel en Europe (Publication des discours du 7ème Forum européen de la télévision et du cinéma, Elounda 2-4 novembre 1995), Düsseldorf, Institut Européen de la Communication. 179-180.

NOB (1994): Stijlboeck NOB: Vertaling en Ondertiteling, Amsterdam, 82p.

ObSERVATOIRe européEn DE L'AUdiovisuel (1997). Statistical Yearbook 98. Annuaire statistique 1998. Statistisches Jahrbuch 98. Cinéma, TV, vidéo et nouveaux médias en Europe, Strasbourg. 412p.

SBS (1998): SBS Subtitling Manual, Sydney. 


\title{
ELS RECURSOS DEL TRADUCTOR
}

\author{
JoAn Fontcuberta I GeL \\ Universitat Autònoma de Barcelona
}

\section{INTRODUCCIÓ}

En una tesi doctoral presentada recentment a la Universitat de Vigo sobre Metàfora i Traducció, hi sortia, entre d'altres, aquest exemple: It's raining cats and dogs. Aquesta dita anglesa, bastant coneguda, apareix amb un dibuix (una espècie de targeta postal, encara que jo també l'he trobada en un diccionari de frases fetes i locucions multilingüe) que reprodueix gràficament -i literalment- l'expressió: gats i gossos, barrejats amb aigua, caient del cel.

La doctoranda proposava traduir-la per l'equivalent gallec (una cosa així com Ploure a bots $i$ barrals i, alhora, naturalment, canviar el dibuix (el vehicle visual). Li vaig preguntar si sabria donar-nos alguna solució per al cas que la dita sortís en uns dibuixos animats. La noia, molt modesta, va contestar que jo segurament la sabria millor que ella.

Sigui com sigui, aquest exemple ens serveix per a introduir (ni que sigui de passada) el tema dels recursos del traductor audiovisual. En efecte, tota traducció demana un mínim de recerca, sigui de documentació, sigui de lèxic, etc. Ara bé, la gran diferència entre la traducció estrictament escrita (i fins i tot la de còmics, anuncis, etc.) i l'audiovisual és justament que les imatges no les podem canviar: manen per damunt de tot. 


\section{LA RECERCA DE LA CREATIVITAT EN LA PRÒPIA LLENGUA}

En aquest cas, el traductor ha de fer un ús intensiu i extensiu de la imaginació i dels seus recursos: ha de jugar molt més amb la llengua d'arribada. Dos exemples de recerca lèxica:

a) Qui no arrisca, no pisca.

b) De lladre a lladró, quaranta dies de perdó.

Quant a $a$ ), crec que vaig ser el primer a desenterrar aquesta dita. Dic «crec», perquè no l'havia sentida abans per televisió $i$, després, $s$ 'ha anat fent habitual. Però no es tracta de posar-me medalles. Tots els traductors hem contribuït amb alguns encerts (i també algunes espifiades) a normalitzar la llengua de les traduccions.

La segona va ser arran de la pel-lícula Els set magnífics. En anglès, si no recordo malament, deia: It's no crime to steal from a thief. La primera solució que em va venir al cap va ser la dita castellana Quien roba a un ladrón tiene cien años de perdón. (Com és conegut, però, en la traducció al català hi solen intervenir tres llengües i no només dues). El primer pas que vaig fer va ser consultar els diccionaris que tenia a mà:

a) El Diccionari Castellà-Català, d'Enciclopèdia Catalana (1985). Resultat negatiu.

b) Nou recull de modismes $i$ frases fetes, de Josep Balbastre (Pòrtic, 1977). Resultat negatiu.

c) Proverbis, dites i frases fetes de la llengua catalana, de Sever Perramón (Millà, 1979). Resultat negatiu.

d) Cinc mil refranys catalans (Millà, 1979). Resultat negatiu.

Era un cap de setmana (així es treballa en aquest camp) i no podia anar a cap biblioteca. Finalment, se'm va acudir de consultar l'Alcover-Moll i, a l'entrada lladre, hi vaig trobar aquesta solució. Anava bé tant per la llargada de la frase com per a la boca del personatge.

De vegades, els traductors també hem aportat falses solucions. Guy i chap, per exemple, han tingut una història rica i plena en les traduccions cinematogràfiques al català. De tio va passar a paio, manso, fins i tot sorge, passant per individu, subjecte, tipus i jan. I dic falses pel valor d'aquests substantius en anglès quan van amb un article: valor de pronoms de demostratius $\mathrm{o}$ simplement marcadors de gènere. 
La pregunta que em faig és la següent: què fa que el traductor passi de, per exemple, un connector com I mean... (si realment convé buscar-li una traducció) a «(A)nava a dir...»? És a dir, quin procés mental s'esdevé al cap del traductor que desencadena un seguit de mecanismes que desemboquen en una solució, si no ideal, sí acceptable?

Un altre exemple: estarem d'acord que és difícil d'imaginar una situació en una pel-lícula o sèrie de TV en què escaigui l'exclamació Ai las! Tothom la consideraria literària i fins i tot arcaica o carrinclona. I si no es tracta d'un guió original d'aquestes característiques (un Shakespeare, per exemple), diríem que és desaconsellable. Doncs, bé, en una sèrie humorística britànica (Sí, primer ministre), hi anava com anell al dit, tant perquè encaixava amb la boca del personatge com per la ironia que es desprenia de la situació.

\section{TRADUCCIÓ AUDIOVISUAL I ENSENYAMENT}

Tornant a la pregunta d'abans sobre el procés mental de traducció, l'única explicació que hi trobo és la pràctica i més pràctica. Si les facultats de Traducció pretenem formar professionals que s'evitin els problemes i espifiades pròpies de qui comença a traduir (el cas dels autodidactes, dels quals formem part alguns de nosaltres), convé preparar-los també en el camp de la traducció audiovisual. Però jo vaig un pas més enllà i recomano que es facin pràctiques d'aquest tipus de traducció, independentment que els estudiants després s'hi dediquin o no.

L'agilitat mental i l'abundància de recursos que requereix (i que s'adquireixen a base de pràctica) és d'allò més útil també per a qualsevol altre tipus de traducció. Parlo per experiència i puc dir que, després de tretze anys de traduir per a TV, les meves traduccions literàries d'ara no tenen res a veure amb les d'abans. 


\section{QUALITAT I RECEPCIÓ EN LA TRADUCCIÓ PER AL DOBLATGE Joan Sellent Arús Universitat Autònoma de Barcelona}

Hi ha activitats humanes que tenen un prestigi social indiscutit, de vegades fins $i$ tot superior al que mereixerien objectivament, i d'altres en què passa tot el contrari. La traducció, com sap perfectament tothom qui s'hi dedica o s'hi ha dedicat, pertany a la segona categoria. I constato aquest fet no pas amb la intenció de proposar cap exercici col-lectiu de victimisme ni de masoquisme professional, sinó per sospesar la incidència que pot tenir en la qualitat dels productes que genera la traducció en totes les seves variants.

La falta de prestigi social d'una determinada activitat sol derivar d'un d'aquests dos factors: la mala reputació -és a dir, que sigui considerada il-legítima o, com a mínim, de legitimitat dubtosa-, o bé la indiferència dels profans respecte a les dificultats que comporta i els mèrits que exigeix per obtenir uns resultats satisfactoris. També hi ha casos en què poden confluir totes dues causes, i un d'aquests casos és, al meu entendre, la traducció audiovisual en la modalitat del doblatge.

D'una banda, és innegable que el doblatge constitueix una de les formes de traducció més interessants com a terreny d'experimentació lingüística, semiòtica. etcètera, $i$ els reptes que planteja desperten un interès creixent com a objecte de debat teòric en cercles acadèmics. De l'altra, però, hi ha el fet també innegable que el doblatge, ja no com a modalitat de traducció sinó com a procediment en si mateix, té una reputació social bastant dubtosa. Cada vegada hi ha més intel-lectuals, cineastes, cinèfils i crítics cinematogràfics que posen en qüestió la legitimitat del doblatge o el condemnen sense pal-liatius, alhora que reivindiquen la subtitulació com a recurs molt més respectuós amb la integritat de 
l'original. Des d'un punt de vista purament artístic, hi deu haver més raons per condemnar el doblatge que no pas per defensar-lo, però aquesta qüestió ja queda fora dels límits de la nostra discussió. El que m'interessa, com deia al principi, és debatre fins a quin punt aquest estat d'opinió pot incidir en la qualitat dels productes doblats que circulen.

Jo penso, francament, que hi incideix d'una manera decisiva. Quan una activitat no solament és poc valorada, sinó que la seva mateixa existència és posada en qüestió o condemnada obertament, és difícil que aquells qui la qüestionen o condemnen es prenguin la molèstia de fer cap valoració qualitativa dels productes que genera. Aquest rebuig del doblatge per part d'un sector de la població conviu amb l'actitud indiferent i acrítica d'un sector més nombrós: el dels espectadors que consumeixen regularment productes doblats, ja sigui perquè prefereixen aquesta opció o perquè no tenen cap altre remei. Veiem, doncs, que la reacció social majoritària davant del doblatge fluctua entre l'hostilitat i la indiferència, i això, lògicament, provoca una mena de cercle viciós: la indústria del doblatge, davant d'aquesta absència d'un control de qualitat extern, segueix la llei del mínim esforç i acostuma a tenir un sostre qualitatiu bastant baix: compleix els requisits tècnics i interpretatius d'una manera bastant correcta, en general, però, en canvi, des del punt de vista del text, la majoria dels productes doblats presenten sovint unes solucions maquinals, fossilitzades, calcades de la llengua original i allunyades de l'experiència idiomàtica dels espectadors. D'una altra banda, la urgència i els imperatius del mercat amb què sol treballar la indústria del doblatge -tant en el cas del cinema com de la televisiócontribueixen encara més a fomentar la mediocritat dels resultats.

Entre els consumidors de productes doblats, la qualitat estilística dels diàlegs no acostuma a entrar en les seves consideracions quan fan judicis de valor sobre les pel-lícules que han vist. Si mai algú fa cap referència a la qualitat d'un doblatge, aquesta referència no sol anar més enllà dels aspectes tècnics: és a dir, una pel-lícula es qualificarà de ben doblada o mal doblada segons el grau de sincronització del text amb la imatge, però aquí s'acaba la valoració. No sembla que ningú es plantegi que el grau de versemblança idiomàtica, de creativitat $i$ de naturalitat dels diàlegs pugui incidir en absolut en la seva recepció d'una pel-lícula o d'una sèrie televisiva.

Davant d'aquest panorama, doncs, pretendre que les coses siguin d'una altra manera, segurament, és perdre el temps. Potser val més acceptar que la mediocritat és un factor tan inherent a la indústria del doblatge que pràcticament es converteix en un requisit i no donar-hi més voltes. L'oferta ja s'ajusta a les expectatives de la demanda i és massa ingenu esperar que es dediqui cap esforç a millorar un aspecte dels productes que no influeix en la rendibilitat. 
Sóc conscient que, a més de subjectiu, aquest diagnòstic pot semblar excessivament generalitzador. Precisaré, per tant, que només l'aplico al doblatge que es practica i s'exhibeix a Catalunya, ja que és l'únic que conec. Dit això, però, no puc passar per alt que a Catalunya, des de fa setze anys, conviuen el doblatge en castellà i el doblatge en català, sobretot en l'oferta televisiva. Cal que precisi, doncs, si en les apreciacions que acabo de fer els poso tots dos en un mateix sac o no. Abans de fer-ho, però, voldria matisar un tòpic que em sembla que circula sobre el doblatge en català i és que la qualitat dels diàlegs és superior al doblatge en castellà. Jo tinc dubtes seriosos sobre això i, si de cas, aprofito per deixar aquests dubtes sobre la taula per si poden interessar com a objecte de reflexió.

El que sí que té el doblatge en català és el factor afegit de ser un vehicle al servei de la normalització lingüística, cosa que implica la presència d'uns mecanismes de control lingüístic en el procés de producció. En un principi, pot semblar que aquests mecanismes garanteixen una qualitat textual superior en els doblatges, però, en realitat, l'únic que garanteixen és un control de les desviacions dels textos respecte a la normativa lingüística vigent, cosa que no té res a veure amb tot allò que dèiem de la naturalitat, la versemblança i la creativitat dels diàlegs, i no tan sols no potencia aquests aspectes sinó que molt sovint hi representa un obstacle addicional. La recerca i l'experimentació en el camp dels recursos de l'oralitat i del registre col-loquial, en el cas del català, exigia inevitablement $i$ abans que res una revisió a fons de la normativa lingüística, i això, amb la perspectiva d'aquests setze anys, penso que és una qüestió que encara continua pendent.

També exigia, naturalment, un entorn laboral que propiciés la coordinació $i$ el treball en equip entre els professionals implicats (traductors, correctors, directors i actors de doblatge, etc.), però, en la realitat, les condicions de treball són les mateixes que ja arrossegava i arrossega el doblatge en castellà. Les exigències de la indústria del doblatge no fan pas excepcions en el cas del català: els professionals es veuen obligats a treballar amb la mateixa urgència $i$ al mateix ritme sincopat $i$ irracional que els seus col-legues en llengua castellana i aquestes pautes de treball, sovint, ja vénen imposades pel mateix client, en aquest cas Televisió de Catalunya o la Direcció de Política Lingüística. No vull deixar de reconèixer l'existència d'uns traductors i lingüistes que, a títol individual i contra corrent, hi posen més interès del que l'entorn els demana i es mereix $i$, gràcies als quals, de vegades apareixen doblatges que van més enllà de la mediocritat imperant; però això, en definitiva, també passa en el cas del doblatge en castellà i és evident que uns resultats que es basin en el voluntarisme individual es mouran sempre en el terreny de l'excepció i de la imprevisibilitat. Resumint, doncs: no crec que la qualitat general dels doblatges en català que es 
fan a Catalunya permeti ser gaire optimista ni fer gaires distincions respecte al diagnòstic que he formulat abans.

No he pretès fer una intervenció catastrofista: només he volgut exposar una situació que, al meu entendre, fa que el potencial del doblatge com a terreny d'experimentació lingüística i textual quedi ofegat per les condicions socials i de treball que envolten l'exercici professional d'aquesta modalitat de traducció. 


\title{
LA INTERVENCIÓ LINGÜÍSTICA EN VERSIONS DOBLADES I SUBTITULADES. EL CAS CATALÀ
}

\author{
MARTí GARCIA-RIPOLL \\ Assessor lingüístic
}

\section{INTRODUCCIÓ}

Tots els mèdia fets en una llengua en vies de normalització, si es volen fer ben fets, necessiten la figura omnipresent d'uns assessors lingüístics i correctors, per garantir un bon ús de la normativa linguiística, especialment si aquests mèdia s'han creat explícitament per contribuir a la normalització lingüística, com és el cas de les televisions autonòmiques de Catalunya, Euskadi i Galícia.

Feta aquesta consideració prèvia, com que la meva especialitat és l'assessorament lingüístic de les produccions televisives importades (animació, pel-lícules, telefilms, documentals, sèries), em centraré en aquest àmbit i en deixo de banda altres, com la traducció d'espots publicitaris, normalment del castellà al català, o la correcció de notícies elaborades a partir de fonts estrangeres o espanyoles.

\section{ALGUNS PROBLEMES DE LA TRADUCCIÓ AUDIOVISUAL}

En la traducció d'audiovisuals, a diferència de la traducció literària, el traductor, el que fa és un esborrany del que després serà la versió del que veurem i sentirem. Això és així per la subordinació del diàleg a la semiòtica de la imatge. Per això, el traductor, abans de començar a traduir un guió, ha de veure, visionar. el producte audiovisual per saber-ne els continguts, per poder adequar el llenguatge a les situacions contextuals. És molt important mantenir la fidelitat 
estilística del guió original (nivells de llenguatge, registres, etc.). I, en aquest punt, sovint ja es produeixen els primers problemes lingüístics.

Uns tipus de problemes fan referència a la forma. Pot ser que, a l'hora de començar a traduir, no hi hagi guió escrit i s'hagi de traduir a partir de l'àudio d'una cinta de vídeo. També pot ocórrer que el que se sent a la cinta sigui diferent al guió escrit. I un tercer problema que se'ns pot plantejar és que el guió estigui en un idioma i la cinta en un altre.

Però, a banda d'això, també pot ser que el traductor es trobi amb problemes de contingut. Aquests, normalment, fan referència a qüestions lèxiques (vocabularis especialitzats en el cas de documentals científics o de pel-lícules o sèries molt monotemàtiques: de metges, judicis, militars o, també, d'instituts de secundària), quiestions pragmàtiques (nivell de llenguatge, tractaments, referents socioculturals, acudits), qüestions sociolingüístiques (alternances de codi lingüístic: anglès-alemany en pel-lícules de la II Guerra Mundial o anglèsespanyol en pel-lícules ambientades al sud dels Estats Units). També, a vegades, a més dels problemes de lletres, cal solucionar problemes de números, matemàtics, gairebé sempre relacionats amb la transformació de les unitats angleses a les unitats mètriques.

Com veieu, si un es vol dedicar al món de la traducció audiovisual, ha de saber de tot, o al menys ha de saber on es pot trobar, cosa que avui dia, gràcies als llibres d'estil, manuals de traducció o Internet, tenim més fàcil que fa 15 anys enrera, quan buscar un diccionari bo de portuguès del Brasil en una ciutat com Barcelona era un odissea, $i$ això es necessitava per traduir sèries com L'esclava Isaura o Dancin' Days.

\section{ELS ASSESSORS LINGÜÍSTICS}

En el cas de TV Catalunya hi ha uns assessors lingüístics, entre els quals m'hi compto, que donen suport a traductors i correctors d'estudi de doblatge, a través del fons bibliogràfic o bé canalitzant les consultes cap a d'altres serveis lingüístics institucionals (TERMCAT, Direcció General de Política Lingüística, Servei de Normalització de la Universitat Politècnica de Catalunya, Museu de Zoologia, etc.). També pot ser que s'hagin de buscar professionals experts en una àrea determinada (aeronàutica, informàtica, psicologia, zoologia, etc.) per resoldre quiestions molt especialitzades. I, a vegades, cal buscar nadius de llengües o varietats lingüístiques poc conegudes aquí, com ucraïnès, provençal, gal·lès, jidisch, romanès, sicilià, francès-quebequès o hebreu modern, per posar uns quants exemples recents. A TV Catalunya, a més, hi ha uns assessors angloparlants nadius que resolen els dubtes que puguin tenir els traductors o els tècnics lingüístics. 
Quan el traductor ha acabat la traducció del guió d'audiovisual, el que ha fet és un canemàs del que serà una versió doblada o subtitulada. Tant en un cas com en l'altre, hi ha un segon procés d'edició de text.

\section{LA SUBTITULACIÓ}

En el cas dels subtítols, que sembla molt fàcil, cal fer un nou guió que es pugui llegir a velocitat lectora normal, perquè, si no, el subtitulat no serveix de res. Això vol dir resumir els diàlegs, però mantenint la coherència interna original. Per tant, no es pot tallar alegrement, sinó que s'ha de jugar amb les redundàncies, els sinònims i la sintaxi. I també s'han de tenir en compte les normes de presentació del subtitulat, tant les de tipus estrictament gràfic (com són un màxim de dues línies per subtítol, la simetria, la sintaxi del subtitulat - procurar que els canvis de subtítol coincideixin amb acabaments de frase-, etc.), com les relacionades amb la semiòtica de l'àudio (la sincronia entre el diàleg real i el subtitulat) o la semiòtica de la imatge (la sincronia entre canvis de plans i canvi de subtítol). Avui dia, gràcies a la informàtica, tot el procés del subtitulat (tallat, codificat i inserció), l'acostuma a fer una sola persona, que normalment és llicenciada en filologia catalana. De tota manera, en el cas dels subtítols, els traductors sovint fan ells mateixos la versió reduïda del guió traduït.

\section{EL DOBLATGE}

En el cas del doblatge, la forma més senzilla -més que el subtitulat-són els documentals per ser locutats, ja que, en aquest cas, no cal fer ajustos perquè normalment es fa com una traducció consecutiva. És a dir, la locució doblada segueix, sense interpretació artística, l'original en off d'una veu narrativa, que se sent parcialment. I, en aquest cas, és l'únic en què la traducció inicial, la que ha fet el traductor, és pràcticament la definitiva, tret de les correccions.

En el cas del doblatge dels gèneres de ficció, cal fer l'ajust, és a dir, establir sequència a seqüència el text complet que han de gravar els actors, resseguint els moviments de la parla que ens presenta la imatge i també la coherència, el ritme i el nivell del llenguatge. L'ajustador ha d'anotar les pauses, els sorolls (sospirs, rialles, plors), la sincronia d'entrades i sortides, i aixồ vol dir modificar el text que ha lliurat el traductor perquè pugui ser interpretat pels actors. Per facilitar les coses, a vegades, els traductors fan també d'ajustadors. No és tan senzill com en els subtítols, perquè s'ha d'haver passat per hores de sala de gravació i aprendre'n amb algú que en sàpiga. Però el cas és que cada vegada hi ha més traductors-ajustadors. 
Un cop s'ha ajustat, el guió es revisa lingüísticament i s'hi fan les correccions pertinents, no solament les normatives, sinó també les estilístiques. En aquest procés, com que som una llengua desnormalitzada, ens podem trobar que la normativa i l'estilística entrin en conflicte, sobretot quan s'ha de fer servir argot. En el cas de llengües normalitzades, la correcció lingüística no se sol fer, perquè tant el traductor com l'ajustador tenen prou competència lingüística $i$ pragmàtica. D'una altra banda, el corrector, per facilitar la feina dels actors o dels locutors, fa una llista dels noms propis estrangers i n'assenyala la pronúncia. Així s'aconsegueix una pronunciació homogènia.

En el doblatge, quan s'arriba aquí, es grava. Prèviament, un director de doblatge ha fet una selecció de veus i, com que som una llengua encara desnormalitzada, el tècnic lingüístic ha de dir quines condicions ortològiques han de tenir aquestes veus.

Quan s'ha acabat de gravar la versió doblada, el tècnic lingüístic la visiona i proposa les modificacions pertinents. En el cas d'una llengua normalitzada, aquí tampoc no cal el corrector perquè el director de doblatge té prou competència lingüística.

Llavors es fan les mescles d'àudio, s'edita i s'envia al client. No obstant això, com que els doblatges els fan unes empreses especialitzades que treballen per a televisions, distribuïdores de cinema o de vídeo o institucions i, com qui paga mana, pot ser que el client (o els seus tècnics lingüístics) trobi que hi ha alguna cosa que no ha quedat prou bé i s'hagi de modificar. Aquest seria l'últim control lingüístic.

Tot això pot semblar molt complicat, però pensem que hi ha un gran paral-lelisme amb les edicions de llibres i les successives correccions d'originals, de primeres galerades, de segones galerades $i$, a vegades, de terceres galerades.

\section{BIBLIOGRAFIA}

Agost, R. (1996): La traducció audiovisual: El doblatge, Col-lecció

Micromagna, 11, Castelló de la Plana, Publicacions de la Universitat Jaume I.

- (1999) Traducción y doblaje: palabras, voces e imágenes, Barcelona, Ariel. ÁvILA, A. (1997 a): El doblaje, Madrid, Cátedra.

- (1997 b): Historia del doblaje, Barcelona, CIMS.

BAssols, M. i altres (1997): La llengua de TV3, Barcelona, Empúries.

FonTCUBERTA, J. (1994): «La traducció de guions cinematogràfics» dins Actes del I Congrés Internacional sobre Traducció, Barcelona, Universitat Autònoma de Barcelona, 315-317. 
GarCia-Ripoll, M. i C. Niqui (1990): «La televisió en llengüies estrangeres a Europa» dins El repte (sòcio)lingüístic de l'Acta Única, Barcelona, Publicacions de l'Institut de Sociolingüística Catalana, Generalitat de Catalunya.

IZARD, N. (1992): La traducció cinematogràfica, Barcelona, Centre d'Investigació de la Comunicació, Generalitat de Catalunya.

MANERo, F. (1983): Estudio de las traducciones para TVE de una selección de obras de teatro contemporáneo (tesi de llicenciatura), UAB.

Mendieta, S. (1993): Manual de estilo de TVE, Barcelona, Labor.

Mollà, T. (1990): La llengua dels mitjans de comunicació, Alzira, Bromera.

NIR, R. (1984): «Traslation of TV films in Israel», International Journal of Sociology of Language, 48.

Palau, S. (1996): La traducció de guions cinematogràfics. Problemes específics de l'anglès al català (memòria), Barcelona, Universitat Autònoma de Barcelona.

Paloma, D. (1995): El català col-loquial a les sèries de producció aliena de Televisió de Catalunya (treball de recerca), Barcelona, Universitat Autònoma de Barcelona.

PAternost, J. (1985): «Language value and language reality in contemporary Slovenian», International Journal of the Sociology of Language, 52.

Rico, A. (1999): «Música per a camaleons: traducció i subtitulació», Jornada sobre l'oral i l'escrit a la televisió [fitxer digital], Barcelona, UAB, Grup Llengua i Mèdia.

Rousseau, B. i M. Watier (1999): Le doublage au Québec [en línia] <http:// www.doublage.com>.

Sellent, J. (1993): «Misèries i esplendors del llenguatge», Cultura, gener.

- (1998): «La traducció teatral i la traducció audiovisual», VI Seminari sobre la traducció a Catalunya. Quadern divulgatiu.

Televisió de CATAlunYa (1997): Criteris lingüístics sobre traducció i doblatge, Barcelona, Edicions 62.

- (1997-1999): Versió doblada, 1 al 5, Sant Joan Despí, Televisió de Catalunya.

- (1998): El català a TV3. Llibre d'estil. 2a edició, Barcelona, Edicions 62.

- (sense datar): Subtitulació per a persones sordes de programes enregistrats. 1. Aspectes formals. 2. Aspectes de contingut (text multicopiat). 


\title{
SOUS-TITRAGE: LE CAS DE LA TRADUCTION DE L'ALLEMAND VERS LE FRANÇAIS
}

\author{
JeAn-JacQues AlCandre \\ Université Marc Bloch de Strasbourg
}

\section{INTRODUCTION}

Les études menées sur la traduction audiovisuelle se sont jusqu'à présent peu préoccupées d'analyser les problèmes spécifiques liés à la confrontation de langues et de cultures données lors de l'opération de transfert linguistique. L'objet de cette contribution est d'esquisser une analyse de cette confrontation en ce qui concerne la traduction de l'allemand vers le français. La linguistique et la stylistique comparée permettent en effet de dégager un certain nombre de faits caractéristiques qui ne sont pas sans incidence sur l'exercice de la traduction audiovisuelle. Pour mener cette expérience, nous analyserons quelques séquences de la traduction sous-titrée de l'adaptation du Zauberberg de Thomas Mann (La montagne magique) dont la première partie a été diffusée sur la chaîne franco-allemande ARTE le 3 juin 1995 (Réalisation Hans Geissendörfer pour le ZDF, le sous-titreur n'est pas nommé). Le choix de cette œuvre nous permet en effet d'avoir accès - même dans le cadre d'une adaptation audiovisuelle - à toute la richesse et la spécificité de la langue allemande dont Thomas Mann est un des meilleurs connaisseurs et un des plus grands orfèvres. 


\section{L'ORDRE DES MOTS}

La première différence significative et difficulté potentielle concerne l'ordre des mots. L'organisation très différenciée de cet ordre des éléments à l'intérieur de la phrase allemande et française n'est en effet pas sans répercussion sur le transfert d'une langue à l'autre en situation audiovisuelle. On sait que la phrase allemande trouve la manifestation la plus directe de sa structure profonde dans la subordonnée et se caractérise par l'ordre récursif de ses connexions (Pastré, 1998: 261-262). Autrement dit, le verbe sous sa forme conjuguée se situe en fin de phrase et les expansions successives du groupe verbal s'effectuent selon la hiérarchie de leur appartenance au verbe de la droite vers la gauche, ainsi que le montrent les exemples donnés par les grammairiens:

\section{Exemple 1a}

(dass) Dieter morgen mit seinem Bruder nach Berlin fährt.

Dans la proposition indépendante, le verbe sera déplacé vers la position 2 (Dieter fährt), sans qu'il y ait pour autant modification de l'ordre des autres éléments de la phrase.

On sait que la langue française procède de façon fort différente, que l'ordre des connexions y est progressif et s'exerce donc de la gauche vers la droite, ce qui a pour conséquence que les éléments les plus porteurs de la signification sont donnés très tôt dans la proposition française (indépendante ou subordonnée) et qu'en tout cas les formes personnelles du verbe ne s'y trouvent pas en toute fin de proposition:

\section{Exemple 1b}

(que) Dieter va à Berlin demain avec son frère.

On pourrait ajouter d'autres remarques complémentaires sur la place de la négation et des éléments prépositionnels, mais nous nous intéressons ici avant tout à la configuration générale de la phrase et à ses conséquences.

Il résulte en effet de tout ceci que l'information est distribuée de façon très différente dans la proposition allemande par rapport à ce qui se passe en français. La conséquence pour la traduction audiovisuelle est un décalage possible dans la distribution de la signification entre la production originale (allemande) et sa traduction (française). Ce décalage est davantage sensible à celui qui y prête attention dans le cas du sous-titrage dans la mesure où version d'origine orale et traduction sous-titrée sont co-présents lors de la diffusion de l'œuvre audiovisuelle concernée (contrairement au doublage synchronisé où la voix 
d'origine disparaît de la version doublée). Les conséquences ne sont certes pas trop dommageables dans la mesure où le sous-titreur procède de toute façon à une traduction-synthèse et n'a pas pour consigne de respecter systématiquement l'ordre des mots de la version originale. Cependant, lorsque la phrase s'allonge et que les structures de phrase sont fortement différenciées, l'étalement de la traduction de certaines phrases sur plusieurs sous-titres peut produire un décalage significatif qui mérite qu'on y prenne garde, ainsi qu'on pourra le constater dans l'exemple suivant de La montagne magique:

\section{Exemple 2}

Ich nehme an, dass Sie, wie die meisten hier oben, den ersten Tag Ihres Aufenthalts an diesem Lustort in - wie man hier sagt - horizontaler Lage verbracht haben.

Je présume que comme la plupart ici/ vous avez passé votre premier jour dans ce lieu de plaisir/ en position horizontale, comme on l'appelle ici.

A l'évidence, le personnage use de la structure de phrase allemande pour retenir l'effet qu'il veut produire avec les termes in horizontaler Stellung verbracht. Ici, le traducteur a retenu à juste titre l'expansion «en position horizontale» jusqu'au dernier sous-titre. L'avancer davantage à l'intérieur de la phrase aurait été une erreur qui aurait même provoqué un décalage par rapport à l'image (gestuelle, mimique).

\section{LES SUBSTANTIFS ABSTRAITS}

Seconde caractéristique qui ressort très nettement face à la langue très riche. très dense de Thomas Mann: la difficulté du français à rendre compte des substantifs abstraits allemands, dont la variété est considérablement enrichie par la facilité de composition et de dérivation de cette langue - face à la rigidité du français en ce domaine. On voit alors le traducteur lutter pour rendre compte de:

\section{Exemple 3}

Gönnen Sie mir doch das bißchen Ungebundensein, das mir aus dieser Tatsache entsteht.

Accordez-moi le peu de liberté auquel mon état me donne droit.

\section{Exemple 4}

[...] eine krankhafte Kurzweiligkeit der Zeit.

$[\ldots]$ un état morbide d'abrègement du temps. 


\section{Exemple 5}

Es strebt nach Erfüllung im Dunklen und im Tiefgeheimen.

Il aspire à sa réalisation dans l'obscurité, les profondeurs.

La difficulté est particulière en contexte de traduction audiovisuelle, dans la mesure ou la place disponible est strictement comptée et ne laisse pratiquement aucun recours au développement explicatif.

\section{LA MODALISATION}

On constate de même que la modalisation pose souvent des problèmes de transposition en français et que ce sont souvent les particules modales (ou la nuance correspondante) qui disparaissent dans la lutte constante que mène le sous-titreur pour préserver son capital d'espaces et de caractères:

\section{Exemple 6}

(Ihr Vetter)..., der nun hoffentlich bald sagen kann, dass er mal krank gewesen ist.

(Votre cousin)...qui pourra bientôt parler de sa maladie au passé.

\section{Exemple 7}

Sie sind ja ganz schön spöttisch.

Vous êtes sarcastique.

\section{Exemple 8}

Dienstag oder Mittwoch nächster Woche muss es wohl sein.

Mardi ou mercredi prochain.

L'observation attentive du traitement des particules modales en situation de traduction audiovisuelle conduit à la conclusion que celles-ci sont trop souvent négligées même lorsque l'espace disponible devrait permettre un meilleur traitement à leur égard (c'est le cas notamment pour le second exemple cidessus). D'importantes nuances sont ainsi perdues, ce qui est regrettable en situation de transposition écrite de communication orale.

\section{LA CONDENSATION}

Une différence importante est à l'avantage du traducteur de l'allemand vers le français en ceci qu'elle permet une plus grande concision de l'expression. L'allemand, particulièrement en ce qui concerne les verbes, dispose d'une très 
grande diversité lexicale qui repose sur la volonté de préciser autant que possible la nature du fait exprimé. Cette extrême précision, cette volonté de rendre compte de l'acte dans son déroulement concret et son mouvement entraîne dans la plupart des cas une caractérisation très précise, bien souvent atteinte par l'emploi de particules et par la création de termes composés. Bien plus pauvre en ce domaine, le français procède davantage par représentation abstraite et rend l'expression plus dense autour de termes-signes à usages multiples, ce qui va finalement, en situation de traduction audiovisuelle, dans le sens de la condensation. Ainsi. dans La montagne magique:

\section{Exemple 9}

Im Winter müssen sie die Leichen per Bobschlitten herunterbefördern.

En hiver, ils expédient les corps en bob.

\section{Exemple 10}

Wird schon steigen, wird schon emporwandern, der Mercurius.

Il grimpera bien assez tôt, le mercure.

\section{LES TRANSFERTS SYNTAXIQUES}

Une autre conséquence de la différence d'approche du réel et de la pensée entre le français et l'allemand est la fréquence des transferts ou même croisements syntaxiques à l'occasion de l'opération de traduction. Un adjectif ou un substantif devient alors verbe, un adjectif substantif, etc. C'est en jouant de cette large palette de substitutions que le traducteur se dégage de la plate transposition terme à terme très vite repérée comme allemand traduit contraire à la nécessaire fluidité de la traduction audiovisuelle. Citons de nouveau quelques exemples de semblables transferts :

\section{Exemple 11}

Er betreibt Seelenzergliederung mit seinen Patienten.

Il dissèque l'âme de ses patients.

\section{Exemple 12}

Da sind Sie ja eine höchst studienwerte Erscheinung.

En ce cas / vous valez la peine qu'on vous examine.

\section{Exemple 13}

Nun wissen Sie ja endlich, wie vorzüglich ein Husten sein kann.

Vous connaissez enfin / le plaisir exquis de la toux. 


\section{CONCLUSION}

On peut conclure cette esquisse d'analyse comparative en constatant que l'allemand langue source pose au traducteur audiovisuel travaillant vers le français d'importants problèmes de transfert liés aux nombreuses et profondes différences de représentation entre les deux langues. Le décalage, la superposition terme à terme de la version d'origine et de la traduction n'est certes pas exclue:

\section{Exemple 14}

Hans Castorp war weder ein Genie noch ein Dummkopf.

Hans Castorp n'était ni un génie ni un imbécile.

\section{Exemple 15}

[...] im Vollgefühl Ihrer untadeligen Gesundheit.

[...] dans la pleine conscience de votre irréprochable santé.

Mais dans la plupart des cas, le travail de transfert est important et il s'effectue essentiellement selon les axes qui ont été précédemment mentionnés. L'aspect positif de ce travail, en dehors bien sûr de son caractère indispensable, est que ce transfert de l'allemand vers le français va dans le sens d'une densification, d'une rationalisation de l'approche du réel et de la pensée qui rejoint l'exigence de condensation indispensable en situation de traduction audiovisuelle. Le traducteur audiovisuel de l'allemand vers le français a donc tout intérêt à porter son attention sur les travaux de stylistique comparée et à en tirer les conclusions dans la perspective de son activité de traducteur. ${ }^{1}$

\section{BIBLIOGRAPHIE}

Malblanc, A. (1968): Stylistique comparée du français et de l'allemand, Paris, Didier.

PASTRÉ, J. M. (1998): Nouvelle grammaire de l'allemand, Paris, Ophrys.

1. Cf. notamment l'ouvrage de référence de Malblanc (1968). 


\title{
CUESTIONES SOBRE LA NORMA CULTA Y LOS CRITERIOS DE CALIDAD PARA LA TRADUCCIÓN DE DOBLAJE Y SUBTITULACIÓN EN ESPAÑA
}

\author{
Xosé Castro Roig
}

Traductor

\section{INTRODUCCIÓN}

Permítame el lector traer a colación en este breve artículo tres puntos polémicos sobre la traducción general y la traducción de películas en España. Son, en realidad, tres temas abiertos a discusión y mi intención no es tanto llegar a conclusiones como presentarlos para su reflexión o, quizá, para fomentar el debate en el aula. Puede que por eso haya elegido tres cuestiones basadas en la autocrítica. Entiéndase con ello «una crítica a mí mismo como traductor y persona» (pues difícilmente podemos llegar a un código deontológico desde unos principios éticos personales errados), al resto de los colegas, a centros de enseñanza y a las empresas de este sector profesional. Espero que su lectura les aporte alguna incomodidad (productiva, eso sí), pues esa es mi intención. 


\section{LA PARADOJA DE UN PAÍS PLURICULTURAL Y PLURILINGÜE O «DEL CASTELLANO, ¿QUIÉN SE OCUPA?»}

En España, vivimos una extraña paradoja. En ciertos sectores políticos, se quejan de la prioridad (económica y política, quieren decir) que se da a los idiomas de ciertas comunidades autónomas y también del aumento de la presencia de esos idiomas en la educación y otros ámbitos culturales de cada comunidad. Sin embargo, en los sectores políticos y empresariales en los que se pronuncian estas críticas, poco se hace por tomar ejemplo de las positivas repercusiones que tienen ciertas políticas de defensa de la lengua.

Actualmente, en Galicia, el País Vasco, la Comunidad Valenciana o Cataluña, hay un mayor cuidado y esmero lingüístico con las lenguas propias de estas comunidades que el que se tiene con el español en zonas exclusivamente castellanohablantès. En todas estas comunidades, se están desarrollando, con mayor o menor acierto e intensidad, políticas de investigación en terminología y lexicografía que reciben apoyos institucionales de los que, paradójicamente, carece en igual medida el idioma español tanto en esas zonas como en otras puramente castellanohablantes.

Así pues, para que una película de televisión traducida al gallego, vasco, valenciano o catalán llegue a emitirse, pasa antes por la revisión del lingüista del propio estudio de doblaje y, posteriormente, su doblaje y traducción debe ser revisado y aprobado por un lingüista del departamento de producción ajena de la televisión autonómica. Bien es cierto que, aunque estos lingüistas son frecuente objeto de críticas por parte de traductores, estudios de doblaje y espectadores, en estas comunidades pueden decir, al menos, que cuentan con varias personas cuyo cometido es supervisar el correcto uso del idioma en televisión, tanto en un plano léxico como fonético.

Por otro lado, varios colegas míos gallegos y catalanes prefieren, siempre que pueden, hacer traducciones al castellano antes que hacerlas al gallego o catalán y tener que pasar por lo que denominan, y cito literalmente, «una revisión encorsetada y corta de miras de su traducción desde un punto de vista normativo». Esta polémica quizá sea ignorada por muchos traductores de zonas exclusivamente castellanohablantes.

Para mayor paradoja, en estos momentos (finales de 1999), los programas de mayor audiencia de las televisiones gallega y catalana son, respectivamente, Mareas vivas y Plats bruts, series de producción propia que destacan por su lenguaje coloquial y poco normativo. Concretamente, en aquélla se emplea constantemente un gallego dialectal salpicado de un léxico y una fonética nada normativos. Sin embargo, su gran semejanza con el lenguaje de la calle ha 
atraído la atención del público. Quizá la gente está algo harta -y aquí sólo puedo hablar del caso de Galicia- de oír películas dobladas en las que el delincuente habla un gallego tan normativo y correcto como el del aristócrata u otras en las que la población marginal emplea una esmerada fonética que nada tiene que ver con el idioma de la calle. Quizá la gente esté inconscientemente cansada de oír cómo los bustos parlantes de los noticiarios gallegos les hablan un gallego con fonética castellana.

En cualquier caso, mi intención es constatar este hecho y no analizarlo: tenemos, por una lado, una serie de comunidades autónomas que han dispuesto unas beneficiosas normas de control sobre la calidad de su idioma (que su aplicación sea incorrecta o discutible es otro cantar) y, por otro, comunidades exclusivamente castellanohablantes o parcialmente castellanohablantes (esto incluiría a todas) en las que el cuidado del idioma español en televisión es escaso o nulo. ¿Tememos aplicar al español unas normas que no dudamos en promulgar y acatar en vasco, gallego, valenciano y catalán? ¿No deberían tener similares fundamentos de defensa del idioma todas las televisiones públicas, sea cual fuere el lugar en el que estén ubicadas? ¿Por qué algunos lingüistas, redactores y traductores se muestran iconoclastas y antiacadémicos con la lengua española y no con otras? ¿Por qué en algunas regiones no es grave cometer solecismos en una lengua y sí en la otra?.

Hace ya mucho tiempo que Televisión Española no supervisa la calidad de sus programas traducidos. La última cadena de habla española que lo hizo fue Canal+ y un recorte de presupuestos acabó con el otrora eficaz y beneficioso departamento de supervisión lingüística.

¿De qué modo influye en el sector de la traducción todo lo antedicho? La respuesta es obvia: si el cliente final (la cadena de televisión o distribuidora cinematográfica) se despreocupa de la calidad, ésta quedará en manos del buen hacer del estudio de doblaje. Desgraciadamente, su buen hacer se reduce a contratar a buenos actores de doblaje y a un buen traductor y sus posibilidades son pocas si contamos con que las tarifas de doblaje están congeladas desde hace ocho años aproximadamente, aunque bien es cierto que este hielo ha enfriado más las tarifas de los traductores que de los actores de doblaje. Al menos, ellos están asociados o sindicados...

\section{EL EMPLEO DE NUEVAS TECNOLOGÍAS}

Es curioso que siempre estemos hablando de nuevas tecnologías cuando son, más bien, algo viejas; no tanto por los años que llevamos utilizándolas, sino por la implantación que tienen en nuestras vidas y formas de trabajar. 
Como ejemplo extrapolable de cuánto puede ayudar al traductor audiovisual el correcto manejo de la tecnología, yo siempre cito la columna de personajes de una película traducida. Como quizá ya sepa el lector, los traductores de películas debemos entregar a los estudios de doblaje la traducción de los diálogos de una película dispuestos en dos columnas: a la izquierda, aparecen los personajes y, a la derecha, los diálogos respectivos.

Cuando traduje los diálogos de la película The Postman (El mensajero del futuro), protagonizada por Kevin Costner, mi traducción tenía 12.000 palabras, de las cuales, 2000 estaban en la columna de la izquierda. O, por decirlo de otro modo, la película tenía poco más de una quincena de personajes que intervenían unas dos mil veces en la película. Con un mínimo conocimiento de Word y de las macros que ofrece este programa, la introducción de esos dos mil nombres se convirtió en una tarea sencilla, rápida y segura que redujo en unos 45 minutos el tiempo invertido en la traducción. Es más, con la ayuda de la informática, el traductor puede garantizar que los nombres irán siempre bien escritos y así no se produce ningún error de reconocimiento de personajes en el programa que divide los diálogos en tomas o takes. Pero esto es tan sólo un ejemplo nimio del ahorro real que produce el correcto manejo de los utensilios tecnológicos y de la mejora en la calidad y productividad que estos pueden aportar.

Otro ejemplo: hace dos años traduje un documental de National Geographic sobre la fauna autóctona australiana. Logré ponerme en contacto, a través de Internet, con el Instituto Nacional Australiano para la Conservación de la Flora y la Fauna y resolver, así, las decenas de dudas terminológicas que se me plantearon en aquellos sesenta minutos de documental. Además, conseguí guardar imágenes estáticas del documental en mi ordenador (mediante una tarjeta de captura que compré para la ocasión) y enviarlas por correo electrónico como apoyo visual a mis consultas.

Sin Internet, no habría podido hacerlo. Aun así, en muchas facultades de Traducción, la asignatura denominada Documentación sigue omitiendo Internet como recurso documental. Como profesor habitual de cursillos, me sorprende comprobar el gran distanciamiento que hay entre el mundo profesional y el mundo académico en materia de tecnología. Esto no es así en todas las facultades ni en todas las ciudades, pero me temo que esta afirmación es válida para demasiados centros.

Hay alumnos de Traducción de cuarto curso que estudian hasta tres idiomas distintos en cuatro años gracias a un plan de estudios cuyo lema parece ser «Cuanto más, mejor», pero no tienen ordenador en casa. Hay estudios de doblaje que aún no saben que existe una carrera denominada Traducción e Interpretación, que se imparte en más de una docena de universidades españolas. No 
cabe duda de que la responsabilidad de esta falta de comunicación recae en gran medida en la universidad, pues debe ser ésta la principal interesada en establecer acuerdos con el mercado profesional privado para el cual están preparando a sus alumnos. Es un mero hecho de visibilidad: la facultad sabe que existe una empresa para su carrera, pero la empresa especializada puede que no sepa que existe la facultad que produzca futuros empleados o proveedores. ¿Esperamos, quizá, como en otros países, que las empresas acuden a las facultades a buscar a sus alumnos?

En definitiva: la profesión del traductor está extremadamente vinculada a las tecnologías y a un mercado laboral especialmente competitivo. El estudio y conocimiento de estos dos aspectos -desde las aulas- es esencial para el desarrollo profesional del licenciado.

\section{LA VIGILANCIA DE LA CALIDAD O EL LINGÜISTA COMO ACTIVISTA}

Un viajero y escritor inglés que pasó por España a mediados del siglo pasado decía que aquí «se tenía más costumbre de protestar en los bares y botillerías que en el Parlamento».

Esta visión tan acertada del talante español también se aplica a los traductores de audiovisuales. Es lo que yo denomino queja improductiva, esa que no genera nada bueno excepto frustración y enconamiento. He dado y doy cursillos y conferencias sobre Internet, teletrabajo y traducción para alumnos de muchas facultades de traducción. Miles de estudiantes de casi todas éstas han asistido a algún curso mío. El $99 \%$ de los alumnos que asistieron a mis cursillos admiten haber visto películas mal traducidas y admiten asimismo haberse indignado por la gravedad de los errores de traducción que habían visto u oído en la pantalla. El $99 \%$ de estos alumnos reconoce, sistemáticamente, no haber hecho nada por cambiar la situación. Tan sólo se quejan pero se quejan mal. Se quejan ante sus padres, ante sus amigos, ante sus profesores... creando un círculo de frustración constante y sin salida. Buscan chivos expiatorios, como el intrusismo, la falta de lectura y el sursuncorda. La causa del mal empieza en uno mismo. A nadie se le ocurre quejarse ante los responsables de esa mala traducción, llámese departamento de producción ajena de la televisión de turno, departamento de doblaje de la distribuidora cinematográfica, etc. Quizá vivimos en un país en el que, durante decenios, quejarse equivalía a marginar$s e$. Quizá concebimos la queja como una cuestión personal en lugar de un simple ejercicio de corrección. Pero la pregunta es: ¿si no nos quejamos los que podemos y sabemos hacerlo, quién lo hará? La queja dinámica es ese proceso de retroalimentación que mejora la relación entre el servicio y la calidad. Las 
quejas, cuando están fundadas, suelen conducir a mejoras. He comprobado personalmente que muchas empresas ignoran que sus productos están mal traducidos porque nadie se tomó la molestia de decírselo.

Con que cada uno de los miles de alumnos de traducción y traductores profesionales enviase una sola queja en su vida (justificada y razonada con argumentos válidos, y en un tono respetuoso), cambiaría notablemente la visión que de nuestra profesión tienen las empresas, los destinatarios de las traducciones y los propios traductores. El proceso de dignificación de esta profesión pasa por nosotros mismos y nuestra queja, que no sólo es un derecho, sino una obligación. 


\section{EXTRANJERIZACIÓN O ADAPTACIÓN}




\title{
CLONING CULTURES: THE RETURN OF THE MOVIE MUTANTS
}

\author{
Candace Whitman \\ Universität Saarbrücken
}

Man to friend: "So where are you living now?" Friend in financial straits: "One step ahead of the finance company."

"¿Dónde vives ahora?" "Justo al lado de la compañía de finanzas."

\section{A STEPAHEAD ERROR ANALYSIS}

Although amusing, mistranslations based on simple misunderstanding are of little linguistic interest. What is more intriguing for the linguist and translator than error analysis (an academically approved form of one-upmanship) is going one step beyond and asking what happens when understanding is clear, mastery of both source and target language is a given, and yet translation falls short. What is of even greater interest and, above all, need, is an approach to tackling the problems posed with exasperating regularity in the dubbing of motion pictures.

Challenges come in all different flavors. Puns and double entendres in general translate very poorly into other languages. Words and phrases susceptible to more than one interpretation need to be first analyzed. What is the wordplay based on? A homonym, homophone, double entendre, mispronunciation? Is the pun linked to some action happening in the film, some gesture made by the actor, some object we see on screen? What exactly needs to be reconstructed in the target-language version of the film? 
In one scene from Green Card (Peter Weir, 1990), the translator is confronted with a common linguistic hurdle. The background: Andie MacDowell has secretly married Gerard Depardieu so that he can be granted a work/residence permit, a Green Card, to live in the United States. They have not revealed the marriage to her parents, who arrive unexpectedly one afternoon for a visit. MacDowell has instructed her new husband to pretend he is a carpenter making repairs in the kitchen. As she and her parents are daintily sipping tea in the sitting room, the 'carpenter' enters and, in broken English (he is, of course, French), he announces: "I need a screw!" The camera pans to a close-up of the shocked parents' faces, then to the awkward, nonplussed look on their daughter's face. The carpenter/husband repeats the line.

The gag, of course, works on the polysemy of the word 'screw'. Well, what does the translator do here? He needs a word that refers to both sexual intercourse AND some tool or piece of hardware. At the very least, he needs some word preferably having to do with carpentry or kitchens - which can also be construed to mean something obscene that would justify the shocked expressions of the American family.

The final German translation of this, by the way, does no such thing. The word used is 'Schraube', which does refer to the hardware, but has no sexual connotations. The camera close-up, the shocked facial expressions, the 'held beat' in the rhythm of the scene all make no sense when the audience hears the one-dimensional German translation. Apparently, this did not disturb the translators.

There is, conveniently enough, a perfectly good German solution, just begging to be used: 'nageln', a word meaning 'to nail' and a slang expression for 'to engage in sexual intercourse'. Did the German translators think their solution was adequate? Why the parents' indignant reactions? Why the camera angles underscoring the joke? Why indeed the whole scene itself, the only purpose of which is to set up that line?

Perhaps the translators thought there was nothing to be done here. The translation clearly falls short, yet such inadequacies are frequently apparent in dubbed movies. This brings me to my conviction that there is no such thing as 'untranslatability', a term I hear all too often when collaborating with directors and translators working on dubbed versions of American movies. 'The argument

1. Some scripts make it all the way to the screen with their sins upon their heads. Others, by virtue of the intercession from source language collaborators, undergo a more exhaustive vetting process. Thus, the repeated reference in this paper to "originally submitted translation", "translation first handed in", etc., as opposed to "ultimately recorded translation", "final translation", etc. The source language collaborator's job is to spot any shortcomings and nip the linguistic (as well as dramatic and sound) problems in the bud before they reach the screen. 
against searching for an adequate translation of a polysemic wordplay usually runs: "We don't have that in French" (or Spanish or German). Well, admittedly: it may not work to use the direct translation of the particular word or expression in the target language. But there is always a solution lurking somewhere. You merely have to indulge in a little linguistic acrobatics to find it.

One pointer: forget about actual word used. You are indeed not a dictionary. Think panorama, that is, think overall idea, and not detail. What, analytically speaking, is going on in terms of humor or word-juggling? A possible technique to solve the above translation problem would be to scan a catalogue of all words in the target language which have sexual reference and see whether you are fortunate enough to find one that has to do with carpentry. That is, start with all the naughty words until you hit something usable. And if carpentry provides you with no lexical area to bounce off from, make the new husband a plumber or a kitchen installer.

\section{PLAYING WITH LANGUAGES}

Here is another example: In The Bird Cage (Mike Nichols, 1996), a remake of La Cage Aux Folles (Edouard Molinaro, 1978), Robin Williams' character, Armand, a gay father posing as a heterosexual, is serving dinner to the bourgeois parents of his son's fiancée. The mother of the bride-to-be queries whether it is an egg she sees in the soup:

ARMAND: Yes, it is. It's a 'huevo'. It's so Guatemalan. They put hard-boiled eggs in everything down there. You know, chicken is so important to them. It's their only real currency. A woman is said to be worth her weight in hens, and a man's wealth is measured by the size of his cock.

The problem here is more than the sexual pun at the end of the line ('cock' is not only a farm animal but a slang word for male genitals). He also uses the word 'huevo' since the soup was made by the Guatemalan houseboy, who in the original movie has a heavy, comic Hispanic accent. (In the Spanish version of the movie, the Guatemalan was turned into a Cuban, since the latter accent was more recognizable as a contrast to the Castilian Spanish spoken by the other characters.)

The Spanish translation became:

Desde luego. Es un ovo caribis. Eso es algo muy típico del Caribe. Los caribeños ponen huevos duros en todo lo que hacen porque, ¿sabe?, las gallinas son muy importantes para ellos. La gallina es su única moneda de cambio real. De una 
mujer se dice que vale su peso en gallinas. Y la riqueza de un hombre se mide por el tamaño de sus huevos.

The use of 'huevo' ('egg') in the original English has now been changed to 'ovo caribis' and the word 'cock' has now been replaced by the equally ambiguous 'huevos' (a slang term for 'testicles').

The Bird Cage also provides us with another common entanglement encountered in the dubbing of movies, not only from English films, but any one language to another: the rendering of an accent which was foreign in the original, but, once dubbed into that particular foreign language, now no longer stands out from the rest of the dialogue. The houseboy's Spanish accent must somehow be retained in the Spanish version of the film, accomplished in the Castilian version of The Bird Cage by giving the houseboy a Cuban accent.

What about a scene, however, in which one of the original characters speaks in a foreign language, that is, the foreign language into which you are dubbing the entire film? In September (Woody Allen, 1987), the film opens with a shot of an older woman taking a French lesson. We later learn that the high point of this woman's life was a romantic involvement with a Parisian piano player in the Quartier Latin in her youth. Now she is learning French with the hope of one day returning to the site of her youthful romance.

What to do in the French version? She cannot very well struggle through the French lesson, stuttering words out with an American accent, then be heard speaking flawless French in the next scene. Linguistic transplantation surgery must be performed. In the final French version, the Rive Gauche bohemian piano player was transformed into a gondolier, the French lesson became an Italian lesson, and the woman's nostalgic yearnings harked back to Venice.

In The Prince of Tides (Barbra Streisand, 1991), Barbra Streisand's character, a sophisticated, educated psychiatrist, takes Nick Nolte's provincial Carolina football coach out to dine at a chic French restaurant in New York. He takes one look at the menu and confesses to not understanding a word, thus allowing Streisand to read the French dishes aloud and show off her cosmopolitan breeding. What now in the French version? All of the characters are obviously speaking fluent French, including Nick Nolte. Why then would he not understand the French menu and how do we write into the script Streisand's cultured background? Normally, if it were a purely linguistic difference, the restaurant could be made into an Italian pizzeria or a Greek tavern. Here, however, the French dialogue writers claimed that Streisand could not be vaunting her sophistication with any cuisine other 
than Gallic. They refused to transplant the scene to any other foreign food establishment. The scene had to be played with Streisand's character not more knowledgeable of another language, but of the high culinary art of the dishes prepared; in other words, she no longer was displaying her language ability, but her gastronomical expertise.

\section{CULTURAL REFERENCES}

Movies are originally made for an audience of one culture and language community. Writers and directors of the original work make certain assumptions about their audience - for example, that they will all understand a particular play on words, a particular allusion to an event known in that particular culture. the use of a lexical item, the mention of a historical figure, celebrity, the quoting of lines from well-known TV commercials, political campaigns, etc. The assumption is that the audience all share certain collective experiences, a common background. The translation of such material is what adaptation is all about. The spoken material must be re-sculpted to fit the mold of a new cultural setting.

In one scene from The Bird Cage, we see the Hispanic houseboy, Agador, dressed in his transvestite outfit: bouffant red wig, bikini top and short, cut-off jeans. Robin Williams' Armand takes one look at him and dismisses him as "Lucy's stunt double", whereupon the houseboy responds, "Actually, I'm a combination of Lucy and Ricky."

Lucy and Ricky are examples of a cultural allusion which mean nothing to many foreign audiences. The characters appeared in an American television show of the 1950's which starred Lucille Ball, a comic, red-headed actress married in the series to a Cuban bandleader, named Ricky Ricardo. The foreign audience cannot be assumed to know the reference, nor the visual images associated with the characters, nor what the names evoke in the listener: the Latino roots and masculinity of the cliche role of Ricky and the colorfulness, comedy and blowsiness of Lucy.

Translation means being aware of the intent of the original as well as the target audience's common pool of allusions. The solution still has to be 'faithful' in that, although changed, the names mentioned still have to retain elements of the original (the campiness, the 1950's setting) as well as incorporate the unalterable visual features (the overdone hairdo and frilliness of Agador's transvestite getup) coupled with his Latino accent and bare-chasted machismo. The solution was:

Parece que eres el doble cachas de Carmen Miranda.

Soy una combinación de Carmen y Johnny Weissmuller. 
Here two celebrities were selected from the 1950's: one a flouncy, extravagant Latina actress usually seen doing the mambo with bananas and pineapples piled on her head, along with the actor who played Tarzan, the epitome of masculinity, typically seen shirtless, swinging from vine to vine. Thus, a perfect replacement for Lucy and Ricky. By being unfaithful to the letter, we are even more faithful to the spirit.

What is crucial is that the translator must not whitewash, not render it bland by translating with the generic abstract. In the Lucy and Ricky line, for example, we must avoid translating as: "You look like a floozy actress" ("Pareces una actriz chabacana'). The target audience must be given a name they recognize, even if it is not the same name used in the original.

Yet a word of caution: we cannot have a line which could never have occurred in the original American movie. The target audience will recognize it as a patchon. For example, we could never have translated Lucy and Ricky with Sarita Montiel and Manolete. Nobody has ever heard of these people in the United States. It would jar the Spanish audience out of the American context. Even though we are listening to Spanish, we know that the action is taking place in America. Spanish is not really Spanish. It is just a replacement, by convention, for English. Thus, if the people mentioned in the original are 'international' enough, we can retain them. If they are only locally known in the movie's original setting, they must be re-invented. The television host, Jay Leno, played himself in The Bird Cage and was written the line: "We'll be right back with Colin Powell and Kate Moss." The incongruous pair was rendered with "Yasar Arafat and Claudia Schiffer" in the foreign versions.

Another common rhetorical device in humor (and thus in movies) is what I will call the 'twisted idiom' (e.g., in Stuart Little [Rob Minkoff, 1999], the little mouse says to the pet cat, "I think we got off on the wrong paw.") Surprisingly frequent in movies, these twisted idioms also include culture-specific references. Difficulties are greatly compounded.

The National Enquirer, the yellow press newspaper featured in The Bird Cage which sends the scandal-scrounging journalists to snoop into the sex life of the Republican politician, is indeed a real publication available in the United States. The paper has existed for decades and alone the name of the paper automatically evokes in the listener notions of sleaze-mongering and unethical journalistic practices. Obviously, leaving the name 'National Enquirer' would not have elicited the same response among the audience.

The following are the solutions in Spain, France and Germany. 
a) Washington Morbo (a fictitious name clearly connoting scandalmongering).

b) Ici Washington (an allusion to Ici Paris, the equivalent of The National Enquirer in France).

c) Washington von Hinten (incorporating in the name an expression that means both 'behind the scenes' and 'from the rear').

Yet the problem becomes pricklier when reference to the paper is used to twist an already existing idiom. In the same film, one journalist discovers that the conservative politician is spending the evening in a transvestite bar. He turns to his colleague and remarks, "We are in Enquirer heaven." The original expression, 'I'm in pig heaven', means 'I couldn't be happier', 'I'm delighted'. The original translation submitted for this line in Spain was: "El paraíso del Enquirer es nuestro", which is not only devoid of emotional impact, but perilously close to being devoid of meaning. The object here was to reconstruct the idea of the journalists' delight at having arrived at the height (heaven) of sleazy journalism.

The Spanish, French and German solutions were as follows:

Gracias a la santa prensa del morbo. (Subiremos a los altares del morbo was a runner-up.)

On est a Paradis sur Presse. (Evoking the name of a location, such as Épinaysur-Seine.)

Wir sind im siebten Skandalhimmel. (A play on 'We're in seventh heaven'.)

We should remember that the audience reaction to a funny line is far more important than any literal fidelity to the original sense.

In one more scene from this movie, the gay couple has invited the conservative politician and his wife to dinner. We see the wife inspecting the newly 'redecorated' house, emptied of campy gay furnishings and paraphernalia and hastily filled with whatever accoutrements the transvestite entourage thought would be appropriate to the staid, bourgeois guests. The wife discovers some books on a sideboard: "Oh, look at all these books: Nancy Drew and the Case of the Burning Candle." The humor of the line is based on the inappropriateness of the choice of literature, a well-known series of books written for little girls. Nothing need be explained to the American audience.

Even if there is no real equivalent in the target culture, titles can be invented that evoke similar associations in the listener. In Spain, the solution "Vicky la Huerfanita y el Caso Misterioso de la Vela Encendida", incorporated all the elements of little-girl-literature: a little orphan girl and an image reflecting 
mystery. The German solution: "Hanni und Nanni und das Abenteuer auf dem Bauernhof', rhyming two little girl names, incorporating the word 'adventure' and the locale where many children spend their holidays.

An amusing problem occurred in the French dubbing of Big Daddy (Dennis Dugan, 1999), a film in which a young girl leaves her coeval boyfriend and embarks upon a romance with an older man. Jealous, the former boyfriend often derides his replacement's age. "Now she's banging the Pepperidge Farm guy", a reference to the old man in a series of well-known commercials advertising Pepperidge Farm bread. It was debated whether the same funny image could be transported by using the entire title of the novel The Old Man and the Sea so that the French line would then have become, 'Maintenant elle baise le vieux et la mer.' Unfortunately, it then sounded vaguely incestuous since 'sea' ('mer') and 'mother' ('mère') are homonyms.

I would like to offer another example of a cultural reference, interesting not because it is a particularly witty line, but because it illustrates a creative solution and can open the translator's mind to the flexibility possible - indeed requiredin rendering movies in another cultural context. Again the example is from The Bird Cage. Asked to describe his drive from New England to Florida, Gene Hackman's character, the Republican political candidate, waxes eloquent on the beauty of the American countryside in autumn.

Talk about your purple mountains' majesty!

The reference to the song America, the Beautiful is immediately recognizable by any American. Equivalent foreign lines (Einigkeit und Recht und Freiheit; Allons enfants de la patrie; Con el azul del mar y el caminar del sol) are obviously unusable in an American context. A word-for-word translation of the lyrics will also remain opaque for the target audience. Here, what is needed is some creative leaps.

In Germany, the actor dubbing Gene Hackman actually hummed the translated lyrics, making it clear to the audience that these were lines from a song. In Spain, after the flowery translation of the lyrics, "sus majestades las montañas púrpuras", the words "como dice la canción" ("as the song goes') were added. Some happy ground must be located between the blunting of cultural exactitude and the use of inappropriate parochial allusions.

Let's take a look at a scene that uses a literary reference in a playful use of words and dialogue. In Annie Hall (Woody Allen, 1977), one by now classic scene shows Alvy and Annie waiting in line to see a film. They are having a quarrel about their relationship and Annie continues to raise her voice inappropriately to the social situation: 
ANNIE: OK, my sexual problem. $M y$ sexual problem!

Alvy (embarrassed that others nearby have surely overheard): My Sexual Problem. No, I've never read that. Wasn't that by Henry James? The sequel to The Turn of the Screw?

Here the joke resides in Alvy's turning Annie's remark into a book title. insinuating that it is the sequel to a novel by Henry James, the title of which has nothing to do with sexuality, but does contain a word ('screw') which is also a slang term for sexual intercourse. The Spanish film translation was as follows:

No lo he leido. Es de una novela de Henry James, ¿verdad? Es la continuación de La vuelta de tornillo.

This translation misses on several counts. Most important, there is no sexual pun in the title of the novel that Alvy names so that there is nothing funny about the line, which sounds like a non sequitur in the target language script. The Spanish audience can probably also not be expected to know Henry James and if they did, they would not recognize the title of the novel, which was mistranslated to boot (Otra vuelta de tuerca was the authentic Spanish title). What we end up with is an unskillful translation, inaccurate and unsuccessful.

A phrase must be found which: 1) sounds like it could be the title of a novel; and 2) contains a word used in an innocent, non-sexual sense, but one that also could carry a sexual meaning. If there is no real title that lends itself to this end, one must be invented. One in Spanish might contain an expression such as 'polvo de estrellas', an innocent enough term meaning 'stardust', but also incorporating the word 'polvo', which is indeed a slang term for sexual intercourse.

\section{HURDLES: VISUALLY-LINKED CULTURAL REFERENCES, ACCENTS, RHYMES}

Let's raise the bar a bit. The following is an example of a culturally specific line that is at the same time linked to picture. In Good Morning Vietnam (Barry Levinson, 1987), Robin Williams plays an insubordinate radio disc jockey working for the US Armed Forces in Vietnam. In response to an impertinent remark, his superior officer points to the chevron of stripes on his sleeve and asks rhetorically, "See that? Three up and three down. What does that mean to you?" Williams replies, "The end of an inning?" ('Three up and three down' might be a baseball commentator's description of an inning in which three players get up to bat and are retired one after the other.) What is assumed is that the 
audience knows the rules and terminology of baseball. Equally challenging, remember, is that we are now bound by the image of the chevron stripes on the officer's sleeve, which are obviously immutable.

The line must not be translated literally. It would not be funny and, more important, it would be devoid of meaning for the Spanish audience. The original line is intended to produce a laugh and that is what we have to do in the translation. It is too easy to claim that this line is untranslatable.

For the Italian and German audiences, the following solutions were found:

Tre sopra e tre sotto. ('Three on top and three on the bottom') Che cosa significa perte?

Un' ammucchiata? (a term meaning 'a heap' and used to refer to a sexual orgy)

Drei oben und drei unten. Was bedeutet das für Sie?

Ein kleiner Gruppensex?

In France, the popular design of the chevron throughout the country as a logo made the following line possible:

Trois en haut et trois en bas. Qu'est-ce que ca evoque pour vous?

Une agence de Citroën?

One of the most problematic things about American movies is the fact that American directors conceive of and play to American audiences. Even though the box office figures should prompt otherwise, no real account is taken of the huge numbers in the foreign audiences. And the burden falls on the foreign translator.

\section{ACCENTS}

As seen earlier, accents in the original present another hurdle, confronting us with perhaps the trickiest of challenges. Any pronunciation color, whether it stem from a foreign language, a social or geographical dialect of the source language, an imitation of a well-known person (actor, politician, etc.), carries with it undeniable, intricate messages, interpreted by the original film-going audience with surprising consistency.

A case in point: In The Bird Cage, we have a scene in which Robin Williams imitates John Wayne's voice, accent, inflection. So now what? English speakers or those familiar with the real voice of John Wayne will all recognize the imitation. But the dub-going audience cannot. If John Wayne's dubber had a characteristic way of talking, the dubbed version of the film could simply imitate that. This, however, will be the exception. 
The content of the line, the words Robin Williams uses, are not as important here as the way he says it, and the way he says it cannot be duplicated. Here the solution is to change text in order to awaken the same response among the audience as the paralinguistic effect of the accent.

The original line was:

Just get off your horse and walk into the saloon.

The following lines were dubbed in the foreign versions:

SPANISH: Yo que tú, forastero, no cruzaría el Mississippi (incorporating the common lexical term in cowboy movies, forastero, and improvising the evocative expression 'crossing the Mississippi').

FRENCH: Tout le monde a cheval, les autres viennent avec moi (using the wellknown, humorous nonsensical line: 'Everybody get on your horses. The rest of you come with me.').

GERMAn: Steig von deinem Gaul ab und räum in Saloon auf (choosing the more old-fashioned term for 'horse' and using the anglicism 'saloon').

In order to elicit a similar response, very different stimuli must often be used. The point again, though, is that often the only way to be faithful to the original is by betraying it.

\section{RHYME}

I would like to cite one more example of the creativity needed in dubbing. Translators are often daunted by rhymed lines, understandably, considering that the chore of meeting sync standards as well as content is now compounded by adding rhyme and meter exigencies. The result is that the translator/dialogue writer quite frequently surrenders and simply ignores rhyme.

The following example has been again taken from The Bird Cage. Nathan Lane's comedic talents are displayed when he succumbs to a baker's freshly made pastries, feigning helplessness in the face of temptation:

When the schnecken beckons!

The original Spanish solution suggested by the translator was: "Cuando los schnecken te reclaman", a literal translation imparting irrelevant denotative meaning yet adding nothing to the humor present in the original. 
The versions which were ultimately put on screen were:

SPANISH: Las rosquillas me hacen cosquillas.

FRENCH: Un petit schnecken pour chacun.

GERMAN: So wie die Schnecken schmecken.

It is surprising how often translators make the mistake in such cases of translating content and not form. What is important is that the translator not throw up his hands in defeat. It is all do-able: what it takes is a flexible, creative approach to what is required for the rendering of the original intent. And certainly, a good eye for what is going on in the source language. This is indispensable: the translator must recognize what is operating linguistically, dramatically, lyrically in the original. Here is where so many mistakes arise.

\section{COMMON PITFALLS}

Let's get back to principles. Basically, what makes a good translation? Or, put more negatively, what makes a bad translation, that is, where do things go wrong?

One common defect in dubbed versions is that the target language text often loses in color, liveliness, and punch. Variety is translated with sameness, originality is translated with banality and living color is translated in black and white.

In Nobody's Fool (Robert Benton, 1994), starring Paul Newman, fifteen words were used to call people stupid. There was: 'idiot', 'pea-brain', 'airhead', 'schmucko', 'doofus', 'moron', 'rubber-head', 'numb-nuts', 'pinhead', 'jerk', 'smart-ass', 'dimwit', 'dummy', 'bonehead', and 'sucker'. In the text originally submitted to the Spanish dubbing studio for recording, all of these terms were translated as either idiota or estúpido. In the end, the foreign dialogue included: idiota, estúpido, imbécil, tonto, bobo, capullo, memo, tarado, necio, mamón, lerdo, lelo, tontorrón, cretino and gilipollas.

A script comes alive from these details. I have often been told by my dubbing collaborators that a word, phrase or some problem we were struggling with was "just a detail" and hence, not so important. But a script is nothing more than a series of many details laid end to end from the opening credits to the final fade out. Ignoring that, one detracts from the power of the whole. I do not think, therefore, that the homogenizing of the language in Nobody's Fool was an insignificant flaw in the original translation. I think it is a serious flaw. We lose the life, the power, the vibrancy of a script. Fifteen terms translated with two 
takes all the air out of the balloon; all you are left with is a piece of deflated rubber in your hand.

Moreover, language carries a social message. The people who say 'great' are different from the ones who say 'awesome', and are different from the ones who say 'marvelous'. Every generation and social class has its own word for praising something. Unfortunately, the dozens of words used in original films to mean 'great' ('super', 'cool', 'fantastic', 'terrific', 'awesome', 'far out'. 'marvelous', 'fly', 'phat', 'splendid', 'wonderful' and 'too much') are usually all translated in Spanish, for example, with estupendo. The job of the translator is to find the corresponding word, the word that carries the same social charge. the same connotations, the word that reflects the same characteristics of the speaker. In Spanish, you can indeed choose between, for example: genial, fantástico, alucinante, maravilloso, espléndido, de puta madre, molón, guay, demasié, chachi and cojonudo. This is not just variety for the sake of variety. A character is born into and out of his vocabulary.

Along the same lines of puncturing buoyancy, I would like to give you real solutions originally submitted to translate lines from Nobody's Fool.

Whenever Paul Newman's superstitious character, Sully, deals cards for poker, he recites a brief incantation to bring him luck. His colorful and unique line: "Red river round a green monkey's ass" was originally translated as: " $A$ ver si tengo suerte" ('Let's see if I get lucky'). The distortion of the character is patent. After the dubbing script was rewritten, the line read "Abracadabra, coño de cabra", a vulgarized modification of the common words spoken before magic.

The relationship between Bruce Willis' character and Sully was often reflected in the male banter between the two of them. In one exchange, Willis asks Newman (after having been outsmarted by him), "How they hangin'?", to which the other replies, "By a thread", an amusing play with language combining the 'hanging' from the male greeting with the idiom 'to hang by a thread'.

The first translation of the line was:

¿Cómo va eso? ['How are you doing?']

Bastante mal. ['Pretty bad.']

This was ultimately changed to:

¿Qué huevos tienes! ['You've got some balls']

Sí, revueltos. ['Yeah, scrambled.']

The originally proposed translation completely obliterates the camaraderie, the complicity, the macho flavor of the relationship between the two men, as 
well as the humor of the exchange. The dialogue becomes flat, dull and boring, and more serious, unmemorable. We have, moreover, again distorted the characters in the original movie.

The simplicity of the following example makes it paradigmatic. Paul Newman's character in Nobody's Fool has been sentenced to a week in the local jail for punching a policeman. He tells his son about this euphemistically: "I'll be taking a little vacation at the county's expense", a line with patent irony. This was originally translated as: "Voy a pasar una temporada en la cárcel" ('I'm going to spend a while in jail').

To translate "at the county's expense" with "en la cárcel" yet again detracts from the character himself, not just from his words: the character is his words. We lose what makes him appealing to the audience; we lose his color, his wryness. Instead of ladling some insipid cream sauce over the spice of the original line, we might try instead: 'Voy a disfrutar de unas vacaciones pagadas por el estado.'

Again, a prime crime in rendering screenplays into other languages: the translation of solely denotation, neglecting form, overlooking connotation, and sacrificing what lexical choice, use of register, allusions, etc., inspire in the listener - all the rhetoric devices that add life to a text. What we are interested in here is dramatic impact of language.

Another wrong turn frequently taken is what I will call the specific-to-generic misstep, that is, taking the specific, concrete and explicit and translating it with the generic, general or abstract. A case in point: in Crazy in Alabama (Antonio Banderas, 1999), a line said by a twelve-year-old Alabama boy explains his and his brother's affection for their Aunt Earlene:

PEEJoE: We liked her because she introduced us to Poptarts, Koolaid and Chef Boyardee.

These are three staples of the American canned food and ready-to-eat diet (packaged jam-filled wafers ready for the toaster, an instant powdered beverage and lasagna in cans). The originally submitted Spanish translation was:

[...] porque nos enseñó que se puede comer bien incluso de latas.

['because she taught us that you could eat well even from cans.']

Removing the proper names from the translated line also removes all wit and humor, the child becomes more rational and less child-like, less ingenuous, less appealing. The brand names being unknown in Spain, the solution is to find graphic descriptions of unappetizing products which avoid diluting the color of the original. For example, 'tarta al minuto', 'pizza congelada' y 'limonada de sobre'. 
In France too, the line submitted by the translators were changed:

[...] parce qu'elle nous a appris qu'il suffit d'ouvrir une boite de conserve pour bien manger.

['because she taught us that you only had to open up canned foods to eat well.']

The final French line became:

Elle nous a fait connaitre des tartes instananées, l'orangeade en poudre et les nouilles en boite.

In the end, I am convinced that to produce a top quality translation of a film, what is needed is both a native speaker of the source language and a writer of the target language. I say 'writer' and not 'translator', although what I mean is a translator who is also a writer, a creator. Poetry is translated by poets. Alexander Pope's translation of The Iliad and The Odyssey is in rhymed couplet, in other words, they are original works by a poet. Movies should be translated by those capable of creating an original screenplay. The translator must possess all the skills and talent that go to make a screenwriter: a feel for dialogue, speech rhythms, lexical and register nuances, along with the innate, unlearnable gift of knowing what makes a line funny, what makes a line actable, what makes a line powerful. 


\title{
CULTURE AND TRANSLATION. THE REFERENTIAL AND EXPRESSIVE VALUE OF CULTURAL REFERENCES
}

\author{
LAURA SANTAMaria \\ Universitat Autònoma de Barcelona
}

\section{DEFINITIONS OF CULTURE}

When discussing the advantages and disadvantages of foreignizing and domesticating our translations, we should not forget the external factors that shape translators' decisions as far as cultural references are concerned. I am not talking about the preferences outlined by the company paying for the translation or norms in the sense described by Toury (1980). Rather, I would like to underline the importance of awareness of how users of the translated text process the information deriving from the references to the original culture.

First of all, I would like to present a number of definitions of 'culture' to lay the basis for my interpretation of how different translation strategies may affect the referential and expressive value of cultural references.

1. Culture as the characteristic which differentiates human beings from nature

2. Culture as a synonym for society

3. Culture as a cognitive category

4. Culture as intellectual and social development

5. Culture as artistic manifestations

6. Culture as a social category 
This last definition, culture as a social category, has not been thoroughly contemplated by Translation Studies. Usually, as in Nida's (1975) and Newmark's (1988) work, theoretical reflection on this topic has set out from the second definition of the term, culture as a synonym for society, but they have paid little attention to the differences among the microgroups that exist within all societies, and, in consequence, to their linguistic and cultural environment. It seems to me that we should try harder, and go beyond merely defining societies as a whole, and, in fact, as real language users, we are able to discriminate much more. Indeed, we tend to form a given idea of different speakers, whether real or fictitious, not only according to their social and geographical dialect or behavior, but also according to the topics of their conversation and the cultural references they make.

By this, I am not implying that the other definitions of culture I have just presented are of no importance for translation. Indeed, even our perception of nature depends to a great extent on our point of view. The dividing line between nature and our vision of nature is not by any means a clear one, and this whole area is worthy of deeper study. This point could be illustrated by reference to Christopher Monger's film, The Englishman who went up a hill but descended a mountain. The plot illustrates how words make nature become culture: an English topographer goes to a Welsh village to decide whether it is going to be included in an atlas they are preparing, and it all comes down to whether one of the hills is tall enough to be considered a mountain. Speakers decide what they are going to call things, and the very act of naming something can have a special effect on it.

The other definitions of culture also influence decisions taken by translators during the translation process. In fact, they all show the necessity to account for the social microgroups present in societies. Some of these groups are more influential disseminating their perceptions, tastes, and attitudes. For example, not everybody enjoys visiting art galleries or exhibitions, although the majority of citizens would agree that art is important despite the fact that they might never show an active interest in it. Therefore, not all manifestations of culture enjoy the same status.

\section{THE ROLE OF IDEOLOGY}

A key concept in explaining the value ascribed to cultural objects which may belong to various groups in societies is ideology. Ideology allows each group to harbor a construct of symbolic forms, which at the same time serves to provide group cohesion. Despite the existence of numerous groups with different ideologies, and therefore different sets of values, humans are nevertheless organized in societies. Different groups share affiliation to the same society because there is a solid and homogenizing structure built around the dominant group in that society. 
The central social structures are the ones that bear the dominant ideology, while the peripheral groups can be termed dominated ideologies.

Ideologies play a two-fold role: they define the group internally, for each member to feel part of it, and externally, for members of other groups to recognize

it. Cultural references have a central function in the identification of individuals because they define their environment.

In order to recreate the fictitious background of characters in a film, it is important that translations reflect the whole set of attitudes that each cultural reference may give rise to. Therefore, faithfulness to the original wording may lead to mistranslation when viewers from different cultures interpret the cultural reference differently. Work done in cultural studies and sociolinguistics may help us to disentangle this point.

Going back once again to the last definition of culture, culture as a social category, it has to be stressed that not only do characters belong to different microgroups, but, in each film, the facts are also presented according to a given point of view. So, if translators do not want to produce an adaptation of a film, their aim must be to reproduce the intrinsic ideology of the group depicted in the film, and the ideology, or point of view, through which the plot is presented.

Social fragmentation in society is seen in all kinds of films. Let us take as an example the films Surviving Picasso, by James Ivory, and Michael Collins, by Neil Jordan. From the list of cultural references present in the original version and through the subtitles, we learn about the social groups that the director wanted to present, but not about the others. That is, you could be mistaken for thinking that Paris under the Vichy government was all art and painting, and we only find a few references to the Nazi invasion. Similarly, in Michael Collins we hardly hear about the Irish poets who were so involved in the struggle for Irish independence.

These two films then illustrate how each group within a society has its own ideology, or construct of symbolic forms, and that each director portrays situations from a different perspective, and, in consequence, he or she brings his or her own ideology to bear. The problem arises when some ideology, characteristic of a social group in the source culture, does not match with the social representations the target audience has for them.

\section{SOCIAL REPRESENTATIONS AND TRANSLATION STRATEGIES}

There is a third issue I wish to deal with together and which is closely related to the translation strategies chosen by translators: social representations. Social representation can be defined as "the end product and the process of a mental 
activity by which an individual or a group reconstructs the reality with which he or it is faced and attributes to it a specific importance" (Abric 1984: 170).

Thus, if we want to base our translation strategies on the principle of helping our target audience to socially locate any fictional situation or character, it is important that translators be aware of the cognitive processes that take place whenever we encounter something new.

Various authors (Farr and Moscovici 1984; Breakwell and Canter 1993: Lambert and Schanks 1997) have indicated how new information is integrated into the individual's system of social representations:

1. In a first stage, in a process called 'anchoring', and with the help of memory, we try to integrate everything into our system of mental representations. even if it is strange and different from what is already stored there.

2. In a second stage, termed 'objectification', the knowledge we have just acquired is integrated into the previous system. This process often leads to a subsequent reorganization of our previous classification of social representations.

Let us see a practical example of the first stage postulated above: when we go to the movies, we have some previous knowledge, sometimes merely limited to social stereotypes, but which also usually proves helpful for understanding the situations depicted in the film. For instance, if we decide to watch a film such as The van, we may probably go there with three Irish stereotypes in mind: religion. soccer and beer. But not all of these three topics have the same presence in The van. Therefore, we adjust our previous knowledge to the flow of information presented in the film. In turn, this new information will grow old and will become part of our previous knowledge for the next film we watch on Ireland.

With regard to the second point, objectification, when watching Michael Collins, I saw a Spanish word in the subtitles which was completely new to me, the term 'fenianos'. Thanks to my knowledge of Spanish, I could identify the word as an adjective for a group of people, but the question was: what group of people? Some minutes later, a new context helped me to realize that it was a synonym for Republicans. Therefore, the system of mental representations I had for the groups involved in the Irish struggle for independence was enlarged. After that, when I saw a second film, on a similar topic, The Devil's Shadow by Alan J. Pakula, and the word 'fenianos' appeared in the subtitles once again I felt relieved that I understood what they meant by it.

Although context, images in a film, helps us understand what is going on, it is also true that on other occasions context acts as a constraint. Let us take the film Lolita, by Stanley Kubrick. Lolita, her mother, and the professor who wants to seduce her talk about different topics to confirm the nature of their personalities for the audience. If we have to portray a superficial adolescent, her conversation. 
and therefore her cultural references have to comply with the viewers' expectations, defined according to their previous social representations.

Speakers of minority languages, since they are more used to being faced with translations than speakers of languages such as English, in which the majority of commercial films are produced, tend to more willingly accept situations linked to the original culture. Sirkku (1996) confirms this view. Whenever the target audience knows the reality described in the original text, it is easier for a foreignizing translation to be accepted.

Domestication, of course, has its own limitations. Rabassa (1996) reminds us of this when he says that 'gauchos' and 'cowboys' cannot be used interchangeably as a translation. In fact, the wish to learn more about 'gauchos' and 'cowboys', and their culture, can be a reason to go to watch a film or read a book. However, reference to the foreign culture has to be carried out in such a way that it builds up new knowledge on the basis of the previous information the audience of the target text may have on the foreign culture.

Sometimes the reference demands that the viewers have some previous knowledge of events taking place elsewhere. In Casablanca, by Michael Curtis, the French officer tells Rick, the character played by Humphrey Bogart, that his past reveals his political attitude. He informs the audience that Rick was in Spain in 1936 and in Ethiopia in 1935. The only way these two references can make any sense is in association with the struggle for freedom taking place in those countries at those times. It is also helpful to turn to cognitive studies to learn how the referential, and expressive value, of Spain and Ethiopia can be recovered. The reference was censored in the dubbing of the film during the dictatorship in Spain.

\section{CONCLUSIONS}

Translators then must be aware of the fact that viewers of dubbed or subtitled films will interpret cultural elements, that is, they will assign them expressive value from the referential value, according to the previous knowledge they have of any given cultural reference.

This is the reason why different translation techniques may be used in the same translation, producing the effect that translators have not followed a coherent strategy throughout the translation. For instance, in the translation into Spanish of the film The Devil's Shadow, we find that the word 'marine' is borrowed from English (basically because this branch of the American army is well known is Spain), while 'RUC officers' become "policías del Ulster", and the word "residencia" is used to translate 'green card'. 
As a general conclusion, I would like to underline that when translating cultural references, the priority must be to reflect a particular social reality in such a way that viewers can understand it through the usual cognitive processes.

\section{REFERENCES}

ABRIC, J.C. (1984): 'A theoretical and experimental approach to the study of social representations in a situation of interaction' in FARR, R. M. and S. Moscovici, Social Representations, Cambridge and Paris, Cambridge University Press and Editions de la Maison des Sciences de l'Homme.

Bourdieu, P. (1993): Sociology in Question, London, SAGE Publications (Translated by Richard Nice).

Breakwell, G.M. and D.V. Canter (eds.) (1993): Empirical Approaches to Social Representations, Oxford, Clarendon Press.

Fairclough, N. (1989): Language and Power, New York, Longman.

FARr, R.M. and S. Moscovici (1984): Social Representations, Cambridge and Paris, Cambridge University Press and Editions de la Maison des Sciences de l'Homme.

Hechter, M., L. NAdel and R. Michod (eds.) (1993): The Origin of Values, New York, Aldine de Gruyter.

Lambert, K. and D. Schanks (1997): Knowledge, concepts, and categories, Cambridge (MA), MIT Press.

Newmark, P. (1988): A Textbook of Translation, New York, Prentice Hall International.

NidA, E. (1975): Componential Analysis of Meaning. An Introduction to Semantic Structures, Paris, Mouton.

Rabassa, G. (1996): 'Words cannot Express... The Translation of Cultures', Translation Perspectives, IX: Translation Horizons Beyond the Boundaries of Translation Spectrum, 183-192.

SIRKKU, A. (1996): Acculturation of the Other. Irish Milieu in Finnish Drama Translation, Saarjärvi, University of Joensuu Publications in the Humanities, 17.

Toury, G. (1980): 'The Nature and Role of Norms in Literary Translation' in Toury, G. (1980): In Search of a Theory of Translation, The Porter Institute for Poetics and Semantics, Tel Aviv. 


\title{
DOBLAJE Y NACIONALISMO. EL CASO DE SANGRE Y ARENA
}

\author{
Ana BaLlester \\ Universidad de Granada
}

\section{INTRODUCCIÓN}

El año 1991 marca un hito en la investigación sobre traducción audiovisual (en adelante, TAV). Ese año, Martine Danan (1991) cuestionaba por primera vez las motivaciones económicas del doblaje y defendía que la elección de esta modalidad en Europa, y especialmente en Francia, había estado vinculada a una política nacionalista. Hasta entonces, la preferencia por el doblaje o por la subtitulación como modalidades de traducción cinematográfica se había explicado en términos de rentabilidad económica: ${ }^{1}$ mientras que los países dobladores, como España, Italia, Francia, Alemania o Gran Bretaña, cuentan con un mercado importante, otros con una población menor, como Bélgica, Suiza, Holanda o los países escandinavos, se han visto obligados a subtitular. ${ }^{2}$

Como Danan respecto a Francia, nosotros estamos convencidos de que la opción del doblaje en España estuvo motivada por una política nacionalista (Ballester, $1995 a$ y $1995 b$ ). Nuestra opinión está basada, por una parte, en el discurso cinematográfico y político que se produce en España desde que nace el

1. El coste del doblaje es, según Shuttleworth y Cowie (1997: 161), quince veces superior al de la subtitulación.

2. Defensores de esta posición son, por ejemplo, Reid (1977: 428), Nir (1984: 82), Luyken (1991: 32, 181) o Whitman (1992: 18-19). 
cine sonoro, a finales de los años veinte, hasta que se impone obligatoriamente el doblaje en España, a principios de los cuarenta y, por otra, en las estrategias concretas que se emplearon en la primera traducción para doblaje de una película americana, Blood and Sand (Rouben Mamoulian, 1941) (Ballester, 1999). Desde una perspectiva sociosemiótica y polisistémica de la traducción, resumimos aquí estos dos aspectos del doblaje en España sobre la base, compartida entre otros con Lambert (1988: 222), de que las estrategias de traducción en el doblaje no vienen sólo dadas por consideraciones puramente lingüísticas, sino que están condicionadas por la función sociocultural de la traducción.

\section{EL NACIMIENTO DEL CINE SONORO. EL DOBLAJE COMO SOLUCIÓN}

La instauración del doblaje tanto en España como en el resto de los países que lo adoptaron como principal modalidad de traducción cinematográfica viene precedida de una lucha de poder que se origina en 1927, cuando aparece el cine sonoro. Desde 1927 hasta 1932-35, EE.UU. libra una batalla linguíisticocultural con algunos países de Europa en la que el doblaje -coincidimos con Danan- emerge como solución de consenso.

El origen del conflicto está en el carácter nacional que el cine adquiere con la sonorización de la palabra. Al incorporar sus voces, los personajes cinematográficos dejan de ser universales: la lengua, necesariamente, les da una identidad cultural. De ahí que, con el sonoro, el público empiece a querer ver películas no sólo en su propia lengua sino también sobre su propia cultura-especialmente en los países europeos con mayor conciencia nacionalista- y reaccione con verdadera hostilidad ante el cine americano, que, desde finales de la Primera Guerra Mundial, mantenía una posición hegemónica en el mercado internacional.

El conflicto se calma cuando se instaura el doblaje. Con él, como desvelan las estadísticas, Hollywood recupera la supremacía que había ido perdiendo desde 1927. Su éxito - de nuevo, coincidimos con Danan- radicó en que, al ser económicamente rentable tanto para Hollywood como para los países importadores de sus películas, atenuó el carácter extranjero del cine americano y apaciguó así el sentimiento nacionalista de los públicos locales. El doblaje fue, por tanto, una solución de consenso.

\section{DOBLAJE Y NACIONALISMO EN LA ESPAÑA DE POSGUERRA}

Aunque en España el doblaje se empezó a usar en tiempos de la República, se implanta obligatoria y definitivamente con la Orden de abril de 1941. A 
partir de ese momento, y hasta diciembre de 1946, queda prohibida la proyección de películas extranjeras en versión original o subtitulada.

El padre de la historiografía cinematográfica española, Román Gubern, desarrolla en su libro sobre la censura franquista (1981: 51-68) varios argumentos que hacen pensar que la decisión de doblar en España fue más política que económica.

Desde el punto de vista ideológico, la Orden de 1941 se inscribe en el periodo inmediatamente posterior a la Guerra Civil (1939-1945). Marcados por un predominio de militares y miembros de Falange en el Gobierno, la firma del tratado de amistad germano-español (1939), la aprobación de la Ley de Represión de la Masonería y el Comunismo (1940) y la Ley de Seguridad de Estado (1941), son estos los años de consolidación del franquismo, los «más acendradamente autoritario[s] y militante[s] del régimen en tiempo de paz», según Gubern (1981: 51).

Este mismo espíritu impregna el cine español de posguerra, cuando el régimen produce películas de exaltación del Ejército y su alzamiento, como Vía Crucis del Señor por tierras de España, dirigida en 1940 por Sáenz de Heredia, primo de José Antonio Primo de Rivera, o Raza, una epopeya política escrita por el propio Franco con el seudónimo de Jaime de Andrade y realizada también por Sáenz de Heredia. Además, el modelo cinematográfico de Mussolini juega un papel determinante en la configuración de la industria española, incluida la imposición obligatoria del doblaje, que en Italia data de 1930.

Desde el punto de vista político-lingüístico, la Orden de 1941 estuvo precedida de «una virulenta campaña españolizadora» (Gubern, 1981: 68). El precedente más inmediato lo encontramos en la norma que en 1940 prohibe el uso de dialectos en el cine. Pero, desde 1937, se iba prohibiendo paulatinamente el uso de otras lenguas distintas al castellano en el registro civil, así como en estatutos, reglamentos, establecimientos, cooperativas, hospedajes y calles.

Sobre la base de este discurso represor de diferencias, el régimen elabora buena parte de su retórica en torno a un sentimiento de unidad, autenticidad y pureza, un orgullo de raza, lengua y nación, que, como afirma Fishman (1972: 5), caracterizan a todo nacionalismo. Esto afecta especialmente a la lengua, que, como señalaba Herder ya a finales del siglo xvill, es el mejor instrumento para salvaguardar o recuperar el patrimonio de una nación, subrayar su autenticidad y, en última instancia, aglutinar. De ahí que los nacionalismos, añade Fishman (1972: 62), empleen conscientemente el registro estándar de lenguas unificadas. Y el nacionalismo español de los años 30 no fue ninguna excepción pues, como subraya López García (1985: 123), empleó la lengua española como expresión de una ideología, como herramienta en la definición de una sola iden- 
tidad cultural. En España, en definitiva, la lengua fue cauce o instrumento del sentimiento nacionalista.

Además, el cine, aseguran Shohat y Stam (1994: 101-102), es un medio ideal para construir narraciones alegóricas de la identidad de un pueblo. De hecho, según McIntyre (1985), el cine juega un papel clave en la articulación del concepto de identidad nacional, porque se presta a erigirse en su representación como si ésta fuese algo coherente y estable, exento de diferencias, tensiones y contradicciones internas. En otras palabras, se presta a representar los intereses de un determinado grupo como si se tratara de intereses nacionales y colectivos.

Estas circunstancias - aquí muy resumidas- nos hacen creer que la elección del doblaje en España estuvo en su mayor parte motivada por una política nacionalista $y$, aunque hasta ahora nunca se haya hecho esta afirmación, son varios los autores que establecen una conexión entre doblaje y nacionalismo: Gubern y Font (1975: 34), Pozo (1984: 50), Vallés (1992: 46) y Fanés (1989: 158), éste último de un modo más explícito cuando afirma que el doblaje era considerado «una forma de nacionalismo».

Con todo esto, no pretendemos negar que existieran factores económicos en la imposición del doblaje. Sin duda, éste interesaba tanto a actores de doblaje como a distribuidores y exhibidores, que, con él, podrían sacar beneficios a corto plazo y con una inversión y un riesgo mínimos. De hecho, el testimonio de Victoriano López García (técnico del Estado en materia cinematográfica en los años 40) cuando sostiene que «el doblaje se instauró en España por indicación [...] de los cuatro productores más importantes que había en aquel momento en España [...] porque tenían estudios de doblaje» (Pozo, 1984: 50), confirma que el factor económico tuvo mucho peso. Pero, por ahora, no conocemos documento que corrobore sus declaraciones. Además, en un régimen nacionalista y totalitario, las consideraciones económicas suelen estar supeditadas a las ideológicas.

En cualquier caso, si los beneficios que reportó el doblaje en el terreno económico son dudosos -hay quienes aseguran que impidió el desarrollo de una industria cinematográfica autóctona, mucho más rentable a largo plazo-, en el terreno político son indudables. Con él se neutralizaba buena parte del nacionalismo del cine americano y, en ese sentido, fue un arma utilísima al servicio de un régimen xenófobo que veía en España el reducto espiritual de Europa. Por una parte, el doblaje le quitaba al cine americano la lengua como código, el inglés. Así cumplía una de sus funciones: «Proteger la lengua nacional del país importador de todo imperialismo lingüístico» (Yvane, 1996: 134, 142). Por otra, despojaba al cine de la lengua como vehículo de transmisión de ideas y valores, es decir actuaba, tomando la expresión de Whitman (1992: 11), como «filtro cultural». 
De todos es sabido que en España esta última función la ejercieron las instituciones censoras. Menos conocida, sin embargo -y a ella dedicamos el resto de este artículo-, es la manipulación que ejerció el propio traductor.

\section{ANÁLISIS DE LA TRADUCCIÓN PARA DOBLAJE DE BLOOD AND SAND}

Dos son las normas principales que, en el sentido en que Toury (1980: 51) las define - grosso modo, estrategias recurrentes de traducción-, hemos encontrado en el guión traducido para doblaje (en adelante, VT) de Blood and Sand: la naturalización y, muy especialmente, la que vamos a llamar eufemización.

\subsection{La naturalización}

Esta norma consiste en conformar la versión original (en adelante, VO) de una obra a la cultura meta con el fin de ocultar su origen extranjero y así hacer que parezca una versión original. La naturalización actúa sobre la pronunciación de palabras extranjeras, el tratamiento de las referencias socioculturales y, fundamentalmente, sobre la sincronización. Porque, como asegura Goris (1991: $84,106)$, la sincronización esconde la traducción, creando la ilusión de que la versión doblada es la única versión original, ilusión por otra parte esencial cuando se trata de apropiarse de un producto.

Desconocemos la importancia que se dio a la sincronización de los diálogos en la primera traducción de Blood and Sand, porque, como ha ocurrido con la enorme mayoría de cintas proyectadas antes de 1975 -cuando gran parte de ellas se volvieron a traducir-, no se conserva en la actualidad. Tampoco hemos tenido en cuenta la pronunciación de las palabras extranjeras porque en Sangre $y$ Arena son todas españolas. Éste, sin embargo, es un aspecto muy interesante, como señala Goris (1991: 105), según el cual, en Francia, la pronunciación de los nombres propios extranjeros suele adaptarse a la reglas fonológicas del francés.

En España, aunque apenas hay estudios empíricos que lo demuestren, éste también suele ser el caso. Agost (1996: 268-269, 290), de hecho, lo confirma en su estudio sobre el doblaje al español de la serie francesa Premiers Baisers (Primeros Besos). En la versión de TV3 (el primer canal de Televisió de Catalunya), sin embargo, el traductor va más allá y catalaniza los nombres de los protagonistas -la Isabel, el Lluc, el Josep...-, estrategia que, según el asesor lingüístico de la cadena catalana, responde a la política lingüística de TV3, que resume en estas palabras: «Tomar una serie y catalanizarla al máximo». 
Donde sí que se aprecia claramente la naturalización como estrategia recurrente es en el tratamiento de las referencias culturales, que aun siendo todas españolas, se adaptan a la realidad social y cultural española. Esto lo hace el traductor, por una parte, empleando lexemas o construcciones mucho más contextualizadas que la $\mathrm{VO}$, como en la traducción de manager por apoderado, de ranch por cortijo, o de when I get to be a matador por cuando me den la alternativa. Por otra, rectifica la visión un tanto desvirtuada de la realidad española que, a veces, muestra Mamoulian. Es el caso de la traducción «Some day I'll make the church bells ring» por «Algún día haré que toque la música para mín, enunciado que pronuncia el torero protagonista de la película -Juan Gallardo-como expresión de sus ansias de triunfo en el toreo. Especialmente significativa nos parece, para finalizar este apartado, la traducción que se ha dado al siguiente diálogo que mantiene Gallardo con su mujer:

\section{Ejemplo 1}

\section{JUAN: What do you do with yourself when I'm in the ring? \\ CARMEN: I sit by the window and count the seconds. (VO: 66) \\ JuAN: ¿Qué haces todo el tiempo que yo paso en la plaza? \\ CARMEN: Rezo continuamente a la Macarena. (VT: 28)}

Porque, efectivamente, rezarle a la Macarena es lo que hacían -y siguen haciendo- la gran mayoría de las esposas de toreros en Andalucía, y no, como sugiere la $\mathrm{VO}$, contar los minutos. Con esta traducción, que además añade una nota religiosa no presente en la VO -estrategia también recurrente en la VT-, el traductor, por otra parte, rectifica el «tratamiento inexacto» de una «costumbre nacionalista española», uno de los aspectos del cine americano que más ofendía en España, según un artículo publicado en $1928 .^{3}$

Esta práctica, además, coincide con la que han observado Bovinelli y Gallini (1994), y Nowell-Smith (1968: 146-147) en el doblaje en Italia, Müller (citado en Whitman, 1992: 17), en los primeros tiempos del doblaje en Alemania, Goris (1991: 73-76, 102-103; 1993: 177-178), en Francia, y Agost (1996: 268-270), en Cataluña.

Bovinelli y Gallini, sin embargo, señalan que la estrategia frente a las referencias culturales puede ser, en ocasiones, la contraria, es decir, acercar al público a la cultura fuente. Pero lo habitual, y con ellas coinciden Shohat y Stam (1985: 50), es que las idiosincrasias culturales de las películas extranje-

3. «Foreign countries full of reasons for eliminations in U.S. pictures», Variety, 11 de julio de $1928,7$. 
ras -èspecialmente las americanas, según Goris- se suavicen y se pierdan en el doblaje. La naturalización, por tanto, podría ser una norma universal de] doblaje con la que, como opinan Bovinelli y Gallini (1994: 97-98), se pretende favorecer la identificación del espectador. Coincidiendo con Agost (1996: 268-270) y Nowell-Smith (1968: 146-147), nosotros creemos que incluso puede ser una norma estrechamente vinculada con el sentimiento nacionalista.

\subsection{La eufemización}

Definimos la eufemización como la estrategia que, mediante la omisión. adición o sustitución de información, suaviza la VO en aspectos ideológicamente inaceptables para la cultura meta. Sin ninguna duda, ésta es la principal norma de Sangre y Arena y la que más modifica la lectura global de la película. Por ejemplo, se transforma, con una simple inversión en el orden de palabras, una referencia política en otra apolítica, de manera que se atenúa la denuncia que el personaje con más conciencia política-nacional-hace del toreo en el siguiente parlamento:

\section{Ejemplo 2}

NACIONAL: How much better it would have been if we'd joined the Workmen's Federation, and served our class. (VO: 26)

NACIONAL: Cuánto mejor hubiera sido si nos hubiéramos unido a los trabajadores de la Federación poniéndonos al servicio de nuestra clase. (VT: 12)

O convierte, con un cambio de nombre propio, un miembro de alto rango del ejército español (Vicente) en otro de nacionalidad francesa (Pierre), trasladando así al ejército francés las diversas críticas y humillaciones que recibe en la película el ejército español.

Pero lo que resulta más manipulado en la versión doblada de Blood and Sand es la imagen de Gallardo, el torero protagonista -y, por extensión, de la fiesta nacional-, un personaje sin más virtud que la generosidad, desprovisto de todo sentido de la fidelidad o la solidaridad, que sólo busca fama y dinero, víctima, en último término, de una sociedad que convierte el toreo en una de las pocas alternativas a la miseria. Es aquí donde el traductor despliega todos sus esfuerzos para cambiar de signo su lectura: $a$ ) por una parte, impregna la película de un espíritu católico que no está presente en la VO-por ejemplo, suprimiendo expresiones poco reverentes, muchas de ellas relacionadas con la muerte, como desear morir o matar, experimentar placer ante la posibilidad de morir 
ante un toro, infravalorar la vida humana, etc.-; $b$ ) por otra, atenúa u omite el carácter adúltero y delictivo de Gallardo, que, para llegar a ser torero, allana una finca, roba un caballo o le rompe a un crítico taurino una botella en la cabeza y, para introducirse en la buena sociedad sevillana, mantiene relaciones adúlteras con una marquesa.

El siguiente parlamento, que recoge las críticas que recibe Gallardo el día de su alternativa, nos ha parecido un buen ejemplo:

\section{Ejemplo 3}

(AD LIBITUM): More engagements than any other torero... He won't last long; he's much too reckless... One of these days he'll be brought home in a basket... (VO: $55-56)$

Curro: Yo, Curro, estaba presente la tarde de la alternativa de Juan en Madrid. Toreó un Miura grande como una catedral. En mi vida había visto tanta limpieza, tal elegancia, ligereza, corazón y, por encima de todo, serenidad y valor. Permitanme que les lea lo que escribí aquella noche en el Heraldo: "Albricias, admiradores, llegamos al término de la decadencia de nuestro gran arte. Estamos en vísperas de un gran renacimiento... el Cid Campeador ha venido a devolvernos la gloria de España. La arena ha vuelto a poseer de nuevo pasión y dignidad.» (VT: 23)

Aunque, aparentemente, no existe ninguna relación entre el parlamento inglés y el español, podemos asegurar que la versión española es la traducción de la versión americana -imaginamos que la sincronización permite aquí que la VT sea mucho más larga que la VO. Pero lo más interesante de esta traducción -porque es una de las que más implicaciones tiene- es que el traductor convierte una crítica negativa de Gallardo en otra positiva, de tal forma que si en la VO le auguran una vida profesional corta porque es demasiado temerario, en la VT el traductor aprovecha la ocasión para ensalzar su grandeza y compararlo nada menos que con un héroe épico, el Cid Campeador. De donde podemos inferir que la grandeza del toreo es la grandeza de España o viceversa.

El traductor introduce así en la VT una imagen medieval que no está presente en la VO, estrategia muy significativa por cuanto la recuperación de la imaginería medieval fue precisamente una de las líneas maestras del régimen (Fanés, 1989: 143), además de ser una de las características de toda ideología nacionalista (Fishman, 1972: 8). No podemos dejar de asociar esta estrategia, por otra parte, a las palabras que en 1943 pronunciaba el falangista Bartolomé Mostaza para subrayar la necesidad de «hacer un cine de caballeros y de hidal-

4. Primer Plano, 138, 6 de junio de 1943 (citado en Gubern y Font, 1975: 43). 
gos». «En España debe valer más El Cid que Don Juan», y sus valores, añadía. deben alzarse «frente al cine forastero en que el cuatrero, el gángster y el neurópata actúan de protagonistas, dándole su anárquico y repulsivo signo a la ética». ${ }^{4}$ De hecho, gran parte de las estrategias que empleó el traductor de Blood and Sand estuvieron encaminadas precisamente a cambiar el signo ético de la película, a convertir un villano en un héroe, un crítica del toreo en un elogio de él y, en última instancia, a hacer de Sangre y Arena una película no ya más española, sino incluso más franquistamente española.

Por todo esto, estamos convencidos de que el doblaje fue una herramienta que permitió al régimen franquista afirmar la supremacía de la lengua nacional. así como de su inviolabilidad política y cultural. Eisenman (en Izard, 1992: 92). subraya que «Doblar una película era una manera de convertirla en un producto nacional». Sin duda la subtitulación se presta igualmente a la manipulación. Pero en menor medida, porque, como sẹnala Lambert (1988: 131), en las versiones subtituladas, la banda sonora original no desaparece. Por eso resulta más difícil apropiarse de un producto subtitulado que de uno doblado.

\section{BIBLIOGRAFÍA}

Agost, R. (1996): La traducció audiovisual: el doblatge, Castellón de la Plana. Publicacions de la Universitat Jaume I, Col. Micromagna, 11.

BALlester, A. (1995 $a$ ): «The politics of dubbing. Spain: a case study» en JANSEN. P. (ed.) (1995): Translation and the manipulation of discourse. Selected papers of the CERA research seminars in translation studies 1992-1993. Lovaina, The Leuven Research Center for Translation, Communication and Cultures (CETRA), 125-132.

- (1995 b): La política del doblaje en España, Eutopías, 94, Documentos de Trabajo, Centro de Semiótica y Teoría del Espectáculo, Valencia, Universidad de Valencia.

- (1999): Traducción y nacionalismo: la recepción del cine americano en España a través del doblaje (desde los inicios del sonoro hasta los años 40) [tesis doctoral], Granada, Universidad de Granada.

Bovinelli, B. y S. Gallini (1994): «La traduzione dei riferimenti culturali contestuali nel doppiaggio cinematografico» en BACCOLiNI, R. y otros (eds.) (1994): Il doppiagio. Trasposizioni linguistiche e culturali, Bolonia, CLUEB. 89-98.

DANAN, M. (1991): «Dubbing as an expression of nationalism», Meta, 36: 4, 606-614. 
- (1994): From nationalism to globalization: France's challenges to Hollywood's hegemony [tesis doctoral], Michigan, Michigan Technological University.

FANÉs, F. (1989): El cas Cifesa. Vint anys de cine espanyol (1932-1951), Valencia, Filmoteca Generalitat Valenciana, Col, Textos 3.

FisHMAN, J.A. (1972): Language and nationalism: two integrative essays, Rowley (MA), Newbury House.

GambieR, Y. (ed.) (1996): Les transfers linguistiques dans les médias audiovisuels, Villeneuve d'Ascq (Nord), Presses Universitaires du Septentrion, coll. Traductologie.

GoRIS, O. (1991): À la recherche de normes pour le doublage. État de la question et propositions pour une analyse descriptive [tesina], Lovaina, Universidad Católica de Lovaina.

- (1993): «The question of French dubbing: towards a frame for systematic investigation», Target, 5: 2, 169-190.

Gubern, R. y D. Font (1975): Un cine para el cadalso. 40 años de censura cinematográfica en España, Barcelona, Euros, Col. España, Punto y Aparte.

GUBERn, R. (1981): La censura. Función política y ordenamiento jurídico bajo el franquismo (1936-1975), Barcelona, Península.

IzARD, N. (1992): La traducció cinematogràfica, Barcelona, Generalitat de Cataluña, Colección Monografies i Documents, 3.

LAMBERT, J. (1988): «West-European traditions in translational policy: a report on research in progress» en NeKEMAN, P. (ed.) (1988): Translation, our Future. Proceedings of the XIth World Congress of the FIT, Maastricht, Euroterm, 128133.

López GarCía, A. (1985): El rumor de los desarraigados. Conflicto de lenguas en la península ibérica, Barcelona, Anagrama.

LUYKEN, G.M. y otros (1991): Overcoming language barriers in television. Dubbing and Subtitling for the European audience, Manchester, The European Institute for the Media.

McINTYRE, S. (1985): «National film cultures: politics and peripheries», Screen, 26-1, 66-76.

NIR, R. (1984): «Linguistic and sociolinguistic problems in the translation of imported TV films in Israel», International Journal of the Sociology of Language, 48, Amsterdam, Mouton, 81-97.

Nowell-SMITH, G. (1968): «Italy sotto voce», Sight and Sound, 37-3, 145-147.

Pozo, S. (1984): La industria del cine en España, Barcelona, Publicaciones de la Universitat de Barcelona. 
Reid, H. (1977): «Subtitling, the intelligent solution» en Horgueuin, P. (ed.) (1977): Translation, a Proffession/ La Traduction, une Profession. Proceedings of the VIIIth World Congress of the FIT, Montreal.

Sнонат, E. y R. Stam (1985): «The cinema after Babel: language, difference. power», Screen, 26: 3/4, 35-58.

- (1994): Unthinking eurocentrism. Multiculturalism and the media, Londres y Nueva York, Routledge.

Shuttleworth, M. y M. Cowie (1997): Dictionary of Translation Studies, Manchester, St. Jerome Publishing.

Toury, G. (1980): «The nature and role of norms in literary translation» en In search of a theory of translation, Tel Aviv, The Porter Institute for Poetics and Semiotics.

Vallés, A. (1992): Historia de la política de fomento del cine español, Valencia, Filmoteca Generalitat Valenciana, col. Textos, 7.

Whitman, C. (1992): Through the dubbing glass. The synchronization of American motion pictures into German, French and Spanish, Francfort del Meno, Lang.

YVANE, J. (1996): «Le doublage filmique: fondements et effets» en GAMBIER, Y. (ed.) (1996): Les transfers linguistiques dans les médias audiovisuels, Villeneuve d'Ascq (Nord), Presses Universitaires du Septentrion, coll. Traductologie, 133-143. 


\title{
INEVITABLE EXOTICISM: THE TRANSLATION OF CULTURE-SPECIFIC ITEMS IN DOCUMENTARIES
}

\author{
Eliana P. C. Franco \\ Catholic University of Leuven
}

\section{FOREIGNIZATION AND ADAPTATION IN TRANSLATED DOCUMENTARIES}

In order to find an answer to the question foreignization or adaptation my contribution will be based on a corpus of documentaries about Brazil produced by Western Europeans that were translated, or rather, voiced-over from Brazilian Portuguese into French and German, as well as addressed to the communities that speak these languages (which includes the Walloon community in Belgium).

I would like to suggest two ways of answering the same question. Firstly, from a purely textual-linguistic viewpoint, it was observed in the corpus that a greater degree of exoticism or foreignization is almost inevitable in translated documentaries. The voicing-over of documentaries shares some characteristics with the dubbing of feature films. Both modalities have been used by dominant cultures as instruments to reinforce nationalistic feelings and political and cultural centralization (Goris, 1993: 171). ' Both modalities are also similar in terms of the type of discourse produced, which according to Goris is "a more homogeneous discourse, because they convey an oral translation of an oral source text" (Goris, 1993).

1. See more on the topic in the interesting works of Danan (1994) and Ballester Casado (1999). 
Nevertheless, the different audiovisual genres to which dubbing and voiceover are applied, namely fiction and factual respectively, make it unlikely that translation strategies and norms applied to cultural items and verified in studies of dubbing ${ }^{2}$ coincide with those applied in the translation of documentaries. The difference is then determined first and foremost by genre. As informative programmes, documentaries about a foreign culture are meant to 'teach' something about this culture to the receptor culture, so that a certain degree of exoticism is expected and, at a certain level, even desired in voiced-over versions. Thus, unlike dubbing, the objective of voiced-over versions of documentaries is not to create the illusion of being an original, an illusion regulated by the naturalization norm, ${ }^{3}$ but to find a balance between the known and the unknown, that is, to convey a degree of exoticism ('foreign flavour') that does not impair the target viewer's comprehension of the whole information.

\section{TRANSLATORS' PROCEDURES: SOME EXAMPLES OF THE BALANCE BETWEEN EXOTICISM AND ADAPTATION}

Such an objective was evident in the description of the translators' most commonly adopted procedures to cope with culture-specific information observed in the documentaries of the corpus. These procedures generally consisted of additions and substitutions (usually combined with the 'borrowing'/'addition' of the foreign item in the translated version) which aimed to explain, clarify, make the meaning of the cultural referent less vague to the target audience. Accordingly, omissions of the source culture-specific items as well as their cultural adaptation/localization/ naturalization represented a very tiny proportion of the translation procedures.

Along with the names of people and places, those cultural items that were conveyed visually and/or acoustically to the target viewer, and simultaneously with or consecutively to the speaker's words, were all kept in the translation. The frequent

2. I refer mainly to Olivier Goris' descriptive study of French dubbed versions of American and Flemish films A la recherche de normes pour le doublage (1991).

3. The naturalization norm is defined by Goris (1991: 101) as: "la naturalisation consiste à conformer les versions originales. [...] Elle agit sur les références socio-culturelles, les messages graphiques, la prononciation et la synchronie visuelle." To create the illusion of being an original is actually impossible in voice-over versions due to the simultaneous presence of the original. The illusion created by these versions is rather that of authenticity, of faithful reproduction of documentary testimonies. 
substitution of an abstract/general item by the foreign cultural referent is illustrated below, in a fragment from the documentary Surfavela broadcast by ARTE: ${ }^{4}$

(middle close-up shot of adolescent)

(1a) dans une favelá, on est au courant de tout ce qui se passe

(1) você tá ali vendo as coisa acontecê

[you are there watching things happening]

In the example above we notice the explicitation of the meaning of abstract information (i.e. "ali"/ 'there') by the addition of a cultural referent which is not mentioned in the original utterance (i.e. "favelâ"). Another procedure used constantly in the treatment of cultural reference, i.e. the addition of explanation or definition to the cultural referent, is illustrated below, in a fragment from Carlinhos Brown also broadcast by ARTE:

(close-up shot of Carlinhos Brown)

(2a) Pintado do Bongó c'est le candomblé dans la rue

(2b) Pintado do Bôngo hat den CANDÔMBLE, die Religion der Yoruba auf die strabe gebracht

(2) Pintado do Bongó é o candomblé na rua

[Pintado do Bongó is the candomble in the street]

Although both French and German versions make use of the cultural borrowing "candomble", we notice that it is just in the latter version that the translator adds an explanation to the foreign item (i.e. "die Religion der Yoruba") in order to optimize the viewer's understanding.

As an example of one of the least adopted procedures by translators to cope with cultural reference, i.e. cultural adaptation with omission of the foreign item, let us compare the French and German versions of the fragment below, also from Surfavela:

(medium close-up shot of two adolescents-speakers)

$(3 a)$ on est arrivés à préférer les types du lotto clandestin

(3b) uns sind die Leute vom Bicho Spiel lieber!

4. Transcription conventions used in the examples are: CAPITAL LETTERS for stressed words and phrases, commas (,) for short pauses, three dots (...) for long pauses/hesitation, and exclamation marks (!) for rising intonation.

Information in italics (between parentheses) refers to the description of the visuals and segments [between brackets] stand for the English translation of the original utterances in Portuguese. Italics (with no parentheses), in turn, are used to call the reader's attention to the items under discussion. 
(3) aqui a gente dá mais preferência assim ao pessoal do sabe... ao pessoal do bicho mesmo

["here we give more preference to I mean to the crew of you know... to the crew of the bicho]

In this scene, the Brazilian speaker, an inhabitant of one of the slums in Rio de Janeiro, is actually complaining about the violent behaviour of the police by affirming that the people who live in the slums feel safer if protected by the organizers of the popular illegal game called 'jogo do bicho' ['game of the animal'], where people bet on animals. Here, the foreign cultural referent itself is not so important as the function it has within the informative context (i.e. to emphasize the absurd that people would rather be protected by outlaws than by the police), so that it was replaced by a recognizable parallel or equivalent in the French version.

By using "lotto" instead of "bicho", the French translator approximates the cultural referent to the target viewer's reality, making clear the reference to a game. The same effect is achieved by the addition of a definition to the cultural item in the German version (i.e. "Spiel"). Nevertheless, the connotation of illegality implicit in the original cultural item "bicho" could be recovered only in the French version, with the addition of the adjective "clandestin" to the cultural adaptation "lotto". For the German audience, in turn, "die Leute vom Bicho Spiel" have a great chance to be viewed as honest and respectable citizens. So, even in passages like that, when the whole point of the message could be compromised, the German translator opted for a greater degree of exoticism.

\section{CONCLUSIONS}

It can be concluded then, firstly, that the general treatment of cultural items in documentaries follows basically an explicitation norm which regulates the optimization of the target viewer's understanding of informative content and, secondly, that moderate exoticism is a positive aspect in documentary translation.

However, if we try to answer the question 'foreignization or adaptation'? from a purely cultural-sociological viewpoint, the concept of cultural reference must be broadened. I would like then to suggest that every production of a documentary about a certain culture (in this case, Brazil) by producers/ filmmakers from other cultures (in this case Western Europe) should be viewed as a type of translation.

Thus, I would say that every documentary production involves 'naturalization' as a type of 'adaptation' because it reveals, above all, the target 
producer's subjective perceptions of a given source culture, which in turn may bring consequences to translation. That is why we have, for example, the same documentary theme being approached differently by different filmmakers, as well as the same documentary being translated differently by the different target cultures that host the programme, such as the case of some of the French and German versions broadcast simultaneously by ARTE.

As a conclusion, we may claim that the treatment of cultural reference in translated documentaries entails foreignization, on the one hand, once it seems to take the notion of informative genre as the point of the departure for the translating process; while, on the other hand, this treatment also entails naturalization/adaptation, because it reflects the active role of target cultures as producers and hosts of translated documentaries.

\section{BIBLIOGRAPHY}

Ballester Casado, A.B. (1999): Traducción y Nacionalismo: La recepción del cine americano en España a través del doblaje, University of Granada (unpublished $\mathrm{PhD}$ thesis).

Danan, M. (1994): From Nationalism to Globalization: France's Challenges to Hollywood's Hegemony, Michigan Technological University (unpublished $\mathrm{PhD}$ thesis).

GoRIs, O. (1991): A la recherche de normes pour le doublage: Etat de la question et propositions pour une analyse descriptive, Catholic University of Leuven (unpublished Master thesis).

- (1993): 'The Question of French Dubbing: Towards a Frame for Systematic Investigation', Target, 5: 2, Amsterdam/Philadelphia, John Benjamins.

\subsection{DOCUMENTARIES}

Santiago, C. (filmmaker and director) (26 October 1996): Carlinhos Brown, ARTE.

Pinto, J. and N. LeONEL (filmmakers and directors) (05 November 1996): Surfavela, ARTE. 


\title{
EXTRANJERIZACIÓN Y ADAPTACIÓN EN LA TRADUCCIÓN DE ESPOTS PUBLICITARIOS
}

\author{
Cristina Valdés Rodríguez \\ Universidad de Oviedo
}

\section{INTRODUCCIÓN}

Hablar hoy de traducción audiovisual sin aludir a la traducción de textos publicitarios supone ofrecer una perspectiva incompleta de cualquier tipo de aproximación al tema. La omnipresencia de los anuncios publicitarios en los medios de comunicación facilita la observación y el estudio de las estrategias empleadas en su traducción y, asimismo, muestra un panorama complejo de la multiplicidad de factores y recursos que intervienen en la producción y traducción de este tipo de textos. Esta complejidad hace que profundizar acerca de las estrategias adoptadas y acerca de las restricciones y prioridades que afectan a las decisiones tomadas por los traductores de anuncios en el ámbito audiovisual requiera un análisis más intenso que el presente, en el que únicamente pretendemos ofrecer un esbozo de dichos aspectos.

Aunque han surgido nuevos medios de comunicación, sin duda, el medio publicitario por excelencia en la actualidad sigue siendo la televisión, como señalan algunos autores: «hablar hoy en día de publicidad es hablar de televisión» (Rodríguez del Bosque, 1997: 116). A pesar del alto coste del tiempo en televisión, éste es el medio estrella favorito de todo publicista debido a varias razones: el número elevado de receptores $\mathrm{y}$, en consecuencia, las posibilidades de difusión del producto promocionado, así como los avances tecnológicos que 
permiten una mayor aplicabilidad de nuevas técnicas creativas. La televisión es, sin embargo, el medio de comunicación que más limitaciones presenta para el publicista y el traductor de textos publicitarios, dadas, por ejemplo, las numerosas legislaciones de control del medio nacionales y supranacionales o las políticas linguísticas de países como Bélgica o España, que afectan a la elección de la lengua meta.

Por consiguiente, tanto las estrategias de creación del texto publicitario como las estrategias traductoras, si se trata de un anuncio para otro mercado, han de adaptarse a las restricciones del medio televisivo en cada contexto. Uno de los principales obstáculos que impone la legislación tanto al traductor como al publicista se refiere a la duración de los espots publicitarios. A pesar de existir leyes internacionales sobre el tiempo permitido para la emisión de espots, 'todavía se producen diferencias significativas entre los países, que determinan el diseño del texto en la lengua meta. El criterio de brevedad que, por razones económicas, caracteriza a la televisión obliga tanto al creativo del espot como al traductor a limitarse al tiempo permitido en cada país. Por tanto, el traductor ha de conocer cuál es la norma al respecto en la cultura receptora. En España, la corta duración de los espots - veinte segundos-dificulta el trasvase de anuncios de la televisión norteamericana o de la británica, por ejemplo, donde tienden a ser más largos.

\section{CARACTERÍSTICAS DEL TEXTO PUBLICITARIO}

Las características formales a las que la televisión subordina el diseño del anuncio hacen de la traducción de espots publicitarios un género más de traducción audiovisual, en la que la combinación de imagen y sonido depende de un único fin claramente persuasivo. En un primer momento, se asocia el concepto de traducción audiovisual de anuncios con el término de espot publicitario, término con el que se designa a cada película corta emitida en los cortes entre programas televisivos, cuya finalidad es la de promocionar un producto o servicio de consumo entre un segmento de población determinado y que se caracteriza por su estrategia persuasiva y seductora (González y Ortiz, 1995). Llegado este punto, es necesario añadir que este tipo de películas breves también se emiten en pantallas de gran formato, precediendo a una película cinematográfica de larga duración en salas comerciales e incluso en soportes

1. La Ley de la Televisión sin Fronteras (Ley 25/1994, de 12 de julio) unifica los criterios respecto a la duración y al número de espots emitidos en televisión en Europa. Esta ley favorece la internacionalización de anuncios en un mismo idioma y supone una restricción formal al traductor: si la traducción de un espot es más larga que el texto origen, habrá que ajustarla al tiempo concedido. 
multimedia como el CD-ROM o Internet. Respecto a este último medio, existe. por ejemplo, un anuncio de la marca Sony para promocionar sus nuevas cámaras de videofilmación digital en el que se reproducen la imagen de una cámara Sony en la pantalla del ordenador y una serie de mensajes escritos con instrucciones dirigidas al receptor sobre cómo filmarse a sí mismo en vídeo.

Este anuncio promocional enviado a través de Internet comparte la mayoría de las características de los espots publicitarios difundidos por televisión en los que se basa este estudio: un código visual y un código oral, ambos combinados de forma compleja y subordinados tanto al soporte o medio para el que se diseña el espot como a la función persuasiva que define al texto publicitario. El código visual del espot se manifiesta de formas diversas: la imagen móvil, que consiste en una película compuesta de fotogramas yuxtapuestos y/o superpuestos formando un todo único; el código cromático, según el cual cada color aporta determinados significados; las imágenes fijas, que casi siempre sirven para mantener la mirada del espectador sobre un elemento esencial del mensaje; el código tipográfico, clave para identificar algunas marcas, como en el caso del acento circunflejo de la marca Lancôme, y el código lingüístico, que aparece escrito sobre la pantalla. La dimensión oral del espot publicitario también se caracteriza por su complejidad: el texto se presenta de forma sonora mediante, por ejemplo, el empleo de la voz en off o del texto de la canción; y el componente musical, con un papel cada vez mayor en la publicidad actual. La relación entre cada uno de estos aspectos, visuales y orales, y el significado global que ésta aporta al anuncio marcan pautas distintas a la hora de su traducción. La mayor dificultad a la que se enfrenta el traductor de un espot publicitario, como al de cualquier otro texto de carácter audiovisual, es la de mantener en todos los componentes del mensaje un sincronismo de significado (Mayoral, Kelly y Gallardo, 1986: 102). Para trasvasar el texto fílmico sin destruir la función prioritaria del espot publicitario, es necesario que exista un sincronismo de caracterización, un sincronismo de contenido y un sincronismo visual (Agost, 1999: 16), que haga del texto meta un texto coherente con las expectativas del público y con las restricciones formales que impone el medio. Una aproximación a la traducción de espots publicitarios, por tanto, ha de tener en cuenta todas las operaciones tanto en el plano verbal como no verbal (Delabastita, 1989: 195) que conlleva el trasvase de los mismos a otro contexto y, en muchos casos, a otro medio.

\section{ESTRATEGIAS DE TRADUCCIÓN}

Atendiendo tanto a las estrategias de marketing como a la naturaleza semiótica compleja de los espots publicitarios, pueden darse diversas combinaciones de estrategias traductoras que varían desde la no traducción del anuncio, que 
supone emplear el mismo espot para todos los mercados en los que se oferta el producto, hasta la total adaptación del mensaje, que conlleva la creación de un anuncio completamente nuevo para el contexto meta. En el primero de los casos, el resultado es una traducción más o menos extranjerizante en la que se importan los valores de la cultura de origen del producto o los valores asociados a una determinada cultura y ligada de alguna forma al producto que se anuncia. La segunda opción, como ya se ha señalado, da lugar a textos diseñados exclusivamente para el segmento de mercado meta al que se dirige el anuncio. Las variaciones existentes entre esas dos posiciones extremas proceden de decisiones tomadas por los traductores basadas tanto en criterios lingüísticos como culturales.

El estudio realizado a partir de la observación de un corpus de anuncios emitidos en distintas cadenas de televisión en los últimos dos años (1998-2000) muestra una serie de estrategias traductoras de espots publicitarios en la que se combinan las modalidades de traducción propias de los medios audiovisuales: el doblaje, la subtitulación, las voces superpuestas o la interpretación, si bien esta última no se aplica en el trasvase de espots publicitarios. La elección de una estrategia u otra depende de factores diversos, siendo quizás el más significativo el nivel de aceptación de las modalidades de doblaje o subtitulación por parte de la audiencia meta. El siguiente espectro de posibilidades resume las estrategias traductoras de espots publicitarios emitidos en el contexto español, partiendo de las dos posiciones extremas características tanto de las tendencias internacionales de marketing como de la traducción:

No traducción

Transferencia

Subtitulación

Voz superpuesta

Doblaje

Creación de un texto nuevo

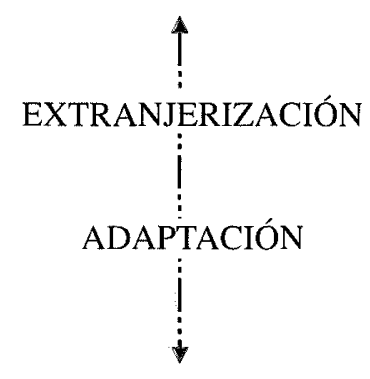

\section{EXTRANJERIZACIÓN}

En uno de los polos del espectro de posibles estrategias se sitúa la no traducción del anuncio publicitario, es decir, la exportación de un mismo texto para todos los mercados en los que se pretende promocionar el producto o ser- 
vicio en el que el concepto, el diseño y las asociaciones que se esperan de los receptores son los mismos a pesar de tratarse de contextos diferentes. Ejemplo de esta estrategia lo constituyen los espots publicitarios de productos de alta gama o dirigidos a un público objetivo, o target, joven; son productos lanzados internacionalmente por anunciantes defensores del modelo global, para los que el mercado constituye un todo integrado y la lengua franca suele ser el inglés y, en el caso de la mayoría de los perfumes femeninos y algunas marcas de joyería, el francés. Éste es el caso de los espots de relojes Swatch y de los perfumes Eternity de Calvin Klein y 5th Avenue de Elizabeth Arden. El primero de ellos consiste en una secuenciación de distintas imágenes en las que el tiempo se acorta por segundos de acuerdo con el texto inglés que aparece en la pantalla. El eslogan final reproduce la siguiente expresión en inglés: "Time is what you make of it.» Respecto al segundo espot mencionado, el diseñador norteamericano Calvin Klein escoge imágenes cálidas relacionadas con el sol, la playa, la pareja o la familia, siendo el único texto el nombre del producto y el de la marca y la voz en off la de un hablante nativo de inglés repitiendo el nombre de marca. En el tercer espot, el perfume 5th Avenue se promociona en distintos mercados con el eslogan «It takes you there», escrito sobre la pantalla al final del anuncio. El texto se limita a la letra de la canción que hace referencia a la ciudad de Nueva York, donde se encuentra la Quinta Avenida que da nombre al perfume. Las palabras mantienen una estrecha relación con las imágenes y con los gestos de la actriz protagonista del anuncio.

La siguiente estrategia se denomina transferencia, si bien no hace referencia a la total transferencia del anuncio en la lengua de origen, sino a la transferencia de algún componente de éste en el espot emitido en la cultura meta. Así ocurre en varios anuncios de hace algunos años de la famosísima bebida CocaCola, en los que se ofrecen imágenes de distintas personas en diferentes lugares del mundo cuyo denominador en común es el hecho de consumir dicho producto. Lo más interesante de este espot es la transferencia de las mismas fotografías y de igual melodía, pero no del texto, ya que el eslogan «Sensación de vivir» y el texto de la canción se traducen a las lenguas meta según sea el mercado receptor y se sobreimpresionan en la pantalla del televisor. El concepto central de la campaña y el componente no verbal no varían, pero sí los elementos verbales orales y visuales.

\section{UNA POSICIÓN INTERMEDIA}

Respecto a la traducción de espots con subtítulos, ésta supone un grado similar de extranjerización y adaptación, reflejando una posición más interme- 
dia entre la cultura de origen y la receptora del anuncio. Esta opción parece ser cada vez más común en el mundo de la publicidad televisiva, si bien plantea las dificultades que impone al traductor las limitaciones del tiempo de permanencia en pantalla y de la velocidad de lectura del receptor. En el espot de promoción del perfume Poême de Lancôme la actriz francesa Juliette Binoche aparece componiendo una canción sentada al piano. La voz del anuncio original se mantiene en el texto meta en la lengua origen, el francés; sin embargo, el texto cantado y escrito en la partitura que se muestra en el espot ha sido traducido a la lengua meta, el español, e incorporado a la película en forma de subtítulos. La principal razón de esta estrategia en el caso particular de esta campaña es la de enfatizar el origen francés del producto y subrayar la elegancia y el valor estético que aporta a la fragancia la anteriormente mencionada actriz, como símbolo de lo francés. En relación a esto, es importante señalar en qué grado las asociaciones de las que depende la comprensión idónea del anuncio se definen por ser asociaciones de tipo cultural, siendo algunas compartidas más o menos internacionalmente, como ocurre con los valores de elegancia, sofisticación o glamour, que casi siempre se relacionan con lo francés.

A principios del año 2000 , ha comenzado a emitirse un espot publicitario para promocionar un servidor de Internet y cuya estrategia traductora es también la subtitulación del texto oral narrado por el actor norteamericano Christopher Reeve, protagonista de la serie de películas Superman. Se trata de frases cortas, por lo que las restricciones de tipo temporal y espacial del medio televisivo no plantean demasiados problemas. En este espot la subtitulación no se emplea como forma de evocar los valores propios de la cultura de origen, sino como modo de destacar el hecho de que la voz que se oye en el espot es la de Christopher Reeve, de vital importancia para la comprensión del eslogan: «Freedom of movement.» Este eslogan es particularmente dramático y de gran fuerza, ya que, por un lado, hace referencia a la libertad de movimiento que supone la comunicación mediante Internet y, por otro, a la incapacidad de movimiento del conocido actor, parapléjico desde hace unos años. Asimismo, se destaca el hecho de que el servidor de Internet anunciado ofrece posibilidades de libertad de movimiento para personas que carecen de ello físicamente, como en el caso del actor. A menudo, la práctica de la subtitulación en el trasvase de anuncios publicitarios se debe a la intención del anunciante de crear la imagen de que el producto posee un alcance mundial, como, por ejemplo, en una de las campañas de IBM en la que distintos personajes de países lejanos aparecían explicando en su propio idioma que usaban la tecnología IBM y este texto era traducido y subtitulado en la lengua meta (Valdés, 1998: 103-111).

Las voces superpuestas, o voice-over, es un recurso empleado en publicidad cuando parece relevante subrayar la personalidad que anuncia las cualidades 
del producto. Este personaje famoso respalda el prestigio y las bondades del producto mediante el uso de su propia voz, la cual llega directamente al receptor. Sin embargo, la superposición de voces es necesaria para la comprensión del mensaje en la lengua meta. En esta modalidad traductora, se produce una presencia simultánea de los dos textos en la lengua de origen y en la lengua meta. Un ejemplo conocido del uso de esta estrategia en la televisión española es el de la Cuajada Danone, en el que Steve Miller, prestigioso fotógrafo de la revista Geo, destaca las cualidades del producto en un momento de descanso en su trabajo. En este espot, pueden oírse tanto la voz del personaje que sirve de imagen al producto en la lengua de origen como, superpuesta a ésta, siempre con un brevísimo espacio de tiempo de diferencia, la banda sonora que reproduce la voz del doblador enunciando el texto meta. La serie de anuncios de la marca de artículos de maquillaje Max Factor también tiene como principal estrategia traductora la superposición de voces; algunos de los últimos espots de esta marca muestran los rostros de actrices de fama internacional que están siendo maquilladas con dichos productos en su trabajo. Para el receptor, escuchar las propias voces de estas personalidades supone un testimonio directo y personal y una cierta autoridad del producto, pero, al mismo tiempo, la traducción oral del texto es necesaria para la comprensión del mensaje.

\section{ADAPTACIÓN}

Dentro del panorama audiovisual español, la tendencia más generalizada y la más aceptada por parte del público se caracteriza por el doblaje tanto en cine como en televisión. Esta política traductora también es la norma generalizada en la publicidad televisiva, si bien ya no se trata de la única estrategia empleada en la traducción de espots, como era frecuente en épocas anteriores. Gran parte de los espots que se ven en televisión son fruto de fuertes campañas internacionales, de cuyo diseño y planificación se responsabiliza una agencia publicitaria centralizada en un país (Estados Unidos o el Reino Unido, principalmente) o una agencia con múltiples oficinas locales que se encargan de la adaptación de las campañas en la cultura receptora del anuncio y, como parte de ese proceso, del doblaje. El doblaje de la banda sonora de los espots publicitarios plantea algunas dificultades como la sincronización visual entre los movimientos labiales del actor que aparece en pantalla y los sonidos reproducidos en la lengua meta que oye el espectador. Las restricciones son, por tanto, mucho mayores que en el caso de las voces superpuestas donde no existe una voluntad manifiesta de ocultar que la lengua del espot original no es la misma que la del receptor.

En términos de extranjerización o adaptación, por consiguiente, el doblaje supone una mayor adaptación a las expectativas de los receptores de la cultura 
meta y, como resultado de ello, la desaparición de toda huella acerca del origen del espot en lo que se refiere a la lengua empleada. Cuando otros elementos, de naturaleza visual u oral, aluden claramente a la procedencia del anuncio, puede llegar a producirse un trastorno en la recepción del anuncio (Valdés, 2000: 27 1 280). Esto sucede cuando, en algunos espots, la apariencia física o los movimientos articulatorios o gestuales del actor no corresponden con aquellos propios de la cultura o de la lengua meta. Ejemplo de ello son algunos anuncios de la marca de cosmética L'Oréal Media Excellence, en los que el receptor puede ver a un personaje famoso como Natasjia Kinsky y oír la voz de la dobladora en español. Es claramente visible que se trata de una versión doblada en la que no se ha tenido en cuenta la sincronización labial, decisión tomada quizás de forma consciente.

En la mayoría de las ocasiones, pese a la utilización de personalidades para promocionar una determinada marca, como ocurre en los espots de la marca de ropa y material deportivo Adidas, en los que aparecen atletas o jugadores de baloncesto de reconocimiento internacional, los espectadores ven y oyen los espots doblados al español sin pensar siquiera en que se trata de una traducción. Este hecho resulta de gran interés, puesto que refuerza la idea de que algunos textos ampliamente difundidos en los medios son, en realidad, textos traducidos con un origen distinto al de la cultura meta, pero que los receptores aceptan como si se tratara de textos meta producidos por y para la cultura meta. En este sentido, es posible confirmar el carácter invisible de un buen número de traducciones, entre las que se encuentran los textos publicitarios. El doblaje oculta el elemento que, ante los ojos del receptor meta, podría indicar que el espot ha sido traducido: la lengua de origen.

Sin embargo, en general, los responsables de la traducción de los anuncios tienden a ser bastante cuidadosos en lo referente al doblaje de las bandas sonoras, al menos en España. El espot publicitario para promocionar las maquinillas de afeitar Gillette Sensor Excel ha sido traducido y doblado de forma bastante literal en cuanto al contenido con algunos recortes en el texto oral, debido a la rapidez con que se pronuncian las palabras en la banda sonora del texto origen inglés. En la versión doblada al español se insiste menos en la diferencia entre Gillette Sensor Excel y las demás maquinillas desechables. Sólo un comentario breve tras subrayar las cualidades del producto señala que éstas son características de la maquinilla anunciada y no de las desechables: «Las desechables no.» La traducción y el doblaje de este espot también plantean otra dificultad, ya que se combinan imágenes en las que los dos actores realizan numerosos movimientos y gestos para comparar los modelos de maquinillas de afeitar anteriores con la nueva y en las que se muestra en detalle el sistema de afeitado de esta 
maquinilla. Ha de existir, por tanto, una perfecta correspondencia y armonía entre el texto doblado, de carácter oral, y el componente visual del anuncio.

La estrategia que supone una total adaptación a la cultura meta es la creación de un anuncio más o menos nuevo para ese contexto. El concepto o idea central de la campaña es casi siempre el mismo, por lo que permanece también en el texto meta nuevo. Los distintos espots de la campaña internacional de la bebida Bailey's comparten el mensaje de que consumir esta bebida significa compartir algo nuevo con los amigos $\mathrm{y}$, mediante un juego, probar la bebida supone plantear un reto a los amigos. Aunque los actores y el escenario del espot para el mercado británico y los del espot español son diferentes, la idea es prácticamente idéntica. Lo mismo ocurre en los espots del suavizante Mimosín, en los que el concepto de suavidad e inocencia que se asocian al producto se manifiesta a través tanto de la imagen del osito de peluche como del nombre de marca del producto, que es traducido para los distintos mercados atendiendo a las evocaciones de los sonidos en la lengua meta: en Estados Unidos recibe el nombre de Snuggle, en Francia el de Cajoline, en Italia se llama Coccolino, en Portugal Fofo y en Alemania Kuschelweich. Todas estas variantes preservan la connotación que la realización fonética del nombre posee de mimo, caricia y suavidad, haciendo referencia al cuidado con que el suavizante trata la ropa. Los espots televisivos refuerzan esta idea por medio del componente visual, ya que siempre aparece la imagen de un osito de peluche de apariencia inocente que abraza diversos objetos con mucha ternura. ${ }^{2}$

\section{CONCLUSIÓN}

Para concluir, cabe señalar que esta descripción de las estrategias traductoras de los espots televisivos empleadas en el contexto español demuestra que, a pesar de las políticas económicas internacionales tendentes a la globalización de los mercados y, por consiguiente, a la estandarización cultural de los mensajes, en España la norma traductora al respecto continúa siendo el doblaje de los anuncios a la lengua meta, modalidad traductora que facilita al receptor meta la comprensión del anuncio. Sin embargo, la no traducción del texto, en particular, de las letras de las canciones, o el empleo de imágenes y sonido comienzan a afianzarse como formas publicitarias de carácter internacional en las que cada vez menos será necesario traducir el componente verbal. Estas nuevas tendencias conllevan una mayor homogeneización de las culturas y una polémica

2. Un análisis más exhaustivo sobre el tema se encuentra en: VALdÉs RodríGuez, C. (1999): La traducción publicitaria como acto de comunicación intercultural [tesis inédita], Oviedo, Universidad de Oviedo. 
extranjerización de las costumbres y valores que suponen un reto para las identidades nacionales.

\section{BIBLIOGRAFÍA}

Agost, R. (1999): Traducción y doblaje: palabras, voces e imágenes, Barcelona, Ariel Practicum.

Chaume, F. (1997): «Translating non-verbal information in dubbing» en Poyatos, F. (ed.) (1997): Nonverbal Communication and Translation, Amsterdam y Filadelfia, John Benjamins, 315-326.

DelabastiTa, D. (1989): «Translation and Mass Communication: Film and T.V. Translation as Evidence of Cultural Dynamics», Babel, 35: 4, 193-217.

González Requena, J. y A. Ortiz de ZÁrate (1995): El espot publicitario. Las metamorfosis del deseo, Madrid, Cátedra, col. Signo e imagen.

Mayoral, R., D. Kelly y N. Gallardo (1986): «Concepto de "traducción subordinada" (cómic, cine, canción, publicidad). Perspectivas no lingüísticas de la traducción (I)» en Fernández, F. (ed.) (1986): Pasado, presente y futuro de la lingüística aplicada en España. Actas del III Congreso Nacional sobre Lingüística Aplicada, Valencia, Servicio de Publicaciones, 95-105.

DE PEDro, R. (1996): «Beyond the Words: The Translation of Television Adverts», Babel, 42: 1, 27-45.

Rodríguez del Bosque, I. A., J. de la Ballina y L. Santos (1997): Comunicación comercial: conceptos y aplicaciones, Madrid, Civitas.

VALDÉs, C. (1998): «Estrategias traductoras de los textos publicitarios televisivos» en ORERo, P (1998): Actes del III Congrés Internacional sobre Traducció, Barcelona, Departament de Traducció I d'Interpretació, Universitat Autònoma de Barcelona, marzo 1996, 103-111.

- (2000): «Reception Factors in Multimedia Translation: The Case of Advertisements» en Chesterman, A., N. Gallardo e Y. Gambier (eds.) Translation in Context. Selected Contributions from the EST Congress, Granada 1988. Amsterdam/Filadelfia: John Benjamins, 271-280.

ZABALBEASCOA, P. (1997): «Dubbing and the nonverbal dimension of translation» en Poyatos, F. (ed.) (1997): Nonverbal Communication and Translation, Amsterdam y Filadelfia, John Benjamins, 327-342. 


\title{
IN VIDEO VERITAS: ARE DANISH VOICES LESS AMERICAN THAN DANISH SUBTITLES?
}

\author{
Henrik Gottlieb \\ Center for Translation Studies and Lexicography \\ University of Copenhagen
}

\section{AIMS AND PERSPECTIVES}

Against the backdrop of the present, and seemingly permanent, AngloAmerican dominance in the contemporary media worldwide, the primary concern of this paper is to evaluate the role of dubbing and subtitling in one aspect that follows from this situation, namely the anglification of other languages.

In order to be able to compare the potential for anglification in the two rival types of screen translation in Europe, an empirical investigation was set up, comparing the dubbed and the subtitled translations of three American feature films into the same language, Danish. Making this comparison has until recently been impossible in strongly pro-subtitling Scandinavia. But since the late 1990s, dubbed versions of foreign (family) films — often with a dubbed and a subtitled film sold on the same VHS tape - have become increasingly common.

\subsection{Dubbing vs. subtitling}

With special reference to the introduction of English language features (Anglicisms) in other languages via subtitling or dubbing, their relative strengths 
and weaknesses could now be put to the test. However, before examining the material in this study - and without entering the often emotionally loaded "dubbing vs. subtitling" discussion which goes back to the introduction of the American talkies in Europe around 1929 (Gottlieb 1997: 51-57) - two central and slightly paradoxical facts need to be mentioned here:

a) Subtitling, often considered the more authentic of the two methods, constitutes a fundamental break with the semiotic structure of sound film by reintroducing the translation mode of the silent movies, i.e. written signs. Unlike most forms of translation, where the verbal channel of the translation is identical to that of the original (isosemiotic translation), subtitling is diasemiotic: it "crosses over" from speech to writing.

b) Dubbing, a "natural", isosemiotic type of translation, generates a conglomerate expression in which the voices heard, severed as they are from the faces and gestures seen onscreen, will never create a fully natural impression. Only total remakes (as described in Wehn 2000) will be able to fully supplant the original film.

All in all, the two methods of screen translation differ in the following respects:

1. In semiotic terms, i.e. with regard to

a) written vs. spoken language mode, and

b) supplementary mode (subtitling) vs. substitutional mode (dubbing).

2. In wording, where

c) subtitling tends to condense the original dialogue, unlike dubbing, and

d) the two types of translations are often not made by the same person.

When judging the quality and language-political consequences of the language found in the material investigated in this study, one will have to keep in mind the fundamental differences stated above.

\subsection{The study}

Based on a contemporary and comprehensive typology of Anglicisms (Gottlieb 1999) with special emphasis on "invisible" loans such as Englishsounding constructions, this study looks at all language features that show English influence in the two Danish video versions of each of three recent American family films (Flubber, Dr. Dolittle and Antz). These three film pairs are compared systematically with respect to the types and frequencies of Anglicisms displayed in the dubbed Danish dialogue vs. the Danish subtitles. 


\section{METHODOLOGICAL REMARKS}

Unlike most contemporary empirical translation studies, where observations are based on electronic text files or, at least, on printed manuscripts, all data in this study were extracted manually from the audiovisual sources and listed in special text files, which then served as data banks for further analysis.

As all counts were made by ear, eye and hand, errors in the calculations may indeed have happened. More interestingly, classifying certain Danish language features as Anglicisms because they seem to be triggered by cognate words or constructions rather than selected for their idiomaticity is also, strictly speaking, subjective. However, although machine-readable files might have been a great help in the compilation of data, many Anglicisms can only be spotted by a human observer watching them as they appear onscreen. Thus, I can say with some confidence that whatever defects the present study may have in terms of human intervention, there is simply no way it could have been done without repeated "human browsing" through the six film versions under discussion here. One simply cannot operationalize an Anglicism search. No algorithms, no sophisticated search facilities, no concordance programs could find all those Anglicisms that hide in a film but are missing on the compiler's "shopping list". Only by looking directly at the object of study in vivo can satisfying results be obtained. For this type of empirical study, in vitro observations would be of little use.

\subsection{Defining the concept of Anglicism}

Anglicisms not only reflect how the world looks, tastes, or sounds (cf. "Internet", "burger" or "hiphop"), they also dictate how it is looked at, what "good taste" is, and what "sounds right" in other languages. Still, Anglicisms are not merely vehicles of some Anglo-American mental imperialism; they are the offspring of other languages" voluntary intercourse with English. Having been conceived this way, Anglicisms are prone to being considered bastards by purists, whereas more eclectic observers may see them as exotic pictures on the walls in the world's national galleries of linguistic art.

The standard terminology when discussing language contacts -and the resulting Gallicisms, Anglicisms, etc.- operates with notions of "loanwords" or "linguistic borrowing". Although it is difficult to avoid such terms altogether, they should not be taken at face value, since neither individual words nor other linguistic features are ever handed back to the "lending" language, in this case English. More than the simile of a lending library, with a limited amount of 
copies available for temporary borrowing, the concept of Anglicisms can be compared to a cyberspace public-domain catalogue of linguistic features that may be downloaded by anybody and used, abused or discarded ad infinitum. No deposit, no return, but a major impact on the languages hooked up.

In mixing blood with different mother tongues, the English donor language fosters children that are only half sisters and brothers. Only partly English, raised by their respective mother tongues - and thus not always mutually comprehensible - these Anglicisms have become the epitome of the so-called "globalization".

Unfortunately, neither in public debate, nor among scholars does the term "Anglicism" have a fixed, unambiguous meaning. In witnessing discussions on language contacts today, one meets unbiased - yet often barren - etymological definitions alongside very polemical views on the subject, expressed in bombastic language.

Even within linguistic circles definitions vary a great deal as to their scope and implications. A strictly technical definition of an Anglicism based on traditional linguistic views, as cited by Slovenian lexicologist Eva Sicherl (1999: 12), narrows the notion of "Anglicism" down to "a word borrowed from the English language which is adapted with respect to the linguistic system of the "receptor language" and integrated into it."

For one thing, this type of definition only looks at the most conspicuous elements of language: the individual lexical items; syntactic and other features are ignored.

Secondly, it is presumed that a certain integration process is active in a given language community, a notion not always tenable considering the way English language features are now becoming adopted, rather than adapted, in, for instance, a number of Germanic speech communities. In Danish, for example, "rap" (music) is pronounced with an English " $r$ ", thus creating a mininal pair with the Danish homograph "rap" -which already has three different meanings.

Thirdly, the above definition excludes situations where the receiving language starts adapting itself to English language norms, as is often the case in, for instance, modern Danish (Larsen 1994).

Therefore, it is my firm conviction that in investigating the impact of English on other languages, the researcher must focus wider than merely on "words borrowed from English". Sticking to such a narrow definition, one would have to discard certain issues with major language-political implications: English influence on such central language features as semantics, syntax and morphology. Therefore, as its predecessors (Gottlieb 1999 and Gottlieb, forthcoming) this study operates with an all-encompassing definition of Anglicism, namely "any language feature adapted or adopted from English or inspired or boosted by 
English models, and used in intralingual communication in a language other than English".

Based on this definition, a taxonomy with seventeen Anglicism categories was used to chart the frequencies of the different types of Anglicisms in the six video versions investigated, focusing on the differences between dubbing and subtitling. The taxonomy will be presented in section 4.1 , together with the results of this comparison of three sets of American films in Danish guise. Before looking at the data, however, we need to understand the role of Anglicisms in modern communication, and symmetrically, the role of translations in the proliferation of Anglicisms.

\subsection{Why use Anglicisms?}

Several explanations have been offered as to why Anglicisms gain ground in most of the world's languages. One of the more elaborate models is put forward by Chris Pratt (1986: 361), in his study on Anglicisms in Spanish. Pratt makes the following distinctions:

A. Linguistic causes for borrowing:

1. Extrinsic causes (new phenomena are introduced) leading to

a) adopting "the foreign sign" (i.e. an English word)

b) using "pre-existing native signs"

c) inventing "a new sign of its own"

2. Intrinsic reasons (new linguistic tools are invented, e.g. through suffixation, as in adding -izar or anti- to an existing Spanish stem)

B. Extralinguistic causes for borrowing (prestige):

1. Linguistic snobbery "out of a desire by the user to appear modern, upto-date, well-off, well-traveled, well-read, sophisticated, etc.", as when using the spelling "cocktail" in Spanish (instead of "cóctel")

2. Argotic function (e.g. political and business jargon)

3. Material benefit (e.g. ads and technical texts with expensive-sounding English buzzwords)

Of special interest here are the "extralinguistic causes", all related to the "exoticness" and alleged positive connotations of English-sounding words. comprehensible or not.

Recently, the iconic attractiveness of English has been interpreted as a postmodernist symptom. A copywriter in a Norwegian advertising agency has put it this way: "A feature of postmodern times is that sound often means more than 
content or meaning" (Løvfall 1997: 13, my translation). For this reason Løvfall believes we will witness still more ads and commercials that are "meaningless" in the eyes of linguists, but certainly make sense in a professional advertising perspective. One Danish example of this is the many trendy cinema commercials all in English, yet advertising Danish products such as Evers drops and Stimorol chewing gum. Not only with products, but apparently also with commercials, the wrapping itself may count more than the content.

However, we need not interpret the success of such "incomprehensible" codeshifts or Anglicisms in modern, let alone postmodern, terms. Just imagine kids in front of a fireplace enjoying a fairytale full of old and mysteriously sounding expressions, a Nordic woman relishing sweet nothings from her Latin lover, or a Medieval sermon in Latin, almost incomprehensible to the congregation, but not without an effect on their souls.

It is my claim that as is the case with idioms and other colorful linguistic devices available to the language user, loanwords - in casu Anglicisms - may act as spices in the cuisine of communication. There is only one limit to the use of such devices: the threshold of cliché, above which the intended effect is lost, and innovative features turn trite. For this reason alone, the life expectancy of "spicy" Anglicisms and other buzzwords is often short. In language use, visibility is vulnerability.

\subsection{Translations as conveyors of Anglicisms}

Translated English-language products, including books, technical documentation, films and TV programs, often comprise a major part of the total text consumption in non-Anglophone countries. In Denmark, about $40 \%$ of what people read - TV subtitles included - is translated from English (cf. Gottlieb 1997: 148-153). For decades, Danish subtitles and other mass media texts have been criticized for containing too many English loanwords and constructions, thus contributing to what some observers see as pollution of the national idiom. As the Danish pioneer in Anglicism research, Knud Sørensen, puts it:

There is no doubt that Anglicisms occur with the greatest frequency in the media. Thus journalists, who often draw on English-language sources, are chiefly responsible for the English infiltration of the Danish language. (Sørensen 1986: 45)

In Spain, a dubbing country since the early 1930s, critical observers talk about "the effect that English is having on the Spanish speaker at home as a result of the vast quantities of badly translated material flooding the spheres of 
journalism, radio, television and advertising" (Lorenzo 1996: 18, quoting A. Gooch: Spanish and the Onslaught of the Anglicism).

The effect of English on the domestic language is clearly seen in poor or rather, unidiomatic - translations, no matter the medium. In the case of subtitling, this was first illustrated in a Finnish context (Sajavaara 1991). As far as printed translations are concerned, Martin Gellerstam's seminal paper "Translationese in Swedish novels translated from English" (Gellerstam 1986) was one of the first such studies published. In that study, printed translations from English displayed boosted frequencies of several English-sounding language features, compared with the figures for original non-Anglophone works. In comparing the vocabulary of 27 novels translated from English ("T novels") with that of 29 original Swedish novels ("O novels") - all 56 novels published in Sweden in 1976- Gellerstam (1986: 91-92) makes the following generalizations:

1. English loanwords are significantly more common in the T novels than in the O novels. Examples (given by Gellerstam): chans, charm, chock (chance, charm, shock).

2. Swedish colloquialisms are significantly less common in the $T$ novels than in the O novels. Example: farsan / morsan (daddy / mummy): 384 tokens in $\mathrm{O}$ novels; 8 tokens in T novels.

3. Many English words trigger Swedish standard (often less idiomatic) equivalents in the T novels. Example: anlända (formal word for "arrive") instead of komma (come), etc.

4. "International" words are used in the T novels in their English, less literal senses. Examples: drastisk, lokal, massiv (drastic, local, massive) used in "English" contexts.

5. Semantic or collocational distinctions absent in English tend not to be restored in the T novels. Example: the nuances between begripa, fatta and förstå (all synonyms of "understand") are not fully represented.

In a minor, corpus-based Danish study with a similar aim (Gottlieb (forthcoming)) is it demonstrated that by the late 1990s — a generation after the publication of Gellerstam's sources - simple English loanwords (cf. generalization 1 above) had become equally frequent in non-translated literature. Still, as far as stylistic matters and syntactic imitation are concerned, the contemporary Danish translations behave more or less as the Swedish translations in Gellerstam's study. 


\subsection{Dubbing, a first-rate generator of Anglicisms?}

In comparing printed translation and the two types of screen translation in focus in the present study, we find great variance in translators" degrees of freedom - and thus, in their liberty to be idiomatic in translation. To a large extent, translators of monosemiotic works - texts, typically books, using one sign system only - are free to rephrase sentences and dialogue lines. Translators of polysemiotic works - texts as comics, films and TV programs, in which two or more parallel communication tracks are used-operate with more constraints, which vary according to both text genre and translation method.

In subtitling, one is restricted - and sometimes supported - by the wellknown time-and-space constraints (Gottlieb 1997: 72-74 \& 86-88), which may sometimes trigger a translation very close to the original -at the expense of idiomaticity. Secondly, the feedback caused by the presence of the original dialogue - and by the fact that in most subtitling countries the majority of the audience understand English — produces a certain amount of self-censorship in the subtitler. While this may often result in Englishsounding constructions - "my viewers should be able to follow the dialogue through the subtitles", cf. the Code of Good Subtitling Practice, $\S 21$ (Ivarsson \& Carroll 1998: 158) -the fact that millions of viewers constantly check on each subtitler's work does guarantee a certain degree of care in the preparation of the subtitles.

This safety mechanism is nowhere to be found in dubbing. Here the truthfulness of the translation is attacked from two corners: from the absence of the original dialogue, and from the visual side - especially in close-ups, where some degree of lip-synchrony is needed, though admittedly not always found (Goris 1993). The substitutional nature of dubbing means that viewers are in no position to check on the content or the fidelity of the translation. Only the translator and the actors know the exact phrasing of the original dialogue. No wonder then, that some of the strongest statements concerning foreign (i.e. English) influence on the domestic language through audiovisual translation are uttered by observers belonging to dubbing cultures.

In the words of one Spanish university scholar, lamenting the situation more than a decade before satellite television took the issue from the frying pan into the fire:

La televisión ha llegado a ser como un immenso, un monstruoso laboratorio de idiomas, donde las malas traducciones se manejan constantemente y poco a poco van haciendo mella en los espectadores [...] Si consideramos que la televisión española presenta un promedio de dieciséis telefilms originalmente in- 
gleses o norteamericanos a la semana, podemos sentirnos alarmados ante el futuro de la integridad de nuestra lengua. (Estrany 1970, quoted in Santoyo 1989: 164)

This quotation comes from an article entitled "Calcos sintácticos del inglés", a concept which is absolutely focal in the present study. Inspired by numerous examples of the ubiquity of syntactic calques and other Anglicisms in dubbed films and TV programs, as excellently demonstrated in the works of German linguist Thomas Herbst (Herbst 1994 and 1995), I will put forward the hypothesis that English-language films dubbed into Danish will contain more Anglicisms than subtitled versions, most markedly beyond word level.

\section{THE FILMS UNDER SCRUTINY}

As stated earlier, the aim of this study is to compare the impact of English on Danish subtitling - still the standard method of audiovisual translation in all Nordic countries - with that found in Danish dubbing. Until recently, apart from the method of subtitling, Danes would meet off-screen narration in foreign TV documentaries, and Danish voice-over in imported children's programs never in TV films, as is the case in e.g. the Baltic countries (Grigaraviciute \& Gottlieb 1999). However, they would only encounter dubbing in productions like the "classic" Disney feature-length animated films (including later video versions), from Snow White and the Seven Dwarfs back in 1937 to Tarzan in 1999. However, in the mid-nineties the major American film companies started demanding that certain of their family films be dubbed on all foreign-language markets. This has led to a wave of dubbed feature films on video in Scandinavia; interestingly, very few of these dubbed versions were used for cinema releases. In Denmark, the forerunner seems to have been Free Willy II, a mainstream family film from 1995, released on video in Denmark in 1996. Among many later examples are The Borrowers, featuring John Goodman (dubbed already for the Danish cinema release in 1998), Richie Rich's Christmas Wish from 1998 and Inspector Gadget and Muppets in Space, both from 2000. A single Francophone counterexample was set when the cartoon-based feature film Astérix \& Obélix contre César (featuring Gérard Depardieu) was released in Danish dubbed and subtitled versions in 1999.

As is the case with subtitling in major dubbing countries like Spain, Germany and Italy, dubbing has a bad name in Denmark. As the purpose of this study is to compare translational modes rather than errors, I wanted to make sure that both the dubbed and the subtitled versions in this study were of a reasonable standard. Therefore, three films were chosen that 
1) were American box-office successes, and

2) featured major film stars.

To secure a varied sample, the three films

3) were produced by three different companies, and

4) translated by three different (sets of) translators.

The films investigated were marketed in Denmark in VHS format, with a subtitled and a dubbed version on the same videotape - maybe inspired by the potential of the DVD format, which offers a number of optional dubbed (max. 8) and subtitled (max. 32) versions of the same film (see also DíazCintas 1999: 38).

In the following, I will let the famous Leonard Maltin's Movie \& Video Guide assist me in introducing the three films.

\section{Flubber}

Produced by Walt Disney Pictures in 1997 and directed by Les Mayfield, this full-length film features Robin Williams. All characters are human, except Williams' girlish secretary-like flying computer, Weebo. Screenplay by John Hughes and Bill Walsh.

Maltin's summary, as found in The Internet Movie Database (www.imdb.com) sounds as follows:

Surprisingly dull remake of Disney's The Absent Minded Professor, with Williams as the fragile genius who accidentally invents flubber - flying rubber - but forgets to attend his own wedding. Needlessly complicated by John Hughes" heavily rewritten script, which manages to leave out most of the funny stuff from the original, except for the springy basketball game. Nancy Olson (the female lead in 1961) has a cameo as a secretary.

\section{Dr. Dolittle}

This Twentieth Century Fox production from 1998, directed by Betty Thomas and featuring Eddie Murphy, casts as many (talking) animals as human actors, so strictly speaking half of the characters to be dubbed or subtitled into Danish are already dubbed in English, their faces morphed (i.e. computermanipulated, as discussed in Wehn 2000) so as to acquire lip-synchrony with the voice of the American human actors. Screenplay by Nat Mauldin and Larry Levin. 
This film unleashes another negative Maltin verdict:

1990s rethink of the Hugh Lofting character has Murphy as a busy, self-absorbed doctor who reacquires the gift he had as a child to understand animals" speech. Comic chaos ensues. Murphy is likable and energetic, but the film is awfully flat; bound to appeal to kids who don't mind that seemingly every other word in the script is "butt".

Antz

The protagonist (ant) in this 1998 production by Dreamworks Pictures and PDI not only borrows Woody Allen's voice, he displays many of his physical features. Only insects, alter egos of a host of Hollywood's finest, have a part in this movie, which is the most "adult" of the films in this study. Antz is directed by Eric Darnell and Tim Johnson, with screenplay by Todd Alcott, Chris Weitz and Paul Weitz.

Maltin sums up his judgment in this way:

Entertaining computer-animated feature about an ant named $\mathrm{Z}$ (with the voice and personality of Woody Allen) who doesn't respond well to regimentation especially after he's smitten with the queen ant's daughter, Princess Bala. Meanwhile, the colony is threatened, not only by termites but by a megalomaniacal general with his own agenda. Clever and enjoyable (all the more so for Woodyphiles), but too sophisticated and violent for young kids.

\subsection{Different versions, different constraints}

As documented in Table 1 below, although the two Danish versions of each film are available on the same videotape, only Dr. Dolittle is translated for dubbing and subtitled by the same person. However, with the two other films, the version first translated may have been known to the translator of the second version. Still, the two parallel versions of all three films (even Dr. Dolittle) display major semantic and stylistic differences - of which only some can be ascribed to the innate differences between dubbing and subtitling already mentioned.

Another slightly surprising fact, albeit of a more trivial nature, is the impressive duration of the end credits, presented on screen after the film is over, against a black background. In order to be able to compare the Anglicism load of the three films under scrutiny, each film and its credits had to be timed manually, so that the exact duration of the action could be established. Only then could one answer the question "How many Anglicisms are there per minute in each of the six video versions?. In Table 1, the end credits (plus those opening 
credits that preceed the action) are listed, together with the accurate video runtime of each film - which, because video runs 25 frames per second, against 24 frames in the cinema, is by definition $4 \%$ shorter than that of the celluloid version normally cited. It turns out that in all three films, the credits account for more than seven percent of the total runtime!

\begin{tabular}{|c|c|c|c|c|}
\hline Table 1 & $\begin{array}{l}\text { Danish } \\
\text { total video } \\
\text { runtime }\end{array}$ & $\begin{array}{l}\text { Opening credits } \\
\text { End credits } \\
\text { Effective runtime }\end{array}$ & Dubbing team & Subtitler \\
\hline Flubber & $90: 05 \mathrm{~min}$. & $\begin{array}{r}\text { 1:36 minutes } \\
\text { 5:55 minutes } \\
\mathbf{8 2 : 3 4} \text { minutes }\end{array}$ & $\begin{array}{l}\text { Translator: } \\
\text { Michael Hoffmeyer, STS } \\
\text { Adaptor: Ole Varde Lassen } \\
\text { Dubbing director: } \\
\text { Lars Thiesgaard }\end{array}$ & Jens Bom \\
\hline $\begin{array}{l}\text { Dr. Dolittle } \\
\text { Videotekst }\end{array}$ & $81: 49 \mathrm{~min}$. & $\begin{array}{l}0: 26 \text { minutes } \\
6: 12 \text { minutes }\end{array}$ & $\begin{array}{l}\text { Lasse Schmidt, } \\
\text { Dansk Videotekst } \\
\text { 75:11 minutes }\end{array}$ & $\begin{array}{l}\text { Lasse Schmidt, } \\
\text { Dansk } \\
\text { (not credited) }\end{array}$ \\
\hline Antz & 79:31 min. & $\begin{array}{r}0: 46 \text { minutes } \\
\text { 4:55 minutes } \\
\mathbf{7 3 : 5 0} \text { minutes }\end{array}$ & $\begin{array}{l}\text { Translator: Hans Kr. Bang } \\
\text { / Medievarket } \\
\text { Dubbing director: } \\
\text { Lars Thiesgaard }\end{array}$ & $\begin{array}{l}\text { Ellen Mygind } \\
\text { Kristensen }\end{array}$ \\
\hline
\end{tabular}

Table 1

As described above, these three films reflect the rather complex situation concerning the translation of (family) films for cinema and video in Denmark, where the subtitled version need not be made by the translator in charge of the dubbed version. This is partly due to copyright matters, partly due to deadlines for Danish cinema releases of Hollywood productions. Together, these and other factors mean that the differences found between dubbed and subtitled versions of the same films are not always directly connected to the different nature of subtitling and dubbing.

Still, the fundamental differences in and around the two methods - as is also described from a Spanish perspective (Agost 1999; Chaume 1999) — are instrumental in keeping the two versions apart:

a) Semiotic structure: translating diagonally (from spoken L1 to written L2, Gottlieb 1997: 107-134) often forces the translator to limit oral features to a 
minimum: subtitles (should) contain fewer "ungrammatical" features and less redundancy than the spoken lines of a dubbed film.

b) Psycholinguistic factors: the majority of the audience comprehend spoken lines faster that they can read subtitles. For this reason, and in perfect accordance with factor $a$ ) above, subtitles tend to be condensed, both in comparison with the original lines, and with the dubbed version, if it exists.

c) Market segmentation: the reasons for producing dubbed versions - which are at least ten times as expensive as subtitled versions (Luyken and others 1991: 105) — in pro-subtitling markets like Scandinavia is that film companies expect certain segments of the population to respond more favorably to this translation method. With dubbed video versions available, even young preliterate children can (make their parents) buy films like the ones studied here. The consequence of this, however, may be that in terms of language, the dubbed version is expected to be more "wholesome" than its subtitled alter ego. An example of this is found in Dr. Dolittle, where the constant anal references (cf. the Maltin quote above) act as a leitmotif, sad to say. Whereas "butt" is consistently rendered as " $r \phi \nu$ " ("ass") in the subtitles - the standard Danish "dirty" equivalent - the actors in the dubbed version keep talking about "numse", a euphemism close to the English term "bottom", but with a childish ring as in the word "tummy" (stomach). Personal communication with the translator confirmed that this "linguistic cleansing" was indeed what the film company ordered.

\section{THE ANGLICISMS FOUND IN THE SIX VERSIONS}

As stated earlier, the analytical tools and theoretical framework of this study is inspired by an earlier study (Gottlieb 1999), although some "unmarked" Anglicisms (categories A through E, see below) have been included in the present study. Naturally, this has yielded higher total Anglicism counts, as will be seen in section 5.2.

The 1999 study focused on the types of Anglicisms found in subtitling. By comparing the Danish TV subtitles of two American general-audience movies, Ghostbusters and Falling Down, a remarkable difference was found. Whereas Falling Down displayed many blatantly overt Anglicisms (including 22 tokens of words including the letters "fuck"), Ghostbusters -against initial expectations - turned out to contain just as many Anglicisms, only of a more "latent" nature, typically unidiomatic calques, i.e. constructions that may look Danish, but would sound English to people who know both languages. Both films, subtitled by two experienced subtitlers and broadcast by Danish public- 
service TV in the mid-nineties, had an Anglicism density of five percent. This means that one in every twenty subtitles in these movies contained an Anglicism.

In the present paper, investigating not two, but six video versions, I have deemed it necessary to avoid extensive exemplification. Instead, a number of tables will sum up and illustrate the exact data and make for easy comparison along two axes: between dubbed and subtitled versions, and across the three films. Table 2 below presents all Anglicisms found in the material, categorized according to a slightly revised version of the taxonomy in Gottlieb 1999. In the table, non-Danish speaking readers might find it difficult to track down the English models for several of the examples listed for illustration - but so would several Danes as well. This is exactly the point here: what happens beneath the lexical and orthographical surface of a language is - for better or worse - at least as important as the arrival of imported neologisms that so easily attracts public attention.

Readers in need of detailed interpretation of such cases of "obscure" Anglicisms may consult Table 4, which contains back-translations of randomly selected Anglicisms found in the material.

In Table 2 below, all the core findings of this study are listed, according to Anglicism categories, film and translation method used. The signs "?" and "?" in the top of the numeric columns stand for Anglicism types (e.g. "Er NN okay?") and tokens hereof (e.g. "Er du okay?" + "Er han okay?" etc.), respectively. Figures below numbers of dubbing tokens show the exact numerical relationship between the frequency of the given items in dubbing and subtitling, i.e. the dubbing/subtitling ratio. As is easily seen, for most categories there seems to exist a pro-dubbing bias. Thus, for overt lexical borrowings (category A) the dubbed versions yielded 1.83 times as many hits (tokens) as the subtitled versions: 


\begin{tabular}{|c|c|c|c|c|c|c|c|c|c|c|c|c|}
\hline \multirow{3}{*}{$\begin{array}{l}\text { Table } 2 \\
\text { ANGLICISM INVENTORY } \\
\text { Category and span of examples }\end{array}$} & \multicolumn{4}{|c|}{ Flubber } & \multicolumn{4}{|c|}{ Dr. Dolittle } & \multicolumn{4}{|c|}{ Antz } \\
\hline & \multicolumn{2}{|c|}{ DUB } & \multicolumn{2}{|c|}{ SUB } & \multicolumn{2}{|c|}{ DUB } & \multicolumn{2}{|c|}{ SUB } & \multicolumn{2}{|c|}{ DUB } & \multicolumn{2}{|c|}{ SUB } \\
\hline & $\neq$ & $\Sigma$ & $\neq$ & $\Sigma$ & $\neq$ & $\Sigma$ & $\neq$ & $\Sigma$ & $\neq$ & $\Sigma$ & $\neq$ & $\Sigma$ \\
\hline Download > nørder & 31 & $\begin{array}{c}42 \\
1.83\end{array}$ & 20 & 23 & 25 & $\begin{array}{c}39 \\
1.15\end{array}$ & 25 & 34 & 12 & $\begin{array}{c}23 \\
1.15\end{array}$ & 10 & 20 \\
\hline & 2 & $\begin{array}{c}2 \\
0.50 \\
\end{array}$ & 4 & 4 & 7 & $\begin{array}{c}8 \\
1.14 \\
\end{array}$ & 6 & 7 & 2 & $\begin{array}{c}2 \\
2.00\end{array}$ & 1 & 1 \\
\hline $\begin{array}{l}\text { C: Loan } \\
\text { Kvalitet }\end{array}$ & 10 & $\begin{array}{c}14 \\
1.40\end{array}$ & 6 & 10 & 12 & \begin{tabular}{c|}
15 \\
0.79 \\
\end{tabular} & 15 & 19 & 4 & \begin{tabular}{|c|}
4 \\
1.00 \\
\end{tabular} & 4 & 4 \\
\hline & 2 & $\begin{array}{c}3 \\
0.50\end{array}$ & 3 & 6 & 1 & $\begin{array}{c}1 \\
0.50\end{array}$ & 2 & 2 & 1 & $\begin{array}{l}1 \\
\infty\end{array}$ & 0 & 0 \\
\hline $\begin{array}{l}\text { E: Cc } \\
\text { [no it }\end{array}$ & 0 & $\begin{array}{l}0 \\
-\end{array}$ & 0 & 0 & 0 & $\begin{array}{l}0 \\
-\end{array}$ & 0 & 0 & 0 & $\begin{array}{l}0 \\
-\end{array}$ & 0 & 0 \\
\hline & 11 & $\begin{array}{c}16 \\
1.33\end{array}$ & 12 & 12 & 16 & $\begin{array}{c}19 \\
1.73 \\
\end{array}$ & 11 & 11 & 31 & $\begin{array}{c}55 \\
4.58\end{array}$ & 12 & 12 \\
\hline $\begin{array}{l}\text { G: } \mathbf{S e} \\
\text { Profe }\end{array}$ & 6 & $\begin{array}{c}10 \\
1.25\end{array}$ & 5 & 8 & 5 & \begin{tabular}{|c|}
5 \\
1.00 \\
\end{tabular} & 5 & 5 & 4 & \begin{tabular}{|c|}
4 \\
1.33 \\
\end{tabular} & 3 & 3 \\
\hline & 0 & $\begin{array}{c}0 \\
0.00 \\
\end{array}$ & 2 & 3 & 0 & $\begin{array}{l}0 \\
-\end{array}$ & 0 & 0 & 2 & \begin{tabular}{c|}
2 \\
1.00 \\
\end{tabular} & 2 & 2 \\
\hline $\begin{array}{l}\text { I-J: } \mathrm{Ch} \\
\text { [no ite }\end{array}$ & 0 & $\begin{array}{l}0 \\
-\end{array}$ & 0 & 0 & 0 & $\begin{array}{l}0 \\
-\end{array}$ & 0 & 0 & 0 & $\begin{array}{l}0 \\
-\end{array}$ & 0 & 0 \\
\hline $\begin{array}{l}\text { n/prosody } \\
\text { n, chef! }\end{array}$ & 0 & $\begin{array}{l}0 \\
-\end{array}$ & 0 & 0 & 0 & $\begin{array}{l}0 \\
-\end{array}$ & 0 & 0 & 1 & $\begin{array}{l}1 \\
\infty\end{array}$ & 0 & 0 \\
\hline $\begin{array}{l}\text { L: Bo } \\
\text { Hvilk }\end{array}$ & 13 & $\begin{array}{c}27 \\
1.80 \\
\end{array}$ & 8 & 15 & 18 & \begin{tabular}{|c|}
41 \\
1.28 \\
\end{tabular} & 16 & 32 & 16 & \begin{tabular}{c|}
22 \\
1.83 \\
\end{tabular} & 6 & 12 \\
\hline $\begin{array}{l}\text { M: B } \\
\text { Styr C }\end{array}$ & 0 & $\begin{array}{l}0 \\
-\end{array}$ & 0 & 0 & 1 & \begin{tabular}{c|}
1 \\
1.00
\end{tabular} & 1 & 1 & 0 & $\begin{array}{l}0 \\
-\end{array}$ & 0 & 0 \\
\hline $\begin{array}{l}\text { N: Tags \& p } \\
\text { Hey }>\text { sir! }\end{array}$ & 8 & $\begin{array}{c}33 \\
11.0\end{array}$ & 2 & 3 & 5 & $\begin{array}{c}74 \\
8.22 \\
\end{array}$ & 2 & 9 & 6 & \begin{tabular}{|c|}
47 \\
3.62 \\
\end{tabular} & 2 & 13 \\
\hline $\begin{array}{l}\text { O: Quotes } \\
\text { Eye of the elg }\end{array}$ & 0 & $\begin{array}{l}0 \\
-\end{array}$ & 0 & 0 & 2 & \begin{tabular}{|c|}
4 \\
1.00 \\
\end{tabular} & 2 & 4 & 0 & $\begin{array}{l}0 \\
-\end{array}$ & 0 & 0 \\
\hline $\begin{array}{l}\text { P: Slogans } \\
\text { "Make love, not war". }\end{array}$ & 0 & $\begin{array}{l}0 \\
-\end{array}$ & 0 & 0 & 0 & $\begin{array}{c}0 \\
0.00\end{array}$ & 1 & 1 & 0 & $\begin{array}{l}0 \\
-\end{array}$ & 0 & 0 \\
\hline $\begin{array}{l}\text { Q: Total shifts } \\
\text { - Oh, what a beautiful morning! } \\
\text { - Oh, what a beautiful day. }\end{array}$ & 1 & 1 & 0 & 0 & 0 & 0 & 0 & 0 & 0 & 0 & 0 & 0 \\
\hline Number of Anglicism types and tokens & 84 & 148 & 62 & 84 & 90 & 207 & 85 & 125 & 79 & 161 & 40 & 107 \\
\hline
\end{tabular}

Table 2 
Pronominal aside

In the data of Table 2, on which the subsequent discussion -including tables 3 through 5- will be based, one feature betraying English influence is missing, although it is richly documented in the material. The reason for excluding this qualified candidate for Anglicism status is that its inclusion would skew the statistical balance between the three films. Thus, this feature might yield the highest score of all, but only in one film $-D r$. Dolittle.

In both versions of this film, nearly all male animals (the great majority of the virtual zoo making up half of its cast) are referred to as "han" or "ham", the Danish correspondents of the pronoun forms "he" and "him". The point is, however, that in Danish society, only extreme animal lovers would use genderspecific pronouns for animals that were not their own pets. Normal usage in Denmark is to refer to animals in this film as the rats, horses, dogs etc. by the common gender pronoun "den" ("it"). That this practice is neglected in both the subtitles and the dubbed dialogue is a clearcut case of English influence. If included, this Anglicism could be labeled either as a morphosyntacic calque, a semantic loan, or a boosted domestic feature.

As this example also illustrates, categorization of the 792 Anglicism tokens found in the six video versions was not always easy. Still, although in principle distinctions in the (linguistic) world we observe and interact with are always more fuzzy-edged than the neat boxes we tend to squeeze worldly data into, probably very few of the findings of this study would be altered if somebody had to categorize the material from scratch - luckily, most Anglicisms fall on one stool.

\subsection{Anglicism categories: dubbing dominates in most}

By extracting and ordering the dubbing/subtitling ratios of Table 2 for all those Anglicism categories for which this makes statistical sense (those with an inventory of minimum two types in each of the six film versions), we obtain the following list:

1. Tags \& partial shifts $(\mathrm{N})$ :

2. Morphosyntactic calques (F):

3. Boosted domestic features (L):

4. Overt lexical borrowings (A):

5. Semantic loans $(G)$ :

6. Loan translations \& hybrids (C): Ratios from 0.79 to 1.40
Average 7.61

Average 2.55

Average 1.64

Average 1.38

Average 1.19

Average 1.06 
Together, these six Anglicism categories account for more than $90 \%$ of the Anglicism tokens found in the material. However, the fact that they all display a pro-dubbing bias in absolute terms does not directly indicate that the dubbed versions studied present higher frequencies of Anglicisms than do subtitled versions. The simple reason is that a dubbed soundtrack rarely prone to condensation - usually represents a fuller rendering of the original than a subtitling. When, in quantitative terms, subtitling typically means a dialogue condensation of more than twenty percent (Gottlieb 1994: 72), one should also - other things being equal — expect at least $20 \%$ fewer Anglicisms in subtitled than in dubbed versions of Anglophone films and TV programs.

As I have had no access to machine-readable versions of the translations under scrutiny here, a small random sample (see Table 4) may serve as an indicator of the relative text volume of the dubbed and the subtitled films studied. Leaving out the exceptional category P example, the number of words in the dubbed dialogue amount to 147, while the corresponding subtitles only contain 111 words. Compared with the 149 words found in the original verbal segments translated, the subtitling examples thus represent a $25 \%$ reduction in text volume, while the dubbed segments account for an insignificant 1.3 percent "reduction".

Taking the 25\% figure as a yardstick, subtitled versions should -if utterances with potential Anglicisms are condensed as much (or as often) as film dialogue in general- contain 25\% fewer Anglicisms than dubbed versions. Thus, the average ratio should amount to 1.33 (100\% divided by $75 \%)$. This means that whereas the top 4 Anglicism categories in the list above are indeed more typical of dubbing than of subtitling, the latter two categories (semantic loans and loan translations \& hybrids) are relatively more frequent in the subtitled films investigated here.

Still, the figures show that dubbed Danish dialogue contains a significantly higher proportion of Anglicisms than Danish subtitles, as hypothesized earlier.

\subsection{Anglicism types: less variation in dubbing}

We have now seen that four out of the six most common categories of Anglicisms are relatively more frequent in dubbing than in subtitling, counting all tokens without caring for variation. This means that situations where one type of Anglicism was found ten times in a film would count the same as where ten types occurred only once each. We will now look at the possible differences between dubbing and subtitling with respect to variation in this field. Returning 
to the data of Table 2, we will compute the type/token ratios for each video version of the six dominant Anglicism categories. This is done by simply dividing the total number of tokens by the number of types for each category. The results of this "cliché test" are shown in Table 3:

\begin{tabular}{|l|l|r|r|r|}
\hline ANGLICISM CATEGORY & & Flubber & Dr. Dolittle & Antz \\
\hline N: Tags \& partial shifts & DUB & 4.13 & 14.80 & 7.83 \\
\hline & SUB & 1.50 & 4.50 & 6.50 \\
\hline F: Morphosyntactic calques & DUB & 1.45 & 1.19 & 1.77 \\
\hline & SUB & 1.00 & 1.00 & 1.00 \\
\hline L: Boosted domestic features & DUB & 2.08 & 2.28 & 1.38 \\
\hline & SUB & 1.88 & 2.00 & 2.00 \\
\hline A: Overt lexical borrowings & DUB & 1.35 & 1.56 & 1.92 \\
\hline & SUB & 1.15 & 1.36 & 2.00 \\
\hline G: Semantic loans & DUB & 1.67 & 1.00 & 1.00 \\
\hline & SUB & 1.60 & 1.00 & 1.00 \\
\hline C: Loan translations \& hybrids & DUB & 1.40 & 1.25 & 1.00 \\
\hline & SUB & 1.67 & 1.27 & 1.00 \\
\hline
\end{tabular}

Table 3: Variation as expressed in Anglicism type/token ratios

Here, high ratios attest to heavy repetition of Anglicism tokens. In only 4 cases (with figures in boldface) out of 18 does dubbing offer a more varied selection of Anglicisms than subtitling. In the case of category $\mathrm{N}$, five out of the six versions display record repetitiveness, no doubt exceeding the threshold of cliché in most (adult) viewers. In both Flubber and Dr. Dolittle, the dubbed versions have a major lead in this fabrication of clichés. The only reason why Antz is almost as numerically successful in this department is the number of "sir" tokens (12 hits) in the subtitled version.

But even in Antz, dubbing is the winner when it comes to repetition of category $\mathrm{N}$ items (ratios 7.83 against 6.50). One prototypical example will show why. Tired of (ant) Princess Bala's arrogant behavior, Woody Allen's protagonist ant, Z, exclaims: "Hey, I got a name, okay?" This is dubbed "Hey, jeg har et navn, okay?" - the phrasing a simple machine-translation program would suggest. However, the idiomatic Danish solution is the one used by the subtitler: "Jeg har 
altså et navn!" (literally: "I really have a name!"). Here, we listen to two already frequent Anglicism tags in the dubbed version, with no such repetition in the subtitles. Ironically, the pro-lip sync phrasing in the dubbed lines is neither warranted by the shot (medium, not close-up) nor by the lip movements, as the film only displays slight approximation between the computer-animated ants and the American actor's articulation and rhythm of speech.

As in many other instances where English utterances are imitated in the Danish dubbed versions (especially categories N, F and L), other factors may be at work - in the translator as well as in dubbing directors and actors:

a) The belief that extreme formal equivalence is the ideal global translational strategy.

b) Habit - it is easy to use the same degree of approximation throughout the film, no matter whether lip movements are detectable or not.

c) Over-exposure to English sources - what is idiomatic Danish drowns in the sea of English. Media people in countries like Denmark not only watch more Anglophone films than Danish ones; much of what they read is also likely to be (untranslated) English-language texts.

d) "Linguistic snobbery" (cf. Chris Pratt's earlier-cited model), leading to the transfer of "smart" phrases and buzzwords to the Danish version.

Of course, not only people involved in dubbing may impersonate these traits; subtitlers - as well as literary and technical translators - sometimes find themselves in the same situation. And let me add that, to my knowledge, most dubbing translators and subtitlers take great care to make their translations sound Danish, whether in the form of written titles or spoken lines. One can only guess what might happen to the idiomaticity of Danish in dubbed and subtitled productions if translators started not caring about their own-language.

\subsection{Leaving our focus: the emergence of idiomatic dubbing}

In this section, we will pan across the different categories of Anglicisms found in the three films investigated. In order to avoid biased example selection, each example is the earliest one found in the film, and the films are "taking turns" along the way, with Flubber presenting the first category of Anglicism. However, as certain categories are not represented in all films, turntaking could not be consistent.

As promised earlier, back-translations [in square brackets] are provided when necessary. For non-idiomatic Anglicisms, idiomatic alternatives are suggested, 
marked by a hash sign: \#. Subtitles are displayed respecting their original layout, including line breaks and dashes.

Of special importance is the great difference between the dubbed and the subtitled dialogue in most of the examples. It does not take any knowledge of Danish to realize this. An evaluation of the two sets of translations, however, is probably beyond the reach of most readers. Let me therefore hasten to say that, Anglicisms apart, several of the dubbed segments in this sample - and certainly many passages in the films examined - are more idiomatic than the corresponding subtitles. The most common reason for this seems to be the suppression or compression (due to the need for condensation discussed earlier) of typically oral features in subtitling - exactly those features that are not "necessary" in a strict semantic sense and thus have little plot-carrying value. However, such features are the pragmatic oil that lubricates the machine of oral communication, and even subtitles should represent the pragmatic dimension of language. Without pragmatic markers, subtitles may sound like telegrams or mechanical formulas.

Summing up, the need for condensation in subtitling may rid viewers of some colloquial clichés (as the "okay?" tag in the verbose category $\mathrm{N}$ example in Table 4), but it also takes away a lot of the pragmatic features that keep the language alive and constitute a necessary condition for subtitles to deserve the label "authentic". Still limiting myself here to the random sample in Table 4, we have three indisputable examples where the dubbed lines are more idiomatic than the subtitles - due to the following "fillers":

1) the particle "jo", with the pragmatic function of "well" (dubbed version, category C),

2) the idiomatic use of complex verbal tense "er blevet" (dubbed version, category $\mathrm{D}$ ), and

3) the adverbial element "bare" ("just") in the dubbed version, category K. 


\begin{tabular}{|c|c|c|c|c|}
\hline Table 4 & Dubbed version & Subtitled version & Anglicism & Original segment \\
\hline $\begin{array}{l}\text { A: Overt lexical borrowings } \\
\text { (Flubber) }\end{array}$ & $\begin{array}{l}\text { Jeg ser fjernsyn! } \\
\text { Download nogle manerer. }\end{array}$ & $\begin{array}{l}\text { Jeg ser tv. } \\
\text { Download nogle manerer. }\end{array}$ & $\begin{array}{l}\text { "download" } \\
\text { ("tv" belongs to category L) }\end{array}$ & $\begin{array}{l}\text { I'm watching TV. } \\
\text { Download some manners! }\end{array}$ \\
\hline $\begin{array}{l}\text { B: Covert lexical borrowings } \\
\text { (Dr. Dolittle) }\end{array}$ & $\begin{array}{l}\text { Hvis der kommer én med en cykel } \\
\text { hængende ud af numsen, så ring. } \\
\text { Er du med? }\end{array}$ & $\begin{array}{l}\text { - eller med en cykel i røven, } \\
\text { så ring. Forstå̊t? }\end{array}$ & $\begin{array}{l}\text { "cykel" from "bicycle" } \\
\text { (borrowed before 1892, } \\
\text { cf. Sørensen 1997) } \\
\end{array}$ & $\begin{array}{l}\text { If somebody comes in with a } \\
\text { bicycle half way up their ass, } \\
\text { call me. You understand? }\end{array}$ \\
\hline $\begin{array}{l}\text { C: Loan translations \& hybrids } \\
\text { (Antz) }\end{array}$ & $\begin{array}{l}\mathrm{Ja} \text {, et par sekunder er jo ikke } \\
\text { meget, men ... hvis det } \\
\text { bare er kvalitetstid. }\end{array}$ & $\begin{array}{l}\text { Nogle sekunder } \\
\text { er ikke meget - } \\
\text { - men hvis det er kvalitetstid ... }\end{array}$ & $\begin{array}{l}\text { "kvalitetstid" from } \\
\text { "quality time" }\end{array}$ & $\begin{array}{l}\text { Well, a few seconds isn't, } \\
\text { much but ... I guess if it's } \\
\text { quality time ... }\end{array}$ \\
\hline $\begin{array}{l}\text { D: Overt pseudo-anglicisms } \\
\text { (Flubber) }\end{array}$ & $\begin{array}{l}\text { Jeg er blevet smidt af } \\
\text { basketballholdet, } \\
\text { og jeg fik } 03 \text { i kemi! }\end{array}$ & $\begin{array}{l}\text { Jeg er smidt af basketholdet } \\
\text { og er dumpet } i \text { kemi - }\end{array}$ & "basket" from "basketball" & $\begin{array}{l}\text { I got thrown off the basketball } \\
\text { team, and I flunked } \\
\text { chemistry }[. . .]\end{array}$ \\
\hline $\begin{array}{l}\text { F: Morphosyntactic calques } \\
\text { (Dr. Dolittle) }\end{array}$ & $\begin{array}{l}\text { Med tiden blev han en helt } \\
\text { almindelig fyr. I ved ... et } \\
\text { rigtigt pjok. }\end{array}$ & $\begin{array}{l}\text { Og han blev en helt } \\
\text { almindelig fyr ... } \\
\text { I ved ... et pjok. }\end{array}$ & $\begin{array}{l}\text { "I ved" from "you know", } \\
\text { \# "altsa”" [that is] or "ikke" } \\
\text { [right?] }\end{array}$ & $\begin{array}{l}\text { And just like his dad wanted, he } \\
\text { grew up to be a normal, regular } \\
\text { guy. You know ... miserable. }\end{array}$ \\
\hline $\begin{array}{l}\text { G: Semantic loans } \\
\text { (Antz) }\end{array}$ & $\begin{array}{l}\text { Du må hjælpe mig. Hvis jeg ikke } \\
\text { kan se hende igen, har jeg slet } \\
\text { ikke noget at leve for. }\end{array}$ & $\begin{array}{l}\text { Hjalp mig. Hvis ikke jeg får } \\
\text { hende at se igen, har jeg ikke } \\
\text { noget at leve for. }\end{array}$ & $\begin{array}{l}\text { "kan" and "can" are false } \\
\text { friends.\# "mà" [may] }\end{array}$ & $\begin{array}{l}\text { You have to help me. If I can't } \\
\text { see her again, my life is just } \\
\text { not worth living. }\end{array}$ \\
\hline $\begin{array}{l}\text { H: Revivals } \\
\text { (Antz only) }\end{array}$ & $\begin{array}{l}\text { - Bare rolig. Jeg er uskadt. } \\
\text { - Dig!? Du er er uskadt? }\end{array}$ & $\begin{array}{l}\text { - Bare rolig. Jeg er uskadt. } \\
\text { - Du?! Du er uskadt! }\end{array}$ & $\begin{array}{l}\text { "uskadt" is revived by parallel } \\
\text { "okay". \# "Der skete ikke } \\
\text { noget med mig" [nothing } \\
\text { happened to me] }\end{array}$ & $\begin{array}{l}\text { - Don't worry. I'm okay. } \\
\text { - You? You're okay? }\end{array}$ \\
\hline $\begin{array}{l}\text { K: Changes in } \\
\text { pronunciation/prosody } \\
\text { (Antz only) }\end{array}$ & $\begin{array}{l}\text { Jeg fik mig bare en sludder } \\
\text { med min ven, chef! }\end{array}$ & $\begin{array}{l}\text { Jeg sludrede med min } \\
\text { ven, sir! }\end{array}$ & $\begin{array}{l}\text { Emphatic stress on the tag } \\
\text { "chef" [chief] is not idiomatic } \\
\text { in Danish. } \\
\text { ("sir!" belongs to category N) }\end{array}$ & $\begin{array}{l}\text { Sorry, Sir. I was just having a } \\
\text { little chat with my friend, } \underline{\text { Sir! }}\end{array}$ \\
\hline
\end{tabular}




\begin{tabular}{|c|c|c|c|c|}
\hline L: Boosted domestic features & Undskyld mig! & Af banen! & $\begin{array}{l}\text { "Undskyld mig" from "excuse } \\
\text { me". Distinction between } \\
\text { "undskyld" and "undskyld mig" } \\
\text { is not respected }\end{array}$ & Coming through! \\
\hline $\begin{array}{l}\text { M: Bilingual wordplay } \\
\text { (Dr. Dolittle) }\end{array}$ & Styr dit hundicap! & Styr dit hundicap! & $\begin{array}{l}\text { "hund" is "dog" } \\
\text { (This line is uttered to a dog) }\end{array}$ & Oh, go flatter yourself! \\
\hline $\begin{array}{l}\text { N: Tags \& partial shifts } \\
\text { (Antz) }\end{array}$ & $\begin{array}{l}\text { Jeg er måske lidt sart, men ... } \\
\text { jeg har et problem med at drikke } \\
\text { af et andet væsens bagdel, okay? }\end{array}$ & $\begin{array}{l}\text { Det er ikke lige mig at drikke } \\
\text { af andres udstødningsrør. }\end{array}$ & $\begin{array}{l}\text { "okay" tag from “okay?" } \\
\text { \# er du med? [are you with?] } \\
\text { or an inserted particle, e.g. \# } \\
\text { "altså" }\end{array}$ & $\begin{array}{l}\text { Call me crazy, but I have a thing } \\
\text { about drinking from the anus } \\
\text { of another creature, okay? }\end{array}$ \\
\hline $\begin{array}{l}\text { 0: Quotes } \\
\text { (Dr. Dolittle only) }\end{array}$ & $\begin{array}{l}\text { Ikke "eye of the elg", "eye of the } \\
\text { tyr", men "eye of the tiger". }\end{array}$ & $\begin{array}{l}\text { Ikke "Eye of the elg" } \\
\text { eller "Eye of the tyr". }\end{array}$ & $\begin{array}{l}\text { In this quote, the key terms } \\
\text { are translated }\end{array}$ & $\begin{array}{l}\text { Not "Eye of the Moose", not } \\
\text { "Eye of the Bull": "Eye of the } \\
\text { Tiger" }\end{array}$ \\
\hline $\begin{array}{l}\text { P: Slogans } \\
\text { (Dr. Dolittle only) }\end{array}$ & $\begin{array}{l}\text { [segment missing in dubbed } \\
\text { soundtrack] }\end{array}$ & $\begin{array}{l}\text { Attica! } \\
\text { "Make love not war!" }\end{array}$ & $\begin{array}{l}\text { This slogan is often used in } \\
\text { Danish; no Danish } \\
\text { correspondent exists }\end{array}$ & $\begin{array}{l}\text { Attica! } \\
\text { Make love, not war! }\end{array}$ \\
\hline $\begin{array}{l}\text { Q: Total shifts } \\
\text { (Flubber only) }\end{array}$ & $\begin{array}{l}\text { - Oh, what a beautiful morning! } \\
\text { - Oh, what a beautiful day }\end{array}$ & $\begin{array}{l}\text { - Sikke en skøn morgen. } \\
\text { - Sikke en skøn dag. }\end{array}$ & $\begin{array}{l}\text { Well-known lyrics translated } \\
\text { ad hoc in subtitled version }\end{array}$ & $\begin{array}{l}\text { - Oh, what a beautiful morning .. } \\
\text { - Oh, what beautiful day. }\end{array}$ \\
\hline
\end{tabular}

Table 4 


\section{ANGLICISMS: AN INTRICATE MIX}

Should one have had any doubts left as to the scope of Anglicisms in TV translations, one might be convinced by simply looking at Table 4 . This even happens to contain a Danish Anglicism (category L: "undskyld mig") enhanced by similar usage in Swedish, a pivot language often used between Anglophone productions and Danish versions (for discussions of pivot versions in screen translation, Gottlieb 1997: 127-129, and Grigaravičiùte \& Gottlieb 1999).

As a supplement to the random examples contained in Table 4, I will now provide the reader with some more examples of the varied supply of Anglicisms found in just three films, certainly a minimal text corpus in comparison with the electronic corpora -containing several hundred million words— used in modern lexicography, for instance.

As is obvious from the preceding sections, in establishing an operational definition of Anglicism for this empirical study, I chose an etymological, diachronic approach: as witnessed in the definition given in section 2.1, all results of language contact between English and Danish leading to absolute or relative changes in Danish are considered Anglicisms. This implies the inclusion of several "ancient" items, as many simple English loans found in the material date several centuries back. "Blak" (English: "ink"), for instance, has been totally integrated in Danish for generations, and only lexicologists would have any idea of its "black" heritage. Even an overt borrowing like "weekend" found in two of the films investigated - is mentally integrated and used by all Danish speakers, as it fills a semantic void in the language.

Not all lexical borrowings in the material are fully accepted, however. But if they are not, they are always orthographically visible to a Dane, like "download" (used several times in Flubber). Less conspicuous than Anglicisms of the "download" type are calques like "på radioen" (wrong preposition) and "baby-alligator" (misleading prefix) —instead of the idiomatic "i radioen" and "alligatorunge" - and semantic changes in the existing words "kontrollere" and "morgen" (in the direction from "check on" to "command" and "early morning" to "the whole day before noon"). Due to the fact that English lacks a word mirroring the Danish "formiddag" ("forenoon"), this latter instance is one of several where English impact tends to limit semantic precision, rather than create new semantic nuances - as in the case of most lexical borrowings. Similarly, by using the hyperonym "bedstefar" for "grandpa" instead of the precise — and more idiomatic - "farfar" (dad's dad), English produces a semantically weakened Danish utterance.

In the calque department, added article before professions of people -an Anglicism also documented in Spanish (Pratt 1986) - appeared twice in the 
material (e.g. "jeg er en bearbejder" for "I'm an adapter"), together with more than thirty other sub-categories: reversed word order, unmotivated "of"-like genitives, wrong verb tenses, unlikely collocations, stylistic shifts, wrong use of military titles, etc.

A sophisticated type of morphosyntactic calque, often discussed in connection with screen translation in non-Anglophone speech communities, is the transfer of English "question plus affirmative" answer in dialogue situations where many other languages use the opposite pattern to express the same verbal exchange. In our material, five of the six versions contain such questions - all of them tokens of the "Are you okay?" + "Yes!" model— which on Danish TV have nearly ousted the normal model, in which the answer "nej" (no) is expected if everything is all right. Especially in subtitling, the idea of viewers hearing a "yes", but reading a "nej" seems to terrify most translators.

In the Televisió de Catalunya dubbing stylebook (1997: 62) the same phenomenon is described through a counterexample: In order to avoid Anglicisms, translators are encouraged to render the lines

-Because you didn't want to be a witness, right?

-Yes.

as

—Perquè vostè no volia fer de testimoni, oi?

$-N o$.

Finally, the six Danish video versions studied here contained several borderline cases between calques - which one might avoid in translationand close renderings of culture-specific utterances - which may add color to the translation. As stated earlier, I decided not to include constant reference to animals by the pronoun "han" (he) in the Anglicism count. At the same time, expressions as "jeg kan forklare" without an object ("I can explain"), used as an excuse, and "jeg elsker dig" ("I love you"), used as a greeting, were considered morphosyntactic calques and boosted domestic features, respectively.

\subsection{Marked Anglicisms: convergence below the surface}

This section rounds off the discussion by concentrating on the perhaps most controversial categories of Anglicisms - often collectively dismissed as simply errors - namely: morphosyntactic calques $(F)$, semantic loans $(G)$, revivals $(H)$, changes in pronunciation and prosody $(\mathrm{K})$, boosted domestic features $(\mathrm{L})$, and tags \& partial shifts (N). In the following, these categories will be joined under the label "marked". As can be seen in Table 5, they are significantly more frequent 
in the dubbed than in the subtitled versions, with bias figures (i.e. dubbing/ subtitling ratios) ranging almost $50 \%$ higher than those found for Anglicisms in general. Thus, in Dr. Dolittle, the "overweight" of marked Anglicisms in the dubbed version is 2.44, against a more modest 1.66 for all Anglicisms, an "overoverweight" of $47 \%$.

As stated above, there are two good reasons for this proliferation of (marked) Anglicisms in dubbing: its oral nature, and the demand for lip-synchrony in certain shots. However, as with subtitling - where translators sometimes condense "difficult" dialogue with the excuse of respecting time-and-space constraints - dubbing often seems to trigger automatic solutions in translators and adaptors that make the dialogue cling even more to English sentence and word structures than any lip-sync logic would demand.

In the first part of Table 5, which concludes the statistical analysis of the material in this study, the density of marked Anglicisms in the six versions is compared with that of the entire inventory of Anglicisms. In the second part of the table, densities are related to the effective duration (as calculated in Table 1) of the three films studied:

\begin{tabular}{|c|c|c|c|c|c|c|c|c|c|c|c|c|}
\hline \multirow{3}{*}{$\begin{array}{l}\text { Table } 5 \\
\text { ANGLICISM DENSITY } \\
\text { a) Absolute figures } \\
\text { Anglicism types + tokens }\end{array}$} & \multicolumn{4}{|c|}{ Flubber } & \multicolumn{4}{|c|}{ Dr. Dolittle } & \multicolumn{4}{|c|}{ Antz } \\
\hline & \multicolumn{2}{|c|}{ DUB } & \multicolumn{2}{|c|}{ SUB } & \multicolumn{2}{|c|}{ DUB } & \multicolumn{2}{|c|}{ SUB } & \multicolumn{2}{|c|}{ DUB } & \multicolumn{2}{|c|}{ SUB } \\
\hline & 84 & 148 & 62 & 84 & 90 & 207 & 85 & 125 & 79 & 161 & 40 & 67 \\
\hline Anglicism bias in dubbing (tokens) & - & 1.76 & - & - & - & 1.66 & - & - & - & 2.40 & - & - \\
\hline Marked Anglicism types + tokens & 38 & 86 & 29 & 41 & 44 & 139 & 34 & 57 & 60 & 131 & 25 & 42 \\
\hline Marked A. bias in dubbing (tokens) & - & 2.10 & - & - & - & 2.44 & - & - & - & 3.12 & - & - \\
\hline b) Time-related figures & \multicolumn{4}{|c|}{ Flubber } & \multicolumn{4}{|c|}{ Dr. Dolittle } & \multicolumn{4}{|c|}{ Antz } \\
\hline \multirow[t]{2}{*}{ Effective runtime (cf. Table 1) } & \multicolumn{4}{|c|}{$82: 34$ minutes } & \multicolumn{4}{|c|}{$75: 11$ minutes } & \multicolumn{4}{|c|}{ 73:50 minutes } \\
\hline & \multicolumn{2}{|c|}{ DUB } & \multicolumn{2}{|c|}{ SUB } & \multicolumn{2}{|c|}{ DUB } & \multicolumn{2}{|c|}{ SUB } & \multicolumn{2}{|c|}{ DUB } & \multicolumn{2}{|c|}{ SUB } \\
\hline Anglicism tokens per minute & \multicolumn{2}{|c|}{1.79} & \multicolumn{2}{|c|}{1.02} & \multicolumn{2}{|c|}{2.75} & \multicolumn{2}{|c|}{1.66} & \multicolumn{2}{|c|}{2.18} & \multicolumn{2}{|c|}{0.91} \\
\hline Marked A. tokens per minute & \multicolumn{2}{|c|}{1.04} & \multicolumn{2}{|c|}{0.50} & \multicolumn{2}{|c|}{1.85} & \multicolumn{2}{|c|}{0.76} & \multicolumn{2}{|c|}{1.77} & \multicolumn{2}{|c|}{0.57} \\
\hline
\end{tabular}

Table 5

As far as the subtitled versions are concerned, it is interesting to see that density figures fit in nicely with the results found in the predecessor of this study (Gottlieb 1999), in which only marked Anglicisms were counted. The two films investigated, Ghostbusters and Falling Down, contained an average 
of 0.43 and 0.57 tokens per minute, respectively. These figures are quite in line with the 0.50 to 0.76 range found in the subtitled family films studied here.

Turning back to the the dubbing and subtitling data summarized in Table 5, it is striking to see that the number of marked Anglicisms in the dubbed versions is higher than the total number of Anglicisms in the subtitled versions: in Antz there are even almost twice as many (1.77 marked items per minute in the dubbed version against 0.91 items in the subtitled one). This should give a definite answer to the question in the title of this paper: "No, Danish voices are even more American (English) than Danish subtitles."

The potentially negative ramifications of this fact have been touched upon at several instances in the discussion so far. To end on a more positive note, one could argue that the result of continued Anglophone influence might be that

a) not only might "influenced" languages overtake English as the (selfproclaimed) leader in vocabulary and semantic richness, as they keep wedging English-inspired words and constructions into their fabric, already containing many layers and threads of foreign origin, but

b) many non-Anglophone cultures and languages will approach each other by adopting the same English features, and this convergence may in turn enhance mutual understanding between nations (as Denmark and Spain, for instance) already highly exposed to English as a foreign language.

Phrased differently, these two realistic scenarios mean that as English conquers the world, the world conquers English.

\section{REFERENCES}

Agost, R. (1999): Traducción y doblaje: palabras, voces e imágenes, Barcelona, Ariel.

Chaume VARELA, F. (1999): "La traducción audiovisual: investigación y docencia", Perspectives. Studies in Translatology (Hispanic Translation Studies), 7: 2, 209-219.

Díaz-Cintas, J. (1999): "Dubbing or subtitling: the eternal dilemma", Perspectives: Studies in Translatology, 7: 1, 31-40.

Gellerstam, M. (1986): "Translationese in Swedish novels translated from English" in Wollin, L. and H. LindQuist (eds.) (1986): Translation Studies in Scandinavia, Lund, Lund University Press, 88-95.

GoRIs, O. (1993): "The question of French dubbing: Towards a frame for systematic investigation", Target, 5: 2, 169-190.

GoTTLIEB, H. (1994): Tekstning - synkron billedmedieoversattelse, University of Copenhagen, Center for Translation Studies. 
- (1997): Subtitles, Translation \& Idioms, University of Copenhagen, Center for Translation Studies.

- (1999): "The impact of English: Danish TV subtitles as mediators of Anglicisms", Zeitschrift für Anglistik und Amerikanistik, 47: 2, 133-153.

- (forthcoming): "Sample chapters on the Web as a basis for empirical studies of translationese". Paper read at the Research Models in Translation Studies Conference, Manchester University 28-30 April 2000. (To be published in a proceedings volume, St. Jerome Press).

GrigaraviČIŪTĖ, I. and H. GotTlieb (1999): "Danish voices, Lithuanian voiceover. The mechanics of non-synchronous translation", Perspectives: Studies in Translatology, 7: 1, 41-80.

HERBST, T. (1994): Linguistische Aspekte der Synchronisation von Fernsehserien, Tübingen, Niemeyer.

- (1995): "People do not talk in sentences. Dubbing and the idiom principle", Audiovisual Communication and Language Transfer, Translatio - FIT Newsletter, 14: 3-4, 257-271.

Ivarsson, J. and M. Carroll (1998): Subtitling, Simrishamn (Sweden), TransEdit.

LARSEN, F. (1994): "More than loan-words. English influence on Danish", RASK. Internationalt Tidsskrift for Sprog og Kommunikation (Odense University (Denmark): Institute for Languages and Communication), 1, 21-46.

Lorenzo, E. (1996): Anglicismos Hispánicos, Madrid, Gredos, Biblioteca Románica Hispánica.

LUYKEN, G.-M. y otros (1991): Overcoming Language Barriers in Television. Dubbing and Subtitling for the European Audience, European Institute for the Media, Manchester (now Düsseldorf).

LøVFaLL, J. (1997): "Bruk av norsk og engelsk språk i norsk reklame", Språknytt, 3, 11-14. Oslo, Norsk Språkråd.

Mogensen, E. (1998): "New terminology and the translator" in GambieR, Y. (ed.): Translating for the Media. Papers from the International Conference "Languages \& The Media", Berlin, November 22-23, 1996, University of Turku, Centre for Translation and Interpreting, 267-272.

Pratt, C. (1986): “Anglicisms in contemporary European Spanish" in VIERECK and BALD (eds.) (1986: 345-368).

SajavaARA, K. (1991): "English in Finnish: Television subtitles" in Ivir, V. and D. KAlogJerA (eds.): Languages in Contact and Constrast. Essays in Contact Linguistics, Berlin / New York, Mouton de Gruyter, 381-390.

SAntoyo, J.C. (1989): El delito de traducir, Secretariado de Publicaciones, Universidad de León. 
SICHERL, E. (1999): The English Element in Contemporary Standard Slovene: Phonological, Morphological and Semantic Aspects, Ljubljana, Znanstveni inštitut Filozofske fakultete.

Sørensen, K. (1986): 'On Anglicisms in Danish' in Viereck and Bald (eds.) (1986: 31-50).

- (1997): A Dictionary of Anglicisms in Danish, Copenhagen, The Royal Danish Academy of Sciences and Letters.

Televisió de CATAlunya (1997): Criteris lingüistics sobre traducció i doblatge, Barcelona, Edicions 62.

VIERECK, W. and W.-D. BALD (eds.) (1986): English in Contact with Other Languages, Budapest, Akadémiai Kiadó.

WEHN, K. (2001): "About remakes, dubbing and morphing: Some comments on visual transformation processes and their relevance for translation theory" in Gambier, Y. and H. GotTlieb (eds.) (2001): (Multi)Media Translation: Concepts, Practices and Research, Amsterdam / Philadelphia, John Benjamins. 


\section{LA ADAPTACIÓN CINEMATOGRÁFICA Y DRAMÁTICA COMO TRADUCCIÓN}




\title{
ADAPTACIÓN, TRADUCCIÓN Y OTROS TIPOS DE TRANSFERENCIAS
}

\author{
Raquel Segovia \\ Universitat Jaume I
}

\section{INTRODUCCIÓN}

Hace ya un tiempo que los estudios de traducción están expandiendo su campo de trabajo e investigación a otros tipos de prácticas discursivas -aparte de la traducción interlingüística e intercultural-, las cuales, dada su naturaleza interdisciplinar, forman también parte de disciplinas como el análisis del discurso, la literatura comparada o la narratología audiovisual. Entre otros, destacan la adaptación cinematográfica y televisiva, los remakes y algunas otras modalidades que todavía no tienen un nombre más específico para ser designadas. Tal como trataré de exponer a continuación, dicha ampliación del campo plantea un problema terminológico, ya que, según han observado algunos especialistas, tales prácticas no deberían ser consideradas como una clase de traducción, si bien comparten con esta actividad algunas características en común. Por tal motivo, se hace necesaria la introducción de un término diferente y de ahí que en esta exposición vayamos a adoptar el de transferencia o transvase, como categoría superior que engloba dentro de sí a todas ellas, incluidas la traducción y la adaptación (práctica, ésta última, en la que vamos a centrar nuestro interés y que presenta, a su vez, algunos problemas interesantes). 


\section{UN PROBLEMA TERMINOLÓGICO}

Es cierto que para poder estudiar una práctica como la adaptación, algunos investigadores procedentes de los estudios de traducción han partido de la famosa clasificación tripartita de Jakobson (1959), en la que estableció una distinción entre traducción intralingüística o reverbalización, traducción interlingüística o traducción propiamente dicha y traducción intersemiótica o transmutación. Es más, incluso los especialistas de otros campos como la literatura comparada o la narrativa audiovisual han tratado esta cuestión en términos de traducción (Peña Ardid, 1992: 28; García Jiménez, 1993: 61).

Frente a ellos, sin embargo, existen otras voces que consideran la división jakobsoniana bastante insatisfactoria y problemática, ya que en realidad sólo la segunda clase -la traducción interlingüística-, es la forma que normalmente se usa cuando nos referimos a la traducción. Hermans (1995), por ejemplo, recuerda que dicha clasificación ha sido objeto de comentarios por parte de algunos críticos y teóricos desde Toury (1986), quien sugirió que debería de haber también una traducción intrasemiótica, a Derrida (1985), el cual, según explica este autor, dedujo lo siguiente (1995: 17):

If intralingual translation is a form of translation, then in Jakobson's own essay the term 'rewording' is a translation of the term 'intralingual translation'. In this way the first and the third term in the list are both translated intralingually: 'intralingual translation' is rendered as 'rewording', and 'intersemiotic translation', is reworded as 'transmutation'. But the middle term, 'interlingual translation', is not reworded or intralingually translated. It is merely repeated, tautologically restated: this form of translation is translation, 'interlingual translation' is 'translation proper'. The addition of the qualifier 'proper' suggests moreover that the other two are not 'properly' translation. This, it will be appreciated, undermines the whole exercise of ranging them all three together as so many kinds of translation.

De acuerdo con estas observaciones, lo más conveniente sería utilizar una terminología diferente a la hora de trabajar con otras clases de prácticas, ya que, de otro modo, se corre el riesgo de extrapolar el término traducción vaciándolo de gran parte de significado, asociaciones y contexto originales. De ahí que el mismo Hermans (1996: 26) sugiriera posteriormente como una opción mejor el término inglés rewriting, dado por Lefevere (1992):

Translation may be regarded as a particular mode of discursive transfer between cultural circuits and systems. It constitutes one among a number of possible modes of the intercultural movement of texts. Other modes include, for example, importing or exporting a text in untranslated form [...]. Summary, paraphrase, 
gloss, critical commentary and other forms of what André Lefevere broadly calls 'rewriting' (e.g. in Lefevere 1992) constitute a further set of alternative modes, as do transformations into other semiotic media, and so on.

\section{EL PROCESO TRANSFERENCIAL}

En la cita anterior, Hermans (1996) menciona una serie de transferencias discursivas como son, aparte de la traducción, el resumen, el comentario crítico o las transformaciones a otros medios semióticos que se llevan a cabo. Este último tipo de transferencias a la que se refiere este estudioso de manera muy general es la que nos interesa a nosotros destacar, pues constituye por sí sola un subgrupo muy numeroso y con unas características tan especiales como complejas; además, en él es donde se ubica precisamente la adaptación.

Sin embargo, también con respecto a estas prácticas, el término rewriting o reescritura resultaría desde nuestro punto de vista inapropiado, constatación ésta que ha resaltado Mazdon (1996: 50), quien hace la siguiente objeción al tratar la cuestión de las adaptaciones:

Lefevere centres his discussion of rewriting around literary texts. However he does stress that the term 'rewriting' is intended to cover all forms of adaptation including cinematic and televisual work. Clearly it would be foolish to ignore the differences between literature and cinema. Both are multifarious systems and the total cinematic sign is particularly complex. It is both visual and acoustic and it is shaped by numerous codes, for example verbal, narrative, vestimentary, moral and cinematic codes. The polysemic nature of the filmic sign must evidently be considered when examining rewriting for the cinema. It is not sufficient to simply analyze the translation of dialogue, rather than the transposition of all codes outlined above needs to be studied.

El uso de un único término (rewriting) y, lo que es más, un término que hace referencia a la dimensión verbal -en su modo escrito-, no parece, pues, ser lo más adecuado para estudiar un tipo de transferencia como la adaptación audiovisual, ya que, contrariamente al modelo que siempre solemos adoptar, el cual establece una relación directa entre el texto del sistema de partida y el de llegada, una transferencia de este tipo conlleva un proceso que tiene lugar en dos fases:

a) La reexpresión o reformulación en forma de guión del texto original (novela, pieza teatral, relato corto, artículo periodístico, etc.).

b) La transposición semiótica de dicho guión a fin de hacer de él un texto audiovisual completo. 
Es decir, que el proceso no iría de $a$ a $b$, sino de $a$ a $b$ y de $b$ a $c$, por lo que el término rewriting o reescritura debe aplicarse sólo a la primera parte de este proceso transferencial, pero no es apropiado para la segunda, ya que esta fase (que es por la que pasa cualquier guión, sea o no una adaptación, a fin de convertirse en un producto audiovisual), consiste en una transposición o transformación semiótica en la que entran en juego muchos tipos de códigos.

Llegados a este punto, creemos necesario añadir una importante observación y es que el proceso en dos fases que acabamos de describir, en realidad, nunca resulta ser tan simple. Por ejemplo, la adaptación cinematográfica de una obra de teatro clásico es susceptible de realizarse a partir de uno, dos o incluso más textos de partida, ya que en ocasiones coexisten varias versiones originales. Además, el producto resultante puede ser sometido, después, a diversas transformaciones (dando lugar así a otras versiones de la misma adaptación), puesto que una de las características de los textos audiovisuales es, precisamente, su gran capacidad de manipulación. Así, dicha adaptación puede ser traducida posteriormente a otras lenguas mediante el doblaje o la subtitulación, puede ser coloreada o acortada en algunas de sus secuencias por motivos de censura, etc.

\section{4. ¿QUÉ ES EXACTAMENTE UNA ADAPTACIÓN?}

Aunque al hablar del proceso transferencial de la adaptación hemos definido ya en cierto modo este tipo de práctica, también con respecto a ella puede haber confusiones en cuanto a la terminología. De ahí la conveniencia de ubicar la adaptación dentro de un esquema más general de transferencias intersemióticas. Tal esquema podría incluir los siguientes grupos:

a) Transferencias en las que el texto de partida pertenece a un medio de comunicación impreso: prensa (tebeos, cómics, noticias, sucesos, fotonovelas, etc.) o libro (novelas, relatos cortos, obras de ensayo, teatro, cuentos infantiles, etc.); y el texto de llegada -después de haber sido sometido al proceso debidoa un medio de comunicación de naturaleza auditiva, visual o audiovisual: radio (seriales radiofónicos), cine (películas de dibujos animados, dramas, comedias, documentales, etc.), televisión (series, telecomedias, dibujos animados, telefilmes, etc.), ordenador (hipertextos, juegos interactivos).

b) Transferencias cuyos textos de partida pertenecen a medios (audio)visuales y los de llegada a medios impresos; por ejemplo, el transvase de una película a una novela. Este tipo de transferencias no es tan frecuente como el primero y suele realizarse, sobre todo, hacia medios impresos cuya composición contiene códigos visuales (cómics, fotonovelas). 
c) Transferencias en las que tanto el texto de partida como el de llegada pertenecen a un mismo medio, ya sea impreso, como, por ejemplo, la traducción, o (audio)visual, y éste puede ser un medio diferente o incluso el mismo, como en el caso de los remakes, que son transferencias realizadas dentro del medio cinematográfico (Segovia, 1998).

d) Transferencias que se realizan entre otros sistemas semióticos, como la danza, la ópera, el ballet o el teatro, de las cuales no vamos a ocuparnos aquí, pero que comparten con el sistema audiovisual el hecho de conllevar un componente espectacular (es decir, implican una interacción entre exhibición y espectador).

De todas estas prácticas transferenciales, suele aplicarse por tradición el término adaptación a las agrupadas en el primer apartado; es decir, a aquellos transvases realizados a partir de un medio impreso que son sometidos a un proceso de transformación cuyo resultado es un texto perteneciente a un medio audiovisual, más concretamente el cinematográfico (aunque también puede hablarse de adaptación televisiva, por ejemplo). En lo que se refiere a las transferencias incluidas en los demás apartados, quizá debiéramos considerar su tratamiento con otros nombres diferentes al de adaptación, a fin de limitar más este campo, ya de por sí inmenso.

Como puede observarse, los términos en los que yo he definido la práctica de la adaptación, incidiendo sobre todo en el medio de comunicación por el que se transmiten el texto de partida y el resultante, no son los mismos que utilizan otros estudiosos, que tienden a enfocar su análisis desde el punto de vista cultural y hablan más bien de sistemas artísticos (p.ej. literatura y cine). Ello puede deberse, en parte, a que el término medio de comunicación sigue produciendo todavía en el mundo académico e intelectual cierto rechazo, mientras que el de manifestación artística sublima por el contrario el objeto de estudio. Sin descartar aquí ninguna de las dos posibilidades, mi preferencia a este respecto obedece a unas razones muy específicas y es que al hablar de medios de comunicación impresa en lugar de literatura en lo que se refiere al sistema de partida, estamos evitando una cuestión que enlaza con la dicotomía cultura de élitecultura de masas, pues iqué es lo que consideramos exactamente literatura y qué tipo de manifestaciones son susceptibles de ser incluidas en dicha categoría: novelas, relatos cortos, piezas de teatro y poemas, o también cómics, historias infantiles, artículos de prensa, etc.?).

Por otro lado, y en lo referente al sistema de llegada, Peña Ardid (1992) nos dice que ya desde sus primeros tiempos de andadura, el medio cinematográfico (al igual que ha hecho el televisivo posteriormente) empezó a transvasar de forma generalizada todo tipo de materiales pertenecientes a los medios impresos (relatos, folletines, piezas teatrales, artículos periodísticos, 
biografías, etc.), «provocando con ello el recelo de gran parte del mundo literario, que mostró en principio escasa predisposición a entenderse con una modalidad espectacular asociada a la técnica y a la mercancía vendible» (1992: 22). Así pues, no debemos olvidar que, en sus inicios, el cine no fue considerado un sistema artístico y que sólo con el paso de los años se ha ido consolidando como tal.

Quizá no sea arriesgado aventurar que, de todos los elementos que hacen posible un acto de comunicación, el más importante a la hora de tratar la adaptación y, en general, todas las demás transferencias aquí mencionadas es, en definitiva, el medio. De ser así, el objetivo principal de este tipo de prácticas sería la experimentación con los medios y, sobre todo, con los nuevos sistemas mediáticos que siguen surgiendo y que cada vez consiguen llegar a mayor número de destinatarios en un solo acto de comunicación. La aceptación de esta idea nos lleva a ver que en realidad las transferencias entre medios han existido siempre y que, tal como explica García Jiménez (1993: 16), se ha enfocado la cuestión desde el campo de estudio de la narrativa audiovisual: ${ }^{1}$

En una situación de proliferación de soportes audiovisuales como es la que caracteriza a la época actual, el fenómeno del transfert se ha generalizado y popularizado (del cómic al cine, de la fotonovela a la radio, de la literatura a la televisión, de la imagen analógica del cine a la imagen sintética de los relatos virtuales, etc.).

\section{SEMEJANZAS Y DIFERENCIAS ENTRE LA TRADUCCIÓN Y LAADAPTACIÓN}

Teniendo en cuenta que el presente trabajo forma parte de un volumen dedicado a la traducción audiovisual, me gustaría presentar las posibles semejanzas y diferencias que podrían establecerse entre la traducción y la adaptación.

Para empezar, hemos partido del supuesto de que ambas prácticas forman parte de una clasificación más general que aquí hemos denominado transferencias. Ahora bien, mientras que la traducción es un tipo de transferencia que se lleva a cabo entre diferentes lenguas y culturas, la adaptación es susceptible de realizarse tanto de esta forma como dentro de una única cultura y en la misma lengua.

1. La narrativa audiovisual es una disciplina de carácter teórico-práctico que tiene por objeto «descubrir, describir, explicar y aplicar la capacidad de la imagen visual y acústica para contar historias» (García Jiménez, 1993: 61). 
Por otro lado, y en lo que respecta al medio, una traducción, en principio, siempre se lleva a cabo a partir de y hacia un medio impreso y su finalidad es operar con los códigos lingüísticos (ya sea en su modalidad escrita u oral), incluso en aquellos textos de naturaleza audiovisual. Frente a esto, en las adaptaciones se produce un transvase textual a otro medio diferente a fin de experimentar con todos los códigos que componen ese nuevo medio de llegada (lingüísticos, narrativos, gestuales, de vestuario, de luz, etc.). De ahí que sea tan importante para los practicantes y estudiosos de este tipo de transferencias conocer en profundidad el funcionamiento semiótico de todos ellos.

Tal constatación ha llevado a algunos teóricos de la traducción a rechazar la idea de considerar la adaptación como una clase de traducción, ya que en este tipo de práctica se pone en entredicho la clásica noción de fidelidad o equivalencia textual. Y es que una adaptación es más bien un acto consciente de interpretación; es decir, no persigue necesariamente ser lo más parecida al texto de partida que la ha originado y, aunque así sea, el cambio de medio hace imposible dicha fidelidad, algo que puede constatarse mejor al comparar dos adaptaciones realizadas a partir de un mismo texto.

\section{UN CAMPO DE ESTUDIO CON GRAN FUTURO}

Soy consciente de que existen otros muchos aspectos sumamente interesantes -e igualmente discutibles- sobre la práctica y el estudio de la adaptación en relación con la traducción y con otros tipos de transferencias. Me refiero, por ejemplo, al transvase de géneros y formatos, a la cuestión de la autoría colectiva de ciertos textos, a la problemática en torno a los conceptos de originalidad y reproducción textual o a la noción de intertextualidad. Tales cuestiones forman parte de un campo en el que hay todavía grandes lagunas pendientes de investigación y sobre el que los estudiosos de la traducción tienen mucho que aportar. A este respecto, y antes de pasar a analizar casos concretos de adaptaciones (el tipo de trabajos que más abunda hoy en nuestro país), sería necesario, desde mi punto de vista, establecer una serie de principios como los que aquí he intentado exponer, a fin de hacer de ellos un objeto de reflexión que contribuya a delimitar más claramente las características particulares de esta interesante práctica transferencial. 


\section{BIBLIOGRAFÍA}

Derrida, J. (1985): «Des Tours de Babel» en Graham, F.F. (ed.) (1985):

Difference and Translation, Itaca, Cornell University Press.

GarCía JimÉnEZ, J. (1993): Narrativa audiovisual, Madrid, Cátedra.

Hermans, T. (1995): «Translation as Institution» en Snell-Hornby, M., Z. Jettmarová y K. Kaindl (eds.) (1995): Translation as Intercultural Communication, Amsterdam-Filadelfia, John Benjamins, 3-20.

- (1996): «Norms and the Determination of Translations. A Theoretical Framework» en Álvarez, R. y C.A. VIDAL (eds.) (1996): Translation, Power, Subversion, Clevedon, Multilingual Matters, 25-51.

JaKobson, R. (1959): «On Linguistic Aspects of Translation» en BROWER, R.A. (ed.) (1959): On Translation, Nueva York, Oxford University Press, 232-239.

KRISTÉvA, J. (1969): Sémiotiké: Recherches pour une sémanalyse, París, Seuil.

LefeVere, A. (1992): Translation, Rewriting and the Manipulation of Literary Fame, Londres y Nueva York, Routledge.

MAZDON, L. (1996): «Rewriting and Remakes: Questions of Originaliry and Authenticity» en HARRIs, G.T. (ed.) (1996): On Translating French Literature and Film, Amsterdam-Atlanta, Rodopi B.V., 47-63.

PeÑA ARDID, C. (1992): Literatura y cine: una aproximación comparativa, Madrid, Cátedra.

Segovia, R. (1998): «Transvases culturales en cine y televisión: los remakes» en MeSEGUER, L. y M.L. VILLANUEVA (eds.) (1998): Intertextualitat i recepció, Col-leció Summa. Filologia 11, Castelló de la Plana, Publicacions de la Universitat Jaume I, 171-184.

Toury, G. (1986): «Translation: A Cultural-Semiotic Perspective» en Sebeok, T. (ed.) (1986): Encyclopedic Dictionary of Semiotics, vol 2, Berlín, De Gruyter, 1114-1124. 


\title{
TRADUCCIÓN, ADAPTACIÓN Y CENSURA ${ }^{1}$ DE PRODUCTOS DRAMÁTICOS
}

\author{
Raquel Merino \\ Universidad del País Vasco-Euskal Herriko Unibertsitatea \\ Vitoria-Gasteiz
}

\section{INTRODUCCIÓN}

La perspectiva que informa esta aportación no es la del traductor (o adaptador) profesional, ni la del formador de traductores, ni siquiera la del consumidor de traducciones. Buena parte de mi tiempo y esfuerzo lo he dedicado y lo dedico a estudiar traducciones dramáticas (principalmente teatrales) en el contexto en el que surgen (Merino, 2000). Es decir, mi objeto de estudio lo constituyen los productos traducidos que existen ya en la cultura meta. Se trata de observar, describir, explicar, procurar predecir posibles comportamientos futuros y desvelar las regularidades (y normas) que parecen haber regido el comportamiento traductor y el funcionamiento de los productos traducidos en la cultura de llegada. Inequívocamente, me sitúo del lado poco poblado de los Estudios Descriptivos de Traducción (Toury, 1997).

Dicho esto, he de confesar que siempre me ha preocupado de forma muy especial la frontera difusa que separa lo que se entiende por traducciones o por adaptaciones como productos aparentemente diferentes, derivados en ocasio-

1. Los datos descriptivos que sustentan esta aportación son el resultado del trabajo realizado gracias al Proyecto de Investigación UPV 103.130-HA 003/98. 
nes de un mismo proceso. Es un hecho que, a diario, consumimos traducciones y adaptaciones, incluso las distinguimos mediante la utilización de ambos términos. Con el primero, nos referimos a una relación de dependencia de un texto meta respecto a otro texto anterior originado en una lengua diferente, la de partida; con el segundo, a una relación de dependencia de un texto respecto a otro anterior originado en la misma lengua, pero en género, medio, espacio o tiempo ${ }^{2}$ diferentes. Efectivamente, creo que estamos ante procesos no subordinados, sino del mismo rango, que pueden darse de forma encadenada o consecutiva para producir un mismo texto resultante.

Para comenzar, me permitiré explorar algunas definiciones que podrían llegar a delimitar esta tierra de nadie antes de pasar a ilustrar brevemente cómo se presentan los productos traducidos y los adaptados en un contexto socio-histórico concreto, referidos a dos espectáculos públicos: el teatro, donde las adaptaciones son una constante, y el cine, que históricamente se ha nutrido de ellas.

\section{TRADUCCIÓN Y ADAPTACIÓN}

Cuando nos aproximamos al estudio del teatro y del cine, medios dramáticos por excelencia, conviene definir qué es lo que entendemos por traducción y qué por adaptación. Si hablamos del proceso, la traducción (de un texto dramático) sería (Rabadán, 1991: 298):

El conjunto de fases sucesivas de una operación lingüística, determinada por factores históricos y sociales, que consiste en transferir el material lingüístico-textual de un TO [texto original], codificado en una LO [lengua original] y perteneciente a un polisistema origen, a un TM [texto meta], codificado en una LM [lengua meta], que pertenece a otro polisistema en el que funciona de manera autónoma mante-

2. Aparte de la lengua, éstas son las variables que interactúan en la producción de traducciones y adaptaciones a las que en adelante me referiré. Aunque una de las variables puede identificarse en un caso concreto como dominante, lo cierto es que podemos encontrar casos en los que intervienen las cuatro (o cinco).

Género: el transvase se da dentro del mismo género (teatro > cine) o entre géneros diferentes (novela cine).

Medio: el transvase se da dentro del mismo medio (cine > cine, éste sería el caso de los remakes) o entre medios diferentes (teatro $>$ cine o novela $>$ cine).

Espacio: se refiere fundamentalmente a espacio geográfico, por lo que está vinculado con la idea de espacio cultural.

Tiempo: se refiere a transvases de textos pertenecientes a otras épocas.

En el caso de una obra de Shakespeare adaptada a la gran pantalla (una producción con vistas a su distribución internacional), nos encontraríamos con transvase dentro del mismo género (dramático) entre distintos medios (teatro > cine) y espacio y tiempo diferentes. 
niendo el valor comunicativo básico del TO a la vez que se representan las reglas y normas del polo meta y se satisfacen las expectativas de los lectores meta.

Entonces, la definición paralela aproximada de adaptación como proceso sería: el conjunto de fases sucesivas de una operación lingüística, determinada por factores históricos y sociales, que consiste en transferir el material lingüístico-textual de un $\mathrm{T}$ (texto), codificado en una $\mathrm{L}$ (lengua) y perteneciente a un género, medio, espacio o tiempo origen, a un TA (texto adaptado), codificado en la misma L, que pertenece a otro género, medio, espacio o tiempo en el que funciona de manera autónoma, manteniendo el valor comunicativo básico del $\mathrm{T}$ a la vez que se representan las reglas y normas del género, medio, espacio o tiempo meta y se satisfacen las expectativas de los receptores meta.

Ambos procesos de reescritura, traducción y adaptación, deben presentar necesariamente ciertas similitudes, aunque se diferencian en el carácter inherentemente interlingüístico de la traducción, carácter que no comparte la adaptación, proceso que, por definición, se da dentro de la misma lengua.

Cuando con el término traducción nos referimos al producto o resultado. no suele haber dudas respecto a la definición: «texto que resulta de todo proceso de traducción: un TM que mantiene una relación de equivalencia translémica -del tipo que sea- con su TO» (Rabadán, 1991: 298). Mientras que al referirnos a la adaptación como producto o resultado nos encontramos con una única definición (Rabadán, 1991: 288):

Texto aparentemente traducido cuya dependencia del TO correspondiente es escasa, o cuando menos débil, y que al no presentar una relación global de equivalencia no puede considerarse traducción. En estos casos, el TO no es, en sentido estricto, el input del proceso de transferencia, sino la «fuente de inspiración» sobre la que se construye un nuevo texto perteneciente a un polisistema diferente.

Con el término adaptación no sólo nos solemos referir a un resultado extremo de un proceso de traducción, a un TM cuya virmculación con el supuesto TO es tan leve como para no merecer el calificativo de traducción, sino que también, y quizá con mayor frecuencia, nos referimos a un procedimiento de traducción en la línea de la distinción, a veces tan polémica, de Vinay y Darbelnet (Mason, 94). Así Hurtado define la adaptación como «técnica de traducción que consiste en reemplazar un elemento cultural por otro de la cultura receptora» (1999: 245), un concepto común en Estudios de Traducción que aquí simplemente apuntamos por contraste, pues ya hemos dicho que queremos 
centrarnos en las traducciones y adaptaciones como productos que existen y funcionan de manera autónoma en una cultura dada.

\section{TRADUCCIONES Y ADAPTACIONES EN EL CAMPO DRAMÁTICO ${ }^{3}$}

Parece claro que, mientras que la definición de traducción, bien como proceso o como producto, implica el traslado o transvase entre dos lenguas (de la LO a la LM), la definición de adaptación implica el transvase entre géneros, medios, espacios o tiempos diferentes dentro de una misma lengua (LM o LO). Incluso en la definición que cualquier diccionario nos brinda del término (o del efecto o resultado de tal acción), nos encontramos con referencias a la cuestión clave de cambio de función (adaptar: «hacer que un objeto o mecanismo desempeñe funciones distintas para aquellas para las que fue construido»; 0 «modificar un obra [...] para que pueda difundirse entre público distinto de aquel al cual iba destinada o darle una forma diferente de la original», DRAE, 1992: 40), y de cambio de lengua (traducir: «expresar en una lengua lo que está escrito o se ha expresado antes en otra», DRAE, 1992: 2004).

En teatro, cuando hablamos de la adaptación de un clásico nacional o cuando hablamos de la adaptación de un clásico extranjero, nos estamos refiriendo al producto de un proceso de reescritura encaminado a actualizar el texto en cuestión, bajo una serie de premisas establecidas de antemano. Si se trata de la adaptación de un texto originalmente escrito en otra lengua, el texto que se utilice para la adaptación tendrá necesariamente que ser una traducción a partir de la que se re-escriba o adapte el texto clásico extranjero para actualizarlo. Y lo mismo que decimos para los clásicos sirve para textos teatrales, nacionales o extranjeros, que voluntaria o forzosamente (como en el caso de la censura) son sometidos a un proceso de adaptación para cumplir una serie de requisitos preestablecidos y especificados.

Del mismo modo, cuando hablamos de adaptaciones cinematográficas, nos referimos a los textos o guiones que son resultado de un proceso de adecuación

3. Martin Esslin, en The Field of Drama (1987), hace un recorrido por todos aquellos espectáculos que integran lo que él denomina el campo dramático, fundamentalmente el cine y el teatro. Incluso en su formulación escrita, el guión cinematográfico refleja su naturaleza dramática: la doble articulación del tex to teatral (texto primario, texto secundario) escrito para ser representado, puede también distinguirse en el guión cinematográfico, escrito para ser rodado. Lo que parece diferenciar a ambos medios dramáticos es la mecánica de la puesta en escena de los respectivos textos escritos. En el escenario teatral se puede dar un número potencialmente infinito de re-presentaciones y, en la pantalla, el texto fílmico, en una formulación final acabada, es así también infinitamente reproducible pero no re-interpretable. 
al medio dramático para el que se adaptan, en el que se parte de un texto perteneciente a un género (novela o cuento, videojuegos) o medio diferente. En este caso, también si la narración u obra de teatro de partida estuviera en una lengua distinta a la que se utiliza en el texto fílmico, el proceso de traducción sería obligado y anterior al de adaptación. Traducción y adaptación así vistos serían procesos consecutivos y no simultáneos conducentes a la obtención de un solo producto final.

Con todo, aunque se trate de un proceso que ocurre entre lenguas diferentes en el caso de la traducción, y dentro de la misma lengua, y entre géneros, medios, espacios o tiempos diferentes, en el de la adaptación, no cabe duda de que ambos procesos comparten características comunes a todo proceso de transvase o re-escritura. ${ }^{4}$

\section{LA CENSURA DE TRADUCCIONES Y ADAPTACIONES DRAMÁTICAS}

Tanto el teatro como el cine son espectáculos que se enmarcan en el campo dramático $\mathrm{y}$, de este modo parecen haberlo percibido las instancias oficiales encargadas de censurar estas dos manifestaciones en la España de Franco, al englobarlas en una misma Dirección General de Cinematografía y Teatro, con dos secciones específicas. La legislación publicada en dicho período respecto a censura de cine y teatro también era común e incluso la composición de las comisiones y juntas de censura era, en gran parte, coincidente. Esto, de hecho, no es más que un reflejo de lo que se sentía como inherentemente afín. Tradicionalmente, los profesionales del teatro han compartido su actividad en el ámbito del cine. Los primeros guionistas, directores, actores no eran sino gentes de la farándula teatral. Cuando, a finales de los años veinte, las grandes compañías americanas, en un afán de adaptar sus productos a un mercado nuevo, el del cine sonoro, planifican la realización de las ya míticas «versiones lingüísticas» en español (García Dueñas, 1993), recurren a la contratación de dramaturgos y actores de teatro españoles de renombre. El medio cinematográfico podía ser

4. Prueba de ello es el estudio que Patrick Cattrysse (1994) hizo de las adaptaciones en el cine negro clásico norteamericano, utilizando un marco metodológico y teórico concreto del ámbito de los Estudios de Traducción diseñado para estudiar traducciones. De hecho, lo que la adaptación y la traducción en el campo dramático pueden tener en común fue uno de los puntos de partida (y de encuentro) en los congresos de transvases culturales celebrados en Vitoria (Eguíluz, 1994, y Santamaría, 1997). 
técnicamente diferente pero un profesional del teatro no necesitaba más que adaptarse a ese nuevo medio dramático. ${ }^{5}$

Volviendo al caso concreto del filtro censor en la España de Franco, vemos cómo la traducción de obras de teatro extranjero era anterior a la petición de permiso de representación y era el texto traducido el que se sometía al juicio del aparato censor. Del mismo modo, la adaptación de clásicos en español era anterior a la solicitud del permiso de representación. En cuanto al cine, al tratarse de un medio técnicamente más complejo y ser el proceso de traducción de películas más costoso, los primeros visionados para establecer si una película tenía opción a ser exhibida públicamente podían muy bien darse en versión original, antes de proceder al doblaje (o subtitulado) que, en forma escrita, pasaría por el definitivo y exhaustivo control correspondiente, el cual se extendía hasta el formato final que llegaba a las pantallas (Gutiérrez Lanza, 1999).

Tanto la autocensura previa a la presentación del texto teatral o guión cinematográfico traducidos, como la censura oficial posterior, que incluía los cambios, cortes y adiciones propuestos e impuestos por la autoridad competente, se reflejan en los diferentes textos intermedios modificados en forma de adaptaciones parciales: se trata de modificaciones intralingüísticas de fragmentos textuales encaminadas a hacer que el texto resultante, o una parte del mismo, cumpliera una función predeterminada diferente a aquélla para la que el texto de partida había sido elaborado.

Podría muy bien afirmarse que, por extensión, todo texto dramático censurado en la época de Franco, al llegar al consumidor, era ya una adaptación, al menos parcial, del texto en español (traducción, original o adaptación) que se sometía a control. El aparato censor funcionó de forma predominante efectuando, o haciendo que se efectuaran, acciones encaminadas a la modificación textual y, en mucha menor medida, llevó a la prohibición o aprobación total de los textos sometidos a examen. Ninguna actividad cultural o textual quedó libre de la influencia de esta omnipresente censura, pues tanto la traducción de textos extranjeros, como la creación original y la adaptación de textos en español (catalán, gallego o vascuence) estaban, desde su origen, condicionadas por la exis-

5. Éste fue el caso de los dramaturgos José López Rubio (Urías, 1995) y Enrique Jardiel Poncela o del mismo Luis Buñuel, contratados en Hollywood para colaborar en la producción de versiones en español de producciones estadounidenses. 
tencia de un filtro universal para todo producto cultural que se ofrecía al público modificado. ${ }^{6}$

No hay duda de que este tipo de control, unido al ejercicio del poder en cualquiera de sus modalidades, es universal y se puede encontrar en toda época. país o periodo histórico. En España, a partir de 1980 aproximadamente, abolidas las leyes de censura heredadas del régimen franquista, nos encontramos con otras modalidades de censura de espectáculos dramáticos íntimamente relacionadas con las instancias de poder competentes. Simplificando, se podría decir que a la era de la censura política le sigue la era de la censura económica (Merino, 1999) cuyo exponente más destacado lo encontramos en las diferentes políticas de subvención al cine y al teatro, tanto en el gobierno central como en las emergentes administraciones autonómicas.

\section{BIBLIOGRAFIA}

CATtRysse, P. (1994): «The study of film adaptation: a state of the art and some 'new' functional proposals» en Eguíluz, F. y otros (1994): Transvases culturales: literatura, cine y traducción, Vitoria, Departamento de Filología Inglesa y Alemana, Universidad del'País Vasco.

Eguiluz, F. y otros (eds.) (1994): Transvases culturales: literatura, cine y traducción, Vitoria, Departamento de Filología Inglesa y Alemana, Universidad del País Vasco.

Essuin, M. (1987): The Field of Drama, Londres, Methuen.

García de Dueñas, J. (1993): ¡Nos vamos a Hollywood!, Madrid, Nickel Odeon.

GuTIÉRREZ LANZA, C. (1999): Traducción y censura de textos cinematográficos en la España de Franco: doblaje y subtitulado inglés-español (1951-1975), León, Universidad de León (tesis doctoral inédita).

HuRTADO, A. (coord.) (1999): Enseñar a traducir: teoría y fichas prácticas, Madrid, Edelsa.

MASON, I. (1994): «Techniques of translation revisited: a text-linguistic review of 'borrowing' and 'modulation'» en HurTADO, A. (ed.) (1994): Estudis sobre la traducció, Castelló, Publicacions de la Universitat Jaume I.

\footnotetext{
6. El estudio y análisis de la base de datos sobre Traducciones Censuradas (TRACE), referida tanto a cine como a teatro para el periodo que comprende la dictadura de Franco, nos demuestra que, bajo la restricción censora, la inmensa mayoría de los productos culturales, en mayor o menor medida, de forma voluntaria u obligada, tuvieron que ser modificados para ser permitidos y, por tanto, consumidos (Rabadán, 2000).
} 
MERINO, R. (1999): «Censura política y censura económica en el teatro traducido (inglés > español)» en ÁlLVAREZ LUGRís, A. y A. Fernández OcAmpo (eds.) (1999): Anovar/Anosar Estudios de Traducción e Interpretación, Vigo, Universidad de Vigo.

- (2000): «El teatro inglés traducido desde 1960. Censura, Ordenación, Calificación» en RABADÁN, R. (ed.) (2000): Traducción y censura (inglés-español) 1939-1985: estudio preliminar, León, Universidad de León.

RABADÁN, R. (1991): Equivalencia y traducción, León, Universidad de León.

- (ed.) (2000): Traducción y censura (inglés-español) 1939-1985: estudio preliminar, León, Universidad de León.

Real ACAdemia Española (1992): Diccionario de la lengua española, Madrid, Espasa-Calpe.

Santamaría, J. M. y otros (ed.) (1997): Transvases culturales: literatura, cine y traducción 2, Vitoria, Departamento de Filología Inglesa y Alemana, Universidad del País Vasco.

TouRY, G. (1997): «What lies beyond Descriptive Translation Studies, or: where do we go from where we assumedly are?» en VEGA, M.A. y R. MARTínGAITERo (eds.) (1997): La palabra vertida: Investigaciones en torno a la Traducción, Madrid, Editorial Complutense. (Traducción al español disponible en la página del autor en Internet: <http://spinoza.tau.ac.il/ toury/>)

URías, F. (1995): «José López Rubio. La sonrisa elegante», El Semanal, 9-7$1995,35$. 


\title{
TRADUCCIÓ, MEDIACIÓ ${ }^{1}$ I DRAMATITZACIÓ: PROPOSTA PER A L'ESTUDI DESCRIPTIU DE L'ADAPTACIÓ DRAMÀTICA
}

\author{
Vicent Montalt i ResurRecció \\ Universitat Jaume I
}

\section{INTRODUCCIÓ}

Dos són els objectius d'aquesta aportació: constatar la rellevància que pot tenir l'acció mediadora dels traductors en l'adaptació de texts per a l'escena (o dramatització) i proposar alguns elements per a l'estudi dels dramaturgs que, com és el cas de William Shakespeare, fan servir l'adaptació de texts anteriors (o texts font, TF, com els denominarem d'ara endavant) com a procediment de creació. És a dir, ens ocupem no tant de com ha estat adaptat Shakespeare per al cinema, sinó del fet que el mateix dramaturg adaptava, mitjançant traduccions a l'anglès, texts clàssics d'autors grecollatins i els incorporava a les seues obres teatrals en el procés de composició dramàtica. ${ }^{2}$

1. Utilitzem aquest terme per referir-nos a dos fets: que el traductor és un intermediari entre el TF (text font) i el TA (text adaptat) i que el traductor intervé en la traducció en el sentit que apunten Hatim i Mason (1997); és a dir, que l'adaptador accedeix al TF original mitjançant el filtre de mediació o intervenció que estableix el traductor (segons els autors hi ha tres graus de mediació: mínima, parcial i màxima). Això no obstant, en aquest article ens centrem en la funció intermediària del traductor en el procés d'adaptació i no pas en descriure els graus de mediació o intervenció de la traducció i el seu efecte en el TA.

2. La tesi doctoral De la font a la 'partitura teatral': inscriure l'oralitat en Shakespeare (Vicent Montalt, 1996) intenta donar compte de com el dramaturg construeix l'oralitat del text dramàtic en 
Tot i que la traducció té un caràcter interlingüístic front al caràcter intralingüístic de l'adaptació, els límits entre ambdues activitats no sempre són clars. D'una banda, a causa de la naturalesa intercultural de la traducció, aquesta sempre requereix cert grau d'adaptació cultural o naturalització. D'altra banda, com observarem en l'exemple comentat, els processos d'adaptació poden implicar complexes operacions intertextuals en què l'adaptador no es limita als procediments intralingüístics i intersemiòtics (atès que estem parlant de l'adaptació dramàtica de texts literaris) entre un únic TF (text font) i el TA (text adaptat) típics de l'adaptació, sinó que també fa ús de procediments interlingüístics.

\section{TRADUCCIÓ, MEDIACIÓ I ADAPTACIÓ DINS DEL CONTINU INTERTEXTUAL}

La present proposta se situa en la intersecció de dos àmbits d'estudi: la traductologia i la intertextualitat. Des de la traductologia, partim d'una tendència, representada fonamentalment per Cattrysse (1992), que no restringeix la traducció a l'activitat interlingüística, sinó que l'amplia als fenòmens de reescriptura dins d'una mateixa llengua. Com indica Chaume en fer un repàs bibliogràfic al respecte, l'adaptació seria «una mescla entre la traducció intralingüística i la traducció intersemiòtica, tal com les definia Jakobson» (Chaume, 2000: 99).

Des dels estudis intertextuals, entenem que tant la traducció coml'adaptació són dos dels diversos tipus de transferència intertextual possibles. Així doncs, considerem que tant el text adaptat com el text traduït són dos tipus de text meta (TM), concepte que fem servir per designar qualsevol text resultat d'una transferència intertextual. Podem estudiar la relació entre el TF i el TM a partir de cinc criteris generals:

1) el grau de proximitat o distància entre TF i TM, criteri que ens portaria a les tipologies clàssiques de les transferències intertextuals, des de la cita literal fins a l'al-lusió remota, tot passant per l'adaptació o les convencions de gènere;

2) la motivació del procés de transferència i la funció del TM com a producte (en el nostre cas, la funció del TA);

el procés d'adaptació de texts font (tant TF originals en anglès com traduïts). La present reflexió parteix d'algunes de les conclusions de l'esmentada tesi i avança en la línia de proporcionar un model d'estudi dels processos d'adaptació dramàtica. 
3) la diferència o identitat entre el codi lingüístic del TF i el del TM, criteri que contemplaria la traducció interlingüística així com la necessitat o no de la traducció com a mediació entre el TF i el TM en els processos d'adaptació;

4) el gènere del TF $i$, per tant, el grau de transformacions intersemiòtiques (en el cas de la dramatització de textos per a l'escena, la subdivisió més rellevant seria entre texts dramàtics i texts no dramàtics);

5) el nombre de TF presents en el TM en qüestió, ja que, com hem esmentat, en alguns casos el TM conté elements de diversos TF. Des del punt de vista de l'adaptació, cal distingir entre els TF primaris (utilitzats sistemàticament com a base del procés) i els TF secundaris (els que s'incorporen al TA de manera puntual).

Podem parlar, atenent al tercer criteri (el codi lingüístic), de dos tipus de TF (el TF original i el TF en traducció) i de dos tipus d'adaptació. El primer tipus d'adaptació està constituit pels processos no mediats en els quals el TF $i$ el TA estan escrits en la mateixa llengua. El cas paradigmàtic en l'obra de Shakespeare és l'adaptació de les Cròniques de Holinshed que trobem a les obres històriques, com ara Richard II, Macbeth, Richard III o Henry V, entre d'altres.

El segon tipus d'adaptació està constituït per les adaptacions realitzades sobre TF escrits originalment en una llengua diferent a la del TA. En aquest tipus d'adaptació mediada es fa necessària la presència d'una traducció ${ }^{3}$ sobre la qual es puga realitzar l'adaptació. Pel que fa a l'obra dramàtica de Shakespeare, destacarem dins d'aquest segon tipus les adaptacions de Les vides paral-leles, de Plutarc, en traducció de Thomas North (en obres com ara Julius Caesar, Anthony and Cleopatra o Coriolanus) o les Metamorfosis d'Ovidi, en traducció d'Arthur Golding (en obres com ara A Midsummer Night's Dream o The Tempest). Dintre d'aquest segon tipus d'adaptació, ${ }^{4}$ caracteritzada per estar mediada per la traducció, caldria fer una distinció entre les traduccions indirectes o doblement mediades (com és el cas de la traducció que va realitzar Thomas North de l'obra de Plutarc a partir d'una traducció francesa d'Amyot) i les traduccions directes, com la realitzada per

3. Cal recordar el paper imprescindible de traductors com ara Arthur Golding o Thomas North en la transmissió, difusió i popularització d'alguns autors clàssics grecollantins a l'Anglaterra dels segles XVI i XVII.

4. En «Traducció i intertextualitat en la gènesi del text original» (Montalt: 1998) el lector trobarà comentaris sobre la dramatització d'un fragment dels Assaigs, de Montaigne, en traducció anglesa de John Florio a The Tempest, de William Shakespeare. 
Arthur Golding dels poemes d'Ovidi. En la present ocasió, ens centrem en aquestes darreres: adaptacions mediades per traduccions directes.

Pel que fa a la motivació, podem distingir dos tipus d'adaptació: quan la motivació ve imposada per raons externes (des de la censura ${ }^{5}$ política i ideològica fins als condicionaments de caràcter tècnic i escènic) i quan la motivació de l'adaptació respon a raons internes (voluntat de l'autor de canviar alguns aspectes del text, apropiar-se'n, parodiar-lo, etc.), com és el cas de les adaptacions realitzades per Shakespeare.

Des d'aquesta perspectiva doble, i més enllà de la dicotomia a què alguns estudiosos sotmeten els conceptes de traducció i adaptació, en el present treball entenem que adaptació i traducció són dos processos sovint complementaris i interdependents. D'una banda, observem una relació típicament consecutiva entre ambdós, en la qual la traducció satisfà una funció mediadora requerida per l'adaptació. Com assenyala Merino en aquest volum, «el proceso de traducción sería obligado y anterior al de adaptación. Traducción y adaptación así vistos serían procesos consecutivos». Aquesta és la relació que existeix entre la traducció de Golding del text llatí d'Ovidi i el TA de Shakespeare.

D'altra banda, com veurem més endavant, també hem de parlar d'una relació simultània entre traducció i adaptació, si més no en el cas que ens ocupa, ja que puntualment l'adaptador acudeix al TF llatí d'Ovidi i l'adapta sense la mediació de la traducció de Golding. És a dir, que en moments molt concrets, l'adaptador pot deixar de banda la traducció i manipular directament el text original en el procés d'adaptació.

És per això que l'abast i estudi de l'adaptació no s'han de limitar als processos de reescriptura d'un sol TF dins d'una mateixa llengua, com proposen alguns autors, sinó que també han de contemplar altres possibles transferències intertextuals: ús de diverses traduccions ${ }^{6}$ del TF ja existents en la cultura d'arribada que medien entre l'original i el TA; operacions interlingüístiques realitzades per l'adaptador directament sobre el TF quan està escrit en una llengua diferent al TA; incorporació d'altres tipus de transferències, com ara la imitació, l'al·lusió o la cita, procedents d'altres TA del mateix TF primari o d'altres TF.

5. Raquel Merino ha estudiat aquest tipus d'adaptacions en el context de la dictadura franquista a Espanya.

6. Per exemple, en l'adaptació de la narració de Píram i Tisbe, Shakespeare combina puntualment la versió de Chaucer amb la que utilitza com a TF primari, la de Golding. 


\section{PROPOSTA PER A L'ESTUDI DE SHAKESPEARE COM A ADAPTADOR: LA NARRACIÓ DE PÍRAM I TISBE D'OVIDI ADAPTADA A A MIDSUMMER NIGHT'S DREAM}

A continuació, proposem deu àmbits (organitzats del context al text) en forma de preguntes per a l'estudi de Shakespeare com a adaptador i els il.lustrem amb breus comentaris ${ }^{7}$ sobre un exemple concret: la narració de Píram i Tisbe dramatitzada a A Midsummer Night's Dream (V.i.108-356). ${ }^{8}$

\subsection{Quins autors i TF tria l'adaptador? Per quines raons?}

En el cas que ens ocupa, l'adaptador tria l'autor llatí Ovidi i la narració de Píram i Tisbe (Metamorfosis, Llibre IV), escrita a partir de personatges i motius de la mitologia grega.

Una de les raons més òbvies en triar aquest autor i aquest text és que l'adaptador els coneix i n'està familiaritzat, circumstància que depèn tant de la presència d'aquests en el sistema literari de la cultura d'arribada com del bagatge educatiu i de les preferències estètiques de l'adaptador. És ben conegut que Ovidi era un dels poetes preferits de Shakespeare: l'obra del llatí no sols va nodrir la imaginació del dramaturg anglès, sinó la de tota l'època isabelina (Martindale, 1990: 45).

Sabem que Shakespeare coneixia el text llatí original de les Metamorfosis d'Ovidi, on trobem la narració de Píram i Tisbe, bastant coneguda a l'Anglaterra del segle xvi. De fet, Chaucer n'havia fet una versió molt abans a The Legend of Good Women. Gower també n'havia elaborat una adaptació a Confessio Amantis, segurament coneguda també per Shakespeare. Fins i tot, abans de la famosa traducció d'Arthur Golding (1567), en va aparèixer una versió abreujada en forma de vinyeta en la portada d'alguns llibres de l'època.

És a dir, Shakespeare no adapta un material textual i narratiu desconegut, sinó més aviat tot el contrari: es tracta d'una narració que estava ben establerta en la cultura literària i popular de l'Anglaterra del segle Xvı i XVII. Aquesta

7. Un estudi complet i detallat dels deu àmbits que proposem ocuparia un espai del que no disposem en aquest volum, de manera que els comentaris que proporcionem a continuació són necessàriament parcials i incomplets i sols pretenen exemplificar la proposta metodològica.

8. Tant la traducció de Golding com el TA s'han agafat de l'edició de Harold F. Brooks (1979) a The Arden Shakespeare. Per al text original llatí hem fet servir l'edició bilingüe anotada de Ruiz de Elvira (1964).

9. És a dir, que en certa mesura Ovidi també és un adaptador, ja que s'apropia d'uns materials d'origen mitològic grec, els transforma en una narració escrita en vers llatí i els insereix en una unitat literària major com són les Metamorfosis. 
circumstància complica una mica l'anàlisi, ja que, com hem esmentat, el procés d'adaptació no es fa exclusivament sobre un sol text, el de la traducció de Golding, sinó que hi entren en joc, en major o menor grau, alguns altres texts que l'adaptador coneixia i recordava.

Una altra raó bastant probable és el potencial dramàtic del TF. En l'exemple de la narració de Píram i Tisbe, ens trobem amb un TF d'alt potencial dramàtic: presència de personatges, diàlegs en estils directe $\mathrm{i}$ indirecte, estructura narrativa d'origen clarament oral, entre d'altres. En aquest cas, hauríem d'afegir-hi l'alt potencial paròdic que ofereixen les versions que d'aquesta narració se n'havien fet a l'època.

\subsection{L'adaptador utilitza una sola o diverses traduccions o versions del TF en el procés d'adaptació? En quin grau hi són presents en el TA?}

A més de les adaptacions de Chaucer i Gower així com la traducció de Golding, l'adaptador, segons documenta àmpliament Muir (1977), coneixia i va utilitzar tres altres versions de la narració d'Ovidi: A Gorgious Gallery of Gallant Inventions (1578); A Handfull of Pleasant Delites (1584) i la que trobem al poema de Thomas Mouffet, Of the Silkworms, and their Flies, publicada el 1599 i probablement coneguda per Shakespeare en manuscrit. Aquestes tres versions d'autors menors van servir al dramaturg per parodiar la poesia i la dramatúrgia feta per uns escriptors que ell considerava dolents.

\subsection{Quina és la funció total del TA?}

En l'exemple que ens ocupa, la funció del TA és provocar l'efecte còmic mitjançant la paròdia en to burlesc, una paròdia que apunta en dues direccions: ${ }^{10}$ cap al mode en què altres autors menors isabelins adaptaren la narració d'Ovidi i cap a la pràctica escènica i estil d'interpretació d'alguns actors amateurs que mereixen l'actitud sarcàstica de l'adaptador. És a dir, que la paròdia té un sentit clarament metateatral.

L'efecte còmic de què parlem ens situa en el terreny de la recepció i planteja una sèrie de consideracions sobre la relació entre l'adaptació i el públic al qual va dirigida. Com ja hem esmentat, el públic isabelí coneixia tant la història de

10. S'ha especulat sobre la possibilitat que la paròdia apunta cap a la mateixa traducció de Golding o, fïns i tot, que es tracta d'una espècie d'autoparòdia en la que Quince, el personatge de A Midsummer Night's Dream que fa el paper de pròleg en l'escena comentada, representaria el mateix dramaturg/ adaptador. 
«Píram i Tisbe» com els dramaturgs i actors parodiats, de manera que l'eficàcia de la relació intertextual en la ment del receptor estava assegurada.

Des del punt de vista de la traducció interlingüística, aquestes qüestions són de vital importància, ja que el públic actual d'una segona llengua, com ara el català o el castellà, parteix de bagatges i referents culturals totalment diferents.

\subsection{Es tracta d'una adaptació completa o parcial? Com s'integra} el TA en unitats majors, com ara l'escena, l'acte, l'obra en particular o l'obra completa del dramaturg?

En aquest cas, es tracta d'una adaptació parcial en dos sentits. D'una banda, l'adaptador selecciona un relat integrat dins d'una estructura major, que és el llibre, el qual, al seu torn, forma part d'una altra estructura encara major que és l'obra les Metamorfosis d'Ovidi, formada per vint-i-cinc llibres.

D'altra banda, el TA constitueix una sequiència dramàtica que forma part d'una unitat dramatúrgica major, que és l'escena primera de l'acte cinquè. Les sequiències precedent i següent al TA ens donen la clau de la relació de coherència interna amb la resta de l'obra. L'escena en la qual s'insereix el TA s'integra, igualment, en una altra estructura superior que és l'acte, en aquest cas l'acte cinquè i darrer. De la mateixa manera, l'acte és part integrant de l'obra $A$ Midsummer Night's Dream, la qual també ocupa un lloc determinat en la producció dramàtica completa de l'autor.

Des del punt de vista de l'obra completa de l'autor, val a dir que aquesta adaptació manté una relació de paral-lelisme o proximitat intertextual amb la història d'altres dos personatges que donen títol a una de les tragèdies més conegudes, Romeo and Juliet: ${ }^{11}$ dos joves enamorats malgrat l'oposició de llurs famílies moren a causa d'una confusió tan absurda com fatal.

En resum, podem dir que s'hi observa una relació de coherència total entre el TA i les unitats dramatúrgies superiors en les quals s'integra.

\subsection{Quina traducció o traduccions tria l'adaptador com a TF primari? Per quines raons?}

L'adaptador tria la traducció d'Arthur Golding com a TF primari, tot i que hi incorpora elements tant del text original en llatí com dels altres texts que participen en aquesta transferència intertextual com a TF secundaris.

11. Cal suposar que els motius bàsics de Romeo and Juliet els extrau el dramaturg de la narració de Píram i Tisbe. 
Una raó podria ésser la inseguretat de Shakespeare amb el llatí. Des del comentari de Ben Johnson «Small Latin and lesse Greek», s'ha polemitzat molt sobre la competència real de llatí i grec que tenia l'adaptador. En qualsevol cas, hi ha motius per suposar que Shakespeare consultava simultàniament el text llatí i la traducció de Golding.

Una altra raó és que, segons argumenta convincentment Taylor (1990), la traducció de Golding era molt popular i admirada a l'Anglaterra isabelina, fins i tot entre grans autors com ara Spenser i Marlowe. Així doncs, cal suposar que Shakespeare també apreciava la traducció de Golding i la utilitzava en combinació amb el text llatí.

\subsection{Fa servir l'adaptador el TF original en combinació amb la o les traduccions o versions?}

Tot i l'esmentat comentari de Ben Johnson sobre els limitats coneixements de llatí que posseïa Shakespeare, com a individu escolaritzat a l'Anglaterra isabelina, sabem que l' adaptador hauria estudiat, segons documenta Taylor (1990), els texts llatins d'Ovidi i hauria conegut i utilitzat les següents obres lexicogràfiques: l'Abcedarium Anglico Latinum, el Promptorium Parvulorum (1449) i el Thesaurus Linguae Romanae \& Britannicae de Thomas Cooper (1565). És a dir, podem suposar que l'adaptador no sols tenia coneixements de llatí, sinó que comptava amb obres lexicogràfiques bilingües que li permetien entendre el text llatí i realitzar-ne, amb més o menys fortuna, traduccions a l'anglès.

A mode d'exemple, si comparem la seqüència del TA «Did scare away, or rather did affright;/And as she fled, her mantle she did fall,/Which Lion vile with bloody mouth did stain» amb el text llatí i amb la traducció de Golding, resulta evident que el TA és més pròxim al llatí que a la traducció. També resulta evident que aquests tres versos del TA estan clarament influïts per la dicció de la versió de Thomson en A Handfull of Pleasant Delites.

\subsection{Quins elements manté l'adaptador en el TA?}

De la traducció de Golding, l'adaptador manté els següents elements: els noms del personatges centrals Píram i Tisbe; el fil argumental bàsic, llevat del final que, tant en el text llatí com en la traducció, relata la metamorfosi del color de les mores degut a la sang vessada per Píram; els motius centrals de la narració, com ara el mur que separava els enamorats, la fugida nocturna a la llum de la lluna, la tomba de Ninus, la caiguda del vel de Tisbe, la confusió fatal, o el suïcidi, entre d'altres. 


\subsection{Quins elements transforma l'adaptador en el TA?}

Una de les principals transformacions és la realitzada sobre les convencions de gènere. L'adaptador converteix un text típicament literari adreçat al lector individual (com és la narració en vers del TF) en un text dramàtic concebut per ésser representat pels actors com a espectacle escènic en forma de diàleg, acció i gest, i percebut visualment i acústica pel públic del teatre.

Encara que tant al text original llatí com a la traducció anglesa trobem diàleg en estil directe i indirecte, es tracta d'estructures dialògiques subordinades a l'eix central del discurs que és la narració pròpiament. El que fa l'adaptador és convertir el diàleg en l'eix central del discurs, com no pot ésser d'altra manera en els gèneres dramàtics.

El sentit total del TF també es transforma: passem d'una història d'amor amb final fatal de to tràgic a una escena burlesca en clau de paròdia plena de connotacions sexuals.

Si baixem al nivell textual, observem que l'estructura mètrica del vers de Golding (el fourteener) es converteix, d'una banda, en formes versals més pròpies del teatre shakespearià (com ara el pentàmetre iàmbic en boca del Pròleg) i, d'altra, en estrofes i tipus de vers més curt típics dels dramaturgs que parodia.

En el nivell lèxic, observem una transformació del simple motiu del mur que separava els dos enamorats en el text ovidià i en la traducció de Golding («Fissus erat tenui rima, quam duxerat olim,/cum fieret, paries domui communis utrique;», «The wall that parted house to house had riven therein a cranny/Which shronke at making the wall.», respectivament), el qual s'amplia en el TA i es converteix en un dels elements escènics centrals d'aquesta sequiència. Els mots «chink», «cranny», «hole» es repeteixen en distints moments del TA i provoquen un efecte còmic amb connotacions sexuals. També en el nivell lèxic, observem una curiosa transformació que afecta el nom d'un dels personatges: la «Lionesse» de Golding o la «Lea» d'Ovidi es transformen en «Lion» en el TA, en clara connexió amb l'adaptació de Thomson.

\subsection{Quins elements omet l'adaptador en el TA?}

L'adaptador omet molts detalls de la narració original que no li semblen funcionals en el nou context comunicatiu del TA: el nom de la ciutat on té lloc l'acció, Semyramis; els comentaris sobre la passió inicial de Píram i Tisbe; els parèntesis poètics en les descripcions, etc. 
Cal destacar que Shakespeare omet l'element final i essencial de la història ovidiana, és a dir, la metamorfosi o transformació del color de les mores a causa de la sang vessada per la fatalitat dels enamorats.

\subsection{Quins elements nous incorpora l'adaptador al TA?}

Des d'un punt de vista estructural, l'adaptador superposa a l'estructura narrativa del TF una eficaç dramatúrgia de gran potència còmica: presència del pròleg que avança una història i creació d'un context metateatral: l'escena de Píram i Tisbe es representa sobre l'escenari per a la resta dels personatges de l'obra, que es converteixen en espectadors, de tal manera que el públic real del teatre es converteix en segon espectador d'una minirepresentació dins de la representació.

En el nivell lèxic, cal subratllar que l'adaptador afegeix al TA una extensa $i$ ben teixida xarxa de connotacions sexuals mitjançant paraules amb doble sentit, documentades per Eric Partridge al clàssic glossari Shakespeare's bawdy, com ara «horn» (en el sentit de penis erecte, citat per Partridge a l'obra esmentada: MND V.i.230-234), «thorn» (penis), «beast» (en el sentit de desig sexual animal), «draw» (en el sentit d'exhibir l'òrgan sexual), «stones» (testicles), «discharched» (en el sentit d'ejacular) o «deflower» (en el sentit de desvirgar).

\section{RECAPITULACIÓ}

Hem observat en l'exemple comentat que la traducció funciona com a mediació entre el TF i el TA. En aquest sentit, resulta inconcebible l'obra dramàtica de Shakespeare sense la presència d'alguns traductors anteriors a ell i sense les adaptacions que el dramaturg feia d'altres texts mitjançant els esmentats traductors. Igualment, hem constatat que l'adaptació no és necessàriament un procediment lineal entre dos texts, el TF i el TA. També pot definir-se com una complexa operació intertextual que sovint comprèn diversos texts (incloent-hi l'original escrit en una llengua diferent a la del TA) al servei d'uns efectes molt determinats en l'àmbit de la recepció. Així doncs, cal distingir entre fonts primàries i fonts secundàries de l'adaptació.

En aquest exemple, hem observat que l'interès de l'adaptador no rau tant a mantenir una relació de coherència amb el TF, sinó més aviat a crear les condicions de màxima coherència i cohesió internes (dins de l'escena adaptada i entre l'escena adaptada i l'obra en qüestió) al servei del projecte comunicatiu que constitueix qualsevol text dramàtic, en aquest cas construir una paròdia de gran efecte còmic. Amb aquesta mentalitat, l'adaptador no vacil-la a l'hora de 
manipular els texts que conflueixen en l'adaptació: reorganització del relat, expansió dramàtica, incorporació d'al-lusions i connotacions de tota mena, transgressió del sentit del TA, superposició d'una dramatúrgia metateatral, etc.

A través de complexos procediments d'orquestració, l'adaptador assoleix, en terminologia de Bakhtin, una polifonia de veus que constitueix l'essència no sols de les convencions del gènere dramàtic i la seua recepció, sinó també del propòsit paròdic que serveix de motor al procés d'adaptació comentat.

Una de les quiestions que ha despertat aquest estudi és el grau de tolerància d'una cultura respecte a traduir d'altres textos i llengües. En aquest sentit, l'època i l'autor que ens ocupen semblen molt permeables, la qual cosa era, probablement, una norma de traducció. Per tant, un estudi descriptiu no pot obviar les traduccions indirectes. És més, com s'ha vist, aquestes són part del sistema $\mathrm{i}$, fins i tot, poden condicionar les estratègies de traducció directa.

Es desprén de l'estudi que la traducció es considerava a l'època de Shakespeare una tècnica adequada per introduir nous elements i sistemes en la cultura anglesa. La raó d'aquesta introducció de nous elements culturals té a veure amb les expectatives del públic i l'èxit de llur recepció, la qual cosa explica la gran tolerància cap a la mediació i l'adaptació en aquella època.

Finalment, sembla bastant clar que la frontera entre escriptura original i traducció és molt difusa des del punt de vista de l'estatus d'igualtat que totes dues pràctiques gaudeixen a la cultura meta, a diferència del que ocorre en l'actualitat.

L'aplicació d'aquesta proposta d'estudi a altres TA dins de l'obra dramàtica de Shakespeare ${ }^{12} \mathrm{o}$ a altres TA d'altres adaptadors servirà per valorar la seua utilitat i per millorar els aspectes que encara no han estat resolts satisfactòriament.

Comentaris a: montalt@trad.uji.es

12. Una obra de consulta excel-lent i imprescindible per a l'estudiós de les adaptacions realitzades per Shakespeare són els vuit volums de Bullough (1975): The narrative and dramatic sources of Shakespeare. 


\section{BIBLIOGRAFIA}

BAKHTIN, M. M. (1981): The dialogic imagination, Austin, University of Texas Press.

Brooks, H. (ed.) (1979): A Midsummer Night's Dream, Londres, Routledge, The Arden Shakespeare.

Bullough, G. (ed.) (1975): The narrative and dramatic sources of Shakespeare, Londres i Nova York, Routledge, Kegan Paul i Columbia University Press.

CHAUme, F. (2000): La traducción audiovisual: Estudio descriptivo y modelo de análisis de los textos audiovisuales para su traducción. Tesi doctoral presentada a la Facultat de Ciències Humanes i Socials de la Universitat Jaume I.

Delisle, J. i J. WOOdsworth (eds.) (1995): Translators through History, Amsterdam, John Benjamins i Unesco Publishing.

HATIM, B. i I. MASON (1997): The translator as communicator, Londres i Nova York, Routledge.

Martindale, C. i M. Martindale (1990): Shakespeare and the uses of Antiquity, Londres i Nova York, Routledge.

MonTaLT, V. (1998): «Traducció i intertextualitat en la gènesi del text original», en Meseguer i Villanueva (eds.): Intertextualitat i recepció, Castelló, Publicacions de la Universitat Jaume I, Col-lecció «Summa».

MuIR, K. (1977): The sources of Shakespeare's plays, Londres, Methuen.

PARTRIDGE, E. (1955, 1958, 1968): Shakespeare's bawdy, Londres i Nova York, Routledge.

PLETT, H. (ed.) (1991): Intertextuality, en Research in Text Theory, Berlín i Nova York, Walter de Gruyter.

Ruiz de Elvira, A. (ed.) (1964): P. Ovidio Nasón. Metamorfosis, Barcelona, Alma Mater.

TAYLOR, B. A. (1990): «Golding's Ovid, Shakespeare's 'Small Latin', and the real object of mockery in 'Pyramus ans Thisbe' dins Nicoll, A. (ed.): Shakespeare survey, Cambridge, Cambridge University Press, vol. 42, 5364. 